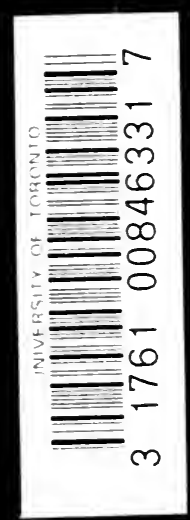




$$
60 ; 4
$$





\section{Digitized by the Internet Archive in 2007 with funding from Microsoft Corporation}




\title{
BOOKS BY DR. FISCHER
}

\author{
PUBLISHED BY
}

\section{JOHN WILEY \& SONS, Inc.}

The Physiology of Alimentation.

viii +348 pages. $5 \frac{1}{6}$ by 8 . 30 figures. Cloth. $\$ 2.00$ net.

Fats and Fatty Degeneration.

A Physico-Chemical Study of Emulsions and the Normal and Abnormal Distribution of Fat in Protoplasm. (With Dr. Marian O. Hooker.) viii +155 pages. 6 by 9.65 figures. Cloth. $\$ 2.00$ net.

Oedema and Nephritis.

A Critical, Experimental and Clinical Study of $t$ ie Physiology and Pathology of Water Abserption in the Living Organism. Third and Enlarged Edition. xvi+922 pages. 6 by 9. 217 figures. Cloth. \$10.00 net.

Soaps and Proteins.

Their Colloid Chemistry in Theory and Practice. (With George D. McLAUGHLiN and Dr. MARIAN O. Hooker.) ix +272 pages. 6 by 9.114 figures. Cloth, $\$ 4.00$ net.

TRANSLATIONS

Physical Chemistry in the Service of Medicine. S sven Addresses by Dr. Wolfgang Pauli, Professor in the Biological Experimer.t Station in Vienna. Authorized Translation by Dr. Martin H. Fischer. ix + 156 pages. 5 by $7 \frac{1}{4}$. Cloth. $\$ 1.25$ net.

An Introduction to Theoretical and Applied Colloid Chemistry.

Five Lectures by Dr. Wolfgang Ostwald, Professor in the University of L inzig. Authorized Translation by Dr. MARTiN H. Frscher. xiv +232 pages. 6 by 9.45 figures. $\$ 2.50$ net. 


\section{$C_{F 529750}$ \\ SOAPS AND PROTEINS}

THEIR COLLOID CHEMISTRY

IN THEORY AND PRACTICE

\section{BY \\ MARTIN H. FISCHER}

Doctor of Medicine

Eichberg Professor of Physiology in the University of Cincinnati

WITH THE COLLABORATION OF

GEORGE D. MeLAUGHLIN

Formerly Mescarch Associate in Physiology in the Unicersity of Cincinnati AND

MARIAN O. HOOKER

Doctor of Mrdicine

Formerly Instructor in Physiology in the University of Cincinnald

NEW YORK

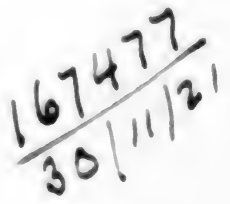

JOHN WILEY \& SONS, INC.

Losdos: CHAPMAN \& HALL, LaMuted 
Copyright, 1921, BY

MARTIN H. FISCHER 


\section{H. C. M.}

IN AFFECTION, ADMIRATION AND GRATITUDE 
". . . thou thyself, a watery, pulpy, slobbery freshman and new-comer in this Planet, sattest muling and puking in thy nurse's arms; sucking thy coral, and looking forth into the world in the blankest manner, what hadst thou been without thy blankets and bibs, and other nameless hulls?"-THOMAS CARLYLE. 


\section{PREFACE}

The studies on soaps detailed in these pages were originally undertaken for the elucidation of various purely biological questions. The proof that widely differing theoretical and practical problems associated with the maintenance of normal physiology in plants and animals or in the treatment of their diseases are essentially problems in colloid-chemistry (more particularly problems in the colloid-chemistry of the proteins) made more and more evident the necessity for a better understanding of the nature of various colloid-chemical changes themselves. The chemistry of the proteins as chains of widely differing aminoacids presented, however, such an infinity of possible variables that every direct attempt to analyze their colloid-chemical behavior was beset with difficulty. For this reason we turned to the soaps, for these substances not only contain a more controllable number of purely chemical variables, but their colloidchemical behavior is much like that of the proteins. From the surer ground of the soaps it was then possible to step over into the more slippery one of the proteins. What are some of the bearings of our various conclusions upon the biological behavior of living cells under normal and abnormal circumstances is detailed in the pages that follow.

The reason why this volume is written as it is, is largely the fruit of circumstance. While my first interests are biological and medical, it happens that generous friends have often asked me to present the work contained in this and some other of my books before their societies devoted to various branches of pure and applied chemistry. Due to such encouragement I have set down in this volume the substance of what was said to them and in which they saw relations to their own fields of endeavor.

Among the scientific journals to which this work was first submitted only Science and The Chemical Engineer could find 
space for some of its fragments. In order that the whole might be presented in sequential form it was therefore necessary to write a book.

I am greatly indebted to DoRIS WulfF for her attention to the manuscript; to Joseph B. Homan for his pen and ink drawings; to JosEF KUPKA for his photographs and tireless devotion to the business of the day.

\section{Eichberg Laboratory of Physiology,}

Martin H. Fischer.

University of Cincinnati, November 24, 1920. 


\title{
TABLE OF CONTENTS
}

\author{
PAR'T ONE
}

THE COLLOID-CHEMISTRY OF SOAPS

I. Soap Making

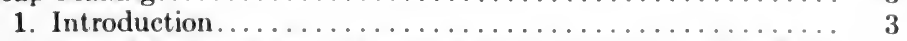

2. Soap Making as a Colloid-Chemical Problem. The Fatty Acids of the Technical and Theoretical Chemists...... 6

II. The System Soap/Water...................... 9

1. Introduction........................ 9

2. Preparation and Gelation Capacities of Some Pure Soaps with Water.............................. 10

a. Soaps with Different Basic Radicals............ 10

b. Soaps with Different Acid Radicals........... 15

c. The Effects of Water Concentration. . . . . . . . 22

III. The System Soap/Alcohol . . . . . . . . . . . . . . . . . 30

1. Introduction .......................... 30

2. Experiments with Monatomic Alcohols............ 30

a. Monatomic Alcohols of the General Composition

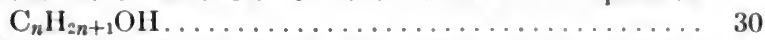

b. Monatomic Alcohols of the General Composition

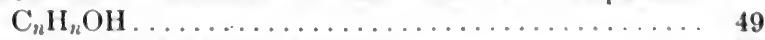

3. Experiments with Diatomic Alcohols............. 50

4. Experiments with Triatomic Alcohols (Glycerin) ......... 52

IV. The System Soap/ $X$. Colloid Soaps in Other Non-Aqueous "Solvents"............................. 60

V. On the General Theory of the Lyophilic Colloids. . . . . . . . 64

1. Historical and Critical Remarks.................. 64

2. Theory of Soap Gels. . . . . . . . . . . . . . . . . . . . 69

VI. Definition of Hysteresis, Swelling, Liquefaction, Gelation Capacity, Solvation Capacity, Syneresis, Sol .......... 74

VII. On the Reaction of Sorps to Indicators.............. 77

VIII. On the Physical State of Soap Mixtures.............. 83

IX. On Reversihility in Sorps. . . . . . . . . . . . . . . . . 89

X. On the "Salting-out" of Soaps. .................. 93

1. On the "Salting-out" of Potassium Oleate........... 93

2. Critical and Historical Remarks................ 107

a. Introduction. . . . . . . . . . . . . . . . 107

b. Historical Remarks on the "Salting-out" of Soaps. . . . 110

c. On the Theory of the "Sulting-out" of Soaps ....... 113

3. On the "Salting-out" of Different Soaps ............. 116 
PAGE

XI. The Foaming, Emulsifying and Washing Properties of Soaps.... 136

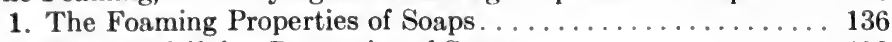

2. The Emulsifying Properties of Soaps............. 150

3. On the Theory of Foaming and Emulsification......... 154

4. The Washing Properties of Soaps............... 157

\section{PART TWO}

\section{THE COLLOID-CHEMISTRY OF SOAP MANUFACTURE}

I. Principles of Hot and Cold Process Soap Manufacture. . . . . . 163

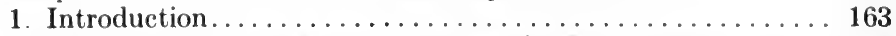

2. The Oils, Fats and Waxes Entering the Soap Kettle...... 164

3. Significance of Some Fat and Oil Constants for the Colloid-

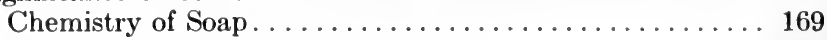

4. Hot and Cold Process Soap Manufacture........... 170

5. The Mixing of Fat with Alkali. Initial Emulsification..... 174

6. Concentration of Alkali, and Method of Adding it for Saponi-

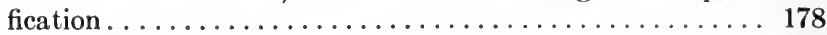

7. The Changes in Soap Systems Consequent upon Cooling. ... 180

8. The Salting-out of Mixed Soaps................ 181

9. The Finishing of Soap . . . . . . . . . . . . . . 183

10. Some Physical Constants of Market Soaps. . . . . . . . 186

11. The Conversion of One Soap into Another........... 190

II. Fillers for Soaps. . . . . . . . . . . . . . . . . . . . . . 192

\section{PART THREE}

THE ANALOGIES IN THE COLLOID-CHEMISTRY OF SOAPS, PROTEIN DERIVATIVES AND TISSUES

I. The Chemical and Colloid-Chemical Behavior of Fatty Acids and Their Derivatives and the Analogous Behavior of "Neutral"

Proteins and Their Derivatives................ 205

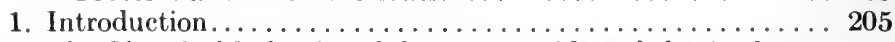

2. The Chemical Behavior of the Fatty Acids and the Analogous

Behavior of the Amino-Acids (Neutral Proteins) . . . . . 205

3. The System Egg-Globulin/Water................ 209

4. The System Gelatin/Water.................. 218

5. Supplementary and Critical Remarks............. 222

6. On Peptization and Coagulation ................ 225 
II. On the Theory of Poisoning by Ammonium Compounds and by Heavy Metals. . . . . . . . . . . . . . . . 235

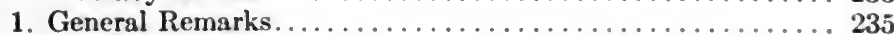

2. Experiments on the Conversion of Heavy Metal Proteinates into Light Metal Proteinates............... 237

3. On the Nature and Relief of Heavy Metal Poisoning. . . . . 240

4. Concluding Remarks........................... 243

\section{PART FOUR}

\section{APPENDIX}

I. Physico-Chemical Constants of Various Fatty Acids......... 253

1. Acids of the Series $\mathrm{C}_{n} \mathrm{H}_{2 n} \mathrm{O}_{2}$. Acids of the Acetic Series... 253

2. Acids of the Series $\mathrm{C}_{n} \mathrm{H}_{2 n-2} \mathrm{O}_{2}$. Acids of the Acrylic or Oleic Series.............................. 254

3. Acids of the Series $\mathrm{C}_{n} \mathrm{H}_{2 n-4} \mathrm{O}_{2}$. Open Chain Acids. Acids of the Linolic Series...................... 255

II. Physico-Chemical Constants of Various Alcohols........... 256

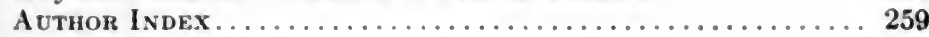

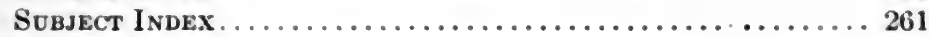





\section{PART ONE}

THE COLLOID CHEMISTRY OF SOAPS 



\title{
SOAPS AND PROTEINS
}

\author{
PAR'T ONE \\ THE COLLOID-CHEMISTRY OF SOAPS \\ I
}

\section{SOAP MAKING}

\section{Introduction}

If there are included in the definition of soap all those compounds which are formed when a metallic base (including ammonium) is united with a fatty acid radical, any effort to emphasize their wide importance is largely superfluous. Not only do various soaps appear, change and then disappear in living animal and plant cells under various circumstances, not only do they constitute, from both a qualitative and a quantitative viewpoint, one of the chief interests of theoretical and practical chemists, but their existence, availability and properties have much to do with the very esthetics of our existence, from clean clothes to the fine arts.

The making of soap-even when carried out in ton lots by the modern manufacturer-does not in our day differ materially from the methods employed by the pristine housewife. "Fats" and "oils" are still stirred or boiled in a kettle with a caustic alkali of some sort. The modern concept of what happens under such circumstances may be said to date from Chrvrrus, who in 1815 showed that "fats" and "oils," whether of plant or animal origin, are compounds of fatty acid with alcohol, usually the triatomic alcohol, glycerin. When such compounds (esters, in other words) are treated with an alkali, double decomposition ensues, the metallic radical uniting with the fatty acids contained 
in the fat or oil to form the corresponding soaps, while alcohol (glycerin) is split off. Expressed graphically and for a single "fat":

$$
\begin{aligned}
& \mathrm{C}_{3} \mathrm{H}_{5}=\begin{array}{l}
\mathrm{O} \cdot \mathrm{C}_{18} \mathrm{H}_{35} \mathrm{O} \\
\mathrm{O} \cdot \mathrm{C}_{18} \mathrm{H}_{35} \mathrm{O}+3 \mathrm{NaOH}=3 \mathrm{NaO} \cdot \mathrm{C}_{18} \mathrm{H}_{35} \mathrm{O}+\mathrm{C}_{3} \mathrm{H}_{5}(\mathrm{OH})_{3} . \\
\mathrm{O} \cdot \mathrm{C}_{18} \mathrm{H}_{35} \mathrm{O}
\end{array} \\
& \text { Glyceryl stearate }+\underset{\text { hydroxid }}{\text { sodium }}=\text { sodium stearate }+ \text { glycerin }
\end{aligned}
$$

It is important for our purposes to note, first, the variables contained in the elements constituting the reaction mixture.

There is (1) the fat. While all the fats are esters, they run the gamut in mere physical attributes from the extreme, on the one hand, of liquids not unlike water, through viscid oils, to the extreme, on the other hand, of solids like "waxes," which can hardly be broken with a hammer. But, from a chemical point of view, it is obvious that these may also differ widely from each other both as to (a) kind of fatty acid found in the ester, and (b) kind of alcohol united to the fatty acid. Even without embracing the theoretical extremes we find at the one end fatty acids with, say, six carbon atoms in the molecule, while at the other may be those with two dozen. The alcohol found in the fat is usually glycerin, but diatomic or monatomic alcohols may take its place.

A second variable concerns (2) the hydroxid employed. Since the commoner soaps of commerce are sodium soaps, sodium hydroxid is the alkali ordinarily employed. In "soft" soap manufacture potassium hydroxid is used, for the soft soaps are potassium soaps. Directly or indirectly, however, other hydroxids or bases are of much scientific or technologic importaniee. Sodium, potassium and ammonium are of significance when ordinary "washing" soaps are under consideration, but the wide distribution of magnesium and calcium compounds in various "waters" makes necessary a knowledge of the properties of the soaps of these metals when "hard" waters are used. The importance of the heavy metals, like zinc and lead, becomes apparent when it is recalled that zinc stearate is used as a dusting powder in skin affections and that the plastic properties of lead plasters and of various paints is dependent upon the lead soaps found or formed in these mixtures. 
Another variable is represented by (3) the water. It must be constantly borne in mind that soap manufacture is carried out in the presence of relatively little water. As ordinarily expressed, soap making proceeds in a highly concentrated reaction mixture. Not without its important influence is the presence of (4) the alcohol (glycerin) split off in the process of manufacture. A final variable that must be considered in the ordinary process of soap manufacture is (5) the temperature. Many soaps can be made, and are made, at ordinary temperatures or by the "cold " process; more commonly, however, they are "boiled."

The so-called Twitchell process of soap manufacture differs from the above only in the fact that instead of the neutral fats (in other words, glycerids or esters) the free fatty acids are used. In this process the original fat is first broken into fatty acids and glycerin, and the separated fatty acids are brought by themselves into the soap kettle. To them is then added an appropriate hydroxid, and the soap is made. Fundamentally, however, the variables in the reaction mixture are, from both a chemical and a physical standpoint, essentially those already listed, except that glycerin is missing.

The conversion of a neutral fat (or of a fatty acid) into soap requires time. However, if the reaction has been carried to completion, and if no excess of any of the ingredients has been employed, it is obvious that the final mixture in the soap kettle must consist of (1) water, (2) alcohol (glycerin) and (3) soap. The soap must be examined (a) from the point of view of the fatty acids which it contains, and $(b)$ from that of the basic radical or radicals which it may hold. This fundamental process of soap manufacture is complicated, however, by a procedure which introduces a new variable into the general problem and which, in consequence, requires special analysis. This is (4) the "saltingout" process. In the manufacture of the ordinary washing soaps, for example, the fat with its added alkali or the fatty acid with its requisite alkali is boiled until soap formation is assumed to be complete. There is then added either $(a)$ a great surplus of the alkali (like sodium hydroxid) or more commonly $(b)$ a neutral salt. Usually sodium chlorid is shoveled into the soap kettle. As generally expressed, the excess of alkali or the presence of the sodium chlorid makes the soap "insoluble " in the "lye," wherefore it "grains" and floats to the top of the boiling soap mixture. 
In commercial soap manufacture, this surface layer of soap (bringing with it a certain amount of water, of excess alkali or salt, and some glycerin if the Twitchell process is not the one employed) is separated from its lye, is permitted to cool and after more or less handling is made into " cakes" for trade purposes.

\section{Soap Making as a Colloid-Chemical Problem. The Fatty Acids of the Technical and Theoretical Chemists}

Until the eighties of the last century, soap itself and the processes of its manufacture were looked at from a purely " chemical" point of view. The soaps were, in other words, regarded as ordinary salts which were either "soluble" or "insoluble" in water or other solvents. When soluble, the resulting soap "solutions" were generally regarded as obeying the laws characteristic of the ordinary solutions. In 1888 Franz Hofmeister ${ }^{1}$ chose the soaps in general and sodium oleate in particular as materials of "colloid" nature and as fit substances upon which to test out the dehydrating effects of various salts. The notion that soaps were " normal electrolytes," that solutions of soap follow the laws of osmotic pressure and in other ways comported themselves as true solutions continued, however, into the nineties, when F. KrafFT ${ }^{2}$ and his co-workers pointed out that the more concentrated solutions of soap did not show the calculated depressions of the freezing point or elevations of the boiling point of true solutions. KRAFFT and his fellow workers therefore declared these more concentrated soap solutions " colloid." Further impetus to the development of this colloid-chemical notion of the soaps was given by F. GoLDschmidt and his pupils, ${ }^{3}$ while various articles subsequently written by J. LeimdörFer, ${ }^{4}$ F. Botazzi, C. Victorow ${ }^{5}$ and $\mathrm{W}$. BachmanN ${ }^{6}$ may be said to have established with finality that the soaps, in the concentrated form

${ }^{1}$ Franz Hofmeister: Arch. f. exp. Path. u. Pharm., 25, 6 (1888).

${ }^{2}$ F. KraffT and H. Wiglow: Ber. d. deut. chem. Gesellsch., 28, 2573 (1895)

${ }^{3}$ F. Goldschmidt: Kolloid-Zeitschr., 2, 193, 227 (1908); F. Goldschmidt and L. WeissmanN: Kolloid-Zeitschr., 12, 18 (1913).

4 J. Leimdörfer: Kolloidchem. Beihefte, 2, 343 (1911).

${ }^{5}$ F. Botazzi and C. Vrctorow: Kolloid-Zeitschr., 8, 220 (1911), accessible only as review.

${ }^{6}$ W. Bachmann: Kolloid-Zeitschr., 11, 145 (1912). 
in which they are encountered in the ordinary processes of the soap manufacturer, represent typical colloid-chemical systems.

The relationship between the older physico-chemical views, which proved that soaps under certain circumstances act as " normal electrolytes," and the insistence of later observers that they are colloids will become clearer as we proceed. Since the "soaps" ordinarily discussed are mixed soaps, and since the properties of such mixed systems are in themselves dependent upon the nature of the soaps entering into these mixed systems, it is best to begin by an investigation of the physico-chemical properties of the pure soaps themselves.

It is well, for this purpose, to list the fatty acids of the technical and theoretical chemists. This is done in the following table which is taken from J. Lew коw ${ }^{2}$ sch. $^{1}$ Those fatty acids of the various categories which receive special study in the succeeding pages are printed in bold face.

\section{TABLE I}

I. Acids of the Series $\mathrm{C}_{n} \mathrm{H}_{2 n} \mathrm{O}_{2}$. Acids of the Acetic Series

\begin{tabular}{|c|c|}
\hline 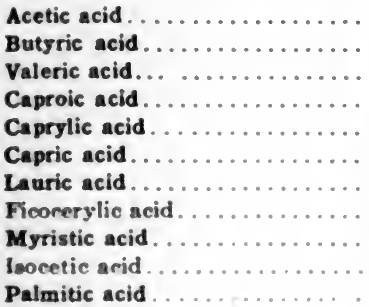 & 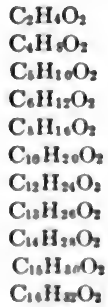 \\
\hline
\end{tabular}

\begin{tabular}{|c|c|}
\hline Mas & $\mathrm{C}_{12} \mathrm{H}_{36} \mathrm{O}_{2}$ \\
\hline Stear & $\mathrm{C}_{12} \mathrm{H}_{3} \mathrm{O}$ \\
\hline Arachidic acid. & $\mathrm{C}_{2} \mathrm{H}_{6} \mathrm{O}_{3}$ \\
\hline ........... & $\mathrm{C}_{2 \mathrm{H}} \mathrm{H}_{4} \mathrm{O}$ \\
\hline Lign & $\mathrm{C}_{24} \mathrm{H}_{40} \mathrm{O}_{3}$ \\
\hline Carna ubic acid.............. & $\mathrm{C}_{24} \mathrm{H}_{42} \mathrm{O}_{2}$ \\
\hline Pisangcerylic acid........... & $\mathrm{C}_{2} \mathrm{H}_{4} \mathrm{O}$ \\
\hline$\ldots \ldots \ldots \ldots \ldots$ & $\mathrm{C}_{3} \mathrm{H}_{44} \mathrm{O}_{2}$ \\
\hline Montanic acid. . . . . . . . . . . & $\mathrm{C}_{2} \mathrm{H}_{24} \mathrm{O}$ \\
\hline$\ldots \ldots \ldots$ & $\mathrm{C}_{m} \mathrm{H}_{m} \mathrm{O}_{2}$ \\
\hline Pвyl & $\mathrm{CnH}_{n} \mathrm{O}$ \\
\hline
\end{tabular}

II. Acids of the Sertes $\mathrm{C}_{n} \mathrm{H}_{2 n-2} \mathrm{O}_{2}$. Acids of the Acrylic or Oleic Serieg

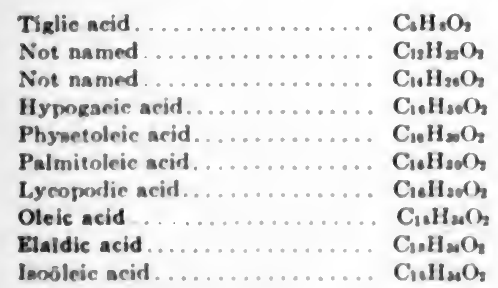

\begin{tabular}{|c|c|}
\hline Rap & $\mathrm{C}_{3} \mathrm{HI}_{4} \mathrm{C}$ \\
\hline Petroselinic acid. . & $\mathrm{C}_{1:}$ \\
\hline Chei & $\mathrm{C}_{1} \mathrm{H}_{2} \mathrm{O}_{2}$ \\
\hline cid. . & C.: \\
\hline Doe & $\mathrm{O}_{3}$ \\
\hline (etred) ..... & $\mathrm{C}_{1} \mathrm{H}_{2} \mathrm{O}_{3}$ \\
\hline Gardolein acid. & $\mathrm{C}_{2} \mathrm{H}_{20} \mathrm{O}_{2}$ \\
\hline Eru & $\mathrm{C}_{\mathrm{n}} \mathrm{HleO}_{\mathrm{n}}$ \\
\hline Bra & $\mathrm{C}_{n} \mathrm{HI}_{\mathrm{ar}} \mathrm{O}$ \\
\hline Inoerucic & $\mathrm{C}_{\mathrm{n}} \mathrm{H}_{65 \mathrm{O}}$ \\
\hline
\end{tabular}

'J. Lewrowitscn: Oils, Fats and Waxes, 5th Ed, 1, 111, Iondon (1913). 
III. Acids of the Series $\mathrm{C}_{n} \mathrm{H}_{2 n-4} \mathrm{O}_{2}$

(a) Open Chain Acids

(a) Acids of the Linolic Series

Linolic acid.

Millet oil acid

. $\mathrm{C}_{18} \mathrm{H}_{22} \mathrm{O}_{2}$

Eleomargaric (Elæostearic)

Telfairic acid.

$\mathrm{C}_{18} \mathrm{H}_{32} \mathrm{O}_{2}$

acid.

$\mathrm{C}_{18} \mathrm{H}_{22} \mathrm{O}_{2}$

( $\beta$ ) Acids of the Tariric Series

Tariric acid.

. $\mathrm{C}_{18} \mathrm{H}_{32} \mathrm{O}_{2}$

(b) Cyclic Acids. Acids of the Chaulmoogric Series

Hydnocarpic arid.

$\mathrm{C}_{16} \mathrm{H}_{28} \mathrm{O}_{2} \quad$ Chaulmoogric acid.

$\mathrm{C}_{18} \mathrm{H}_{28} \mathrm{O}_{2}$

IV. Acids of the Series $\mathrm{C}_{n} \mathrm{H}_{2 n-6} \mathrm{O}_{2}$. Acids of the Linolenic Series

Linolenic acid .................... $\mathrm{C}_{18} \mathrm{H}_{30} \mathrm{O}_{2} \quad$ Jecoric acid (inferred) $\ldots \ldots \mathrm{H}_{20} \mathrm{O}_{2}$

Isolinolenic acid.

$\mathrm{C}_{18} \mathrm{H}_{30} \mathrm{O}_{2}$

V. Acids of the Series $\mathrm{C}_{n} \mathrm{H}_{2 n-8} \mathrm{O}_{2}$. Acids of the Clupanodonic Series

Isanic acid ......................... $\mathrm{C}_{14} \mathrm{H}_{20} \mathrm{O}_{2} \mathrm{H}_{28} \mathrm{O}_{3}$

Therapic acid (inferred) . . . . $\mathrm{C}_{17} \mathrm{H}_{28} \mathrm{O}_{2} \quad$ Arachidonic acid . . . . . . . . $\mathrm{C}_{20} \mathrm{H}_{32} \mathrm{O}_{2}$

Vi. Acids of the Series $\mathrm{C}_{n} \mathrm{H}_{2 n} \mathrm{O}_{3}$. Hydroxylated Acids

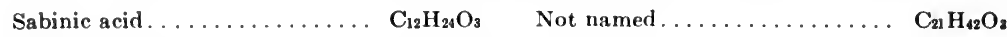

Juniperic acid........................... $\mathrm{C}_{16} \mathrm{H}_{32} \mathrm{H}_{82} \mathrm{O}_{2}$

Lanopalmic acid................ $\mathrm{C}_{16} \mathrm{H}_{32} \mathrm{O}_{3}$

VII. Acids of the Series $\mathrm{C}_{n} \mathrm{H}_{2 n-2} \mathrm{O}_{3}$. Acids of the Ricinoleic Series Ricinoleic acid ............ $\mathrm{C}_{18} \mathrm{H}_{34} \mathrm{O}_{3} \quad$ Ricinic acid................. $\mathrm{C}_{18} \mathrm{H}_{3} \mathrm{O}_{3}$ Isoricinoleic acid . . . . . . . . . $\mathrm{C}_{18} \mathrm{H}_{34} \mathrm{O}_{3} \quad$ Quince oil acid . . . . . . . . . . $\mathrm{C}_{18} \mathrm{H}_{3} \mathrm{O}_{2}$ Ricinelaidic acid............... $\mathrm{C}_{18} \mathrm{H}_{34} \mathrm{O}_{3}$

ViII. Acids of the Series $\mathrm{C}_{n} \mathrm{H}_{2 n} \mathrm{O}_{4}$. Dihydroxylated Acids

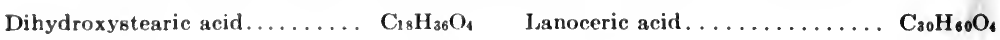

IX. Acids of the Series $\mathrm{C}_{n} \mathrm{H}_{2 n-2} \mathrm{O}_{4}$. Dibasic Acids

Heptadecamethylenedicarboxylic acid........................ $\mathrm{C}_{19} \mathrm{H}_{36} \mathrm{O}_{4}$

Octodecamethylenedicarboxylic

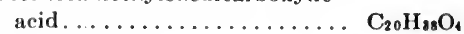

Japanic acid.............. $\mathrm{C}_{21} \mathrm{H}_{40} \mathrm{O}_{4}$

With these remarks, we shall proceed at once to a study of the water-holding power of various pure soaps. 


\section{THE SYSTEM SOAP/WATER}

\section{Introduction}

In the course of our work on the stabilization of emulsions ${ }^{1}$ (in which we showed that the maintenance of a water-in-oil type of emulsion is dependent, in the main, upon the substitution of a colloid hydrate for the pure water) we were struck by the fact that no detailed figures are available which discuss in any systematic fashion the absolute hydration or gelation capacities of various pure soaps. Even though many studies ${ }^{2}$ on the chemistry of soaps and their general colloid behavior are available, and even though we possess much empiric knowledge regarding the water content of various commercial soaps, these investigations deal, for the most part, with mixed soaps, with soaps prepared in alcoholic solution or with such as have been "saltedout." But, as will be shown in this and subsequent sections, all these circumstances may materially modify the water-holding powers of the involved pure soaps, so that we found it necessary for our own purposes to prepare pure soaps with such factors eliminated. Since the values which we have obtained are not only of 1. direct chemical and technological interest, but form the basis for theoretical views covering the nature of the lyophilic colloid state 2. and the behavior of living organisms which are composed of such materials, ${ }^{3}$ we give below our detailed findings. First to be discussed is the system composed of pure soap plus water.

' Martin H. Fischer and Marian O. Hooker: Science, 43, 468 (1916); Kolloid-Zeitschr., 18, 129 (1916); ibid., 18, 242 (1916); Fats and Fatty Degeneration, 29, New York (1917).

Sec for example F. Hofmeisten: Arch. f. exp. Path. u. Pharm., Q5, 6 (1888); F. Krafrt and H. Wianow: Ber. d. deut. chem. Gesellsch., 28, 2573 (1895); F. Mrrkis: Fitude sur la constitution des savons du commerce, Marseilles (1906); F. Goldscumut: Kolloid-Zeitschr., 2, i93, 227 (1908); J. Ls.ıмdörrer: Kolloid-chem. Beihefte, 2, 343 (1911); F. Botazzı and C. Victorow: Kolloid-Zeitschr., 8, 220 (1911), accessible only as review; W. Bachmasx: Kolloid-Zeitschr., 11, 145 (1912); F. Golnscimudt and L. Wrissmans: Kolloid-Zeitschr., 12, 18 (1913); J. Lевwkowitscn: Oils, Fats and Waxes, 5th Fd., 3, 299, Iondon (1915).

'See page 64; also Martin H. Frschen and Makix O. HookrR: Science, 48, 143 (1918); Martis H. Fiscurn: Fideun and Nephritis, 3rd Ed., New York (1920). 


\section{Preparation and Gelation Capacities of Some Pure Soaps with Water}

Unless otherwise noted, we prepared all our soaps in exactly the same way, namely, by neutralizing a definite weight (one mol) of the pure fatty acid with a chemically equivalent amount of the hydroxid, oxid or carbonate of the necessary metal in a unit volume (one liter) of water, keeping the whole mixture at the temperature of a boiling water bath until union between the acid and base had been accomplished. Care was taken to prevent or to make good any loss of water from the reaction mixturewhile in the bath. Under these circumstances we are dealing in the end, of course, only with a unit weight of some pure soap in the presence of a unit weight of water. This detail regarding the histories of their preparation is of little interest from a "chemical" point of view, but, since the soaps are "colloid," it is of vital importance from a physical one and, therefore, in the elucidation of the final result obtained. After we had prepared our soaps, the reaction mixtures were cooled to $18^{\circ} \mathrm{C}$. and the yields of soap weighed. When the entire mixture became gelatinous or solid we considered that all the water had been " absorbed" by the soap." When "free" water began to appear above the soap, the weight of the theoretical yield of "dry" soap was subtracted from the weight of the soap as produced, the difference being expressed as percent of water "absorbed" by the soap in terms of the weight of the theoretical "dry" yield.

a. Soaps with Different Basic Radicals. We began our experiments by preparing a series of linolates. The exact experimental methods followed and the results obtained may be deduced from Table II. The striking differences in the absolute amounts of water taken up by these different soaps is readily apparent to the naked eye. To illustrate the matter Fig. 1 is introduced.

The different water-holding capacities of a series of oleates and stearates is shown in Tables III and IV and Figs. 2 and 3. The experimental procedure in their production was the one described above. A comparison of these figures and findings with those obtained in the linolate series is of interest because the three fatty

${ }^{1}$ This is really not the case, for what we actually determined was the gelation point. How this differs from the hydration (or solvation) point will become clear later. See page 74 . 


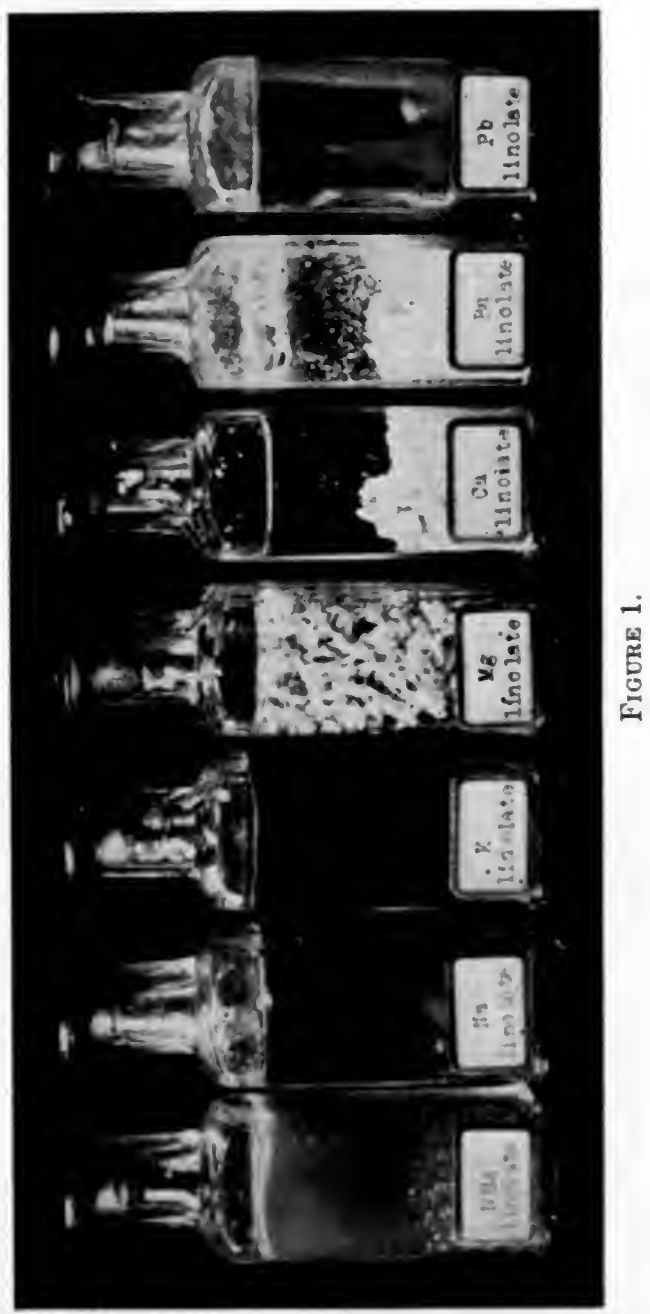




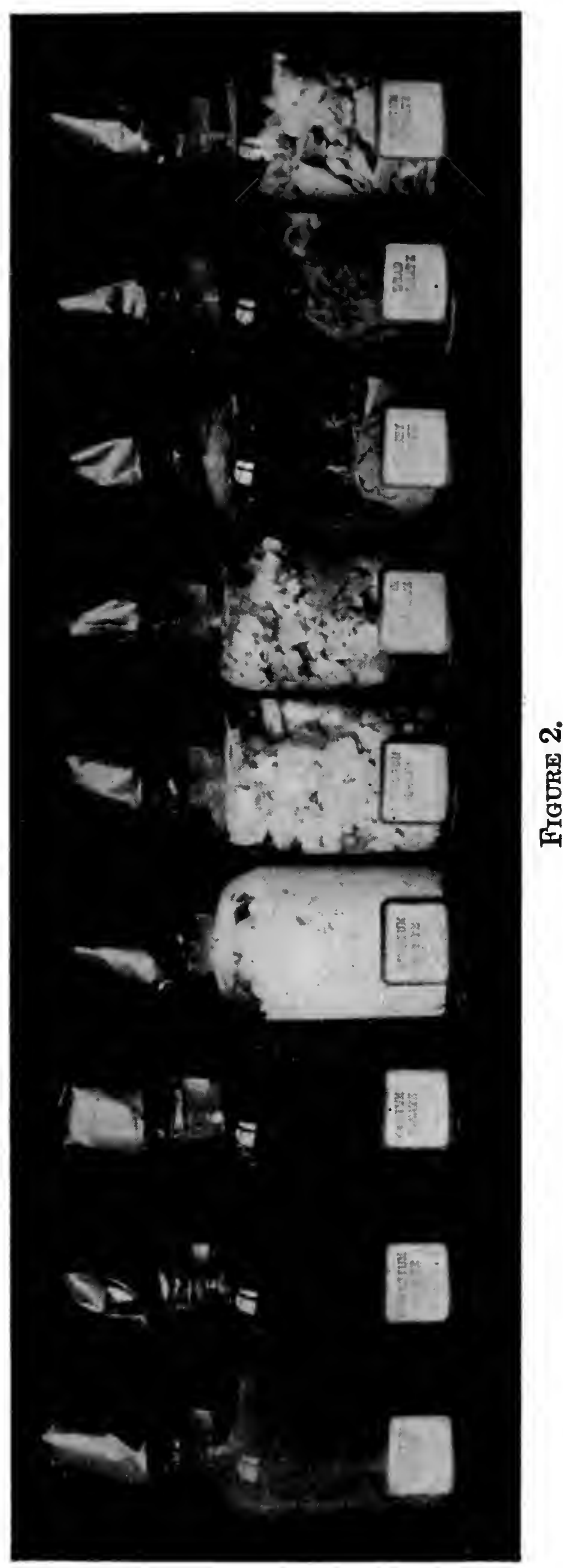




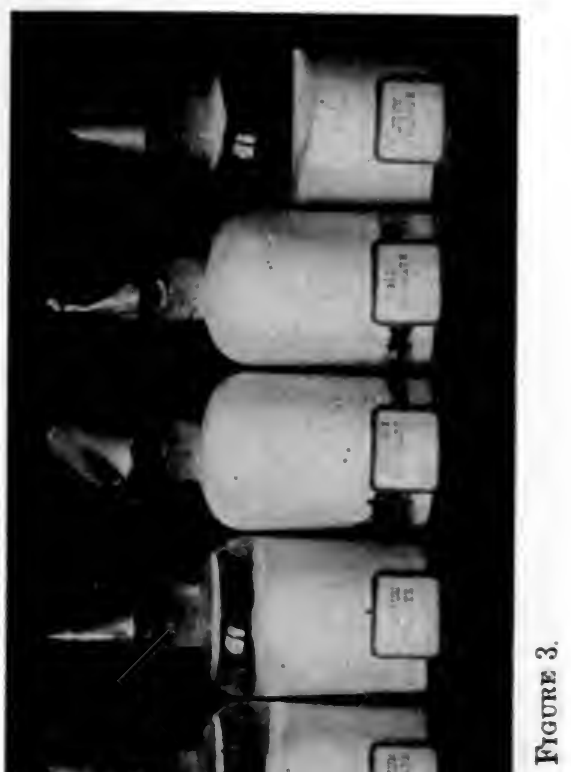

acids are all eighteen carbon atom acids, but are of three different series, varying in their degrees of hydrogenation as is shown in the following empiric formula:

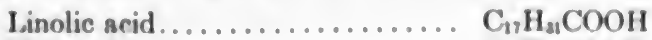

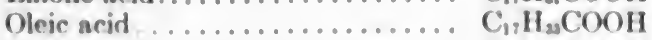

Stearic acid.............. $\mathrm{C}_{37} \mathrm{H}_{3} \mathrm{COOH}$ 
In Tables V and VI and Figs. 4 and 5 are shown the gelation capacities of a series of palmitates and a series of laurates.

These five sets of experiments show that a first factor in the amount of water held by different soaps is resident in the nature of

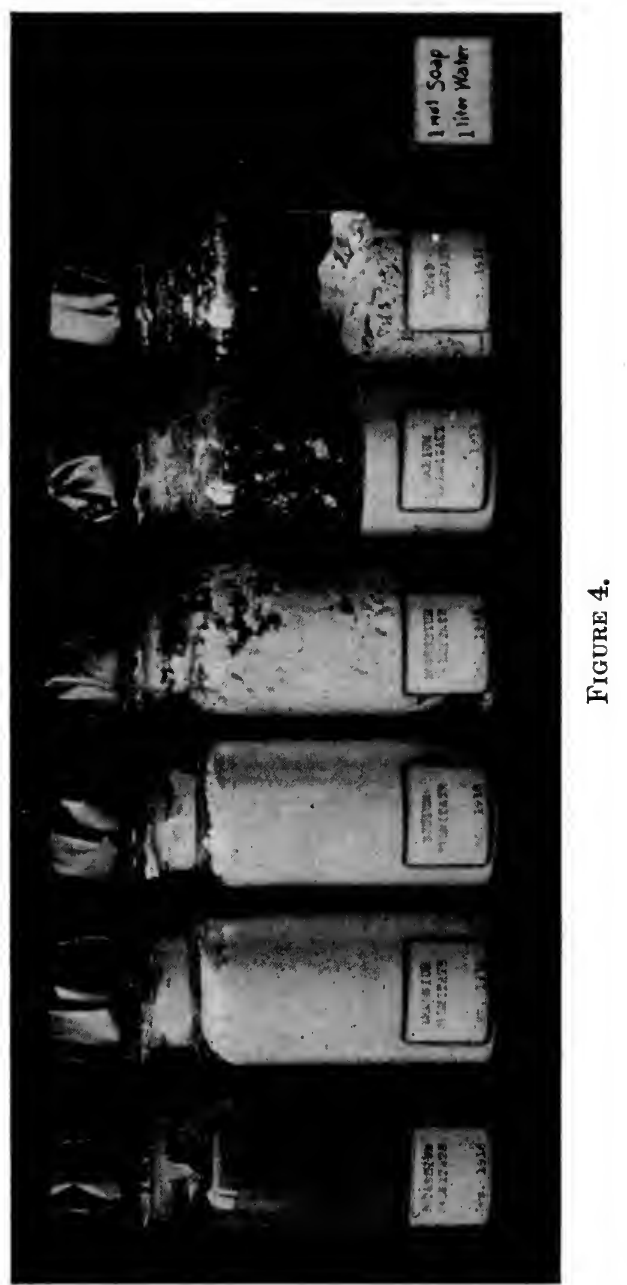

the metallic radical combined with the fatty acid. If the radical most effective in this regard is given first, the sequence is about as follows: 
As reference to the original experiments in the tables shows, it is especially the last mentioned members in the series which are likely to be transposed.

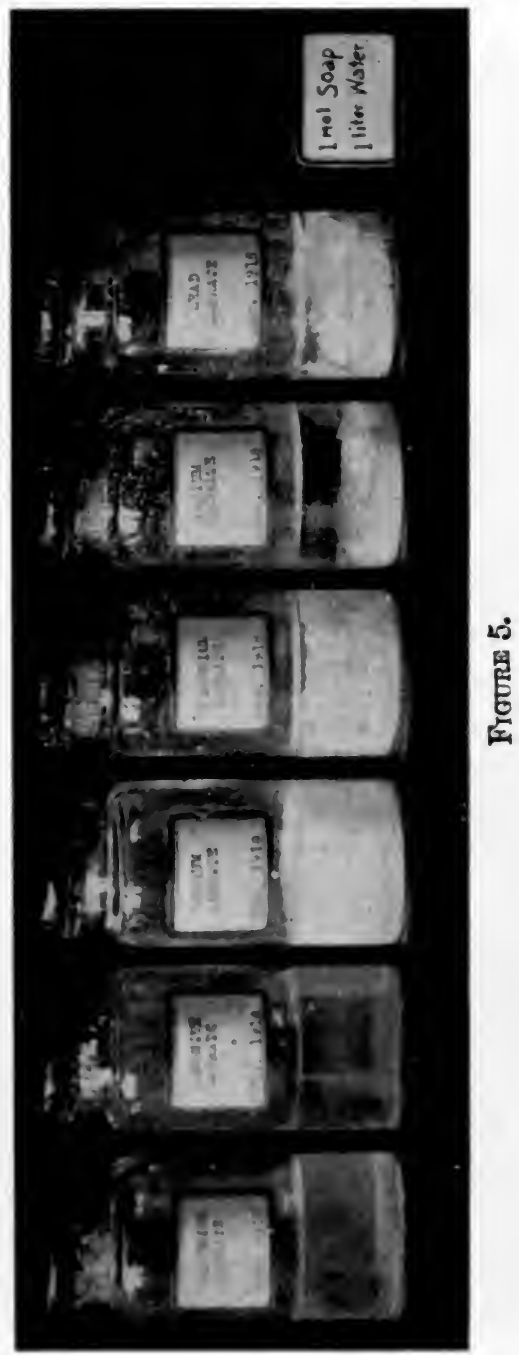

b. Soaps with Different Acid Radicals. We turned next to the question of water absorption by soaps possessed of a common base and prepared under identical conditions but containing differ- 


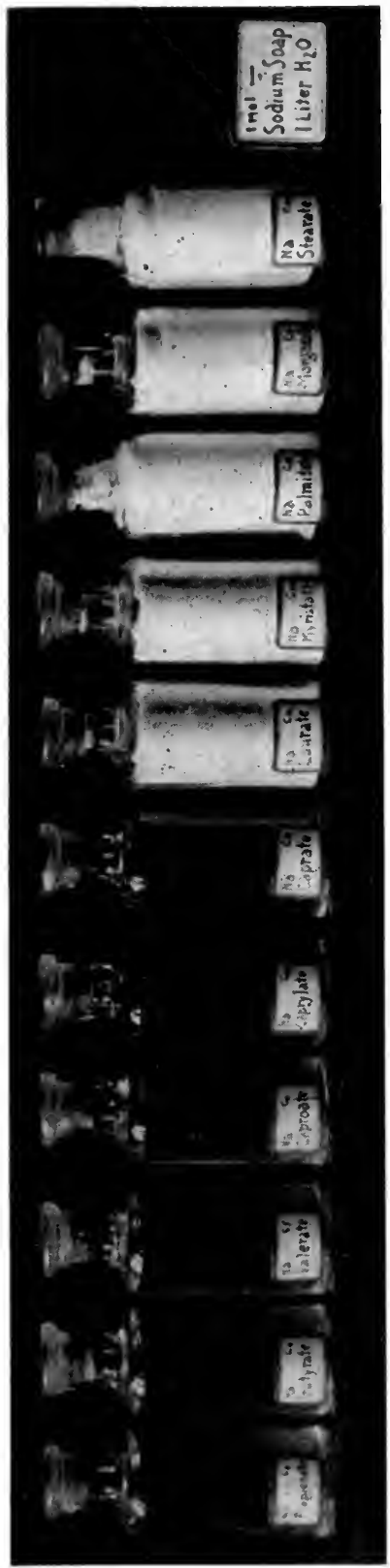

ent fatty acid radicals. The results in the case of the sodium salts of the acetic acid series are shown in Fig. 6. All the soaps were so made that in the end one mol of the soap was produced in the presence of one liter of water.

As Fig. 6 shows (the formate and acetate have been omitted) the lowermost members of this series yield only molecular ("true") solutions under these experimental conditions. The solutions of sodium caprylate and caprate, as here prepared, show decidedly lasting foams, indicating that they are approaching colloid properties. Beginning with sodium laurate, all the remaining soaps yield solid white gels.

The same general truths are shown for the potassium salts of the acetic acid series in Fig. 7 . Here again the lower members yield only "true" solutions, the middle ones liquid colloids, the upper ones solid gels.

These two groups of experiments show that under otherwise fixed conditions the water-absorbing power of any soap depends upon the nature of the fatty acid in the soap, increasing with its height in a given series.

To get a more accurate measure of the amounts of water that can thus be held by a series of different sodium soaps we made the following experiment. 
Molar equivalents of several different sodium soaps of the acetic acid series were prepared as described above, but in the presence of gradually increasing amounts of water. Water was added until, upon cooling the soap mixture to $18^{\circ} \mathrm{C}$., a solid gel, or one not showing "syneresis," was no longer obtained. Stated conversely, it was presumed that the limits for water absorption had been exceeded as soon as we obtained only a "solution" of the given soap or one which showed free liquid at the temperature chosen $\left(18^{\circ} \mathrm{C}\right.$.).

The results of an actual experiment are portrayed in Fig. 8 . The lowermost members of the sodium salts of the acetic acid series take up no water at all; they yield only "true" solutions. Sodium caproate forms a true solution in very little water, but when this is slowly evaporated

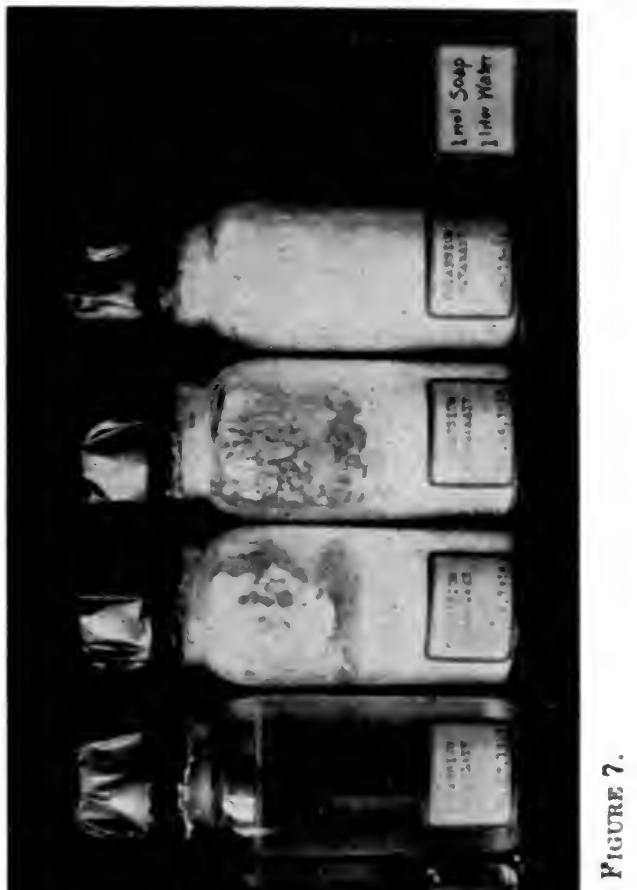




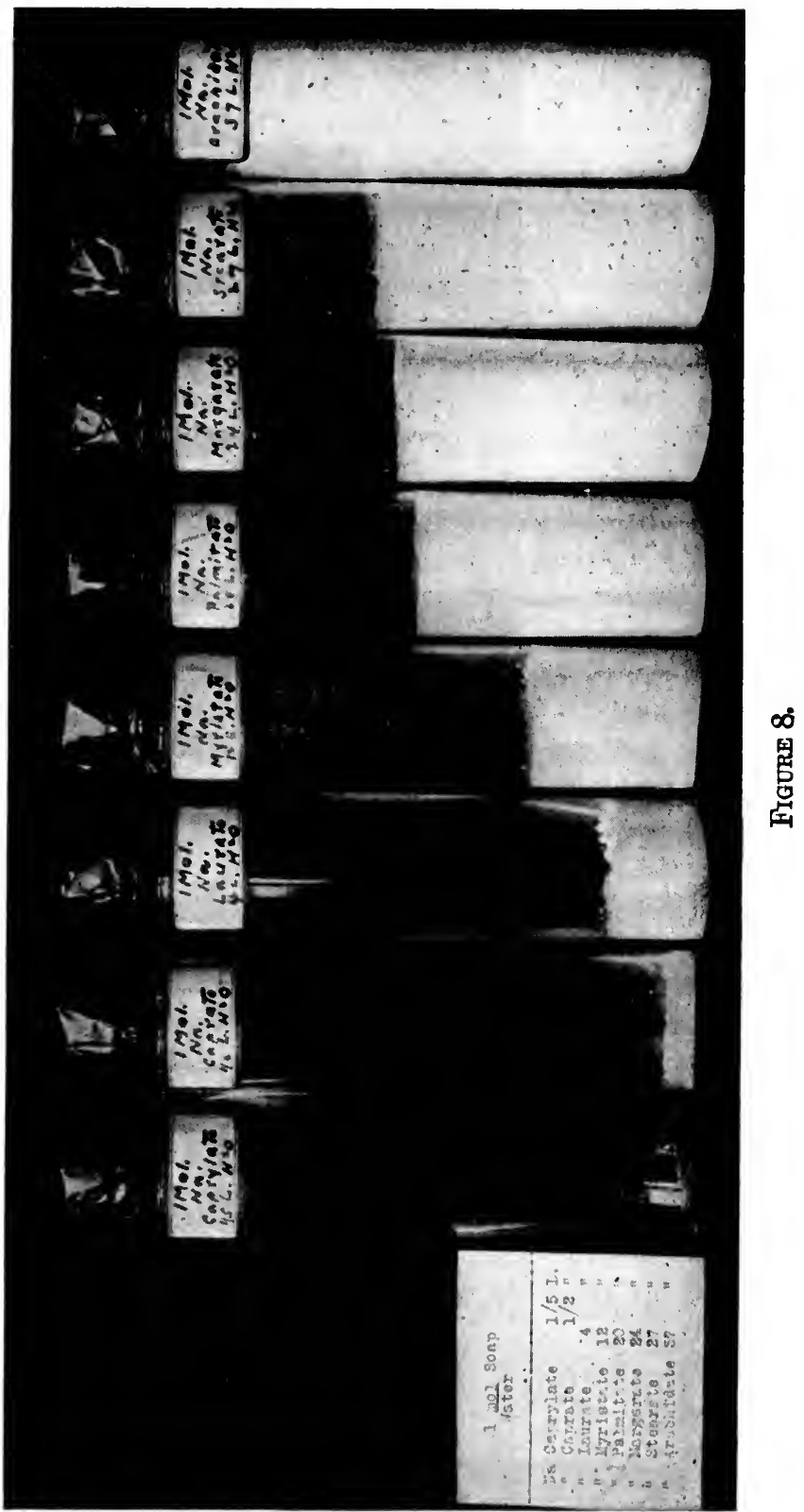


one does not always get a crystalline product. The residue is frequently shellac-like. Sodium caproate may therefore be taken as the first soap in the series to show any waterholding power. Sodium caprylate easily yields true solutions, but if the amount of water is chosen correctly a beautiful gel results at $18^{\circ} \mathrm{C}$. The amount of water for one mol

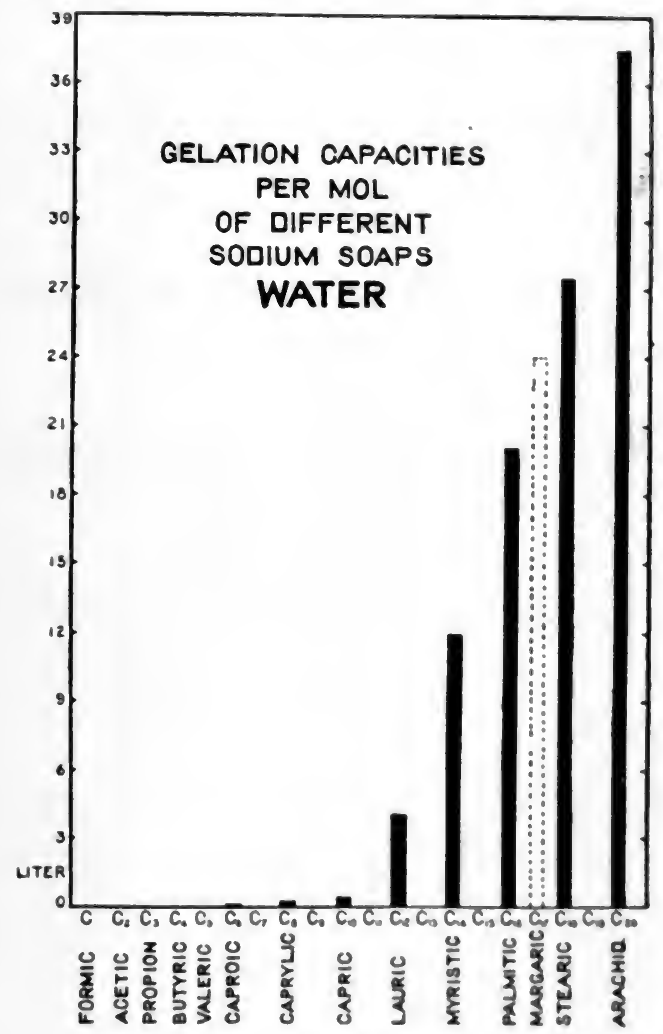

Fioure 9.

of the soap must not exceed 200 cc. The matter is illustrated in the left hand bottle of Fig. 8. Sodium caprate still yields a solid gel if $500 \mathrm{cc}$. of water are present to the mol of sosp. This is shown in the second bottle of Fig. 8. As we mount in the acid series, the water-holding capacity grows tremendously. One mol of sodium laurate will hold 4 liters of water; the same amount of sodium myristate, 12 liters; of sodium palmitate, 20 liters; of 


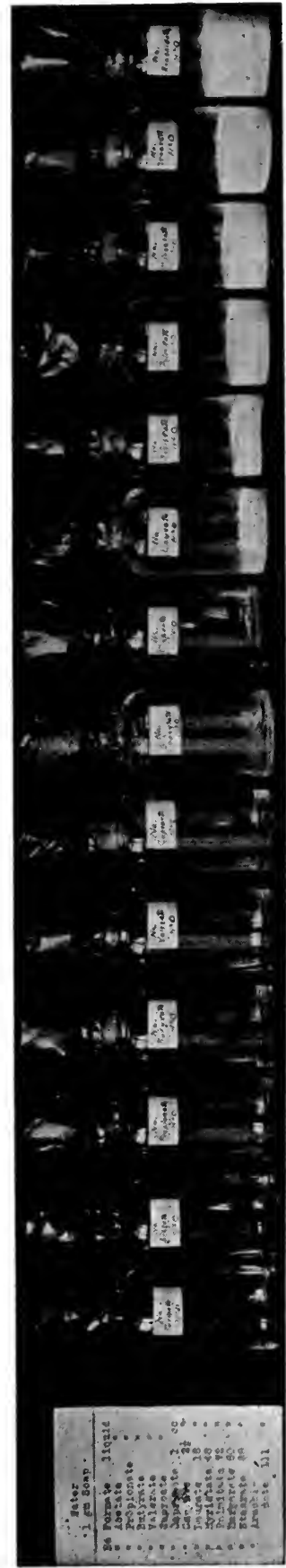

sodium margarate, 24 liters; of sodium stearate, 27 liters and of sodium arachidate, the enormous value of 37 liters. These facts are illustrated in the remaining bottles of Fig. 8 and, in graphic form, in Fig. 9.

Sodium margarate, holding its 24 liters of water to the mol of soap, assumes its rightful place in the acetic series as indicated in the broken line column of Fig. 9, but, since it does not seem to be settled as yet that margaric acid is more than a "eutectic" mixture of palmitic and stearic acids, this point should not be too heavily stressed. The soap of pelargonic acid $\left(\mathrm{C}_{9}\right)$ we have not yet been able to study. Both the sodium and potassium salts of cerotic acid $\left(\mathrm{C}_{27}\right)$ are so slightly hydratable $\therefore$ (even after subjection to high temperatures and increased atmospheric pressure) that this acid does not fit into the smooth series of the soaps already described. Excepting these three acids, it will be noted therefore that all the water-holding soaps are of acids with an even number of carbon atoms in the empiric formula, a fact which may not be without significance in deciding which of the acids of the empiric formula $\mathrm{C}_{n} \mathrm{H}_{2 n+1} \mathrm{COOH}$ belong in a true series.

In the experiment just described, the water-holding power per gram-molecule of soap was determined. In order to get this value for equivalent weights of the different soaps, the series of experiments illustrated in Fig. 10 was performed. In this instance, water was added to one gram of each of the carefully dried sodium soaps until, after 
solution in a hot water bath, a dry gel was no longer obtained on reducing the temperature of the mixture to $18^{\circ} \mathrm{C}$. It is again evident that only liquid mixtures (true solutions) are obtained upon the addition of even trifling amounts of water to

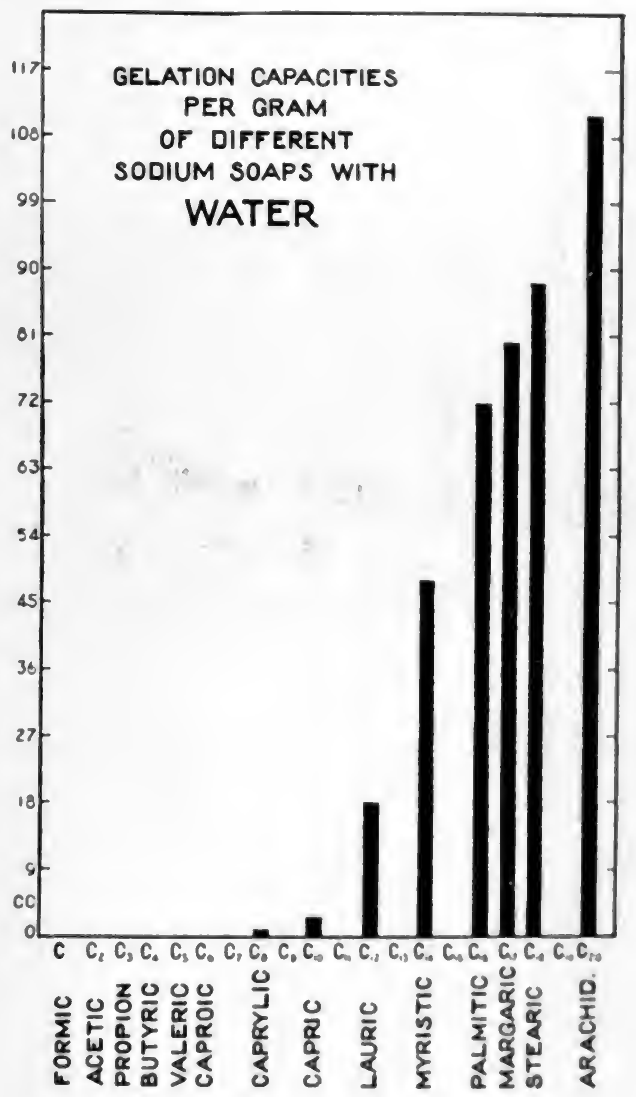

Figure 11.

the lowermost members. The actual amounts of water taken up by the higher members per gram of soap are shown in Table VII and, graphically, in Fig. 11.

The water-holding capacities of three sodium soaps of the oleic series (oleate, elaidate and erucate) and that of sodium linolate are shown in Fig. 12 and Tables VIII and IX. There two tables 
show that, in the oleic series also, the soap of the higher fatty acid has a greater absolute gelation capacity than a lower one.

Because linolic, oleic and stearic acids differ from each other only in the degree of their hydrogenation it is of interest to compare the gelation capacities of their three sodium soaps. The amount of water in cc. held per gram of dry soap is as follows:
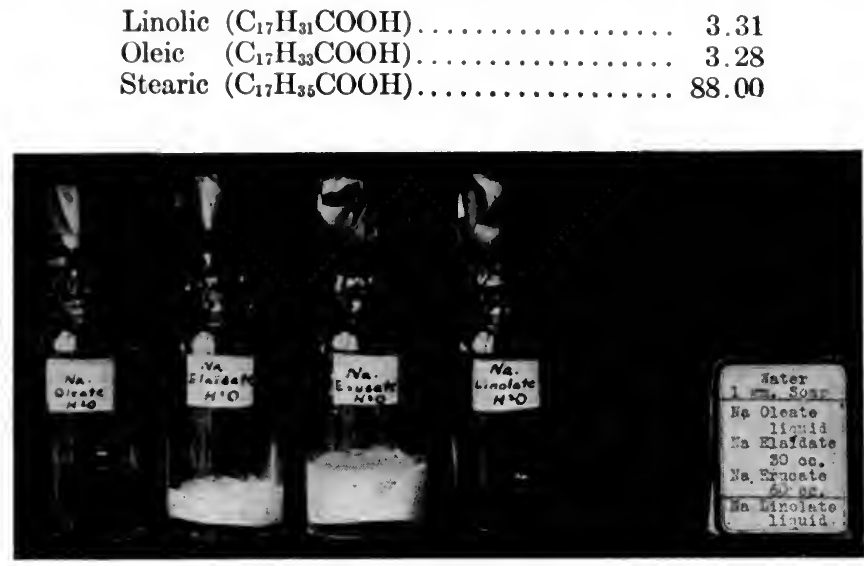

Figure 12.

When comparison is made of the amount of water in cc. held per mol of dry soap, the values are as follows:

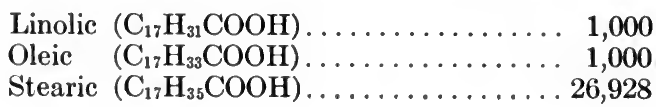

Or, expressed as percent of soap required to yield the described colloid systems:

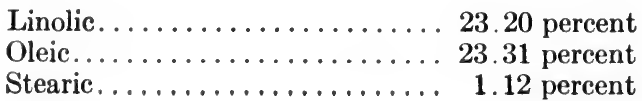

c. The Effects of Water Concentration. The physical state of a soap/water system has in the above paragraphs been shown to be dependent upon (a) the type of base, and $(b)$ the type of fatty acid in the soap. We wish now to emphasize the fact that a third element in the matter is $(c)$ the concentration of the water. This item, which will be considered in greater detail later because 
of its importance for the general theory of the colloid state, ${ }^{1}$ is illustrated for a number of the sodium and potassium soaps of the fatty acids of the acetic series in Fig. 13. Each pair of tubes contains 10 cc. of a half molar "solution" of the sodium or potassium salt of propionic, butyric, valeric, caproic, caprylic, capric, lauric, myristic, palmitic, margaric or stearic acid. It will be observed that the first six pairs of tubes from the left all contain mobile, clear liquids-in other words, liquids that look like true solutions. In the seventh pair (laurates) the sodium salt lies as a colloid mass in a solution of sodium laurate while the potassium salt yields only a solution. In the eighth pair (myristates) the sodium salt yields a solid white gel while the potassium salt still yields in part a "true" solution with a colloid mass lying in the bottom. Beginning with the palmitate pair and through the margarate and stearate, only solid white gels are obtained. This experiment suffices to show that a colloid soap system may be obtained with water only when the concentration of the water is kept sufficiently low and that when equivalent concentrations are compared a sodium soap becomes colloid sooner than a corresponding potassium soap. As we shall see later, this is because potassium soaps are more soluble in water and tend in consequence to yield molecular (true) solutions over higher ranges of soap concentration than the sodium soaps.

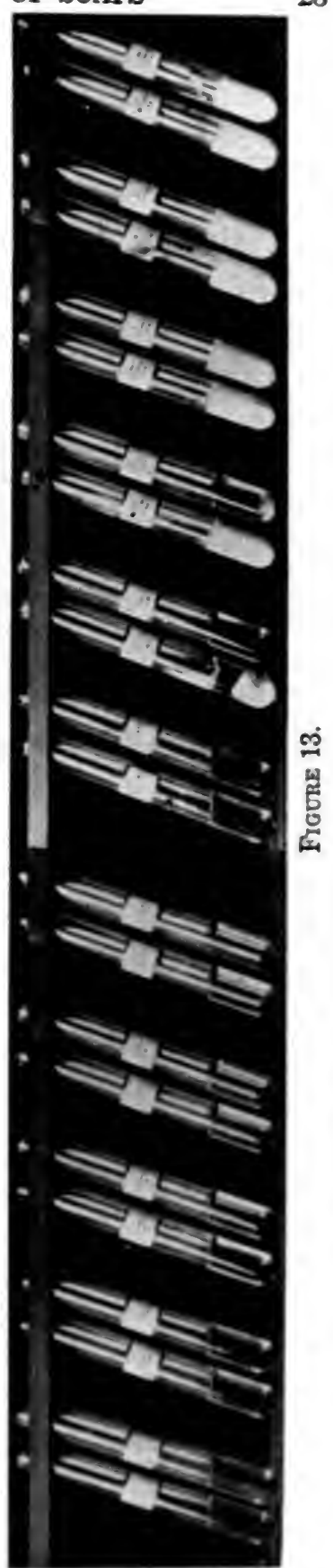

'See page 69. 
TABLE II

Gelation Capacities of Different linolates with Water

\begin{tabular}{|c|c|c|c|c|c|c|}
\hline Soap. & How prepared. & $\begin{array}{l}\text { Theoret. } \\
\text { weight of } \\
\text { dry soap } \\
\text { (m. w. } \\
\text { expressed } \\
\text { in } \\
\text { grams). }\end{array}$ & $\begin{array}{c}\text { Ob- } \\
\text { served } \\
\text { weight of } \\
\text { soap } \\
\text { as } \\
\text { pre- } \\
\text { pared. }\end{array}$ & $\begin{array}{c}\text { Absolute } \\
\text { amount } \\
\text { of } \\
\text { gelation } \\
\text { water. }\end{array}$ & $\begin{array}{c}\text { Percent } \\
\text { of } \\
\text { gelation } \\
\text { water } \\
\text { at } \\
18^{\circ} \mathrm{C} \text {. }\end{array}$ & $\begin{array}{l}\text { Physical } \\
\text { state } \\
\text { at } \\
18^{\circ} \mathrm{C} \text {. }\end{array}$ \\
\hline $\begin{array}{l}\text { Ammonium } \\
\text { linolate }\end{array}$ & $\begin{array}{c}\text { Warm normal ammonium } \\
\text { hydroxid solution poured } \\
\text { into warm linolic acid }\end{array}$ & 297 & 1297 & 1000 & 336 & $\begin{array}{l}\text { Highly vis- } \\
\text { cid, slight } \\
\text { ly cloudy, } \\
\text { y e } 11 \text { o w } \\
\text { liquid }\end{array}$ \\
\hline $\begin{array}{l}\text { Potassium } \\
\text { linolate }\end{array}$ & $\begin{array}{l}\text { Hot normal potassium } \\
\text { hydroxid solution poured } \\
\text { into hot linolic acid }\end{array}$ & 318 & 1318 & 1000 & 314 & $\begin{array}{l}\text { Highly vis- } \\
\text { cid, opal- } \\
\text { escent, } \\
\text { y e } 11 \text { o w } \\
\text { liquid }\end{array}$ \\
\hline $\begin{array}{l}\text { Sodium lino- } \\
\text { late }\end{array}$ & $\begin{array}{l}\text { Hot normal sodium hy- } \\
\text { droxid solution poured } \\
\text { into hot linolic acid }\end{array}$ & 302 & 1302 & 1000 & 331 & $\begin{array}{l}\text { Highly vis- } \\
\text { cid,slight- } \\
\text { ly cloudy, } \\
\text { y e } 11 \text { o w } \\
\text { liquid }\end{array}$ \\
\hline $\begin{array}{l}\text { Magnesium } \\
\text { linolate }\end{array}$ & $\begin{array}{l}\text { Magnesium oxid stirred } \\
\text { into hot linolic acid and } \\
\text { hot water added }\end{array}$ & 291 & 399 & 108 & 37 & $\begin{array}{l}\text { Yellow } \\
\text { sticky } \\
\text { mass }\end{array}$ \\
\hline $\begin{array}{l}\text { Calcium lin- } \\
\text { olate }\end{array}$ & $\begin{array}{l}\text { Dry calcium hydroxid } \\
\text { stirred into hot linolic } \\
\text { acid and hot water added }\end{array}$ & 299 & 404 & 105 & 35 & $\begin{array}{l}\text { White } \\
\text { flakes }\end{array}$ \\
\hline $\begin{array}{l}\text { Barium lino- } \\
\text { late }\end{array}$ & $\begin{array}{l}\text { Dry barium hydroxid } \\
\text { stirred into hot linolic } \\
\text { acidand hot water added }\end{array}$ & 348 & 380 & 32 & 9 & Dry flakes \\
\hline Lead linolatc & $\begin{array}{l}\text { Litharge stirred into hot } \\
\text { linolic acid and hot wa- } \\
\text { ter added }\end{array}$ & 382 & 382 & $382(?) *$ & $(\because)$ & $\begin{array}{c}\text { Sticky yel- } \\
\text { low mass }\end{array}$ \\
\hline
\end{tabular}

* This observation is subject to question because of the possible oxidation of the fatty acid. 
TABLE III

Gelation Capacities of Different Oleates with Water

\begin{tabular}{|c|c|c|c|c|c|c|}
\hline Soap. & How prepared. & $\begin{array}{c}\text { Theoret. } \\
\text { weight of } \\
\text { dry soap } \\
\text { (m. w. } \\
\text { expressed } \\
\text { in } \\
\text { grams). }\end{array}$ & $\begin{array}{c}\text { Ob- } \\
\text { served } \\
\text { weight of } \\
\text { soap } \\
\text { as } \\
\text { pre- } \\
\text { pared. }\end{array}$ & $\begin{array}{l}\text { A besolute } \\
\text { amount } \\
\text { of } \\
\text { gelation } \\
\text { water. }\end{array}$ & $\begin{array}{l}\text { Percent } \\
\text { of } \\
\text { gelation } \\
\text { water } \\
\text { at } \\
15^{\circ} \mathrm{C} \text {. }\end{array}$ & $\begin{array}{l}\text { Physical } \\
\text { olate } \\
\text { at } \\
15^{\circ} \mathrm{C} \text {. }\end{array}$ \\
\hline $\begin{array}{l}\text { Ammonium } \\
\text { oleate }\end{array}$ & $\begin{array}{l}\text { Warm normal ammonium } \\
\text { hydroxid stirred into } \\
\text { warm oleic acid }\end{array}$ & 299 & 1299 & 1000 & $\begin{array}{l}\text { Over } \\
334 .+\end{array}$ & $\begin{array}{l}\text { Clear, solid } \\
\text { gel }\end{array}$ \\
\hline $\begin{array}{l}\text { Potassium } \\
\text { oleate }\end{array}$ & $\begin{array}{l}\text { Hot normal potassium hy- } \\
\text { droxid stirred into hot } \\
\text { oleic acid }\end{array}$ & 320 & 1320 & 1000 & $\begin{array}{l}\text { Over } \\
312.5\end{array}$ & $\begin{array}{l}\text { Clesr, semi- } \\
\text { liguid gel }\end{array}$ \\
\hline $\begin{array}{l}\text { Sodium ole- } 1 \\
\text { ate }\end{array}$ & $\begin{array}{l}\text { Hot normal sodium hy- } \\
\text { droxid stirred into hot } \\
\text { oleic acid }\end{array}$ & 304 & 1304 & 1000 & $\begin{array}{l}\text { Ovet } \\
3289\end{array}$ & $\begin{array}{l}\text { Clear, solid } \\
\text { gel }\end{array}$ \\
\hline $\begin{array}{l}\text { Lithium ole- } \\
\text { ate }\end{array}$ & $\begin{array}{l}\text { Lithium carbonate stirred } \\
\text { into hot oleic acid and } \\
\text { hot water added }\end{array}$ & 288 & $128 s$ & 1000 & $\begin{array}{l}\text { Over } \\
3472\end{array}$ & $\begin{array}{l}\text { White, solid } \\
\text { gel }\end{array}$ \\
\hline $\begin{array}{l}\text { Magnesium } \\
\text { oleate }\end{array}$ & $\begin{array}{l}\text { Magnesium oxid stirred } \\
\text { into hot oleic acid and } \\
\text { hot water added }\end{array}$ & 293 & 510 & 217 & 340 & $\begin{array}{l}\text { White plas- } \\
\text { tic mase } \\
\text { in "free" } \\
\text { water }\end{array}$ \\
\hline $\begin{array}{l}\mathrm{C} \text { a l c i u } \mathrm{m} \\
\text { oleate }\end{array}$ & $\begin{array}{l}\text { Calcium hydroxid stirred } \\
\text { into hot oleic acid and } \\
\text { hot water added }\end{array}$ & 301 & 380 & 79 & 202 & $\begin{array}{l}\text { White plas } \\
\text { tic mane } \\
\text { in "free" } \\
\text { water }\end{array}$ \\
\hline $\begin{array}{c}\text { B a } r \text { i u m } \\
\text { oleate }\end{array}$ & $\begin{array}{l}\text { Hot normal barium hy- } \\
\text { droxid stirred into hot } \\
\text { oleic acid }\end{array}$ & 350 & 360 & 10 & 2.9 & $\begin{array}{l}\text { Jellowis } \\
\text { pla tic } \\
\text { maen in } \\
\text { "free" } \\
\text { water }\end{array}$ \\
\hline Lead oleate & $\begin{array}{l}\text { Lead oxid stirred into hot } \\
\text { oleic acid and hot water } \\
\text { added }\end{array}$ & 354 & 423 & 11 & 107 & $\begin{array}{l}\text { Yellowish } \\
\text { plantio } \\
\text { mane in } \\
\text { "free" } \\
\text { water }\end{array}$ \\
\hline $\begin{array}{l}\text { Mercury ole- } \\
\text { ate }\end{array}$ & $\begin{array}{l}\text { Yellow mercuric oxid stir- } \\
\text { red into hot oleic acid } \\
\text { and hot water added }\end{array}$ & 381 & 425 & 41 & 113 & $\begin{array}{l}\text { Yollowish } \\
\text { plastie } \\
\text { mane in } \\
\text { "frne" } \\
\text { water }\end{array}$ \\
\hline
\end{tabular}


TABLE IV

\section{Gelation Capacities of Different Stearates with Water}

\begin{tabular}{|c|c|c|c|c|c|c|}
\hline Soap. & How prepared. & $\begin{array}{l}\text { Theoret. } \\
\text { weight of } \\
\text { dry soap } \\
\text { (m. w. } \\
\text { expressed } \\
\text { in } \\
\text { grams). }\end{array}$ & $\begin{array}{c}\text { Ob- } \\
\text { served } \\
\text { weight of } \\
\text { soap } \\
\text { as } \\
\text { pre- } \\
\text { pared. }\end{array}$ & $\begin{array}{c}\text { A bsolute } \\
\text { amount } \\
\text { of } \\
\text { gelation } \\
\text { water. }\end{array}$ & $\begin{array}{c}\text { Percent } \\
\text { of } \\
\text { ge!ation } \\
\text { water } \\
\text { at } \\
18^{\circ} \mathrm{C} .\end{array}$ & $\begin{array}{l}\text { Physical } \\
\text { state } \\
\text { at } \\
18^{\circ} \mathrm{C} \text {. }\end{array}$ \\
\hline $\begin{array}{c}\text { Ammonium } \\
\text { stearate }\end{array}$ & $\begin{array}{l}\text { Warm normal ammonium } \\
\text { hydroxid stirred into } \\
\text { warm stearic acid }\end{array}$ & 301 & 1301 & 1000 & $\begin{array}{l}\text { Over } \\
332.2\end{array}$ & $\begin{array}{l}\text { White plas- } \\
\text { tic mass }\end{array}$ \\
\hline $\begin{array}{c}\text { Potassium } \\
\text { stearate }\end{array}$ & $\begin{array}{l}\text { Hot normal potassium hy- } \\
\text { droxid stirred into hot } \\
\text { stearic acid }\end{array}$ & 322 & 1322 & 1000 & $\begin{array}{l}\text { Over } \\
310.5\end{array}$ & $\begin{array}{l}\text { Semi-hard } \\
\text { white } \\
\text { soap }\end{array}$ \\
\hline $\begin{array}{l}\text { Sodium } \\
\text { stearate }\end{array}$ & $\begin{array}{l}\text { Hot normal sodium hy- } \\
\text { droxid stirred into hot } \\
\text { stearic acid }\end{array}$ & 306 & 1306 & 1000 & $\begin{array}{l}\text { Over } \\
326.8\end{array}$ & $\begin{array}{l}\text { Hard white } \\
\text { soap }\end{array}$ \\
\hline $\begin{array}{c}\text { Magnesium } \\
\text { stearate }\end{array}$ & $\begin{array}{l}\text { Magnesium oxid stirred } \\
\text { into hot stearic acid and } \\
\text { boiling water added }\end{array}$ & 295 & 960 & 665 & 225.4 & $\begin{array}{l}\text { Somewhat } \\
\text { plastio } \\
\text { chalky } \\
\text { mass in } \\
\text { "f ree" } \\
\text { water }\end{array}$ \\
\hline $\begin{array}{l}\text { Calcium } \\
\text { stearate }\end{array}$ & $\begin{array}{l}\text { Calcium hydroxid stirred } \\
\text { into hot stearic acid and } \\
\text { hot water added }\end{array}$ & 303 & 705 & 402 & 132.6 & $\begin{array}{l}\text { White, dry, } \\
\text { britt le } \\
\text { powderin } \\
\text { "free" } \\
\text { water }\end{array}$ \\
\hline $\begin{array}{c}\text { B a r i u m } \\
\text { stearate }\end{array}$ & $\begin{array}{l}\text { Hot normal barium hy- } \\
\text { droxid stirred into hot } \\
\text { stearic acid }\end{array}$ & 352 & 587 & 235 & 66.8 & $\left\{\begin{array}{l}\text { W } \mathrm{h} i \mathrm{t} e \\
\text { flakes in } \\
\text { "free" } \\
\text { water }\end{array}\right.$ \\
\hline $\begin{array}{l}\text { Lead stear- } \\
\text { ate }\end{array}$ & $\begin{array}{l}\text { Litharge stirred into hot } \\
\text { stearic acid and boiling } \\
\text { water added }\end{array}$ & 386 & 730 & 344 & 89.1 & $\begin{array}{l}\text { White, hard } \\
\text { flakes in } \\
\text { "f r e e" } \\
\text { water }\end{array}$ \\
\hline $\begin{array}{l}\text { M e r c u r y } \\
\text { stearate }\end{array}$ & $\begin{array}{l}\text { Yellow mercuric oxid stir- } \\
\text { red into hot stearic acid } \\
\text { and boiling water added }\end{array}$ & 383 & 865 & 482 & 125.8 & $\mid \begin{array}{l}\mathrm{W} \mathrm{h} \mathrm{i} \mathrm{t} \theta \\
\text { flakes in } \\
\text { "f f e e " } \\
\text { water }\end{array}$ \\
\hline
\end{tabular}


TABLE V

Gelation Capacities of Different Palmitates with Water

\begin{tabular}{|c|c|c|c|c|c|c|}
\hline Soap. & How prepared. & $\begin{array}{c}\text { Theoret. } \\
\text { weight of } \\
\text { dry soap } \\
\text { (m. w. } \\
\text { expreseed } \\
\text { in } \\
\text { grams). }\end{array}$ & $\begin{array}{c}\text { Ob- } \\
\text { served } \\
\text { weight of } \\
\text { soap } \\
\text { as } \\
\text { pre- } \\
\text { pared. }\end{array}$ & $\begin{array}{c}\text { Absolute } \\
\text { amount } \\
\text { of } \\
\text { gelation } \\
\text { water. }\end{array}$ & $\begin{array}{c}\text { Percent } \\
\text { of } \\
\text { grlation } \\
\text { water } \\
\text { at } \\
15^{\circ} \mathrm{C} \text {. }\end{array}$ & $\begin{array}{c}\text { Physical } \\
\text { otato } \\
\text { at } \\
15^{\circ} \mathrm{C} \text {. }\end{array}$ \\
\hline $\begin{array}{c}\text { Ammonium } \\
\text { palmitate }\end{array}$ & $\begin{array}{l}\text { Warm normal ammonium } \\
\text { hydroxid stirred into } \\
\text { warm palmitic acid }\end{array}$ & 273 & 1273 & 1000 & $\begin{array}{l}\text { Over } \\
366.3\end{array}$ & $\begin{array}{l}\text { Solid white } \\
\mathrm{cel}\end{array}$ \\
\hline $\begin{array}{c}\text { Potassium } \\
\text { palmitate }\end{array}$ & $\begin{array}{l}\text { Hot normal potassium hy- } \\
\text { droxid stirred into hot } \\
\text { palmitic acid }\end{array}$ & 294 & 1294 & $10 \times 0$ & $\begin{array}{l}\text { Ovet } \\
340.1\end{array}$ & $\begin{array}{l}\text { PI a t io } \\
\text { white gel }\end{array}$ \\
\hline $\begin{array}{l}\text { Sodium pal- } \\
\text { mitate }\end{array}$ & $\begin{array}{l}\text { Hot normal sodium hy- } \\
\text { droxid stirred into hot } \\
\text { palmitic acid }\end{array}$ & 278 & 1278 & 1000 & $\begin{array}{l}\text { Over } \\
359.6\end{array}$ & $\begin{array}{l}\text { Solid white } \\
\text { gel }\end{array}$ \\
\hline $\begin{array}{c}\text { Magnesium } \\
\text { palmitate }\end{array}$ & $\begin{array}{l}\text { Magnesium oxid stirred } \\
\text { into hot palmitic acid } \\
\text { and hot water added }\end{array}$ & 267 & $\$ 40$ & 173 & 64.8 & $\begin{array}{l}\text { Rather } \\
\text { brit l l. } \\
\text { m a : } \\
\text { pinutic st } \\
\text { higher } \\
\text { tempera. } \\
\text { tures }\end{array}$ \\
\hline $\begin{array}{l}\text { Barium pal- } \\
\text { mitate }\end{array}$ & $\begin{array}{l}\text { Hot normal barium hy- } \\
\text { droxid atirred into hot } \\
\text { palmitic acid }\end{array}$ & 324 & 670 & 346 & 106.8 & $\begin{array}{l}\text { Dry. Aaky } \\
\text { mamers }\end{array}$ \\
\hline $\begin{array}{l}\text { Lead palmi- } \\
\text { tate }\end{array}$ & $\begin{array}{l}\text { Litharge stirred into hot } \\
\text { palmitic acid and hot } \\
\text { water added }\end{array}$ & 358 & 390 & 32 & 8 9 & $\begin{array}{l}\text { Shiny; hand } \\
\text { fl a kea } \\
\text { plantic at } \\
\text { h I a her } \\
\text { tempera. } \\
\text { turn }\end{array}$ \\
\hline
\end{tabular}


TABLE VI

Gelation Capacities of Different Laurates with Water

\begin{tabular}{|c|c|c|c|c|c|c|}
\hline Soap. & How prepared. & $\begin{array}{c}\text { Theoret. } \\
\text { weight of } \\
\text { dry soap } \\
\text { (m. w. } \\
\text { expressed } \\
\text { in } \\
\text { grams). }\end{array}$ & $\begin{array}{c}\text { Ob- } \\
\text { served } \\
\text { weight of } \\
\text { soap } \\
\text { as } \\
\text { pre- } \\
\text { pared. }\end{array}$ & $\begin{array}{c}\text { Absolute } \\
\text { a mount } \\
\text { of } \\
\text { gelation } \\
\text { water. }\end{array}$ & $\begin{array}{c}\text { Percent } \\
\text { of } \\
\text { gelation } \\
\text { water } \\
\text { at } \\
18^{\circ} \mathrm{C} \text {. }\end{array}$ & $\begin{array}{l}\text { Physical } \\
\text { state } \\
\text { at } \\
18^{\circ} \mathrm{C} \text {. }\end{array}$ \\
\hline $\begin{array}{l}\text { Ammonium } \\
\text { laurate }\end{array}$ & $\begin{array}{l}\text { Warm normal ammonium } \\
\text { hydroxide poured into } \\
\text { melted lauric acid }\end{array}$ & 217 & 1217 & 1000 & $\begin{array}{c}\text { Over } \\
460.8 \\
\text { at } 0^{\circ} \mathrm{C}\end{array}$ & $\begin{array}{l}\text { Semi-solid; } \\
\text { solid gel } \\
\text { at } 0^{\circ} \mathrm{C} .\end{array}$ \\
\hline $\begin{array}{l}\text { Potassium } \\
\text { laurate }\end{array}$ & $\begin{array}{l}\text { Hot normal potassium hy- } \\
\text { droxid poured into hot } \\
\text { laurie acid }\end{array}$ & 238 & 1238 & 1000 & $\begin{array}{c}\text { Over } \\
420.1 \\
\text { at } 0^{\circ} \mathrm{C} .\end{array}$ & $\begin{array}{l}\text { Like water; } \\
\text { solid gel } \\
\text { at } 0^{\circ} \mathrm{C} \text {. }\end{array}$ \\
\hline $\begin{array}{l}\text { Sodium lau- } \\
\text { rate }\end{array}$ & $\begin{array}{l}\text { Hot normal sodium hy- } \\
\text { droxid poured into hot } \\
\text { lauric acid }\end{array}$ & 222 & 1222 & 1000 & $\begin{array}{l}\text { Over } \\
450.4\end{array}$ & $\begin{array}{l}\text { Solid white } \\
\text { gel }\end{array}$ \\
\hline $\begin{array}{l}\text { Magnesium } \\
\text { laurate }\end{array}$ & $\begin{array}{l}\text { Magnesium oxid stirred } \\
\text { into hot lauric acid and } \\
\text { hot water added }\end{array}$ & 211 & $\begin{array}{c}570 \\
.\end{array}$ & 359 & 170.1 & $\begin{array}{c}\text { White flaky } \\
\text { particles }\end{array}$ \\
\hline $\begin{array}{l}\text { Barium lau- } \\
\text { rate }\end{array}$ & $\left\{\begin{array}{l}\text { Hot normal barium hy- } \\
\text { droxid poured into hot } \\
\text { lauric acid }\end{array}\right.$ & 268 & 510 & 242 & 90.3 & $\begin{array}{l}\text { White dry } \\
\text { powder }\end{array}$ \\
\hline Lead laurate & $\begin{array}{l}\text { Litharge stirred into hot } \\
\text { laurie acid and hot water } \\
\text { added }\end{array}$ & 303 & 425 & 122 & 40.2 & $\begin{array}{l}\text { Hard, white } \\
\text { m a s s : } \\
\text { plastic at } \\
\text { hi g h e r } \\
\text { tempera- } \\
\text { tures }\end{array}$ \\
\hline
\end{tabular}


TABLE VII

\section{Gelation Capacities per Gram of Sodium Soaps or the Acetic Serre} with Water at $18^{\circ} \mathrm{C}$.

Values in parentheses indicate percent of sosp in the gel.

\begin{tabular}{|c|c|c|}
\hline Sodium formate......... & $\mathbf{0}$ & \\
\hline Sodium acetate........... & 0 & \\
\hline Sodium propionate.......... & 0 & \\
\hline Sodium butyrate. . . . . . . . . & $\mathbf{0}$ & \\
\hline Sodium valerate............ & 0 & \\
\hline Sodium caproate. . . . . . . . . & (?) & \\
\hline Sodium caprylate............ & & cc. $(50.00)$ \\
\hline Sodium caprate. . . . . . . . . & & $\cdots(28,57)$ \\
\hline Sodium laurate............. & & . (5.26) \\
\hline Sodium myristate. . . . . . . . & 48 & $\because \quad(2.04)$ \\
\hline Sodium palmitate. . . . . . . . & 72 & $\cdots \quad(1.37)$ \\
\hline Sodium margarate........... & 80 & $\because \quad(1.23)$ \\
\hline Sodium stearate........... & 88 & $\cdots \quad(1.12)$ \\
\hline Sodium arachidate......... & 111 & $\because \quad(0.88)$ \\
\hline
\end{tabular}

TABLE VIII

Gelation Capacities per Gram of Sodium Soaps of the Oleic Serues With Water at $18^{\circ} \mathrm{C}$.

Values in parentheses indicate percent of soap in the colloid system.

\begin{tabular}{|c|c|c|}
\hline Sodium erucate... & $60.00 \quad(1.64)$ & Solid white ael \\
\hline Sodium oleate..... & $3.28(23.36)$ & Highly viscid, yellow liguid \\
\hline Sodium elaidate. . & $30.00 \quad(3.23)$ & Solid white $\mathrm{eel}$ \\
\hline
\end{tabular}

TABLE: $1 \mathrm{X}$

Gelation Capacity per Gram of a Somium Soap of the Ianouc Serims with Water at $18^{\circ} \mathrm{C}$.

Value in parenthesis indicates percent of soap in the colloid syatem

Sodium linolate............. $3.31 \quad(23.20) \quad$ Highly vincid, yelloweh-hrow a liguid




\section{THE SYSTEM SOAP/ALCOHOL}

\section{Introduction}

It is the purpose of this section to take up the matter of the production of various lyophilic colloid soap systems from materials in which water is practically or entirely absent. The facts learned under this heading will then serve, with the experiments described earlier ${ }^{1}$ on soap/water systems, for a general theory of the lyophilic colloid state. ${ }^{2}$

Of the many different "solvents" which will in this fashion yield beautiful lyophilic colloid systems with various soaps, we shall first take up the various alcohols, for not only do alcohols (like glycerin) frequently appear in the processes of soap manufacture, but this or some other alcohol is commonly added to soaps from without to make them "transparent."

\section{Experiments with Monatomic Alcohols}

a. Monatomic Alcohols of the General Composition $\mathrm{C}_{n} \mathrm{H}_{2 n+1} \mathrm{OH}$.

1. A first set of experiments consisted in the determination of the gelation capacities of various sodium soaps of the fatty acids of the acetic series in the presence of absolute ethyl alcohol. For this purpose we proceeded as in the experiments on the gelation capacities of these soaps when water was the "solvent." The soaps were made by adding to unit molar weights of the various fatty acids the necessary chemical equivalents of half normal sodium hydroxid in absolute alcohol. The mixtures were kept in a water bath set at $75^{\circ} \mathrm{C}$, , and enough absolute ethyl alcohol was then added to each until on cooling the soap-alcohol mixture to $18^{\circ}$ C. a " dry" gel was no longer obtained. In other words, if the soap/alcohol system remained liquid or showed "syneresis" it was held that its gelation limit had been exceeded. The results

${ }^{1}$ See page $9 ;$ also Martin H. Fischer and Marian O. Hooker: Chem. Engineer, 27, 15.) (1919).

'See page 64; also Martin H. Fischer and Marian O. Hooker: Seience, 48, 143 (1918); Chem. Engineer, 27, 188 (1919). 
(which are readily reproducible) in the case of an actual experiment, are shown in Figs. 14 and 15 and in Table $\mathrm{X}$. "The findings detailed in Table $\mathrm{X}$ are shown graphically in Fig. 16.

A sodium oleate-ethyl alcohol gel prepared under icientical conditions is pictured in Fig. 17.

It is again of interest to note in connection with these experiments in which ethyl alcohol is used that, with the exception of margaric acid (about which there is still a debate as to whether or not it is more than a eutectic mixture of palmitic and stearic acids) all the soaps which show distinctly lyophilic properties are those of acids which have an even number of carbon atoms in the empiric formula. This fact was formerly emphasized in the case of these soaps, when water was the "solvent" concerned.

The tendency to yield colloid gels diminishes not only quantitatively but also qualitatively, as we descend the fatty acid series from sodium arachidate to sodium acetate. The ethyl alcohol gel of sodium acetate tends to crystallize out within a few days after its formation. The butyrate gel (see Fig. 14) may go partly to pieces in the course of weeks, unless carefully protected from temperature changes, but the caproate yields a lasting colloid. These lowermost members of the soap series with an even number of carbon atoms, however, show a clean-cut tendency to gel formation not at all apparent with the formate, propionate and valerate. In the case of the last named substances, repeated trials under the conditions of our experiments yielded only thick crystalline precipitates.

It is further to be noted (Fig. 16) that the regular downward gradation in gelation capacity is interrupted in the series between capric and caprylic acids. This point marks the transition from the fatty acids solid at ordinary temperatures, to those which are liquid.

2. It was our next problem to discover what was the gelation capacily of some picked soaps in different alcohols. We used for this purpose several sodium soaps of the acetic acid series, three sodium soaps of the oleic series and one sodium soap of the linolic series. ${ }^{1}$ The erucate and linolate were prepared through neu-

${ }^{1}$ The matter of getting absolutely pure falty acids for such quantitative experiments as are here described is not an easy one. We arw under gront obligation to the Department of Organic Manufarturea of the Univenoty of Illinois for supplying us with splendid examples of the different fatey acuds used in this study. In another portion of the work we used liahltaum " $K$ " 
tralization of the necessary molar equivalents of acid with standard aqueous sodium hydroxid and desiccated over sulphuric acid at $37^{\circ} \mathrm{C}$. The remaining soaps were similarly prepared but dried

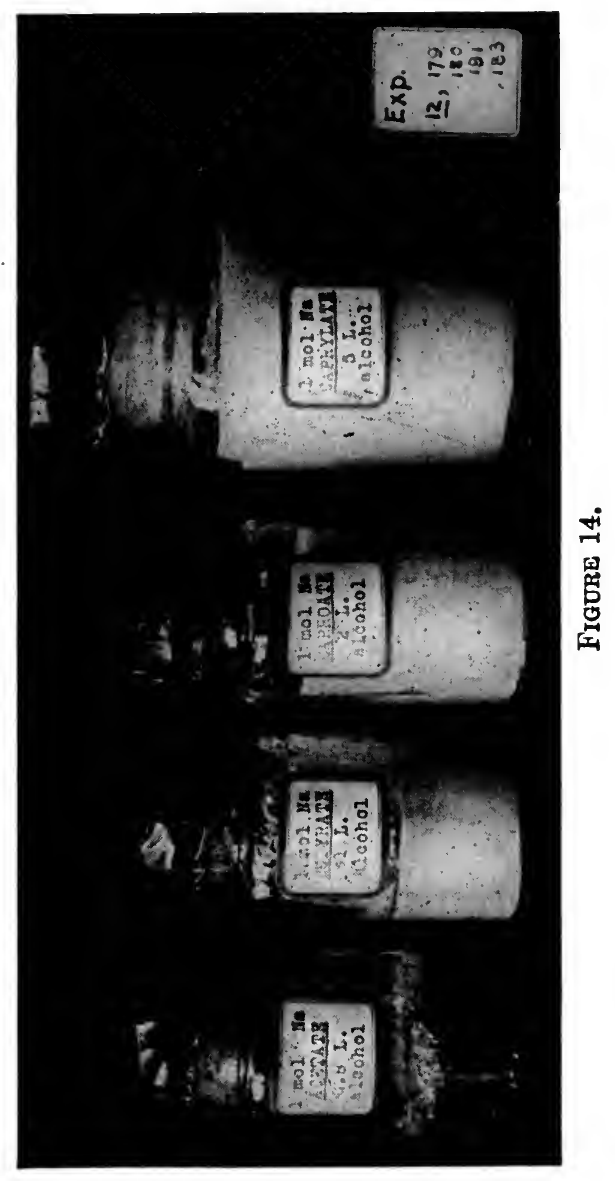

at $90^{\circ} \mathrm{C}$., in a dry air oven, to constant weight, as determined by heating a test fraction to $110^{\circ} \mathrm{C}$.

The gelation capacity per gram of the sodium soaps of nine different fatty acids of the acetic series in nine different monaBrand chemicals. The fact that the fatty acids had different sources explains some of the slight variations in the numerical values obtained in different series of experiments. It should be noted, however, that the relative values obtained were always gotten by using a single specimen. 


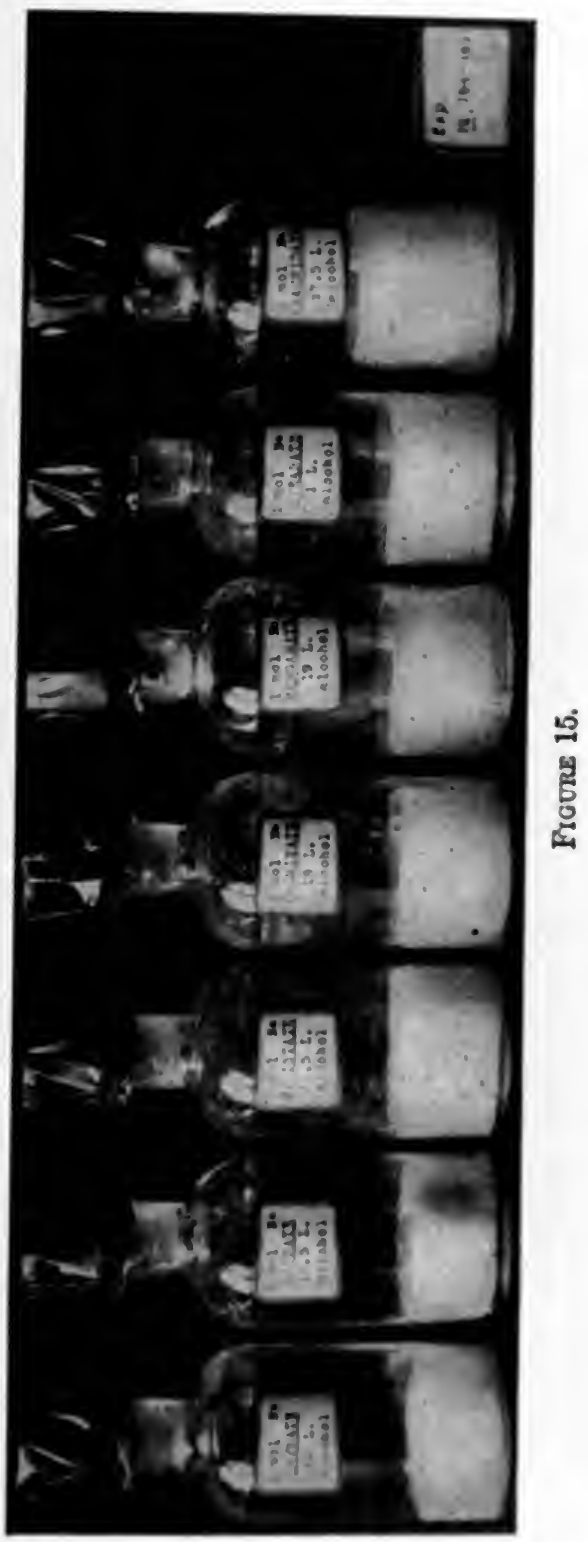


tomic alcohols is shown photographically in Fig. 18 ( $A$ and $B$ ) and graphically in Figs. 19, 20, 21, 22, 23, 24, 25 and 26. The findings are compounded in Fig. 27. In each instance a given weight of soap had more and more of the various alcohols added to it while in a warm water or boiling water bath, until, upon reducing the temperature of the reaction mixture to $18^{\circ} \mathrm{C}$., it would no longer set into a dry gel. The actual volumes that it

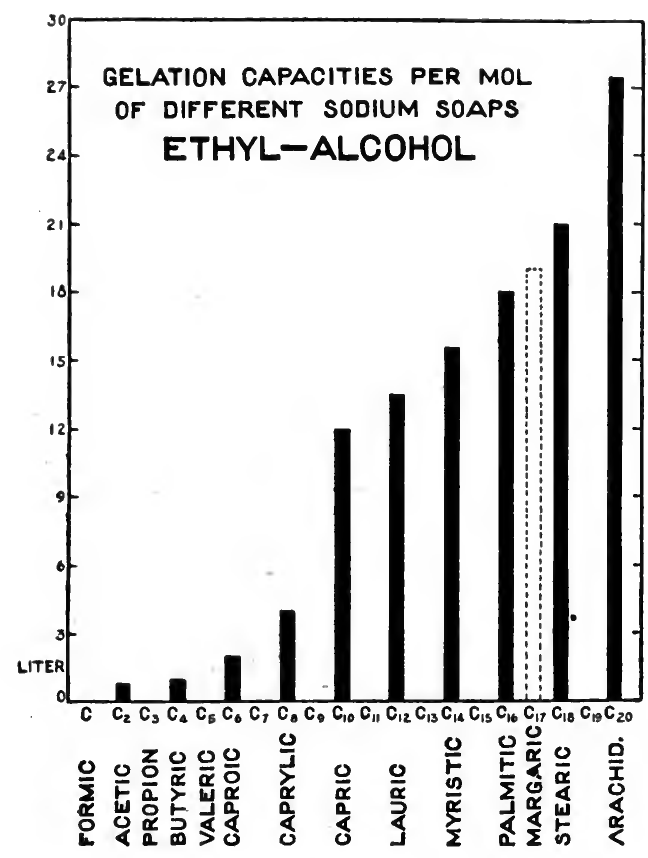

Figure 16.

was found possible to add, while still accomplishing this end are shown in Table XI.

The tables, figures and graphs show that the tendency of the various soaps to yield lyophilic colloid systems grows (1) with the complexity of the soap in any given series and (2) with the complexity of the alcohol used in the system. The only exception in the acetic series is represented by margaric acid, but this may be explained either by the fact that it is an odd carbon atom acid or that it represents a eutectic mixture of stearic and palmitic acids. 
The results in the ease of two soaps of the oleic series (sodium oleate and sodium erucate) with this series of alcohols are shown photographically in the upper two rows of Fig. 28 and graphically in Figs. $29(A)$ and 30.

The behavior of sodium elaïdate (elaïdic acid being an isomer of oleic acid) is shown in the lowermost series of bottles of Fig. 25, and graphically in Fig. $29(B)$. The gelation capacity of this soap differs from that of sodium oleate in that the maximal gelation capacity is obtained with an alcohol in the middle of the series. In general all the gelation capacities lie below the values obtained with sodium oleate.

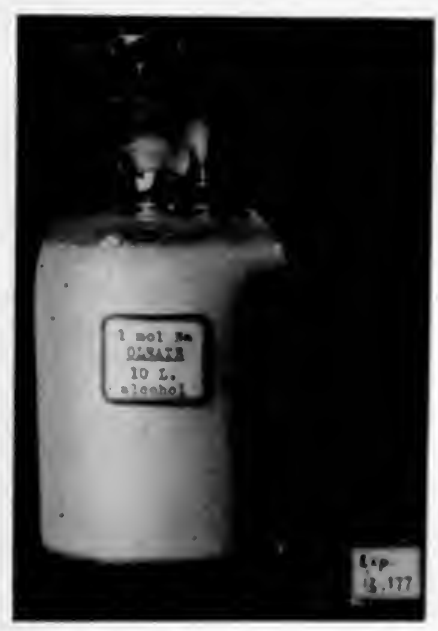

FIGUKE 17.

The experimental results covering these three soaps are given in Table XII. It is again apparent in the oleic series that the gelation capacity increases with the height of the alcohol in the series; while, when the erucate is compared with the oleate, the former has a higher gelation capacity with a given alcohol than the latter, at least as far as the lowermost members are concerned. We were not successful either by direct or indirect means (through primary solution in methyl alcohol) to get gelation values in the higher alcohols above that for ethyl alcohol. We cannot, however, say at this time whether this is a necessarily correct finding. for our erucic acid was not absolutely pure. 


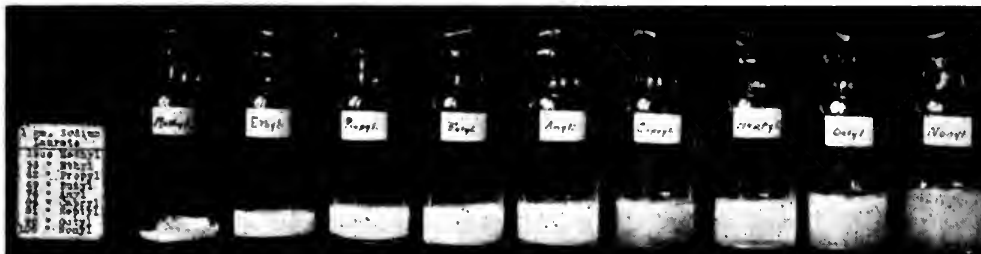

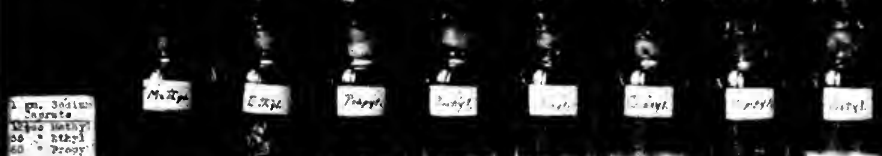

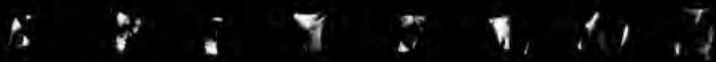

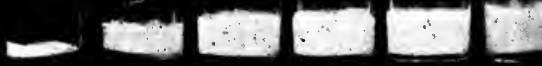

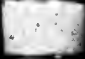

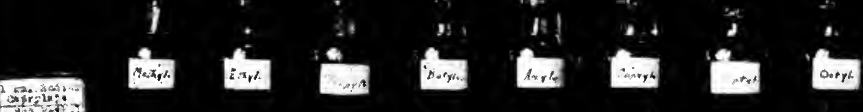
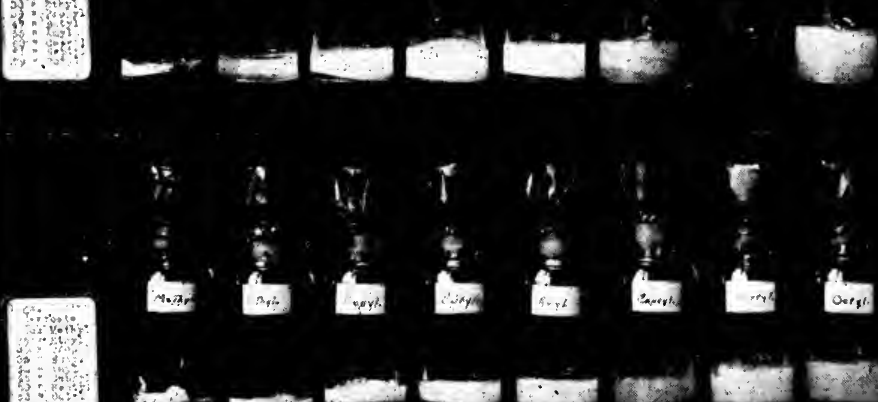

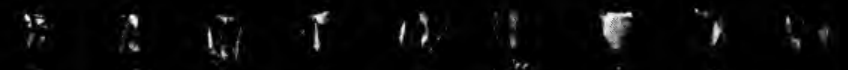

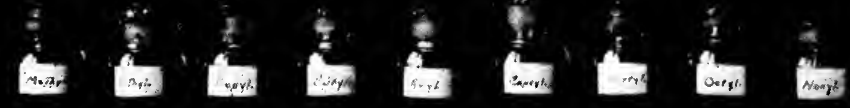
- $-20-\infty$ का

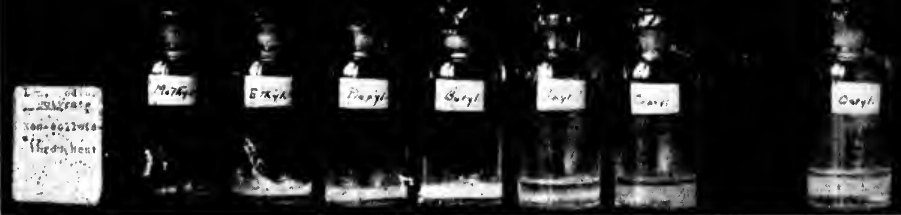
A

Figure 


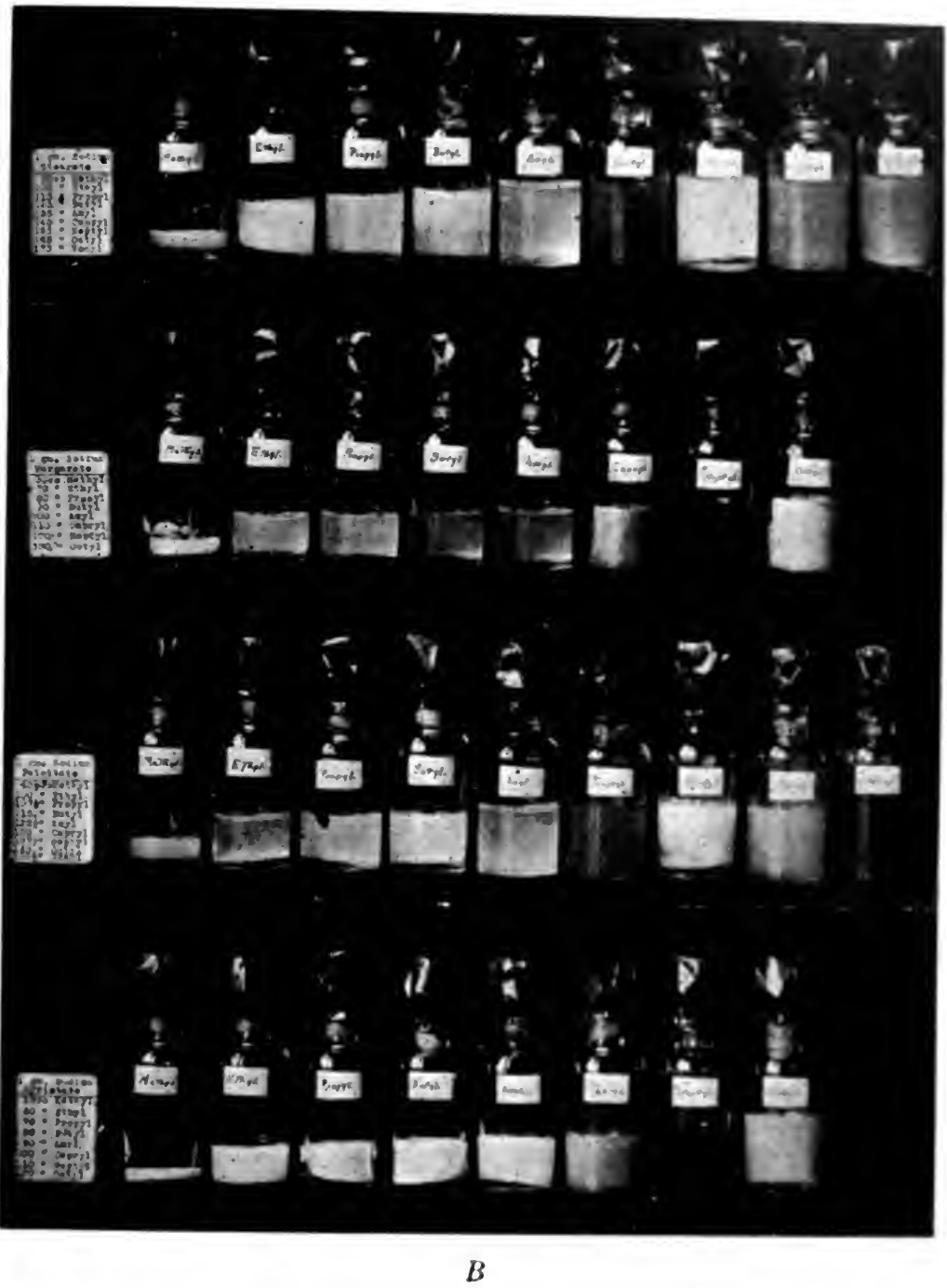

$A$ and $B$ of Fig 18 are segments of the mame picture The vertical rows of butules obould be read upwards as a continuous series in butb inulancrs. 


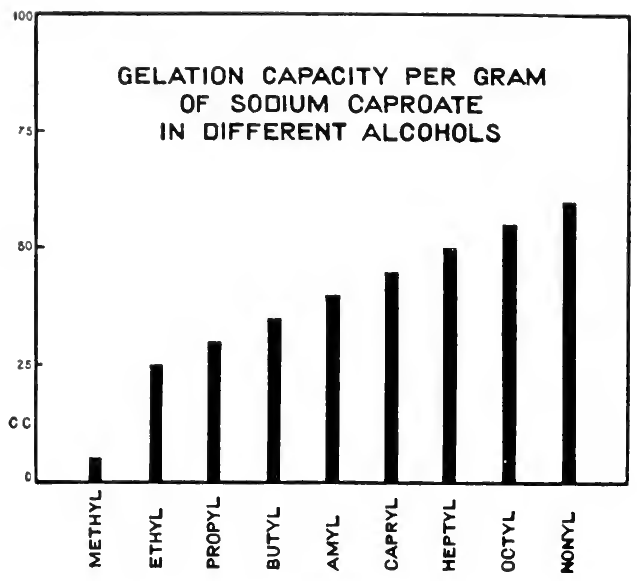

Figure 19.

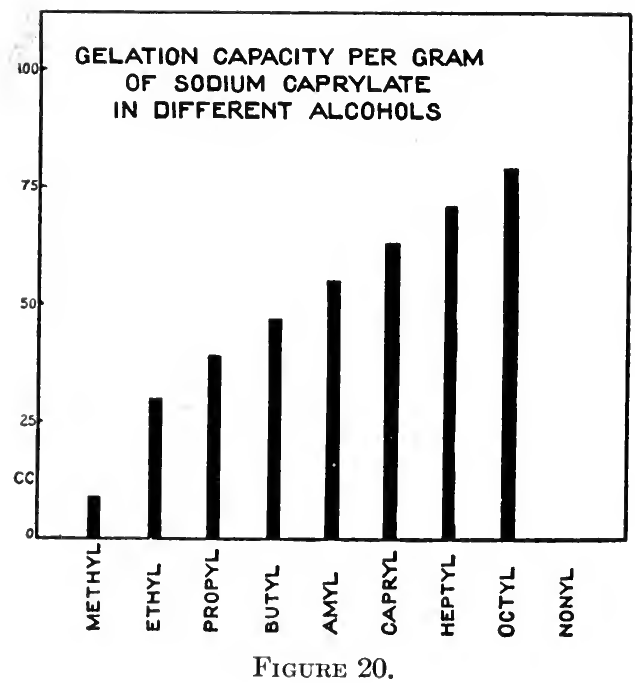




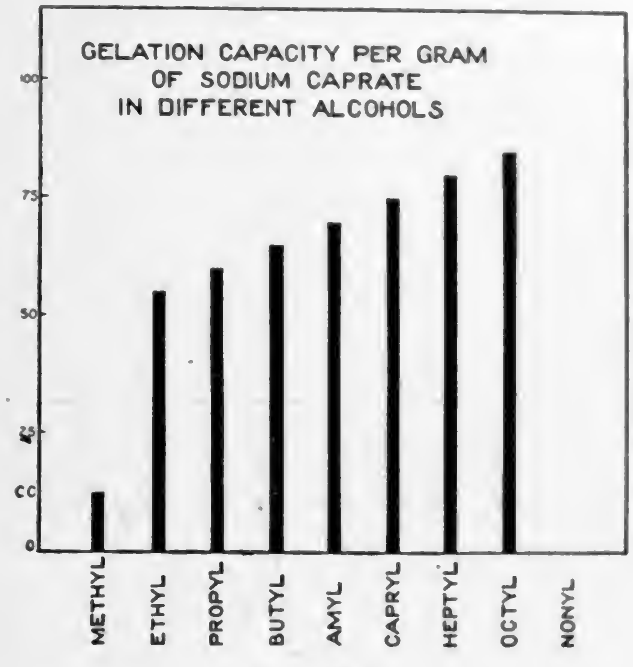

Figure 21.

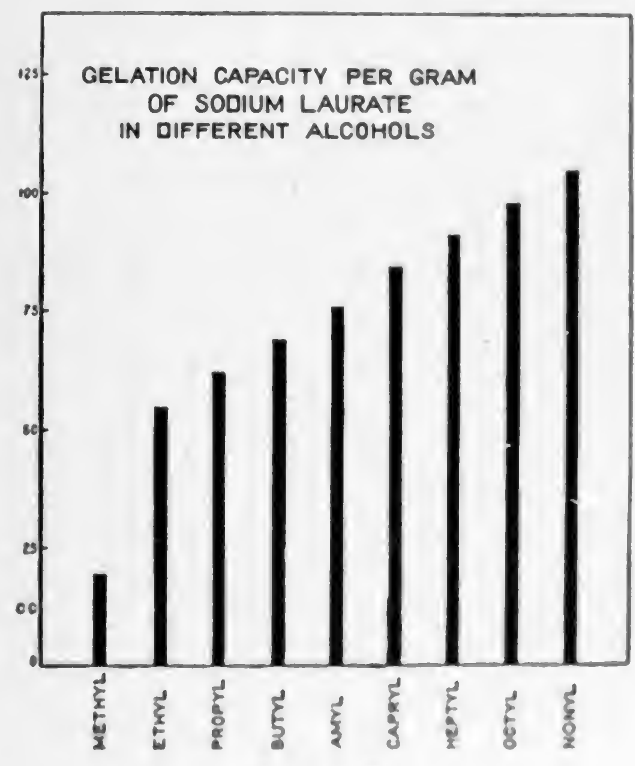

Figuk: 22. 


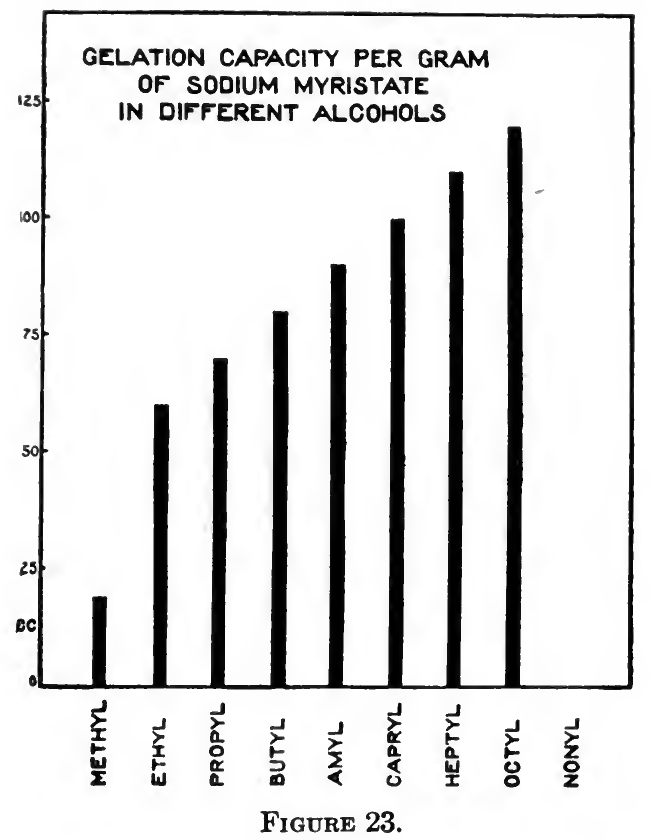




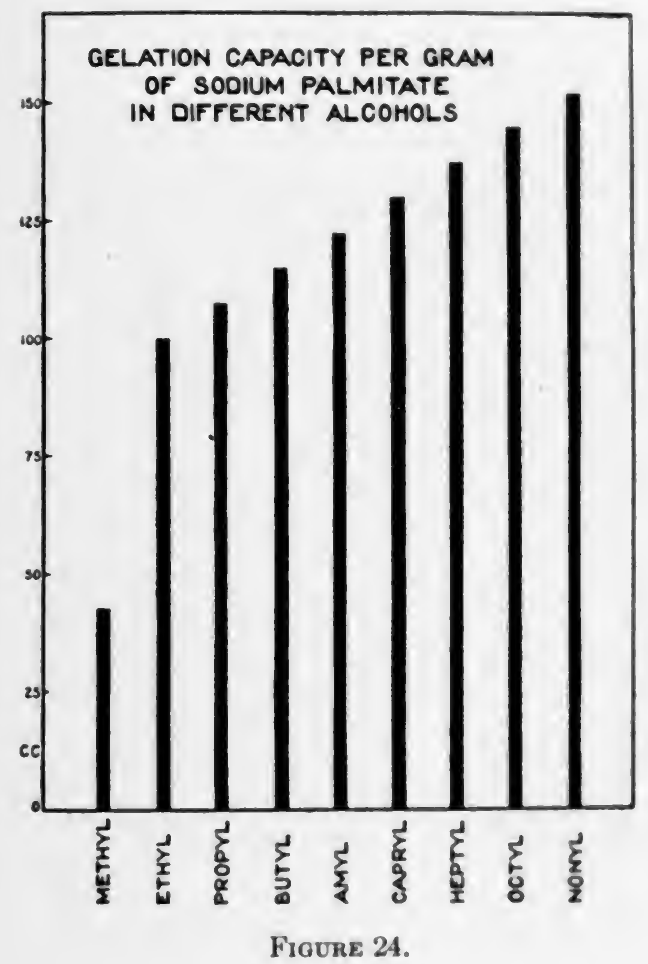




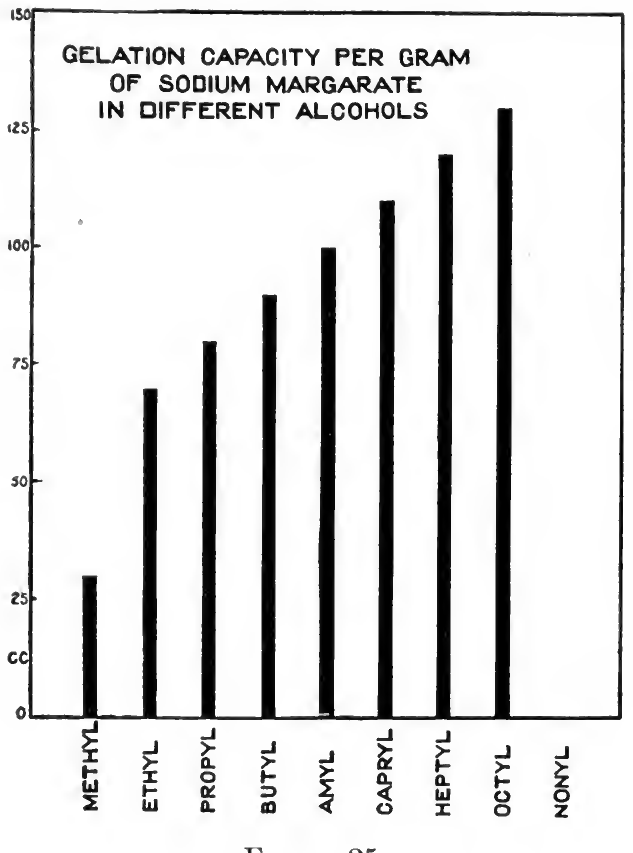

Figure 25. 


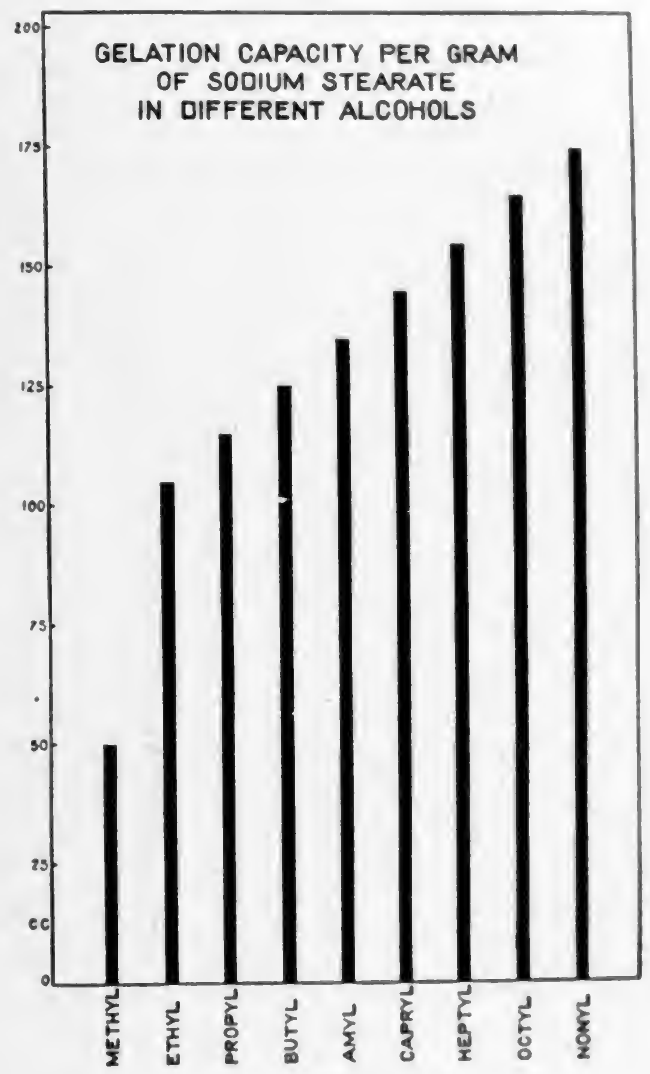

Figuke 26. 


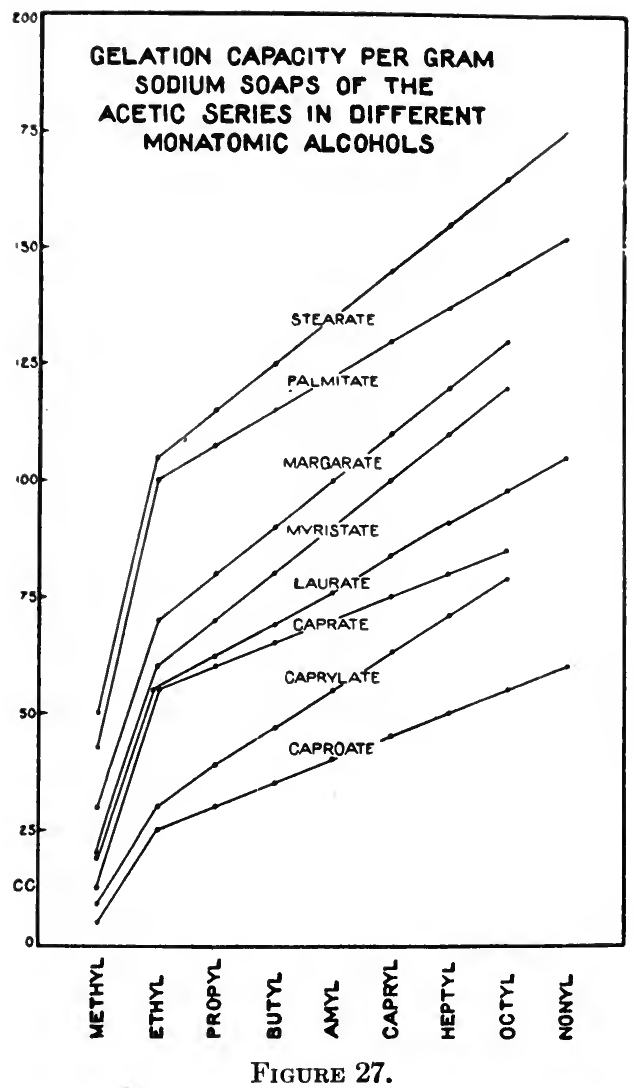




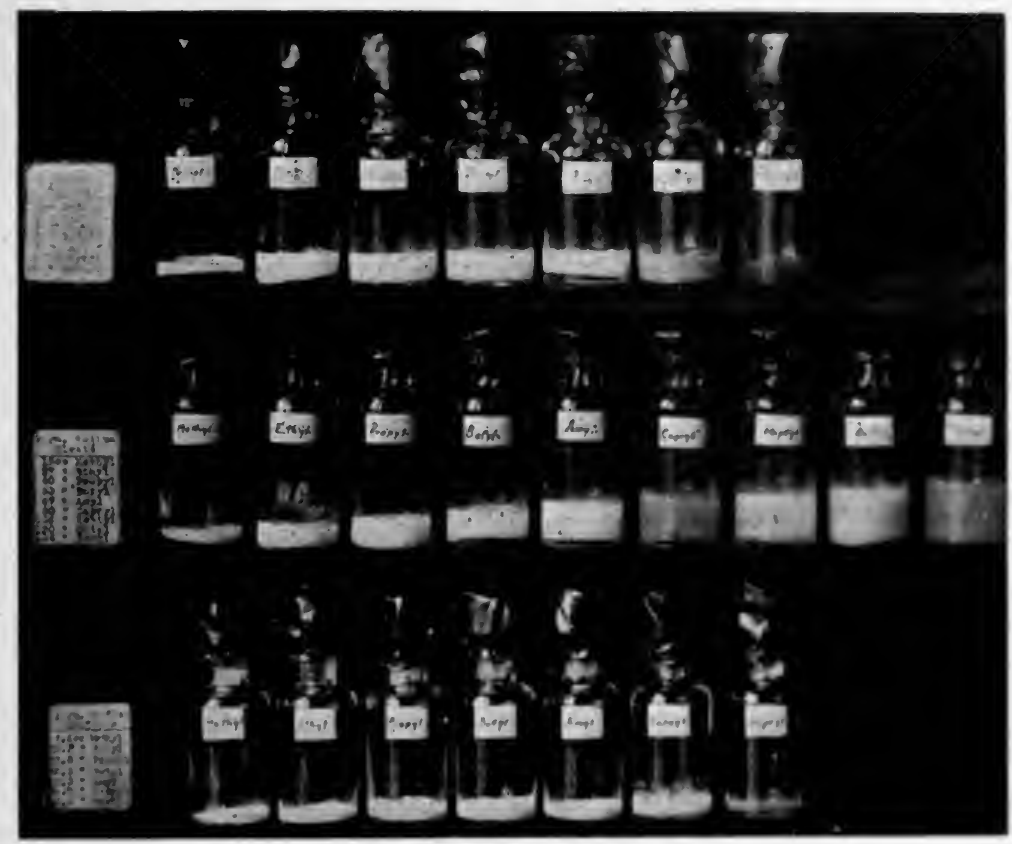

Figure 28. 

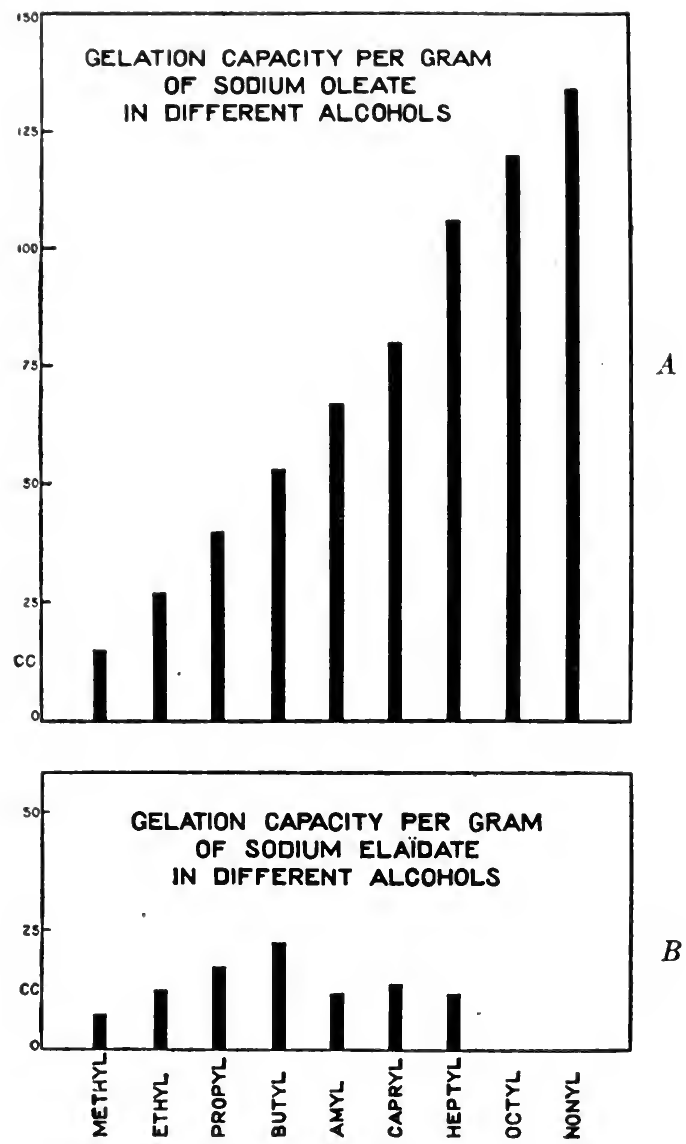

Figure 29. 


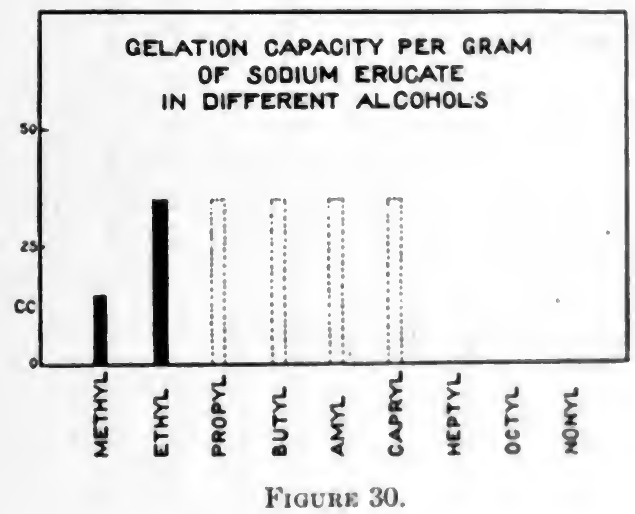


The gelation capacity per gram of sodium linolate in different alcohols is shown photographically in Fig. 31 and graphically in Fig. 32. The graph is based upon values shown in Table XIII.

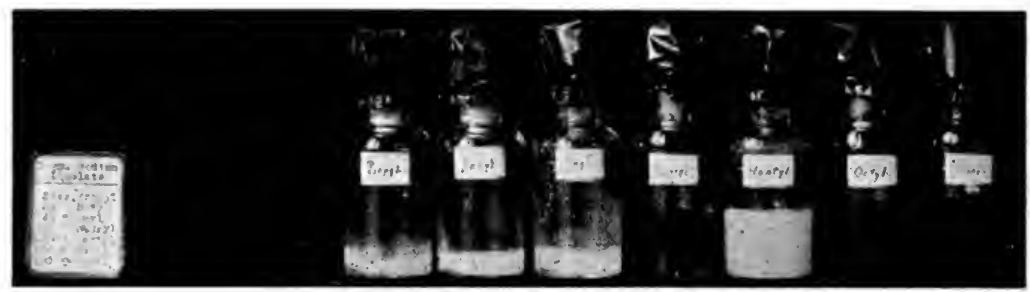

Figure 31.

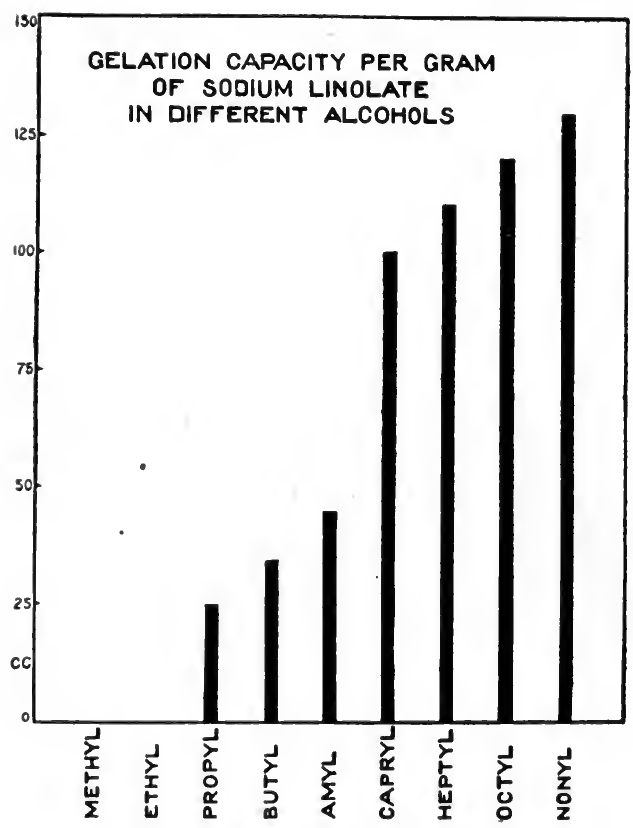

Figure 32.

If the gelation capacities of sodium linolate, sodium oleate and sodium stearate in the different alcohols are compared, reading horizontally across the table, it will be noted that sodium 
linolate shows, on the whole, a lower value than sodium oleate and the latter a lower one than sodium stearate.

It was noted in the making of these solutions of the soap in the different alcohols that the soap dissolved first in the lower members of the alcohol series and last in the uppermost. Upon lowering the temperature the gels formed first in the upper alco-

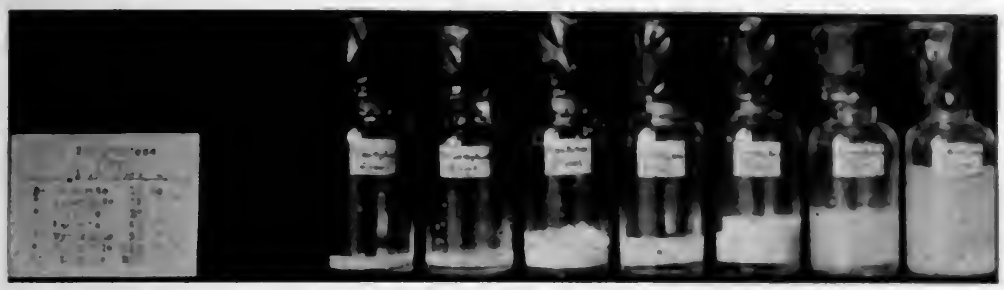

Figure 33.

hols and last in the lowest members of the series. It should be noted, too, that the solubility of sodium oleate in methyl alcohol is so high that slight variations in temperature are sufficient to cause the mixture, in the concentration here used, to pass from the opalescent gel to a clear solution, while a lowering of the temperature brings it back to the gel state. As we ascend to

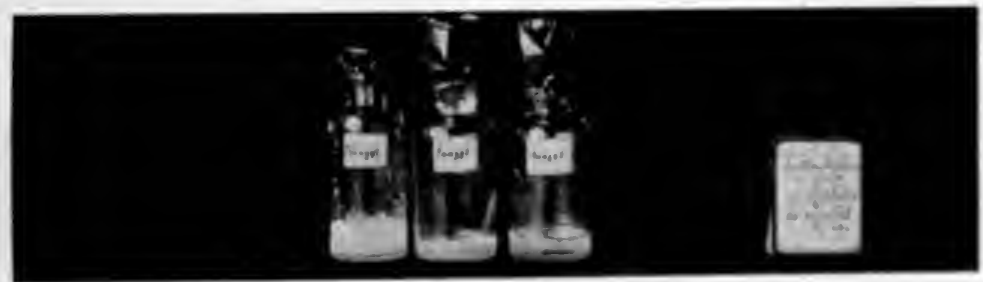

FigURE 31.

the higher alcohols such temperature variations must be made increasingly larger to accomplish the same result.

b. Monatomic Alcohols of the General Composition $\mathrm{C}_{n} / \mathrm{H} O \mathrm{H}$. Of the other monatomic alcohols which have been studied, benzyl alcohol yields beautiful soap jellies with the anhydrous soaps of both the acetic and oleic series, as shown in loiks. 33 and 34 , as well as Tables XIV and XV which contain the actual experimental data. 
Cinnamyl and allyl alcohols yield no gels with either of these two soap series. Sodium linolate yields no gel with benzyl alcohol nor with cinnamyl or allyl alcohol.

\section{Experiments with Diatomic Alcohols}

The solvation capacity of several sodium soaps in two diatomic alcohols, namely, trimethyleneglycol (1, 3 propandiol)

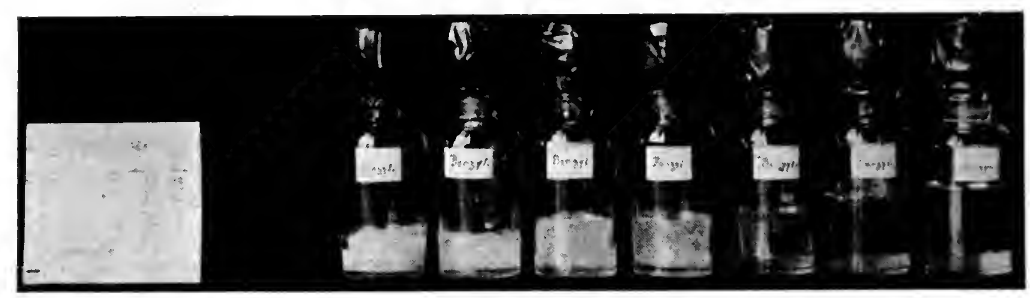

FigURe 35.

and ethyleneglycol, was next studied. The results for seven sodium soaps of the acetic series and three sodium soaps of

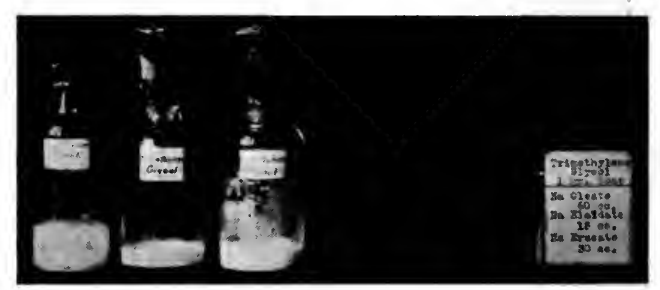

FigUre 36.

the oleic series with trimethyleneglycol are shown in Figs. 35 and 36, and Tables XVI and XVII, which contain the experimental data. There is an obvious and large increase in 
gelation capacity as we ascend the acetic series. Sodium oleate lies far below sodium stearate in its gelation capacity, while sodium linolate was found to yield no gel at all. Both Table XVII and Fig. 36 show that sodium erucate and sodium elaidate (the isomer of the oleate) have a lover gelation capacity in trimethyleneglycol than has sodium oleate, but, as noted above, we were not completely satisfied with the purity of our erucic acid.

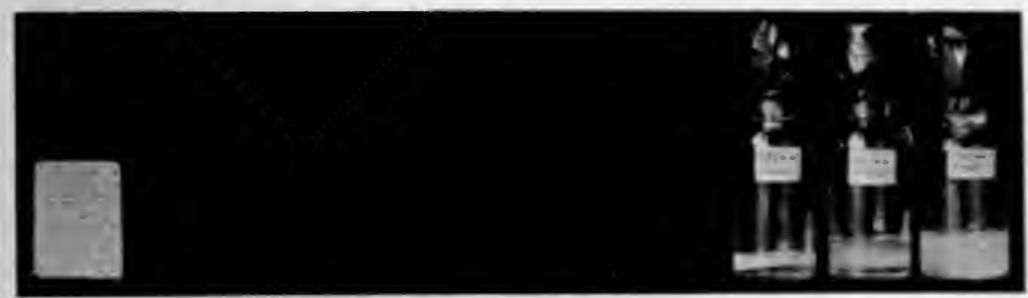

Figure 37.

The results of some experiments with ethyleneglycol and some soaps of the acetic and oleic series are shown in Figs. 37 and 38 . The actual experimental findings are again contained in Tables XVI and XVII. As apparent from the figures and the tables,

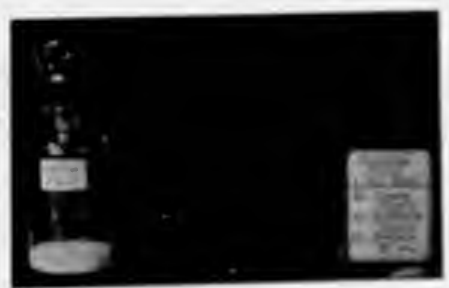

FHOCRE 38 .

only the higher members in each of the soap series will yield gels with ethyleneglycol, the lower members yielding only true solutions or crystalline deposits in the cooled reaction mixtures. 


\section{Experiments with Triatomic Alcohols (Glycerin)}

The solvation capacities of four sodium soaps of the acetic series and three sodium soaps of the oleic series with glycerin are

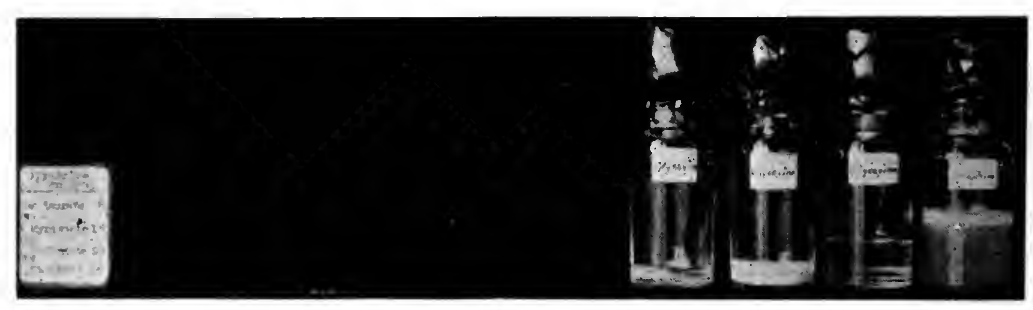

Figure 39

illustrated in Figs. 39 and 40 and Tables XVIII and XIX. Not only does the oleic series stand below the acetic, but in both series the gelation capacity falls rapidly from the high values obtained with the upper series to the low values in the case of the lower.

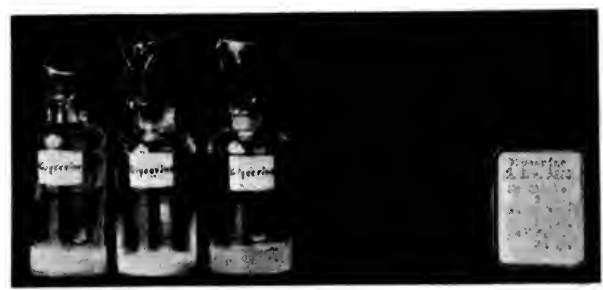

Figure 40 .

Fig. 41 illustrates the system sodium linolate, with a diatomic or a triatomic alcohol. When these mixtures are heated to the temperature of a boiling water bath, "solution" occurs, but on cooling the mixtures to $18^{\circ} \mathrm{C}$. no gelation follows, despite their high soap content (33.3 percent). We shall return later to 
the bearing of this phenomenon on the general theory of gelation.

Fig. 42 shows the result of dissolving 1 gram of sodium stearate or sodium oleate in $50 \mathrm{cc}$. of allyl alcohol at the temperature of

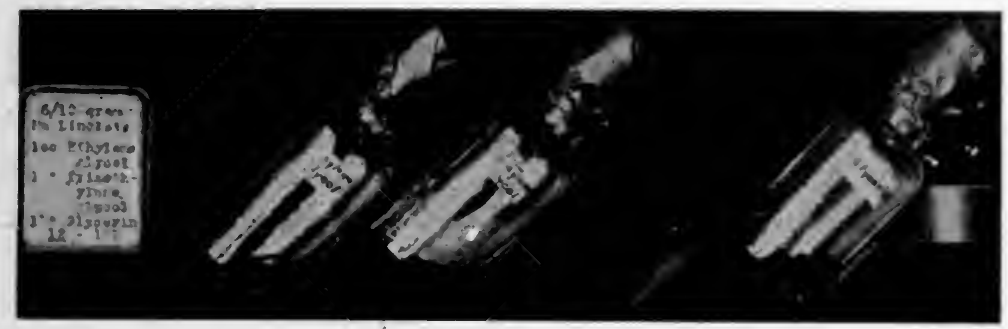

Figure 41.

boiling water and then cooling to $18^{\circ} \mathrm{C}$. At the higher temperature the soap dissolves to form a "true solution"; as the temperature falls, the soap becomes insoluble, but instead of forming

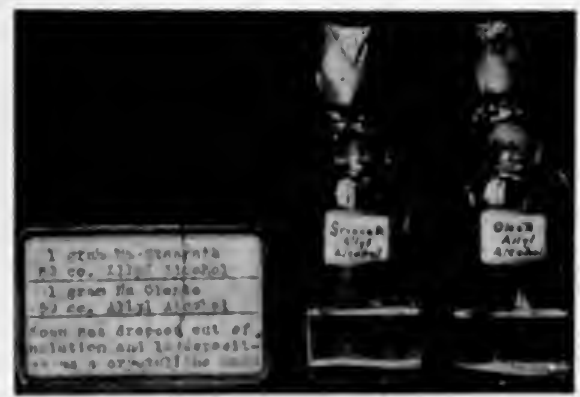

FIGURE 42.

a gel it drops out as a crystalline mass. These experiments suffice to show that not every soap solvent will yield a colloid system with a given soap. We shall use these facts later for their bearing upon the general theory of colloids. 
TABIL X

Gelation Capacities of Different Sodium Soaps witi Èthy Alcohol

\begin{tabular}{|c|c|c|c|c|c|}
\hline Soap. & How prepared. & $\begin{array}{c}\text { Theoret. } \\
\text { weight of } \\
\text { dry soap } \\
\text { ( } \mathrm{m} \text {. w. } \\
\text { expressed } \\
\text { in } \\
\text { grams). }\end{array}$ & $\begin{array}{c}\text { Absolute } \\
\text { amount } \\
\text { ethyl } \\
\text { alcohol } \\
\text { absorbed } \\
\text { (in } \\
\text { liters). }\end{array}$ & $\begin{array}{c}\text { Percent } \\
\text { of } \\
\text { gelation } \\
\text { alcohol } \\
\text { at } 18^{\circ} \mathrm{C} \text {. }\end{array}$ & $\begin{array}{l}\text { Physical } \\
\text { state } \\
\text { at } \\
18^{\circ} \mathrm{C} \text {. }\end{array}$ \\
\hline $\begin{array}{l}\text { Sodiunn } \\
\text { arachidate }\end{array}$ & $\begin{array}{l}\text { Arachidic acid dissolved in warm } \\
\text { absolute alcohol and } \frac{1}{2} \text { normal } \\
\mathrm{NaOH} \text { added to it }\end{array}$ & 334 & 27.5 & 8233 & White gel \\
\hline $\begin{array}{l}\text { Sodium } \\
\text { stearate }\end{array}$ & $\begin{array}{l}\text { Stearic acid dissolved in warm ab- } \\
\text { solute alcohol and } \frac{1}{2} \text { normal } \\
\mathrm{NaOH} \text { added to it }\end{array}$ & 306 & 21.0 & 6863 & White gel \\
\hline $\begin{array}{l}\text { Sodium } \\
\text { margarate }\end{array}$ & $\begin{array}{l}\text { Margaric acid dissolved in warm } \\
\text { absolute alcohol and } \frac{1}{3} \text { normal } \\
\text { NaOH added to it }\end{array}$ & 292 & 19.0 & 6507 & White gel \\
\hline $\begin{array}{l}\text { Sodium } \\
\text { palmitate }\end{array}$ & $\begin{array}{l}\text { Palmitic acid dissolved in warm } \\
\text { absolute alrohol and } \frac{1}{3} \text { normal } \\
\mathrm{NaOH} \text { added to it }\end{array}$ & 278 & 18.0 & 6475 & White gel \\
\hline $\begin{array}{l}\text { Sodium } \\
\text { myristate }\end{array}$ & $\begin{array}{l}\text { Myristic acid dissolved in warm } \\
\text { absolute alcohol and } \frac{1}{2} \text { normal } \\
\mathrm{NaOH} \text { added to it }\end{array}$ & 250 & 15.5 & 6200 & White gel \\
\hline $\begin{array}{l}\text { Sodium } \\
\text { laurate }\end{array}$ & $\begin{array}{l}\text { Lauric acid dissolved in warm ab- } \\
\text { solute alcohol and } \frac{1}{2} \text { normal } \\
\mathrm{NaOH} \text { added to it }\end{array}$ & 222 & 13.5 & 6081 & White gel \\
\hline $\begin{array}{l}\text { Sodium } \\
\text { caprate }\end{array}$ & $\begin{array}{l}\text { Capric acid dissolved in warm } \\
\text { absolute alcohol and } \frac{1}{2} \text { normal } \\
\mathrm{NaOH} \text { added to it }\end{array}$ & 194 & 12.0 & 6185 & White gel \\
\hline $\begin{array}{l}\text { Sodium } \\
\text { caprylate }\end{array}$ & $\begin{array}{l}\text { Caprylic acid dissolved in warm } \\
\text { absolute alcolol and } \frac{1}{2} \text { normal } \\
\mathrm{NaOH} \text { added to it }\end{array}$ & 166 & 5.0 & 3012 & White gel \\
\hline $\begin{array}{l}\text { Sodium } \\
\text { caproate }\end{array}$ & $\begin{array}{l}\text { Caproic acid dissolved in warm } \\
\text { absolute alcohol and } \frac{1}{2} \text { normal } \\
\mathrm{NaOH} \text { added to it }\end{array}$ & 138 & 2.0 & 1449 & White gel \\
\hline $\begin{array}{l}\text { Sodium } \\
\text { valerate }\end{array}$ & $\begin{array}{l}\text { Valeric acid dissolved in warm } \\
\text { absolute alcohol and } \frac{1}{2} \text { normal } \\
\mathrm{NaOH} \text { added to it }\end{array}$ & 124 & $\begin{array}{l}\text { No lyoph- } \\
\text { i l i c } \\
\text { proper- } \\
\text { ties }\end{array}$ & $\ldots$ & $\begin{array}{c}\text { Crystalline } \\
\text { precipitate }\end{array}$ \\
\hline $\begin{array}{l}\text { Sodium } \\
\text { butyrate }\end{array}$ & $\begin{array}{l}\text { Butyric acid dissolved in warm } \\
\text { absolute alcohol and } \frac{1}{2} \text { normal } \\
\mathrm{NaOH} \text { added to it }\end{array}$ & 110 & 1.0 & 909 & White gel \\
\hline
\end{tabular}


TABLE X-Continued

\begin{tabular}{|c|c|c|c|c|c|}
\hline Soap. & How prepared & $\begin{array}{l}\text { Theoret. } \\
\text { weight of } \\
\text { dry soap } \\
\text { (m. w. } \\
\text { expressed } \\
\text { in } \\
\text { grams). }\end{array}$ & $\begin{array}{l}\text { Absolute } \\
\text { amount } \\
\text { ethyl } \\
\text { alcololol } \\
\text { absorbed } \\
\text { (in } \\
\text { liters). }\end{array}$ & $\begin{array}{c}\begin{array}{c}\text { Percent } \\
\text { of } \\
\text { gelation }\end{array} \\
\text { almhol } \\
\text { at } 15^{\circ} \mathrm{C} \text {. }\end{array}$ & $\begin{array}{l}\text { Physical } \\
\text { state } \\
\text { at } \\
15^{\circ} \mathrm{C}\end{array}$ \\
\hline $\begin{array}{l}\text { Sodium } \\
\text { propionate }\end{array}$ & $\begin{array}{l}\text { Propionic acid dissolved in warm } \\
\text { absolute alcohol and } 1 \text { normal } \\
\mathrm{NaOH} \text { added to it }\end{array}$ & 96 & $\begin{array}{l}\text { No ly o- } \\
\text { philic } \\
\text { proper- } \\
\text { ties }\end{array}$ & $\ldots$ & $\begin{array}{l}\text { Sticky mix- } \\
\text { ture, ulti- } \\
\text { mately crys- } \\
\text { talline }\end{array}$ \\
\hline $\begin{array}{l}\text { Sodium } \\
\text { acetate }\end{array}$ & $\begin{array}{l}\text { Acetic acid dissolved in warm abso- } \\
\text { lute alcohol and I normal } \mathrm{NaOH} \\
\text { added to it }\end{array}$ & 82 & $0.8(?)$ & $976(?)$ & White gel \\
\hline $\begin{array}{l}\text { Sodium } \\
\text { formate }\end{array}$ & $\begin{array}{l}\text { Formic acid dissolved in warm } \\
\text { absolute alcohol and normal } \\
\mathrm{NaOH} \text { added to it }\end{array}$ & 68 & $\begin{array}{c}\text { T h i e k } \\
\text { precipi- } \\
\text { tate; no } \\
\text { lyophil- } \\
\text { ic prop- } \\
\text { erties }\end{array}$ & $\cdots$ & $\begin{array}{c}\text { Crystalline } \\
\text { preeipitate }\end{array}$ \\
\hline $\begin{array}{l}\text { Sodium } \\
\text { oleate }\end{array}$ & $\begin{array}{l}\text { Oleic acid dissolved in warm abso- } \\
\text { lute alcohol and } \frac{1}{2} \text { normal } \mathrm{NaOH} \\
\text { added to it }\end{array}$ & 304 & 10.0 & 3289 & White gel \\
\hline $\begin{array}{l}\text { Sodium } \\
\text { elaidate }\end{array}$ & $\begin{array}{l}\text { Elaidic acid dissolved in warm } \\
\text { absolute alcohol and } 1 \text { normal } \\
\mathrm{NaOH} \text { added to it }\end{array}$ & 304 & . 3.8 & 1250 & White gel \\
\hline $\begin{array}{l}\text { Sodium } \\
\text { erucate }\end{array}$ & $\begin{array}{l}\text { Erueic acid dissolved in warm abao- } \\
\text { lute alcohol and normal } \mathrm{NaOH} \\
\text { added to it }\end{array}$ & 360 & 12.6 & 3500 & White gel \\
\hline
\end{tabular}




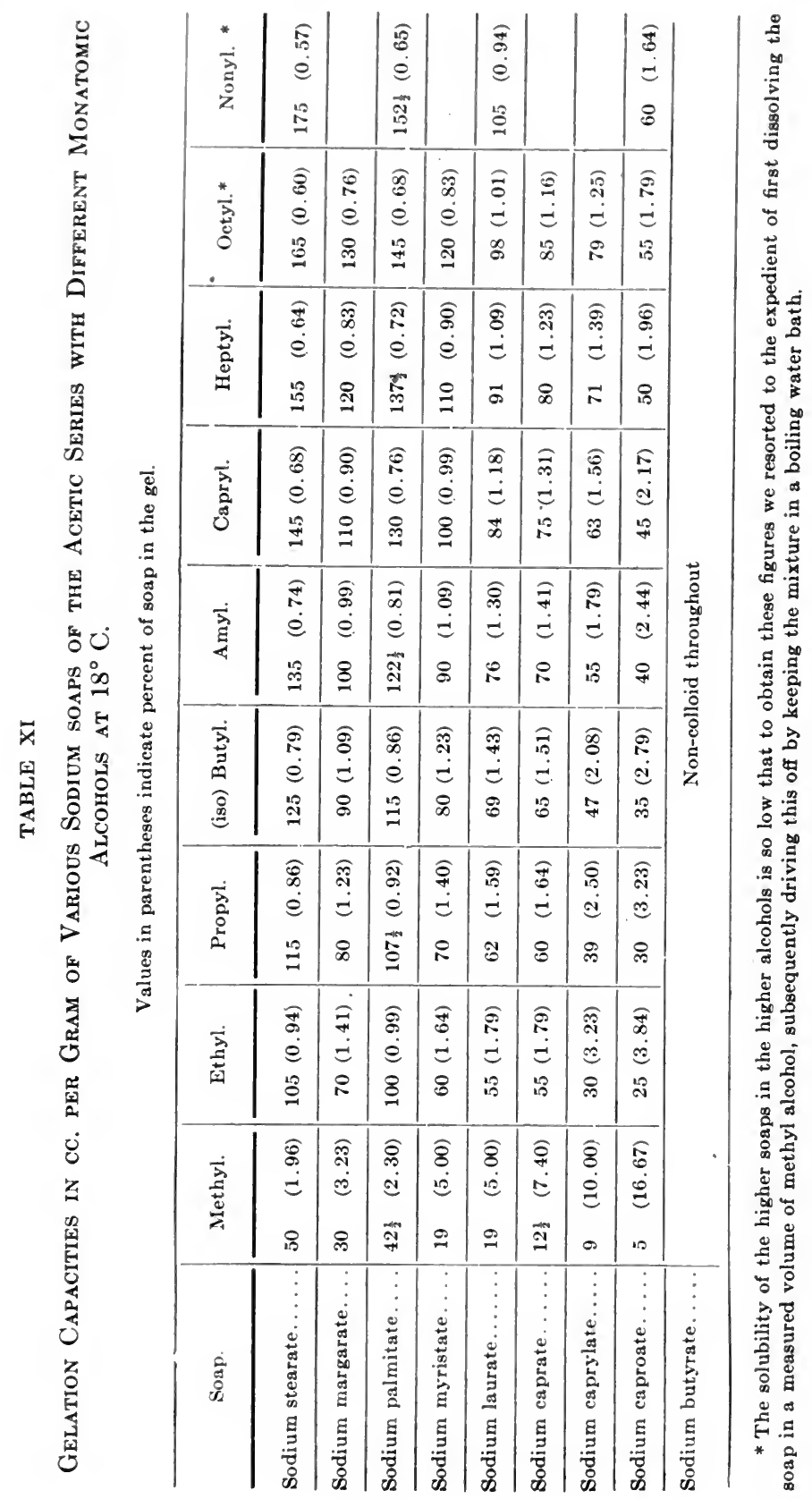




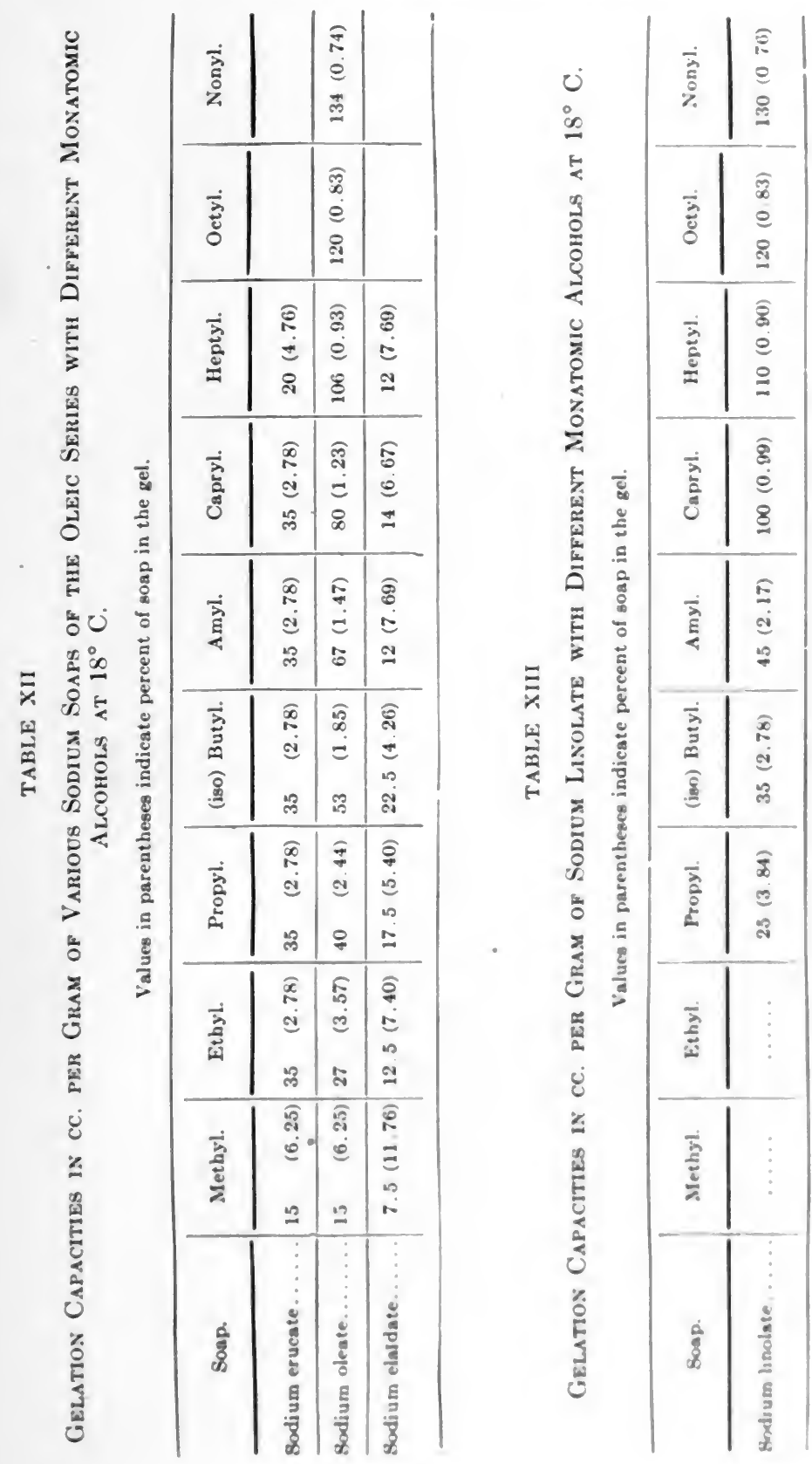




\section{TABLE XIV}

Gelation Capacities in cc. per Gram of Various Sodium Soaps of the Acetic Series with Benzyl Alcohol at $18^{\circ} \mathrm{C}$.

Values in parentheses indicate percent of soap in the gel.

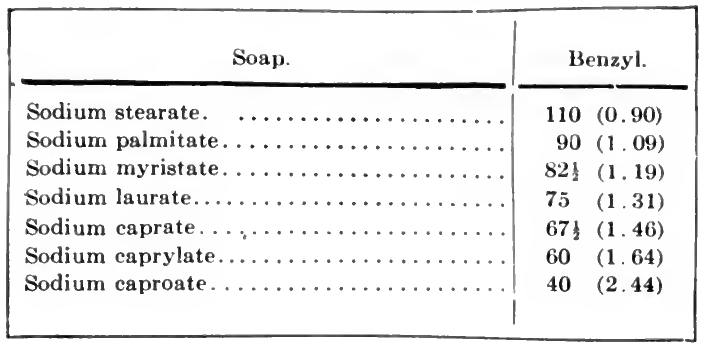

TABLE XV

Gelation Capacities in cc. per Gram of Various Sodium Soaps of the Oleic Series with Benzyl Alcohol at $18^{\circ} \mathrm{C}$.

Values in parentheses indicate percent of soap in the gel.

\begin{tabular}{|c|c|}
\hline Soap. & Benzyl. \\
\hline $\begin{array}{l}\text { Sodium erucate } \ldots \ldots \ldots \ldots \ldots \ldots \ldots \ldots \\
\text { Sodium oleate } \ldots \ldots \ldots \ldots \ldots \ldots \ldots \ldots \ldots \\
\text { Sodium elaìdate } \ldots \ldots \ldots \ldots \ldots \ldots \ldots \ldots\end{array}$ & $\begin{array}{ll}30 & (3.23) \\
50 & (1.96) \\
20 & (4.76)\end{array}$ \\
\hline
\end{tabular}

TABLE XVI

Gelation Capacities in cc. per Gram of Various Sodium Soaps of the Acetic Series with Different Diatomic Alcohols at $18^{\circ} \mathrm{C}$.

Values in parentheses indicate percent of soap in the gei.

\begin{tabular}{|c|c|c|}
\hline Soap. & $\begin{array}{c}\text { Ethylene- } \\
\text { glycol. }\end{array}$ & $\begin{array}{l}\text { Trimethylene- } \\
\text { glycol. }\end{array}$ \\
\hline Sodium stearate........ & $80(1.23)$ & $250(0.39)$ \\
\hline Sodium palmitate....... & $40(2.44)$ & $120(0.83)$ \\
\hline Sodium myristate....... & $10(9.09)$ & $80(1.23)$ \\
\hline Sodium laurate......... & $\ldots \ldots$ & $40(2.44)$ \\
\hline Sodium caprate. . . . . . . & $\ldots \ldots$ & $25(3.84)$ \\
\hline Sodium caprylate....... & $\ldots \ldots$ & $15(6.25)$ \\
\hline Sodium caproate....... & $\ldots \ldots$ & $10(9.09)$ \\
\hline
\end{tabular}


TABLE XVII

Gelation Capacities in cC. per Gram of Varlous sodicy soaps of the Oleic Series with Different Diatomic Alcohols at $18^{\circ} \mathrm{C}$.

Values in parentheses indicate percent of soap in the gel.

\begin{tabular}{|c|c|c|}
\hline Soap. & $\begin{array}{c}\text { Ethylene- } \\
\text { glycol. }\end{array}$ & $\begin{array}{c}\text { Trimethylene- } \\
\text { glycol. }\end{array}$ \\
\hline $\begin{array}{l}\text { Sodium erucate. . . . . . . . } \\
\text { Sodium oleate. . . . . . . . . } \\
\text { Sodium elaidate. }\end{array}$ & $\begin{array}{c}30(3.23) \\
\ldots \ldots \\
\ldots \ldots\end{array}$ & $\begin{array}{lll}30 & (3 & 23) \\
60 & (1 & 64) \\
15 & (6.25)\end{array}$ \\
\hline
\end{tabular}

\section{TABLE XVIII}

Gelation Capacities in cc. per Gram of Various Sodium Soapg of the Acetic Series with a Triatomic Alcohol at $15^{\circ} \mathrm{C}$.

Values in parentheses indicate percent of soap in the gel.

\begin{tabular}{|c|c|}
\hline Soap. & Glycerin. \\
\hline 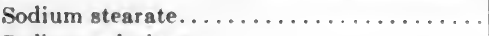 & $1.50 \quad(0.66)$ \\
\hline Sodium palmitate............ & $50 \quad(1.96)$ \\
\hline Sodium myristate. . . . . . . . . & $15 \quad(6.25)$ \\
\hline Sodium laurate.......... & $8(11.11)$ \\
\hline
\end{tabular}

TABLF, XIX

Gelation Capacities in cc. per Gram of Various Soditm Sonps of the Oleic Semes with a Triatomic Alcohol at $15^{\circ} \mathrm{C}$.

Values in parentheses indicate percent of soap in the gel.

\begin{tabular}{|c|c|}
\hline Soap. & Glycerin \\
\hline Sodium erucnte. & $30\left(\begin{array}{lll}3 & 23\end{array}\right)$ \\
\hline Sordium oleste... & $20(4 ; 6)$ \\
\hline Sodium elaidate. . . . . n th & If $(5,26)$ \\
\hline
\end{tabular}




\section{THE SYSTEM SOAP/X. COLLOID SOAPS IN OTHER NON-AQUEOUS "SOLVENTS"}

It is of importance for the theory of the lyophilic soap colloids in particular, and of lyophilic colloids in general, to see how much

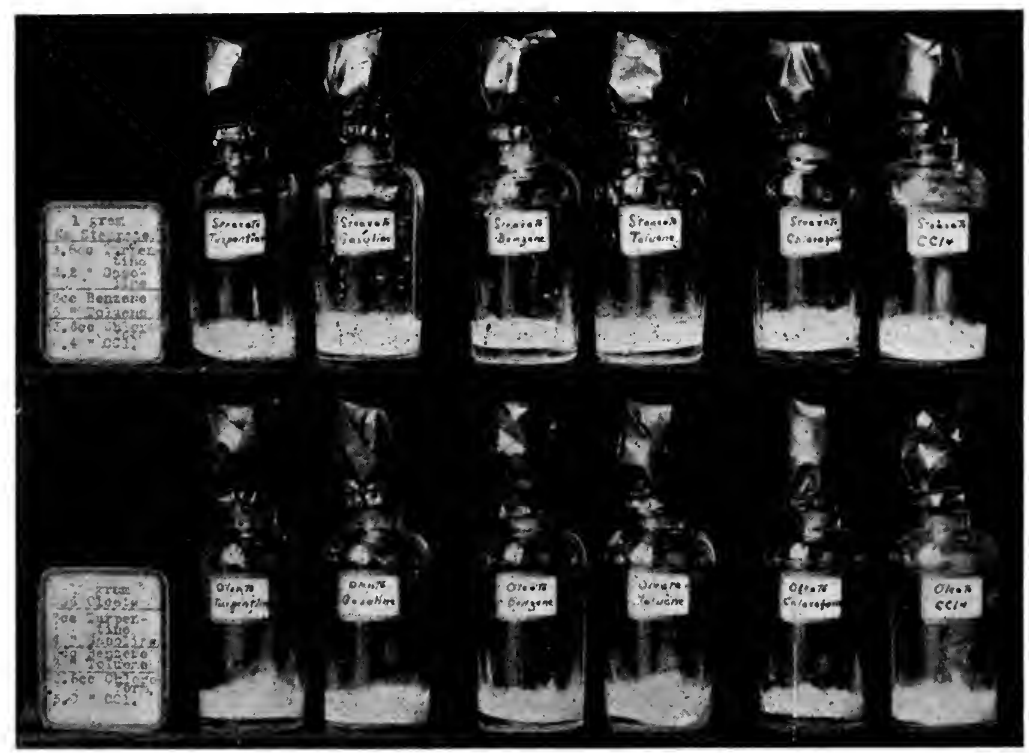

Figure 43.

further the composition of these systems may be broadened and still yield the definitely colloid systems under discussion. The soaps form admirable materials for such a study, for, as already observed, they yield colloid systems not only with water and the various monatomic, diatomic and triatomic alcohols but also with many other liquid " solvents."

Some colloid systems of the general composition soap $/ x$ are illustrated in Fig. 43. Here sodium stearate and sodium oleate 
are seen to yield gels with turpentine, gasoline, benzene, toluene, chloroform and carbon tetrachlorid. The list of "solvents" which yield such results can be further lengthened as shown in Figs. 44,45 and 46 by observing that meta-, ortho- and paraxylene, diethyl and butyl ethers, benzaldehyd and paraldehyd, turpentine, limonene, pinene, gasoline, heptane, ethyl œnanthate, amyl acetate and triacetin all yield satisfactory results. The experimental details covering Fig. 43 are contained in Table XX; those covering Figs. 44, 45 and 46 in Table XXI. It

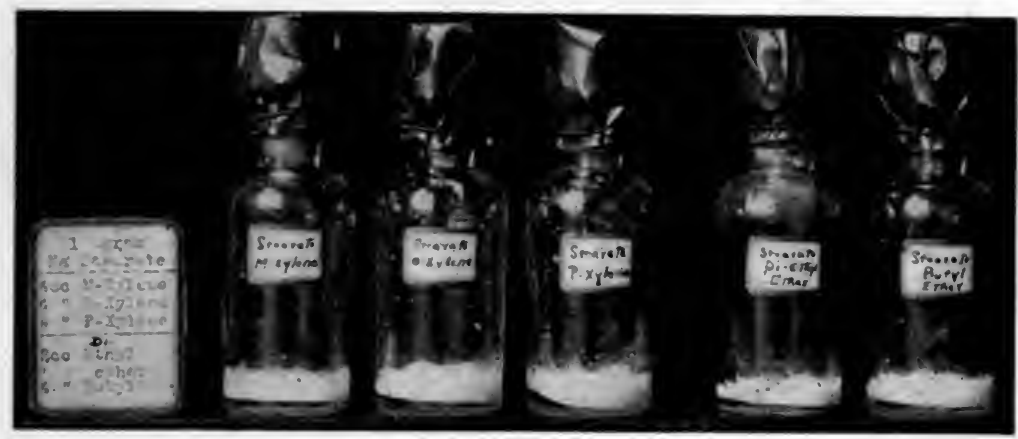

Figure 44.

should be noted that the gelation capacities of Table $\mathrm{XX}$ are the maximal values; in the rest of the series we contented ourselves with the mere finding that lyophilic colloid systems could be produced from the soaps and "solvents" chosen for study.

These findings indicate that a large variety of different " solvents" may all yield lyophilic colloid systems, even though there is little chemical relationship between the members of the various groups studied. What this means for the general theory of the lyophilic colloid state is now to be discussed. 


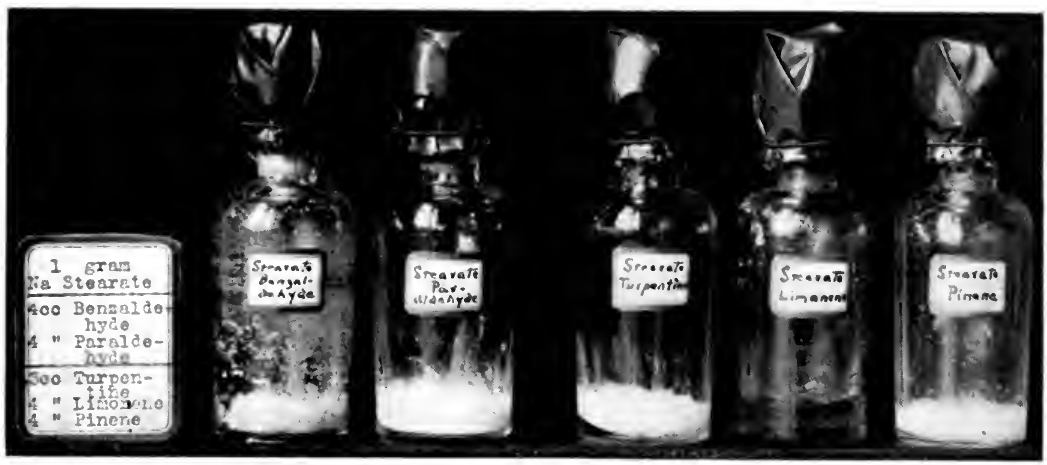

Figure 45.

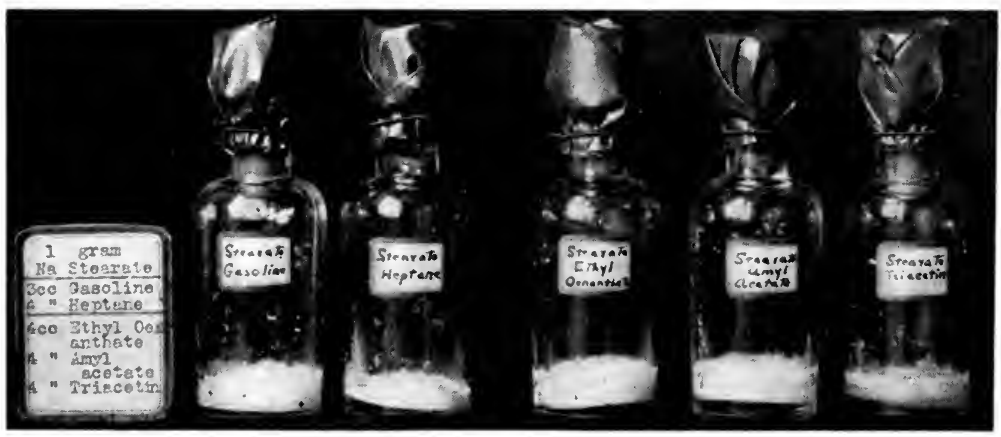

Figure 46. 


\section{TABLE XX}

\section{Gelation Capacities in cc. per Gram of Various Sodium Soaps with Different Non-aqueous Solvents at $18^{\circ} \mathrm{C}$.}

Values in parentheses indieate pereent of soap in the gel.

\begin{tabular}{c|c|c|c|c|c|c|c}
\hline Soap. & Turpentine. & Gasoline. & Benzene. & Toluene. & Chloroform. & $\begin{array}{c}\text { Carbon } \\
\text { tetrachlorid. }\end{array}$ \\
\hline Sodium stearate & $3.8(20.8)$ & $3.2(23.8)$ & $3.0(25.0)$ & $6.0(14.3)$ & $3.6(21.8)$ & $6.4(13.5)$ \\
Sodium oleate.. & $3.0(25.0)$ & $4.0(20.0)$ & $3.0(25.0)$ & $3.0(25.0)$ & $3.6(21.8)$ & $5.0(16.7)$ \\
\hline
\end{tabular}

\section{TABLE XXI}

\section{Gelation Capacities (Not Maximal) in cc. per Gram of Sodium} Stearate with Different Non-aqueous Solvents at $18^{\circ} \mathrm{C}$.

Values in parentheses indicate percent of soap in the gel.

\begin{tabular}{|c|c|}
\hline *M-xylene................. & $4.0(20.0)$ \\
\hline 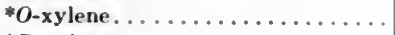 & $4.0(20.0)$ \\
\hline 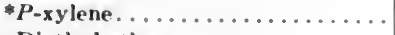 & $4.0(20.0)$ \\
\hline Diethyl ether. . . . . . . . . . . & $2.0(33.3)$ \\
\hline *Butyl ether............... & $4.0(20.0)$ \\
\hline 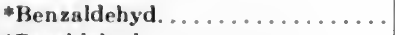 & $4.0(20.0)$ \\
\hline *Paraldehyd. . . . . . . . . . & $4.0(20.0)$ \\
\hline 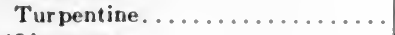 & $3.0(25.0)$ \\
\hline *Limonene................. & $4.0(20.0)$ \\
\hline *Pinene.................. & $4.0(20.0)$ \\
\hline Gasoline................... & $3.0(25.0)$ \\
\hline 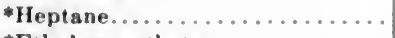 & $4.0(20.0)$ \\
\hline *Ethyl onanthate. ............ & $4.0(20.0)$ \\
\hline * Amyl acetate.............. & $4.0(20.0)$ \\
\hline *Triacetin.................. & $4.0(20.0)$ \\
\hline
\end{tabular}

*Because of the slight "solubility" of the soaps in these solvents at the temperature of a boiling water bath, this was increasei through addition of a small, measured volume of methyl alcohol which was then completely evaporated from the mixture before the system was cooled to $18^{\circ} \mathrm{C}$. 


\section{ON THE GENERAL THEORY OF THE LYOPHILIC COLLOIDS}

\section{Historical and Critical Remarks}

The experiments detailed above on soap/water, soap/alcohol and soap $/ x$ systems help, we think, towards a better understanding of a number of technological, physico-chemical and biological problems. We wish first to comment upon their value for $a$ closer definition of the terms hydrophilic or lyophilic colloid. ${ }^{1}$ In spite of the fact that we now recognize the existence of material in the colloid state and utilize its many important properties for the solution of technological or scientific phenomena, it is nevertheless true that an entirely satisfactory or complete definition of what constitutes the colloid state is not yet at hand.

Perhaps the best established and most universal characterization of the colloids is that which defines them as diphasic or polyphasic systems in which one material is subdivided into a second with the degree of subdivision coarser than molecular and not so coarse as to fall within the limits of microscopic visibility. From the three states of matter, gaseous, liquid and solid, it is obvious, as first clearly developed by WoLfGang OSTWALd, ${ }^{2}$ that nine combinations consisting of the colloid dispersion of any one of these materials in any second are possible. These may be tabulated as follows:

\begin{tabular}{llll|}
$\begin{array}{ll}\text { gas in gas } \\
\text { gas in liquid } \begin{array}{c}\text { (charged } \\
\text { water) } \\
\text { gas in solid }\end{array}\end{array}$ & $\begin{array}{c}\text { liquid in gas } \\
\text { (meerschaum) }\end{array}$ & $\begin{array}{c}\text { liquid in liquid (fine emul- } \\
\text { sion) }\end{array}$ & $\begin{array}{c}\text { solid in liquid } \text { (metallic gold in } \\
\text { water) }\end{array}$ \\
liquid in solid (opal) & solid in solid & (gold ruby glass)
\end{tabular}

Of the nine possible combinations eight have been realized (the colloid dispersion of one gas in a second being impossible).

${ }^{1}$ Martin H. Fischer and Marian O. Hooker: Science, 48, 143 (1918); ibid., 49, 615 (1919); Chem. Engineer, 27, 184 (1919).

${ }^{2}$ Wolfgang Ostwald: Kolloid-Zeitschr., 1, 291, 331 (1907); Theoretical and Applied Colloid Chemistry, translated by MArtin H. Fischer, 42, New York (1917); Handbook of Colloid Chemistry, 2nd English Ed., translated by Martin H. Fischer, 43, 49, Philadelphia (1918). 
Of these dispersoids, the ones of greatest interest in connection with the behavior of the soaps are those embraced within the heavy black square, in other words, those which have the composition liquid plus liquid or liquid plus solid. According to Ostwald, the former are the emulsion colloids, the latter the suspension colloids; or, to adopt the terminology of P. P. von Weimarn, they are the emulsoids and the suspensoids.

The attempt has been made to correlate the physical properties of each of these systems with the fact that the two phases have, in the first instance, a liquid plus liquid composition, or, in the second, a liquid plus solid composition. In the group of the first are found many of the "viscous, gelatinizing and not readily coagulable" "colloid solutions" of A. A. NOYEs, ${ }^{1}$ or the hydrophilic or lyophilic colloids of J. Perrin ${ }^{2}$ and H. Freundlich; ${ }^{3}$ in the second are the "non-viscous, non-gelatinizing, readily coagulable" "colloid suspensions" of Noyes or the hydrophobic or lyophobic colloids of PerRin and Freundich. The correlation between the physical state of the phases and the properties of the mixed systems is not enough, however, to characterize them completely. Liquid mercury in water for example yields only a suspension colloid, and the same is true of (liquid) oil in water; on the other hand, (solid) ferric hydroxid, generally ranked among the suspension colloids, has distinctly hydrophilic properties in high concentration in water.

Such weaknesses in the attempts to make the term lyophilic colloid synonymous with emulsion colloid and lyophobic colloid with suspension colloid were recognized by WoLfGang OsTWALD ${ }^{4}$ himself, and in consequence the effort was made by him to overeome such objection by declaring the lyophilic colloids "colloids of a higher order." Specifically he assumed that emulsion colloids were not "merely" subdivisions of one liquid in a second, but that each of the liquid phases was itself a dispersoid. We shall see below that this view is correct.

It seems to us that the characteristic difference between lyophilic and lyophobic colloids is not to be sought in their liquid plus liquid or liquid plus solid character but in the fact that the phases are cither

'A. A. Noyrs: Jour. Am. Chem. Soc., 27, 85 (190.5)

2J. Perrin: Journal de Chimie physique, 3, 84 (1905)

${ }^{3}$ H. Freusdetcu: lolloid-Zeitschr., 3, s) (1908); linpillarchemie, 309. Leipzig (1909).

4 Wolfgang Ostwald: Kolloid-Zeitschr., 11, 230 (1912) 
mutually soluble or not. (Liquid) water and (liquid) oil yield only lyophobic colloids (suspension colloids in the old terminology) because the two phases are mutually insoluble, but (liquid) water and soap (whether liquid or solid) yield lyophilic colloids (emulsion colloids in the old terminology) because their mutual solubility is high.

The importance of mutual solubility for the understanding of some of the phenomena characteristic of colloids was drawn upon some years ago by W. B. Hardy. ${ }^{1}$ Hardy used the concept of mutual solution to explain the physical phenomena encountered in the gelation of protein-water-salt mixtures, but owing to the objection that the phases did not show the constant chemical composition demanded by theory, this important idea seems to have been largely dropped. For reasons which become apparent as we proceed, this objection is not valid, and it seems possible to make a fairly inclusive analysis of what we mean by hydrophilic colloids and the changes in their states, as soon as we add to the concepts of mutual dispersion in degrees coarser than molecular and mutual solubility of the phases a third important point, namely, that of the enormous increase in viscosity observed whenever two liquids or a liquid and a solid, themselves possessed of low viscosity, are subdivided into each other.

To make the last of these points clear, it is only necessary to introduce the example of Wolfgang Ostwald, of water and dry sand, and the observations of J. FriedLïnder and V. RothMUND on the viscosity of mutually soluble liquids in the zone of their critical temperature. While dry sand "runs" easily and the viscosity of pure water is relatively low, wet sand may be readily molded and hold its shape. The example of the mutually soluble system phenol/water (which is considered particularly apt in the matter of understanding the colloid behavior of soap/ water systems) is shown in Fig. 47. The bottle on the extreme left contains only phenol (which at $18^{\circ} \mathrm{C}$. is a crystalline mass like any "pure" soap at a proper temperature). The succeding bottles contain the same weight of phenol, plus gradually increasing amounts of water. As more and more water is added the phenol fails to crystallize; up to and including the sixth bottle from the left, only." solutions" are obtained, but these are solu-

${ }^{1}$ W. B. Hardy: Jour. Physıol., 24, 158 (1899); Zeitschr. f. physik. Chem., 33, 326 (1900). 


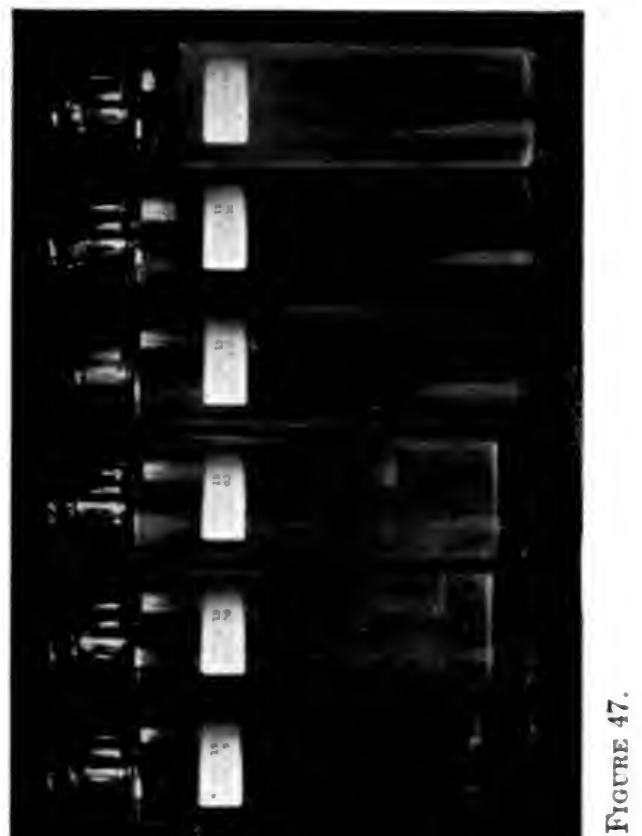

$\equiv$

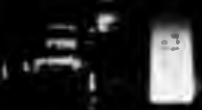

$1+\frac{2}{2}$
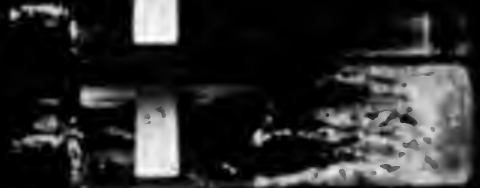

$\checkmark$

茨

1 is

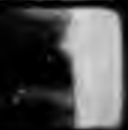


tions of water in phenol. The seventh bottle shows two layersbelow, one of phenol saturated with water; above, a solution of phenol in water. With further additions of water the latter type of solution grows at the expense of the former, until finally, in the bottle second from the extreme right of the series nothing but a solution of phenol in water remains. ${ }^{1}$

Of importance for our further discussion is, first, the existence of the two types of solution, that of water-in-phenol and that of phenol-in-water. The physical constants of these two solutions are totally different and they behave differently, too, toward changes in external conditions like temperature or the effects of added substances (acids, bases, salts, indicators, etc.). A second point of importance is the behavior of such a system as is represented in the fourth or fifth bottle from the right when subjected to increases or decreases in temperature. When the temperature is raised the watered-phenol phase goes over and into solution in the phenolated-water phase. It is characteristic of liquids, when their temperature is being lowered, to show a progressive increase in viscosity. The warmed solution of phenolin-water also shows such a progressive increase in viscosity as its temperature is lowered, but, as first noted by FRIEDLÄNDER and Rothmond, this progressive increase shows a sharp break upon reaching the critical temperature, at which the phenol begins to separate out.

This break expresses itself as a sharp rise in viscosity, which increases for a time and then falls off again, so that with further lowering of temperature a viscosity curve more like the original "normal" is again obtained.

We are indebted to Wolfgang Ostwald for pointing out that, in this critical zone during which the phenol/water system is opalescent, we are in reality dealing with a colloid system (consisting of watered-phenol dispersed in phenolated-water).

"In analogy to what happens in the "salting-out" of soaps, which is the subject of Section X (page 93), it is well to explain the nature of the contents of this right-hand bottle in the series. This was originally nothing but a solution of phenol in water, but through the addition of ordinary table salt the phenol was "salted out" so that now a phenol phase with some water dissolved in it (analogous to the salted-out soap of the manufacturer) is seen floating at the surface of the liquid in the bottle. 


\section{On the Theory of Soap Gels}

It is our purpose now to show that the behavior of the soap/uater, soap/alcohol and soap/x systems previously discussed is also best understood in the terms of the submolecular dispersion into each other of two materials possessed of a fair degree of mutual solubility.'

When one tries to state in the simplest possible terms what it is that happens when a definite mixture of soap with some solvent (like soap and water), which at the temperature of boiling water is a mobile liquid, is seen to set into a dry, solid mass as its temperature is reduced, it seems easiest to think of the whole as a change from what is, at the higher temperature, essentially a solution of soap in water to that which is, at the lower temperature, a solution of water in soap. Between these extremes and as determined by the temperature and by the relative concentrations of soap and of water, we get various mixtures of solvatedsoap in soap-water or of soap-water in solvated-soap. The situation in the case of the soaps in the presence of limited volumes of water is identical, in other words, with the changes which may be seen in mutually soluble systems of the type phenol water, ether/water or protein/water as studied by J. Friedländer, V. Rothmund, W. B. Hardy and their various followers.

Turning first to a study of the mechanism employed for the production of these colloid soap systems, it is evident that they are formed for the most part by "dissolving" a unit weight of soap in a definite volume of water at a rather high temperature. In the accepted parlance, it may be said that through increase in temperature the solubility of the soap in the water is tremendously increased. While the lower soaps of the acetic acid series are readily soluble in water (even at relatively low temperatures), the upper members behave like the lower members if the temperature is raised. The soap goes into solution in the water. The truth of this assertion is indicated by the available physico-

'We are not unaware that the concept "solution " needs itself to be defined. While the field of "solution" constitutes slipwsy ground, we sccept, for pragmatic reasons, as characteristic of the "true" molution, the teachings of Wolboaso Ostwald and P. P. von Wrimans, who define such solutions an diapensions of $A$ in $B$ with the degree of suldivision measurable in molerular or smaller values. To exprese the matter in the terms of A P MATIrws. we may say that $A$ in dissolved in $B$ or vice vena when the solvent has overcome the cohesive forms of the divolied subatances in MAтикw has shown, the forces of cohesion opernte within molecular dinsensions. 
chemical observations which show that the lower soaps behave " normally" even at relatively low temperatures; but all the soaps, even the higher ones, tend to behave osmotically, electrically, optically, etc., as so-called "true" solutions when their temperature is sufficiently raised (KRAFFT).

To illustrate the matter in crude fashion and more particularly for any of the higher soaps (which experiment has shown to be particularly favorable for the production of " colloids") and to illustrate the effects of a lowering of temperature, Figs. 48 and 49 are introduced. Fig. 48 shows the results if the separating phase has a liquid character; Fig. 49, if it is solid or crystalline. The diagrams are supposed to show the results when two mutually soluble

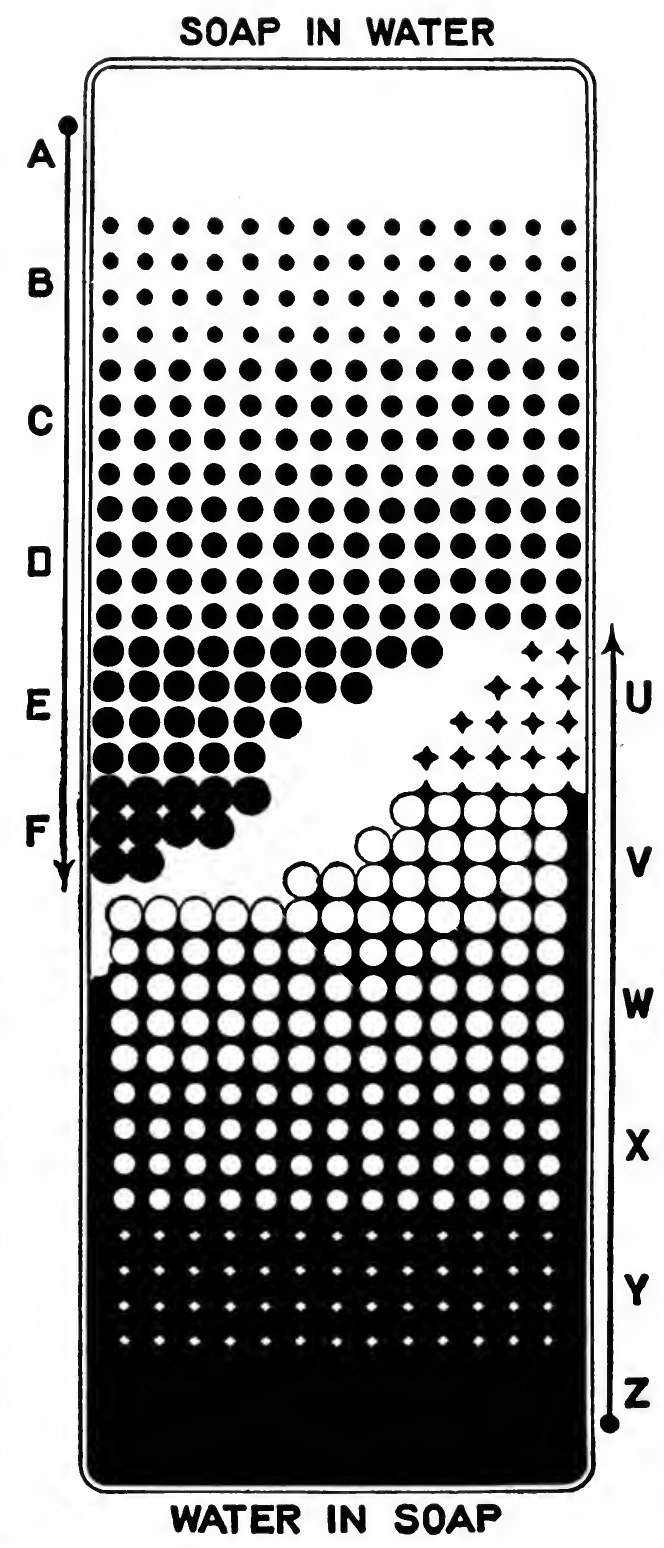

Figure 48. 


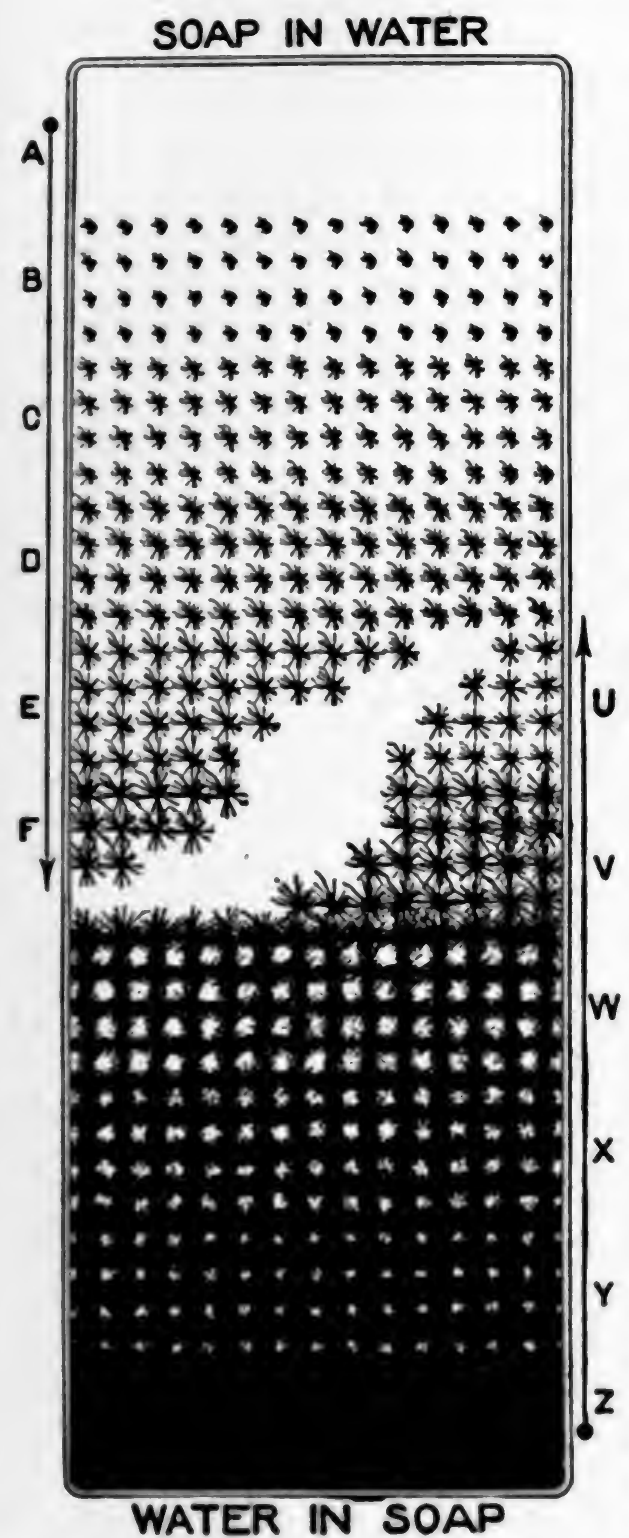

Prouke 49. substances, like $A$ and $B$, (water and soap, or alcohol and soap) are mixed together. When $B$ (or the soap) is readily soluble in $A$ and the concentration is rightly chosen, there results a true solution at the higher temperature. This matter is represented by the region marked $A$ in the diagrams (the soap is dispersed molecularly or ionically in the solvent). The lowermost members of the fatty acid series form systems of this type only, even at relatively low temperatures, but the nembers higher in the series form such systems only at the higher temperatures. The soap manufacturer who makes his product by "boiling," in essence makes his soaps in such true solution.

What happens now when the temperature is lowered? 'The solubility of the soap in the water is obviously decrensed. As the 
saturation point is attained, the soap particles assume not only molecular size but more than molecular size. By definition, therefore, we approach with falling temperature the realm of the colloids, or that of dispersions of one material in a second with the degree of dispersion showing dimensions greater than molecular. The gradual increase in the size of the soap particles (or increase in their number) with lowering of the temperature is represented by the regions $B, C, D, E$ and $F$ in the two diagrams.

Thus far we have explained merely the production of a colloid system by the ordinary process of bringing about supersaturation and an agglomeration of particles previously more highly dispersed. It is obvious that such agglomeration may yield either a lyophobic (or so-called suspension colloid) or a lyophilic (or so-called emulsion colloid). The lyophobic colloid results when the solvent is not soluble in the procipitating phase; the lyophilic colloid when the solvent is soluble in the precipitating phase. When soap falls out of solution from such a solvent as allyl alcohol the former of these possibilities is realized; when it falls out in water, alcohol, toluene, benzene, etc., the latter is realized. The black circles in the diagram of Fig. 48 or the black crystal masses in Fig. 49 represent more therefore in the latter instance than a mere precipitate of pure soap; they are this, plus a certain amount of the water, alcohol or other " solvent" dissolved in them. ${ }^{1}$

At a sufficiently low temperature the soap aggregates will have become so large or so numerous as to touch and coalesce. If this process continues to a sufficient extent the system will ultimately represent, in essence, nothing but soap in which the previous "solvent" has been dissolved. This situation is represented diagrammatically by the zone $Z$ of Figs. 48 and 49 .

A study of Figs. 48 and 49 shows, however, that between the upper extreme $(A)$ of a solution of the soap in the solvent and the

"We do not here distinguish between such "dissolved" water and water of crystallization. Obviously both values are included. While we have no desire to trespass upon the fields of theoretical chemistry we feel strongly compelled to the view that "solution" always means (chemical) union between solvent and dissolved substance. In the "dilute" solutions this effect is largely lost sight of, however, because of the large overplus of the pure "solvent," the properties of which then continue to dominate the whole system. The union between solvent and any substance $X$ need not, moreover, be of one kind only. When phenol dissolves in water one type of union between the two is accomplished; when water dissolves in phenol the combination is a totally different one. 
lower extreme $(Z)$ of a solution of the solvent in the soap, there exist two main zones of mixed systems, one below the upper ( $B$, $C, D$ and $E$ ) consisting of a dispersion of solvated-soap in the soaped-solvent, and a second above the lower $(Y, X, W$ and $V$ ) consisting of soaped-solvent in the solvated-soap. These two mixed systems are in essence "emulsions" (if both phases are liquid) or "suspensions" (if at least one phase is solid) but of opposite types; and as such (even when of the same quantitative chemical constitution) are possessed of totally different physical properties. The former corresponds, for example, to an emulsion of oil-in-water or a suspension of quartz-in-water; the second to an emulsion of water-in-oil or a system of water-in-quartz. And as the former (as illustrated by milk) will mix with water, wet paper and show a certain viscosity value, the latter (as illustrated by butter) will mix only with oil, will grease paper and show an entirely different viscosity. ${ }^{1}$

Returning to the lyophilic soaps and the diagram, it is obvious that as we descend, with lowering of temperature, from the region $A$, we pass, in the regions $B, C$ and $D$, through increasingly viscid liquid colloid "solutions," but all of them emulsions or suspensions of the type solvated-soap in soaped-solvent. In the region $E$, the particles of solvated soap almost touch, and here the highest (liquid) viscosity is obtained. In $F$ they do touch and now form a continuous external phase. At this point we change to the opposite type of emulsion or suspension-the previously liquid colloid becomes solid, or, as we say, it gels. As we shall show later ${ }^{2}$ the two types of system not only have different physical constants but behave differently toward such added materials as indicators.

'See in this connection Martiv H. Fiscuer and MariaN O. HоOKer Science, 43, 468 (1916); MАrtix H. Fiscukк: Fats and Fatty Degeneration, 20, New York (1917).

See page 77; also MantiN Н. Fiscukn: Science, 49, 615 (1919); Chem. Engineer, 27, 271 (1919). 


\section{DEFINITION OF HYSTERESIS, SWELLING, LIQUEFACTION, GELATION CAPACITY, SOLVATION CAPACITY, SYNERE- SIS, SOL}

We should now like to emphasize how this concept of the changes which the soaps suffer in passing from liquid sols to dry gels may help to explain a number of the "strange" characteristics of colloid systems.

1. A first question under this heading is that of the nature of hysteresis, more particularly that observed when a colloid is subjected to changes in temperature. The importance of the thermal history of a colloid system is constantly stressed. It is generally true of the lyophilic colloids that when subjected to heat manipulation they tend to hold fast to the characteristics of their previous states. A colloid on cooling, for example, first sets at a certain temperature; yet the same colloid after setting, fails on reheating to liquefy at this temperature-it usually first " melts" at a higher one. In fact it may be said quite generally that the curve showing the increase in viscosity of a lyophilic colloid with lowering of temperature is rarely identical with that portraying the decrease in viscosity when the temperature is raised through the same range. If the fact is remembered that the absolute values of two mutually soluble substances are rarely the same, and that the rates at which they go into solution in each other are usually different, many of these difficulties disappear. Figs. 48 and 49 show diagrammatically not only what happens when the temperature of a solution of soap in some solvent is lowered but also, in the lower halves of the pictures, the effects of warming a gel. Increasing the temperature of the original solvated-soap shown in region $Z$ increases the solubility of the soap in the water, and so the colloid dispersion $Y$ results, consisting of soaped-solvent in solvated-soap. Further increase in temperature yields the regions $X$ and $W$, but, because of the persistence of the solvated-soap as the external phase, all these regions continue to show a rigidity or viscosity higher than that of systems of the same quantitative composition produced by 
a lowering of temperature from a higher level. The gel first shows signs of liquefaction where the soaped-solvent particles begin to touch and thus to form the external phase, as in the regions $V$ or $U$. It is for these reasons that the region of greatest ambiguity and of greatest hysteresis is found in the broken middle portions of the diagram $(D, E, F$ and $W, V, U)$. Just as long periods of time are required to make solution phenomena attain their final values, just so must mutually soluble systems subjected to changes in their environment be expected to come only slowly into a state of their final equilibrium.

2. Some years ago we showed, in the case of gelatin, ${ }^{1}$ that the "swelling" of this substance and its liquefaction are not identical processes and that the latter is not a mere continuation of the former. When ordinary gelatin is thrown into water, it swells up somewhat, but the amount of this swelling is enormously increased if a little acid is added to the water. If liquefaction were a mere continuation of this swelling, then the addition of a little acid to a gelatin near its gelation point ought to make it set. As a matter of fact, not only does this not happen, but the addition of such acid to a previously solid gelatin makes it liquefy. As maintained at that time, an increased "swelling" was declared to be an increased capacity for taking up the solvent; an increased tendency to liquefy, the expression of an increase in the degree of dispersion of the colloid material.

The concept of the lyophilic colloid as here developed now permits us to state more clearly just what each of these views embraces. Increased swelling due to increase in hydration or solvation capacity means increased solubility of the solvent in the dispersed substance. When acid is added to gelatin (thus forming an acid gelatinate) water is more soluble in the newly formed material than in the neutral gelatin. Acid is therefore said to increase the swelling of protein. But an acid proteinate is also more soluble in water than is the neutral protein. If the concentration of the system is properly chosen, the addition of acid will therefore make a gelatin/water system, solid by itself, tend to remain "in solution" or, as more generally stated, the gelatin fails to "set." Expressed the other way about, the presence

'Martis H. Fiscier: Science, 42, 223 (1915); Martiv H. Fischer and Marian O. Hooker: ihid., 46, 189 (1917); Jour. Am. Chem. Soc., 40, 272 (1918); ibid., 40, 292 (1918); ibid., 40, 303 (1918). 
of acid makes the gelatin "liquefy" or "go into solution." Using Figs. 48 and 49 to illustrate what has been said, the addition of acid to a previously solid gelatin moves the whole system from some such lower region as $Z, Y, X$, or $W$ into one of the upper zones like $V$ or $U$.

3. Throughout the experiments described in the previous sections we have used the formation of a dry gel as the measure of the "gelation capacity" of a colloid. We may now attempt to say just what this means. It obviously includes more than the term solvation capacity. The latter measures the solubility of the solvent in the colloid material and is synonymous with the swelling capacity. Gelation, however, includes not only this value but more - namely, everything embraced within the region of the emulsification or enmeshing of a "solution" of the colloid material in the solvent, within the solvated colloid as an external " dry" phase. It embraces everything in Figs. 48 and 49 up to and including the zone $V$.

4. Just above this region it is apparent that the more solid phase may no longer be adequate to enclose all the "solution" of colloid in solvent. When this upper region is reached the colloid system tends to "sweat" —or to use the term of Thомаs Graham the gel shows "syneresis." We may still have before us a gel, but it is now no longer " dry."

When the dispersion of a liquid in an enveloping phase which is also a liquid is compared with the dispersion of a liquid in a more solid (crystalline) phase, (as indicated in the zones $V$ of Figs. 48 and 49) it is clear that the tendency to "leak" the liquid phase is greater and is more likely to occur early in the case of the latter system than in the former. It is for this reason that the more "solid" gels regularly show earlier and greater syneresis than the more "elastic" or "liquid" gels.

To go sufficiently above the region $U$ is to be in the regions $E$ and $D$. We now no longer say that there is syneresis or that this has become excessive but we say that the gel has gone into or persists in the "sol" state.

5. As a final word we should like to emphasize the fact that the concept of the lyophilic colloid as outlined here sets no limitations upon the nature of the materials that may make up such a system and makes no specifications as to the nature of the forces which guarantee the stability of the colloid system. They are in general any or all 
the forces which appear in or are operative in solutions of the most varied kinds. This is emphasized because there has been much written, for example, regarding the all-important effects of the electrical charges in determining the stability of colloids in general and of the lyophilic colloids in particular. We do not wish to deny the importance of this factor in some colloid systems or under certain conditions, but it is too narrow a view to take of what constitutes the lyophilic colloids in general. While the play of electrical forces may be apparent in systems composed of soaps and water, in those of proteins and water, etc., lyophilic colloid systems may be built up, as illustrated in the preceding pages, of materials in which the electrical factors are either negligible or absent entirely. It will prove somewhat difficult, to say the least, to conjure up orthodox electrical notions in systems containing nothing but soaps with anhydrous alcohol, toluene, benzene, chloroform or ether.

\section{VII}

\section{ON THE REACTION OF SOAPS TO INDICATORS}

In order to get ground materials of strictly reproducible type for the observations on soaps detailed in the preceding pages, we followed the expedient of producing "neutral" soaps by simply adding to each other the necessary gram equivalents of highly purified fatty acids and carefully standardized solutions of alkali. We found that this method yielded more satisfactory results than that of others who tried to obtain " neutral," " slightly alkaline" or "slightly acid" soaps by adding to each other fatty acid and standard alkali until some chosen indicator was presumed to show the mixture neutral, alkaline or acid. As the next paragraphs will show, such indicator methods as ordinarily employed are highly fallacious. As a matter of fact the errors incident to the approach to the problem by the latter method have long been familiar to the practical soap chemists, for they have for decades past determined the presence of "free alkali" or "free fatty acid" in their soaps by indirect methods. The following observations not only show how unreliable are the commonly employed indicator methods but why they must be so, 
not only in the specific instance of the different soaps but in all similar colloid-chemical systems as represented by the most varied types of chemical reaction encountered in technological practice and in living cells under physiological and pathological circumstances. ${ }^{1}$ Incidentally they also bring proof for the theoretical views developed above, according to which the system, soap-dissolved-in solvent is something totally different from the system, solventdissolved-in-soap.

\section{$\S 1$}

Our fundamental conclusion may be stated thus: When a "neutral" soap has been produced through combination of the necessary gram equivalents of pure fatty acid with standard alkali, it is either acid, neutral or alkaline to such an indicator as phenolphthalein, depending upon the concentration of the water in the system.

For purposes of illustration we may choose the behavior of a rather concentrated solution of sodium oleate, as one made by combining one mol of fatty acid with one liter of normal sodium hydroxid solution (practically a molar or 30 percent "solution" of the soap in water). Phenolphthalein added to such a concentrated sodium oleate/water system remains colorless, as shown in the lower portions of the test tube of Fig. 50. As soon, however, as water is added to this colorless mixture it begins to turn pink, and, with increasing dilution of the soap, becomes bright red, as evidenced in the upper portion of the tube in Fig. 50.

What has been said of sodium oleate is true in general of all the soaps (excepting such very low members as the formates, acetates, etc.) though for demonstration purposes the higher fatty acid soaps with their lower solubility in water are better than the soaps of the lowermost members in any fatty acid series. An indicator (like phenolphthalein) added to a chemically neutral sodium palmitate or sodium stearate/water system (either a solid

${ }^{1}$ It may be well to emphasize here that normal cells are essentially systems of water-dissolved-in-protein. Indicators are therefore trickiest when applied to these systems. In disease the affected cells suffer changes which often are in the direction of "true" solution, in other words, the cells tend to develop into systems of the type, protoplasm-dissolved-in-water. Indicator methods become more reliable as this happens but only for those portions of the cell which are of this "true" solution type. See the later pages of this volume. 
gel or a liquid mixture) turns the liquid portion of the system a bright red while the masses of soap floating in this liquid remain pure white.

The common explanation of what happens in these instances is, of course, that of the physical chemists, who assume that in the concentrated soap "solution" there is little hydrolysis of the soap, while in the more dilute one such hydrolysis is increased and, sodium hydroxid being a stronger alkali than oleic acid is an acid, an indicator at once betrays the excess of hydroxyl ions.

Without listing the objections which may be raised against such an explanation (which at best accounts for but a small portion of what happens), it seems necessary, in order to get a more satisfactory interpretation of the whole picture, to call to mind the physical constitution of the lyophilic colloids as previously discussed in these pages and, in the case of the soaps, to distinguish between the behavior of those portions of such systems which have the composition water-dissolved-in-soap and those which have the composition soap-dissolvedin-water. The two are totally different, and, while indicator methods may be used in an attempt to analyze the latter, they need not be (and are not) so applicable to the former. The so-called concentrated soap "solutions" are essentially solutions of the solvent in the soap, while the more dilute ones are systems of the opposite type, and

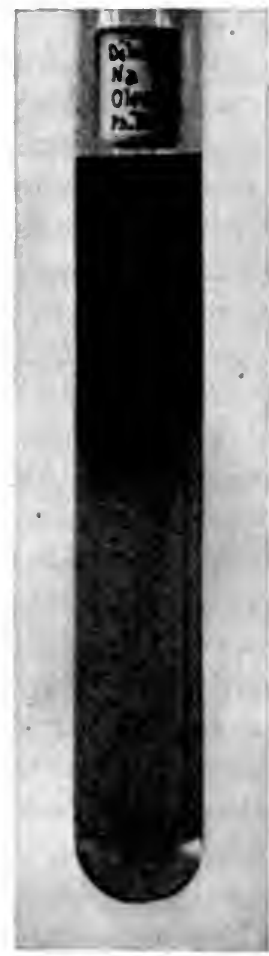

Figure 50 physico-chemical methods and the laws governing dilute solutions may therefore be applied only to the latter.

The correctness of these various deductions may be tested by the use of such an indicator as phenolphthalein upon solid soap gels which, as previously emphasized, represent mixed systems of soap-water in (solid) solvated-soap. If phenolphthalein is applied directly to a fresh section of sodium stearate, for example, the framework of the gel (in other words, the water-in-soap portion 
of the system) remains uncolored while the contents of this framework (the soap-in-water portion) turns bright red. A drop of phenolphthalein solution dropped upon a 10 percent sodium stearate/water gel remains uncolored. If, however, the gel is slightly squeezed (which breaks the encircling hydrated sodium stearate film and squeezes out the enclosed solution of soap-inwater) the spot turns bright-red. Any other solid soap/water system behaves in similar fashion.

Another variant of the experiment may be made by warming a concentrated sodium oleate or other soap solution which at ordinary temperature fails to color to phenolphthalein. Such a mixture, on being warmed, turns pink. While it is ordinarily said that under such circumstances the hydrolysis of the soap is increased, it is equally true that such a temperature change marks a displacement in the system from a solution of the solvent in the soap to one of the soap in the solvent.

To make sure, for experimental purposes, of definitely " acid" or " alkaline" soaps we have added to our chemically " neutral" soaps (like molar sodium oleate) known and large surpluses of free fatty acid or alkali. When free fatty acid is added it emulsifies readily in the soap, yielding a mixture more viscid than the original soap gel and practically as transparent as the original sodium oleate. Phenolphthalein added to the mixture remains colorless. Still, when water is added to such an obviously "acid" soap, the mixture turns pink or bright red as the added water is increased. The opposite type of experiment may be made by adding an excess of sodium hydroxid to the sodium oleate. Under such circumstances the mixture may assume a pinkish tinge, but this is because the excess of sodium hydroxid is hydrated and separates out in emulsified form in the chemically " neutral " sodium oleate. ${ }^{1}$ It is not the hydrated soap but the hydrated sodium hydroxid which turns pink. When instead of sodium hydroxid, sodium chlorid is used, such pinking of the system does not follow. Hydration of the neutral salt occurs and the mixture becomes more viscid, just as when sodium hydroxid is added, but since sodium chlorid is neutral and since the soap is not soluble in the salt-water no change in the color of the indicator becomes manifest.

${ }^{1}$ See page 93 on the salting out of soaps. 


\section{$\S 2$}

We emphasize these points because in technological practice it is often of much importance to know whether the system worked upon is "acid," "alkaline" or " neutral" in reaction. The above observations may serve to show with what extreme care any deductions derived from the application of indicator methods (or other methods of determining hydrogen or hydroxyl ion concentration) must be applied to such systems if they are of the lyophilic colloid type. The indicators may help us for those portions of the system which are of the composition $x$-dissolved-inwater but they do not necessarily tell us anything of those portions composed of water-dissolved-in-x.

With regard to the specific problem of soap manufacture, we may say that the proportions of fat (or fatty acid), alkali and water as chosen in common practice are such as yield only waterin-soap types of systems when the cold process is followed. The same is true for the cooled systems when the soap is made by the hot process and independently of whether the soap has been salted out (by sodium chlorid) or not. While the soap is boiling it represents a mixture of water-in-soap and soap-in-water. If indicator methods are used on such a system and at higher temperatures this much may be said for them. Any boiling soap which is just alkaline to phenolphthalein (decidedly pink) will be less alkaline (colorless) when cooled. It may, on cooling, still contain free fatty acid, but it will not hold uncombined alkali.

We have already emphasized the important applications of these principles to various biochemical reactions and to problems in biology and medicine. ${ }^{1}$ We shall return to the problem later. ${ }^{2}$ Suffice it at this time to emphasize the fact that the reactions in the solid tissues of the body (including for the most part those in the major portions of the blood and lymph) are reactions in a medium analogous to a concentrated soap. The reactions, on the other hand, occurring in the watery secretions from the body (like the urine and sweat) occur for the most part, in a system analogous to diluted soap. Indicator methods may be applied and with a fair degree of accuracy only to the latter systems; their applica-

'See Martis H. Fiscukn: (Fidema and Nephritis, 2nd Fil, 324, 512, 629, New York (1915); 3rd Ed, 365, (412, 765, New York (1921).

2 See page 229. 
tion to the former type of system must be carried out with the greatest caution, if, indeed, they may be used at all. Yet it is the common practice of biochemists and biological workers to hold that protoplasm, too, is something analogous to a dilute solution.

The observations detailed above carry with/them an interesting corollary. The color changes of indicators are in the majority of instances assumed to be dependent upon a play between the concentration of the electrically charged hydrogen and hydroxyl ions. If this assumption is held true for phenolphthalein (or for any other indicator which is held to act in this fashion), and especially if any one maintains that such indicator methods may be applied to concentrated lyophilic colloid systems, then the conclusion is inevitable that these concentrated systems contain no such ions. The matter is of significance because living matter (normal protoplasm) does not behave, as is so widely assumed, as water containing a little colloid, but rather as a colloid containing some water. ${ }^{1}$ If this be true-and all experimental evidence supports such a conclusion-then the material which we call living matter is probably under normal circumstances as electrically bland as is a concentrated soap solution, a conclusion not to be overlooked in a day when the explanation of almost every fundamental life process has been assumed to have been found in an electrical notion of some kind. This criticism is not to be misunderstood. Differences in electrical potential, in ionization, etc., do come about in living matter, but they are more probably the results of and the expression of injury to the involved structures than of their normal life.

1 Martin H. Fischer: Fdema and Nephritis, 3rd Ed., New York (1921) where references to the first publications on this subject may be found. 


\section{VIII}

\section{ON THE PHYSICAL STATE OF SOAP MIXTURES}

The experiments previously detailed show that the different soaps differ among themselves in their absolute gelation capacities. Speaking generally, linolates hold less of various "solvents" (like water) than chemically comparable amounts of the oleates, and these hold less than equimolar amounts of the stearates. Within the acetic series itself the lower members are less hydratable than the upper. The question therefore arose as to what would happen if two such soaps of different hydration eapacities competed for a fixed volume of water. This is, in essence, the question of technological importance when in commercial soap manufacture a mixed soap is prepared in a limited volume of water from the mixture of fatty acids obtained from any ordinary mixed glycerid.

A first experiment under this head was made by adding to a hot sodium stearate solution increasing amounts of hot sodium oleate. The actual mixtures are shown in Table XXII.

The soaps were added to each other at the temperature of a boiling water bath and, after careful mixing, were allowed to cool to $18^{\circ} \mathrm{C}$. The results of this experiment are shown in Fig. 51. As indicated in the first bottle on the left, sodium oleate is, even at the maximal concentration employed in the series, a mobile liquid. The bottle on the extreme right shows that sodium stearate at the concentration chosen is a white solid. As evidenced in the bottles between these two extremes, the presence of the sodium oleate interferes with the solidification of the whole mixture. Even when these mixtures are kept standing for months they do not go solid.

A second experiment under this heading was made by adding sodium oleate to sodium palmitate. The mixtures, prepared in a boiling water bath, had the composition shown in Table Xilll.

The appearance of these mixtures on cooling to $15^{\circ} \mathrm{C}$. is shown in Fig. 52. While the sodium palmitate will by itself yield a white solid, admixture with sodium oleate prevents this, and docs so 


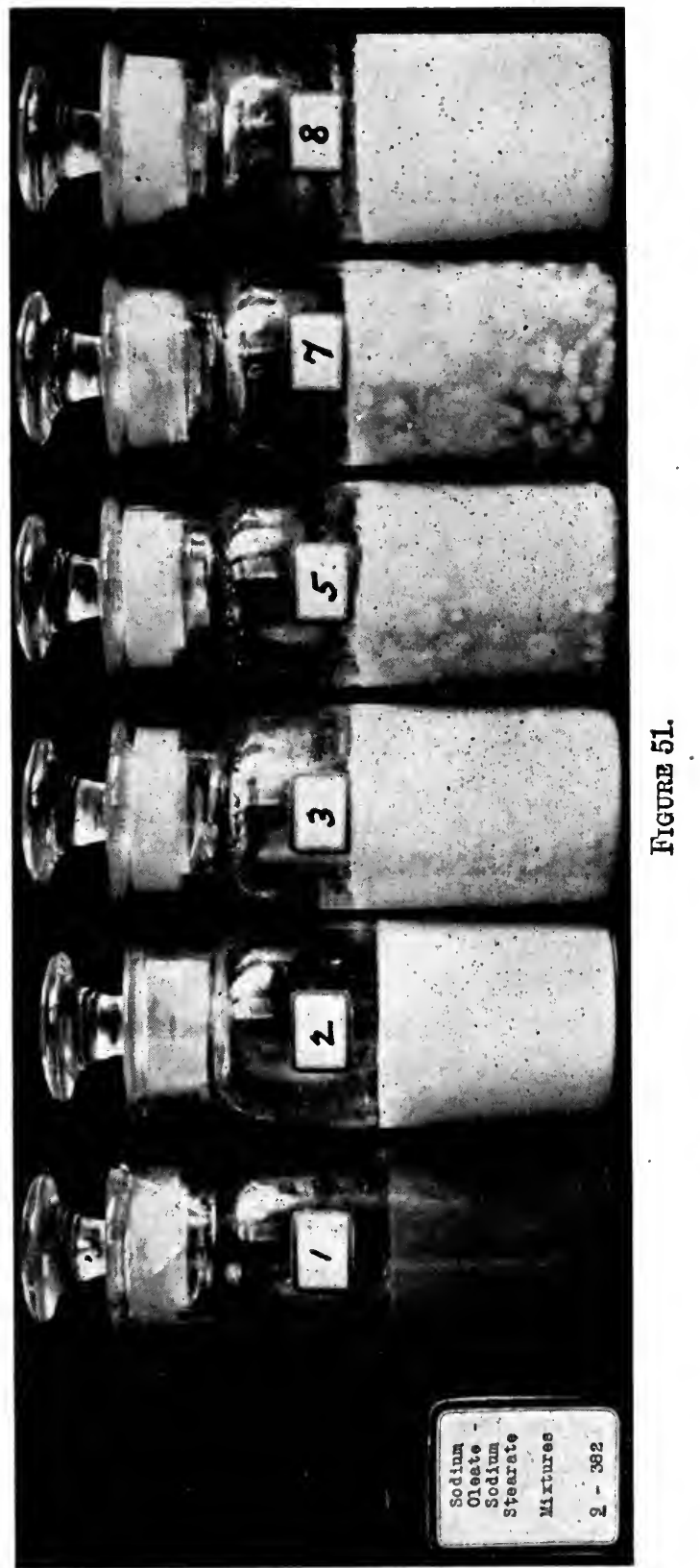



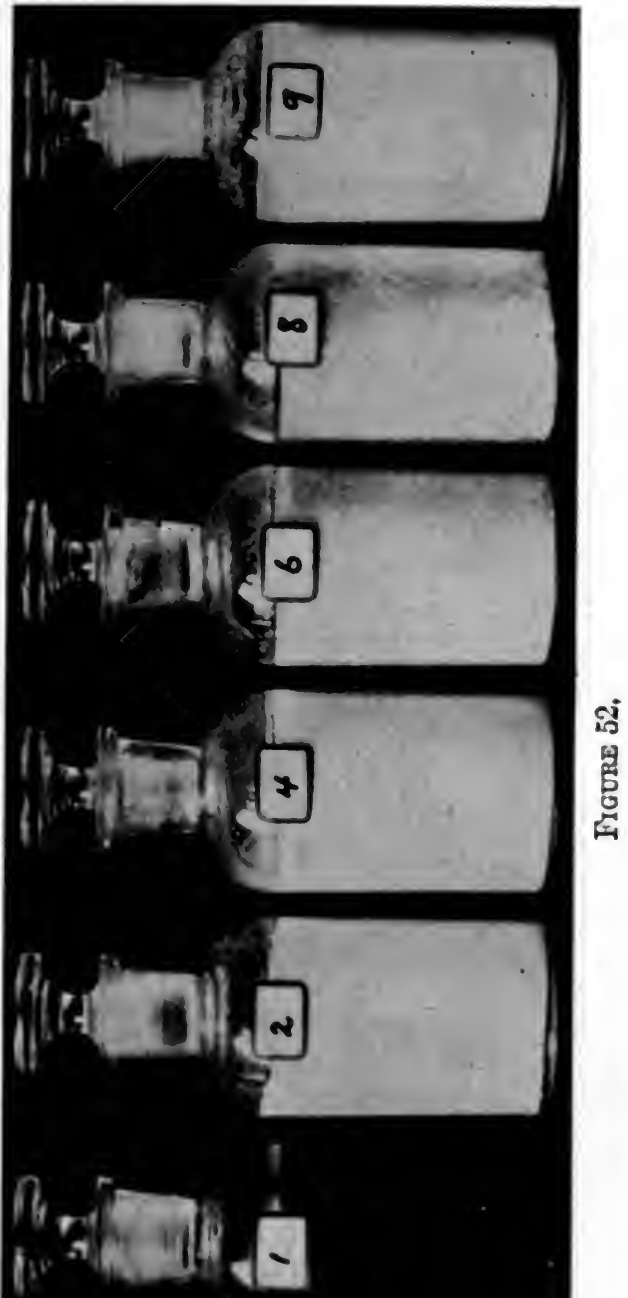

กี่

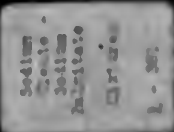


in increasing degree with its concentration in the mixture. In the mixtures containing the larger amounts of sodium oleate, the sodium palmitate floats in masses of silky needles within a liquid menstruum.

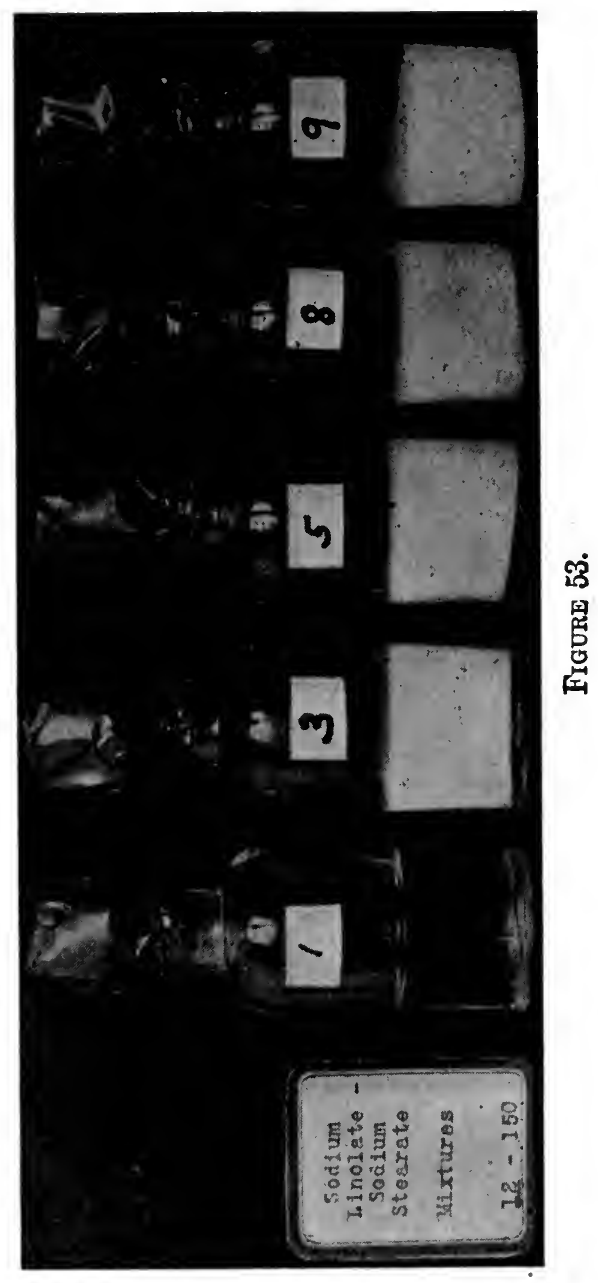

In a third experiment the effects of mixing sodium linolate with sodium stearate were studied. The composition of the mixtures is given in Table XXIV. Fig. 53 shows that when the previously clear mixtures prepared in a boiling water bath 
are cooled to $18^{\circ} \mathrm{C}$. the linolate with its lower absolute gelation capacity again dominates the mixture. While the pure stearate is solid, admixture with sodium linolate yields increasingly softer or liquid systems.

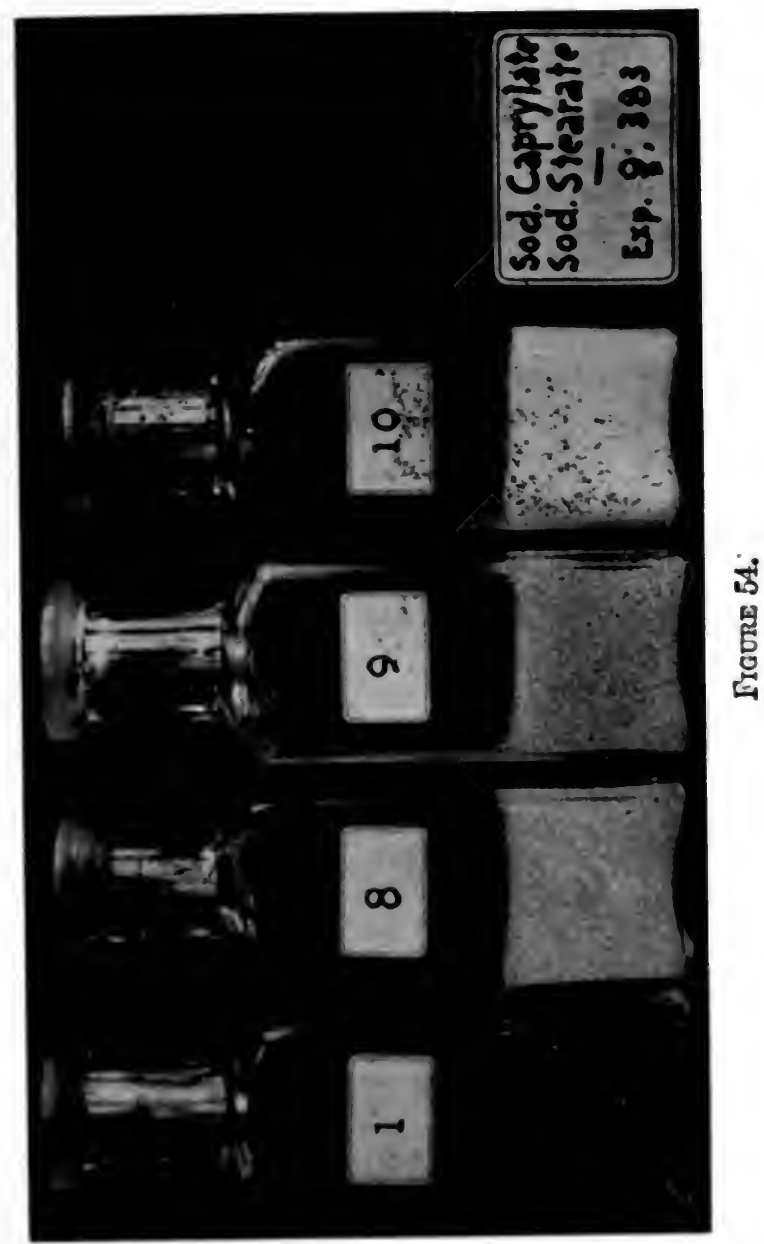

A final experiment was made by mixing two soaps of the same series, namely, sodium caprylate with sodium stearate as indicated in Table XXV. The results of this experiment are visible in Fig. 54. The physical state of the soap mixtures is 
again dominated by the soap of the lesser absolute gelation capacity.

These several experiments show, therefore, that in any soap mixture it is the soap with the lower absolute gelation capacity which gives the deciding character to the mixture. In trying to account for this, it is of interest to point out that the simpler soaps, or those lowest in any series, stand closer to the ordinary "salts" of the physical chemists than do the more complex or higher soaps. The lower soaps, as it were, "salt-out" the higher ones as do the ordinary neutral salts when added to the soaps. This matter will be discussed later. ${ }^{1}$

\section{TABLE XXI1}

\section{Sodium Oleate-Sodium Stearate Mixtures}

(1) 35 cc. $\mathrm{m} / 2$ sodium oleate +70 cc. $\mathrm{H}_{2} \mathrm{O}$ (control)

(2) 7.5 cc. " $"$ " +27.5 cc. " +70 cc. $\mathrm{m} / 10$ sodium stearate

(3) 15 cc. " " $"+20$ cc. " +70 cc.

(4) 20 ce. " " $"+15$ cc. " +70 cc.

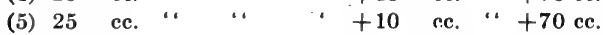

(6) 30 cc. " $" ،+5$ cc. “ +70 cc.

(7) 35 cc. " " " $"+70$ cc. $\mathrm{m} / 10$ sodium stearate

(8) 35 cc. $\mathrm{H}_{2} \mathrm{O}+70$ cc. $\mathrm{m} / 10$ sodium stearate (control)

\section{TABLE XXIII}

\section{Sodium Oleate-Sodium Palmitate Mixtures}

(1) 35 cc. $\mathrm{m} / 2$ sodium oleate +70 cc. $\mathrm{H}_{2} \mathrm{O}$ (control)

(2) 5 cc. " " " " +30 ce. " +70 cc. $\mathrm{m} / 10$ sodium palmitate

(3) 10 cc. " $"$ " $"+25$ cc. " $+70 \mathrm{cc}$.

(4) $15 \mathrm{cc}$. " " “ $+20 \mathrm{cc}$. " $+70 \mathrm{cc}$.

(5) 20 cc. " " " $"+15$ cc. " $+70 \mathrm{cc}$

(6) 25 cc. “ “ $"$ “ +10 cc. “+ +70 cc.

(7) 30 cc. “ $"$ “ “ 5 cc. “ +70 cc.

(8) $35 \mathrm{cc}$ " " " " +70 cc. $\mathrm{m} / 10$ sodium palmitate

(9) 35 cc. $\mathrm{H}_{2} \mathrm{O}+70$ cc. $\mathrm{m} / 10$ sodium palmitate

\section{TABLE XXIV}

\section{Sodium Linolate-Sodium Stearate Mixtures}

(1) $35 \mathrm{cc} . \mathrm{m} / 2$ sodium linolate +70 cc. $\mathrm{H}_{2} \mathrm{O}$ (control)

(2) 5 cc. " " " $"+30$ cc. " +70 cc. $\mathrm{m} / 10$ sodium stearate

(3) 10 cc. $\cdots \quad$ " " +25 cc. $"+70 \mathrm{cc}$

(4) 15 cc. " $" \quad$ “ +20 cc. “ $+70 \mathrm{cc}$

(5) 20 cc. “ $"$ “ +15 cc. " $+70 \mathrm{cc}$.

(6) 25 cc. " “ " +10 cc. " $+70 \mathrm{cc}$.

(7) 30 cc. " $"$ “ +5 cc. “ $+70 \mathrm{cc}$

(8) 35 cc. " “ " +70 cc. m/10 sodium stearate

(9) 35 cc. $\mathrm{H}_{2} \mathrm{O}+70$ cc. $\mathrm{m} / 10$ sodium stearate

${ }^{1}$ See page 93 . 
TABLE XXV

Sodium Caprylate-Sodium Stearate Mixtures

(1) 30 ec. 4 m sodium caprylate +70 cc. $\mathrm{H}_{2} \mathrm{O}$ (control)

(2) 1 cc. $4 \mathrm{~m} \quad \cdots, \quad \cdots+29$ cc. $\cdots+70$ cc. $m / 10$ sodium stearate

(3) 2.5 cc. $+m^{\prime} \cdots \quad \cdots+27.5 \mathrm{cc} . \cdots+70$ ce. $\cdots$. $\cdots$

(4) 5 ce. $4 \mathrm{~m} \quad \cdots \quad$ * +25 cc. $"+70$ cc. $\cdots \quad$ " $\quad \cdots$

(5) 10 ce. $4 \mathrm{~m} \quad \cdots \quad$ * +20 cc. $"+70$ cc. $\cdots \quad \cdots \quad$.

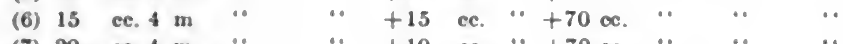

$\begin{array}{llllllllll}\text { (7) } 20 & \text { ce. } 4 \mathrm{~m} & \cdots & \cdots & +10 & \text { cc. } & \cdots+70 \text { cc. } & \cdots & \cdots & \cdots \\ \text { (8) } 25 & \text { ce. } 1 \mathrm{~m} & \cdots & \cdots & +5 & \text { cc. } & \cdots+70 \text { cc. } & \cdots & \cdots & \end{array}$

(9) 30 ce. $4 \mathrm{~m} \quad$ “ $\quad \cdots \quad+70$ cc. $\mathrm{m} / 10$ sodium stearate

(10) 30 ce. $\mathrm{H}_{2} \mathrm{O}+70$ cc. $\mathrm{m} / 10$ sodium stearate

\section{IX}

\section{ON REVERSIBILITY IN SOAPS}

\section{$\S 1$}

We noted early in our experiments that the physical constants of the alkaline earth and heavy metal soaps, as ordinarily prepared by precipitation of a sodium or potassium soap with the salt of a heavier metal, were different from those of these same soaps when prepared directly from a proper fatty acid and a metallic hydroxid or oxid. We attributed the differences to admixture of the heavy metal soap with the original soap. As a matter of fact, we always deal in soaps thus prepared with a mixture, in equilibrium, of the two soaps. In order to study the matter further we performed the following experiments on the reversion of soaps of the alkaline earths and the heavy metals into the soaps of the alkali metals under the influence of alkali hydroxids.

The results in the case of a series of oleates may be thus illustrated. Molar equivalents of the hydrated oleates pictured in Fig. 2 and deseribed in Table III were placed in separate vials. The actual amounts were as follows:

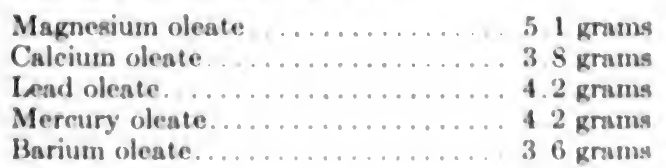

These soaps were covered with $10 \mathrm{cc}$. normal $\mathrm{hOH}$ (the amount necessary to convert, if possible, all the heavy soap into potassium soap). The appearance of the soaps immediately after addition 


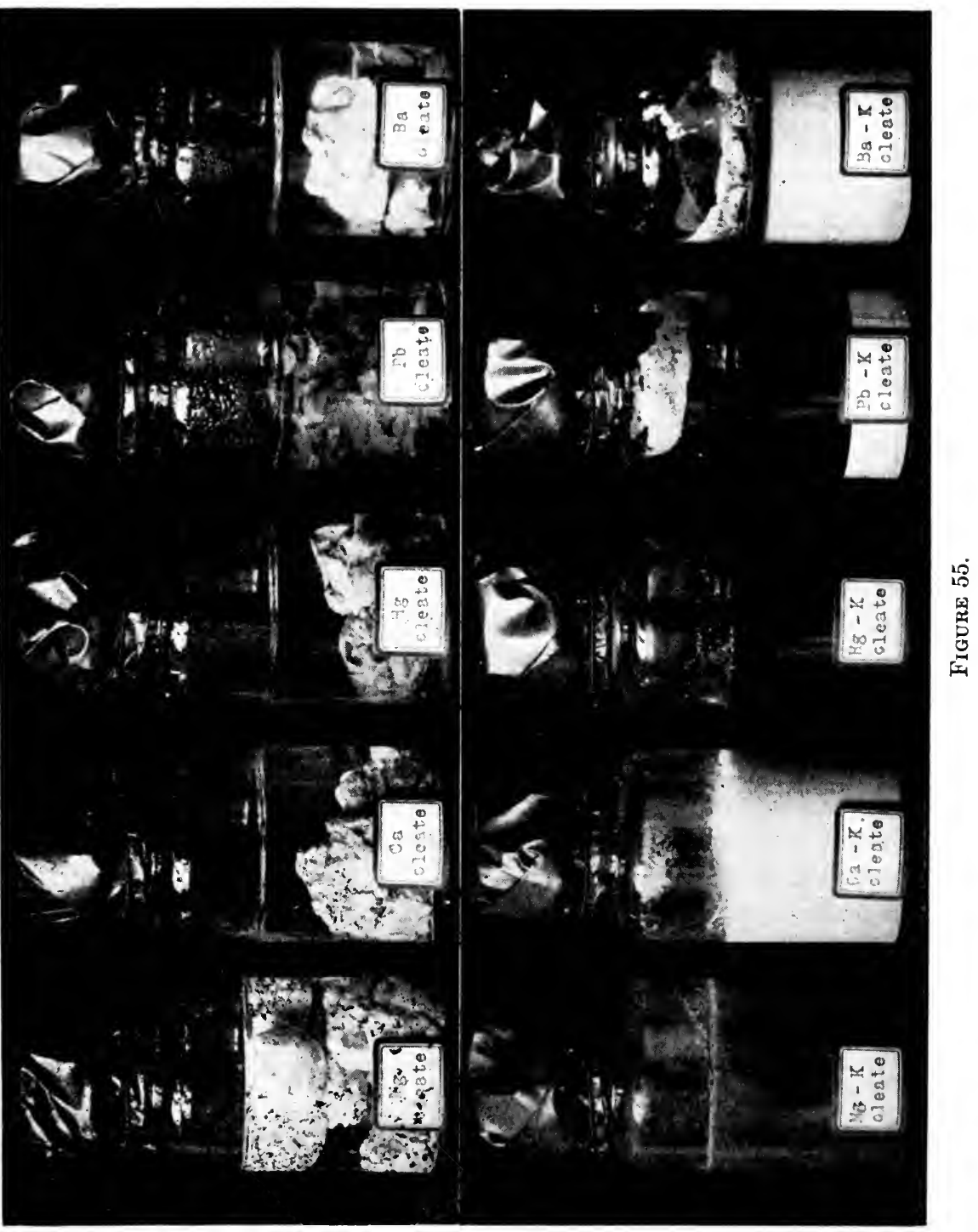




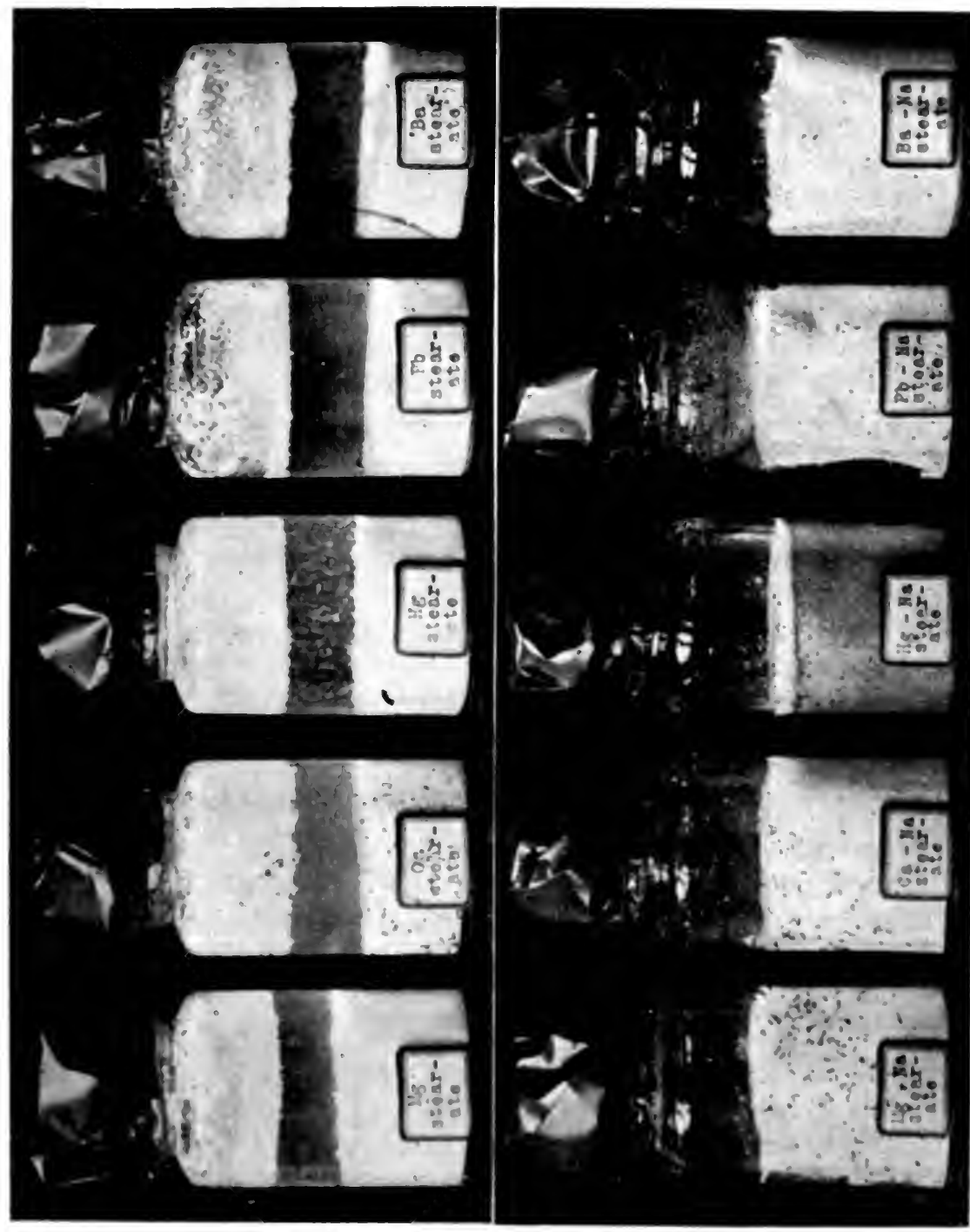

ธุ. 
of the alkali is shown in the upper row of Fig. 55. Within an hour after adding the potassium hydroxid all the soaps began to swell and to become covered with gelatinous films. This change to potassium oleate was particularly rapid in the magnesium and lead soaps. But it occurred in all, so that after an hour enough potassium soap was formed to make the liquids covering the metallic soaps show permanent foams.

These changes occur in the cold and even when the reaction mixtures are not stirred. Heating and stirring, however, hasten the process. In either event a high degree of reversion is obtained as indicated by the lower row of Fig. 55, which shows the appearance of the soap mixtures after standing at room temperature for forty-eight hours. So much potassium oleate had formed that all the systems were highly gelatinous.

A similar reversion from the stearates of the alkaline earths and the heavy metals into sodium stearate is shown in Fig. 56. The upper row shows the vials with their molar equivalents of the different stearates prepared as described in Table IV (and Fig. 3), just after $10 \mathrm{cc}$. normal sodium hydroxid had been added to them. The actual amounts of soap in the vials were as follows:

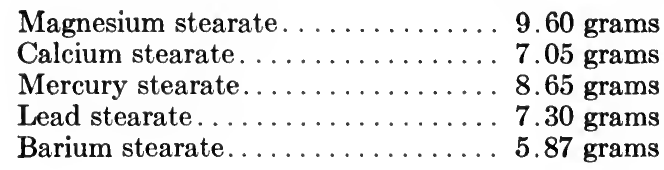

After addition of the sodium hydroxid the mixtures were kept warm for one hour at $75^{\circ} \mathrm{C}$. The appearance of the same soap mixtures forty-eight hours later is shown in the lower row of Fig. 56. The reversion to sodium. stearate is so great that all the mixtures are now solid gels.

These experiments on reversion in soaps are of chief interest to us because the soaps in their colloid-chemical behavior are like the proteins of the living cell. The heavy metal soaps are like the heavy metal proteinates which are produced when the living cell is poisoned with lead, mercury, etc.; and just as the heavy metal soaps may be converted into those of the lighter metals, cells poisoned with heavy metals may be aided in their restoration 
to the more normal state by the administration of properly chosen salts of the lighter metals. ${ }^{1}$

There exist, however, processes in pure soap manufacture which have long made empiric use of the facts detailed above. Instead of hydrolyzing fats with sodium or potassium hydroxid, they are often hydrolyzed with calcium hydroxid. Under such circumstances calcium soaps are produced which, as formed, have little or no "washing" properties. The calcium soaps are then converted into sodium or potassium soaps by treatment with the carbonates of these metals.

\section{$\mathrm{X}$}

\section{ON THE "SALTING-OUT" OF SOAPS ${ }^{2}$}

The previous pages ${ }^{3}$ have shown that the absorption of water by various pure soaps (and hence their physical state) depends upon $(a)$ the kind of base combined with a given fatty acid, or, with a given base (b) upon the nature of the fatty acid. It is the purpose of this section to deseribe the influence which the addition of different electrolytes has upon their physical state. We shall first describe the action of different salts upon a single soap, namely, potassium oleate; later the effects of one salt upon different soaps. The practical and theoretical deductions drawn from these materials will then be correlated with the various empiric practices of the soap manufacturer and allied scientific studies in this field.

\section{On the "Salting-Out" of Potassium Oleate}

The potassium oleate used in these experiments was prepared by adding to the molar weight of oleic acid expressed in grams (282.27) $1000 \mathrm{cc}$. of a normal $\mathrm{KOH}$ solution. The oleic acid and the potassium hydroxid solution were heated separately in a water bath and, at the temperature of the boiling water, the

1 See page 240.

2 Maktis H. Fiscmer and Marian O. Hooker: Science, 48, 143 (1918); ibid., 49, 615 (1919); Chem. Engineer, 27, 225 and 253 (1919). See aleo page 205.

See pmes 10 and 15; also Martis H. Frscher and Marian O. НооквR: Chem. Engineer, 27, 155 (1919); ibid., 27, 184 (1919). 
oleic acid was poured into the potassium hydroxid. The mixture was stirred and heated, with careful avoidance of evaporation, until a clear, viscid liquid was obtained. Whenever our stock or standard potassium oleate solution is mentioned in the following experiments one prepared in this fashion is referred to. At room temperature this stock is strongly alkaline to litmus paper but phenolphthalein when added to it remains colorless. ${ }^{1}$

1. We tested out, first, the effects of adding different amounts of water to the standard potassium oleate. The stock soap when prepared as described has the viscosity of a syrup at ordinary temperatures $\left(18^{\circ} \mathrm{C}\right.$.). The addition to this of progressively greater amounts of water merely serves to decrease its viscosity.

2. We next tried the effects of adding progressively greater amounts of various alkalies $\left(\mathrm{KOH}, \mathrm{NaOH}\right.$ and $\left.\mathrm{NH}_{4} \mathrm{OH}\right)$ to the standard soap. While from a chemical standpoint it matters little how a mixture is made, it makes much difference from a physical point of view as will be discussed later. When not otherwise-specified the mixtures throughout these series were made in the sequence in which they appear in the tables. In Table XXVI, for instance, the water was first added to the soap and mixed; then the $\mathrm{KOH}$ solution was added and the whole again mixed. When not otherwise specified, all combinations were made at room temperature which in the room employed and at the time at which we worked (the winter of 1917 and 1918) remained continuously close to $18^{\circ} \mathrm{C}$. The descriptions and photographs refer to the appearance of the mixtures twenty-four hours later.

Table XXVI and Fig. 57 show the effects of adding potassium hydroxid. It is obvious that the control soap with water mixture is a mobile liquid. The first additions of potassium hydroxid to this mixture serve to increase its viscosity as evidenced in the tubes marked 1,2, 3 and 4 . But beyond this point further addition of the potassium hydroxid begins to bring about a dehydration of the soap which increases progressively until, in the tube marked 10, the soap is found floating as a thin layer at the top of the clear dispersion medium.

The effects of sodium hydroxid upon the standard potassium oleate are similar to those of potassium hydroxid as apparent in

${ }^{1}$ See page 77 for a discussion of the meaning of indicator methods when applied to these soap systems. 
Table XXVII and Fig. 58. There is at first a progressive increase in viscosity until a beautiful gel is formed. Further addition of the alkali then brings about a separation of the soap from the water as already described for potassium hydroxid.

Table XXVIII and Fig. 59 show that none of these things happen when equinormal ammonium hydroxid is added to the potassium oleate. In fact, even if the concentrations of the ammonium hydroxid are carried beyond those in the table no gelation and no separation of the soap occurs. The reasons for this are discussed later.

The fact of interest in these parallel series of experiments is that the sodium hydroxid leads to increase in viscosity and the setting of the soap into a solid jelly at a somewhat lower concentration than is the case for potassium hydroxid; and this same shifting of effect toward the left is true of the separation of the soap from the aqueous dispersion medium in the higher concentrations of the alkali. To the meaning of these things we shall return later.

3. We next compared the effects of a group of salts having a common base and different acid radicals. To simplify matters a series of potassium salts was

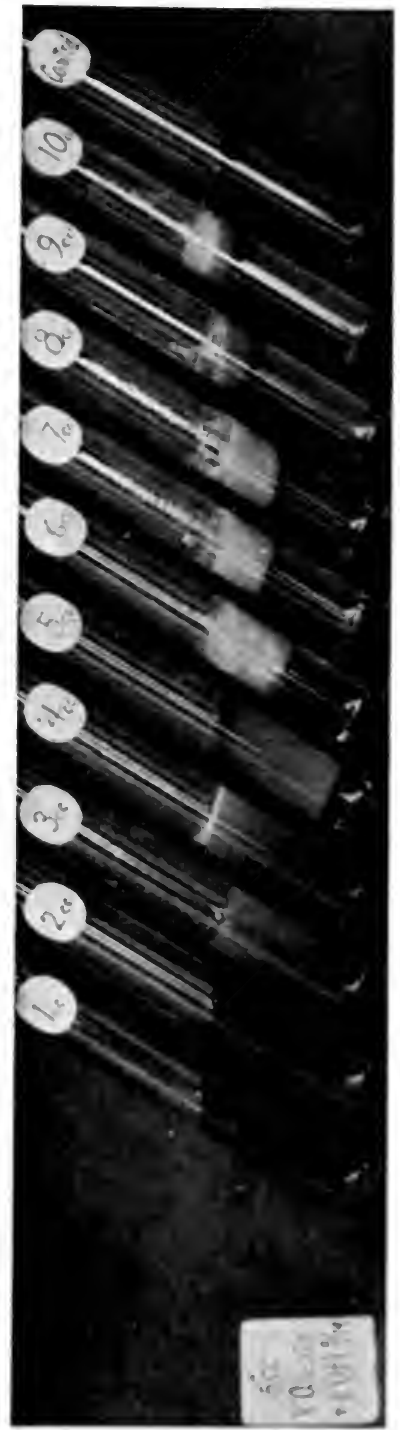
chosen.

The effect of the halogens is shown in Tables XXIX, XXX, XXXI and XXXII. Photographs of the chlorid and bromid 
series are shown in Figs. 60 and 61. It is obvious from the tables and the figures that these neutral salts behave in the same general fashion as the previously described hydroxids. With progressive increase in concentration there is observed in all the series a progressive increase in viscosity of the soap until it sets into a stiff jelly. With further addition of the salt the viscosity falls, a slight turbidness develops and, later still, separation of the soap from the dispersion medium sets in. This separation finally becomes so great that the soap floats as a practically dry white mass upon the underlying clear dispersion medium. Some difference seems to exist in the power with which the four halogens lead to the setting of the soap and its subsequent dehydration and separation. The difference may, however, be one of experimental error only.

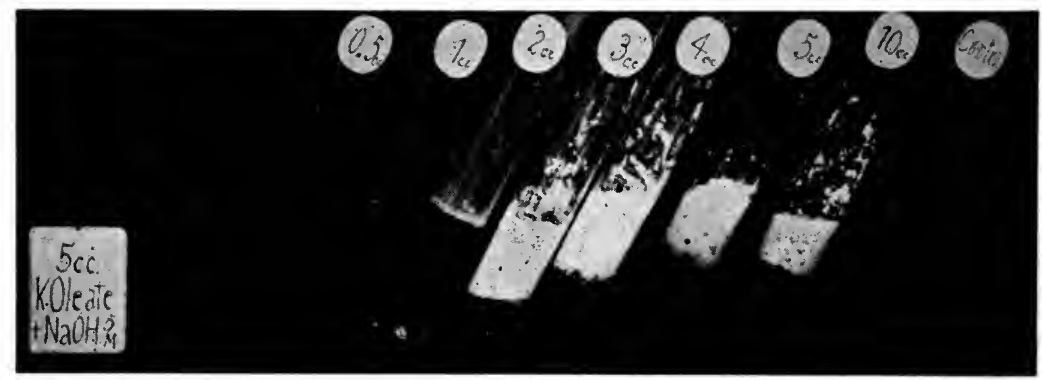

FIGURe 58.

It is exceedingly difficult, as everyone knows who has worked quantitatively in these fields, to be sure of getting absolutely equal rates and degrees of mixing and thus absolutely equal effects when producing these various systems.

Of other monobasic potassium salts the effects of the nitrate, sulphocyanate and acetate have been studied. Potassium nitrate acts very much like potassium chlorid as shown in Fig. 62 and Tables XXXIII and XXXIV. With increasing concentration of the added salt the soap first gels and then softens, though the solubility limits of potassium nitrate, as seen in mixtures 9 and 10 of Table XXXIV are such as to lead to the formation of nitrate crystals in the tubes and not to an actual dehydration and separation of the soap from the dispersion medium.

The range from a liquid to a gel, through a secondary zone of liquefaction succeeded by dehydration of the soap and 
separation of the clear dispersion medium, is seen particularly clearly in the case of potassium sulphocyanate. The concentra-

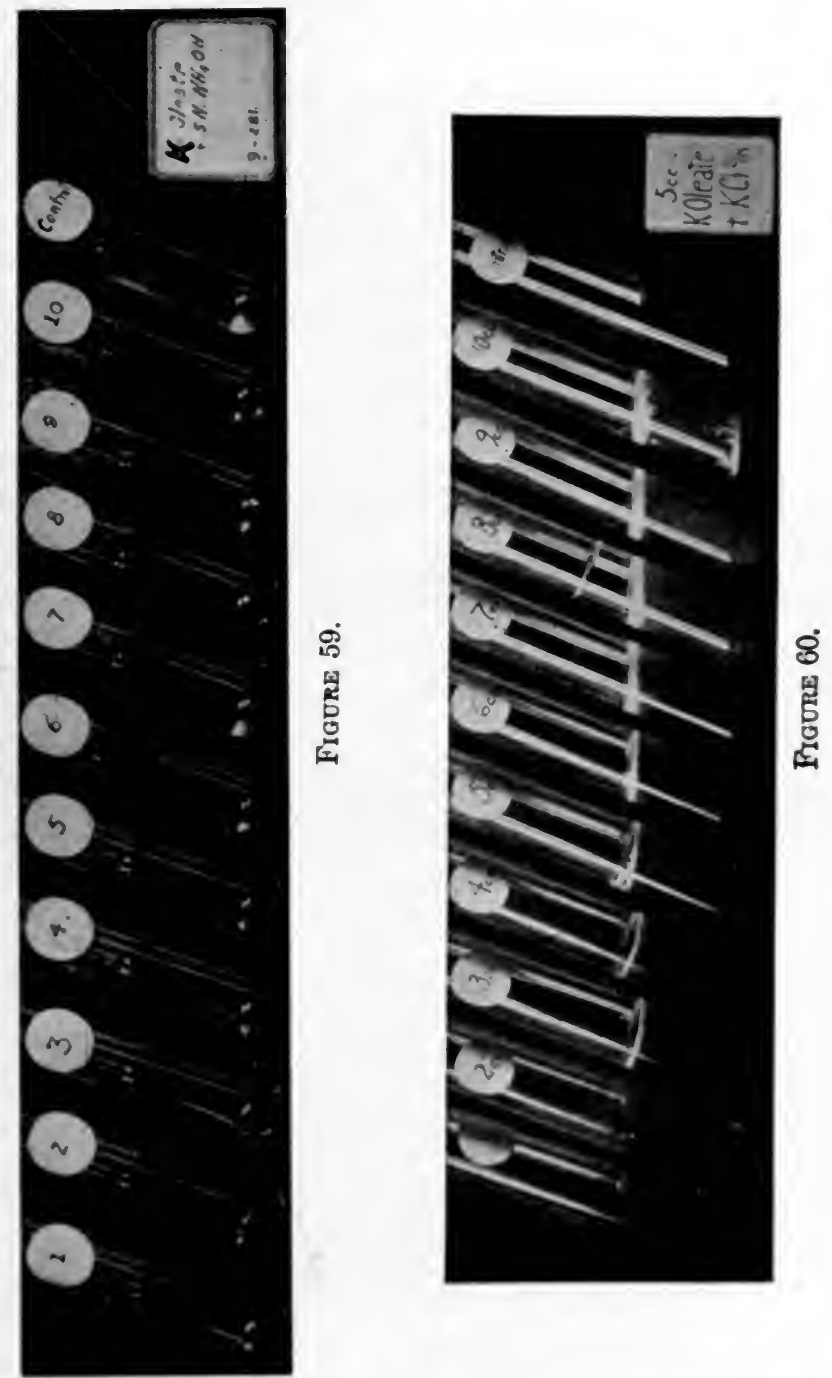

tions necessary for these successive changes may be deduced from Tables XXXV, XXXVI and XXXVII. The actual appearance of the tubes described in Table XXXVII is shown in Fig. 63. 
Table XXXVIII and Fig. 64 show the effects of potassium acetate. As compared with the action of the other potassium salts thus far described, it will be seen that at equimolar concentrations this acts more powerfully. The soap passes through

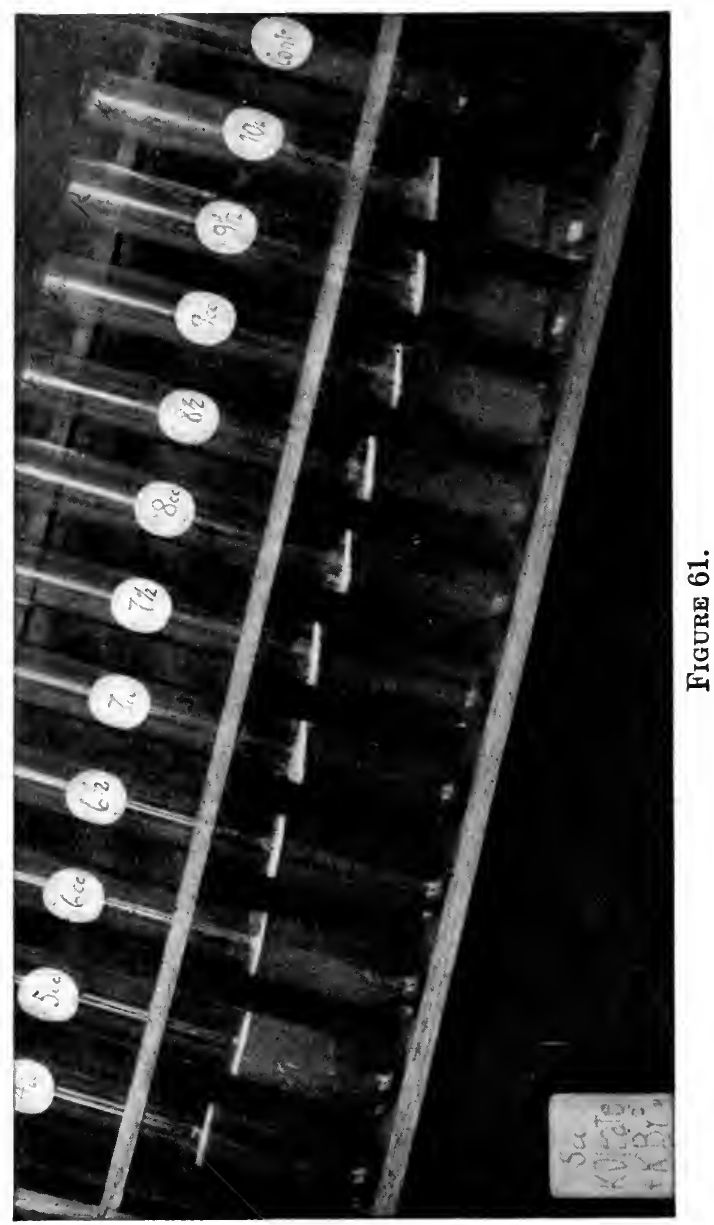

all the various changes to complete dehydration even within the short range of concentrations detailed in the single table.

The effects of several potassium salts of polybasic acids are shown in Tables XXXIX, XL, XLI and XLII and Figs. 65, 66, 67 and 68. Dipotassium sulphate and dipotassium tartrate pro- 

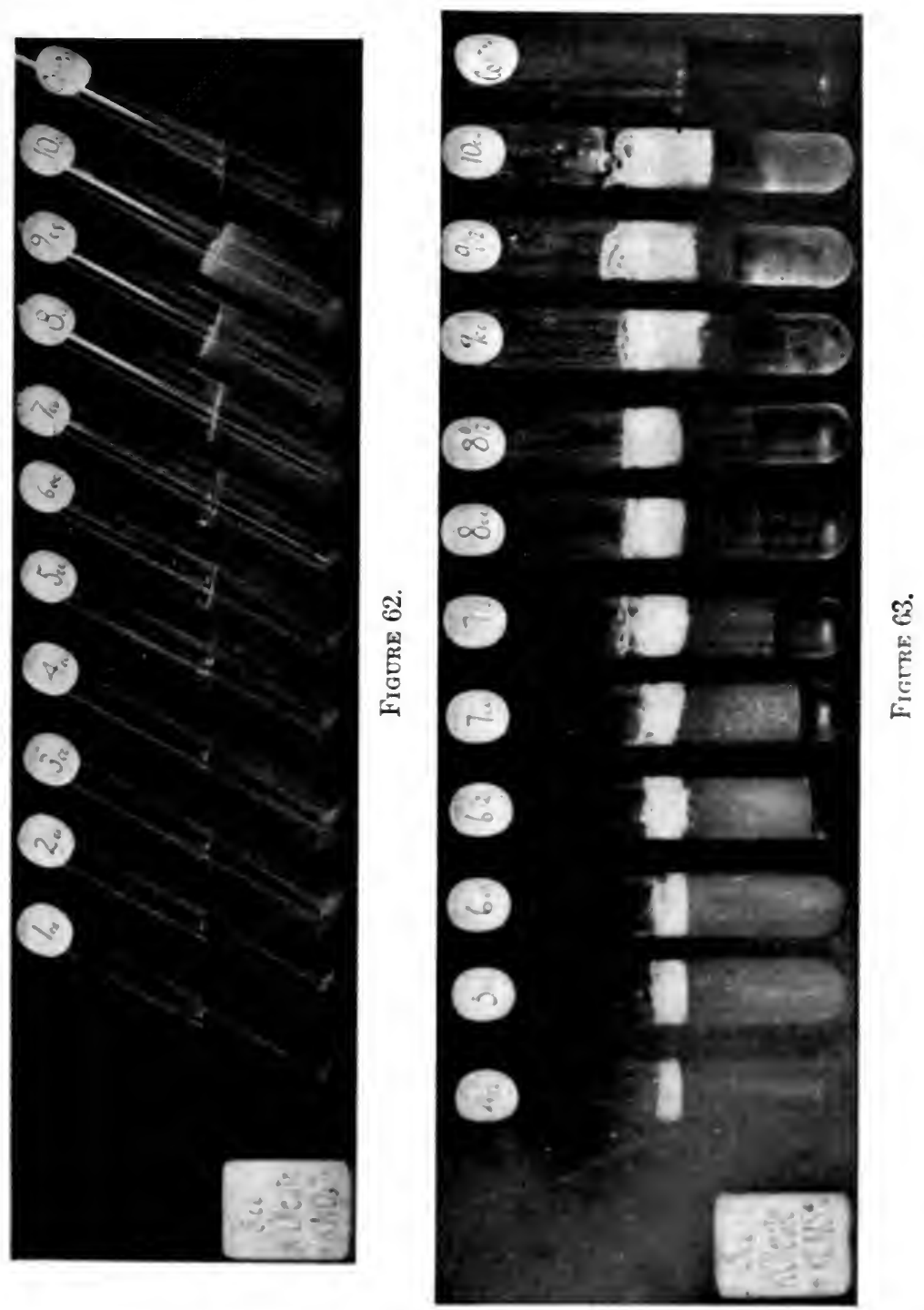

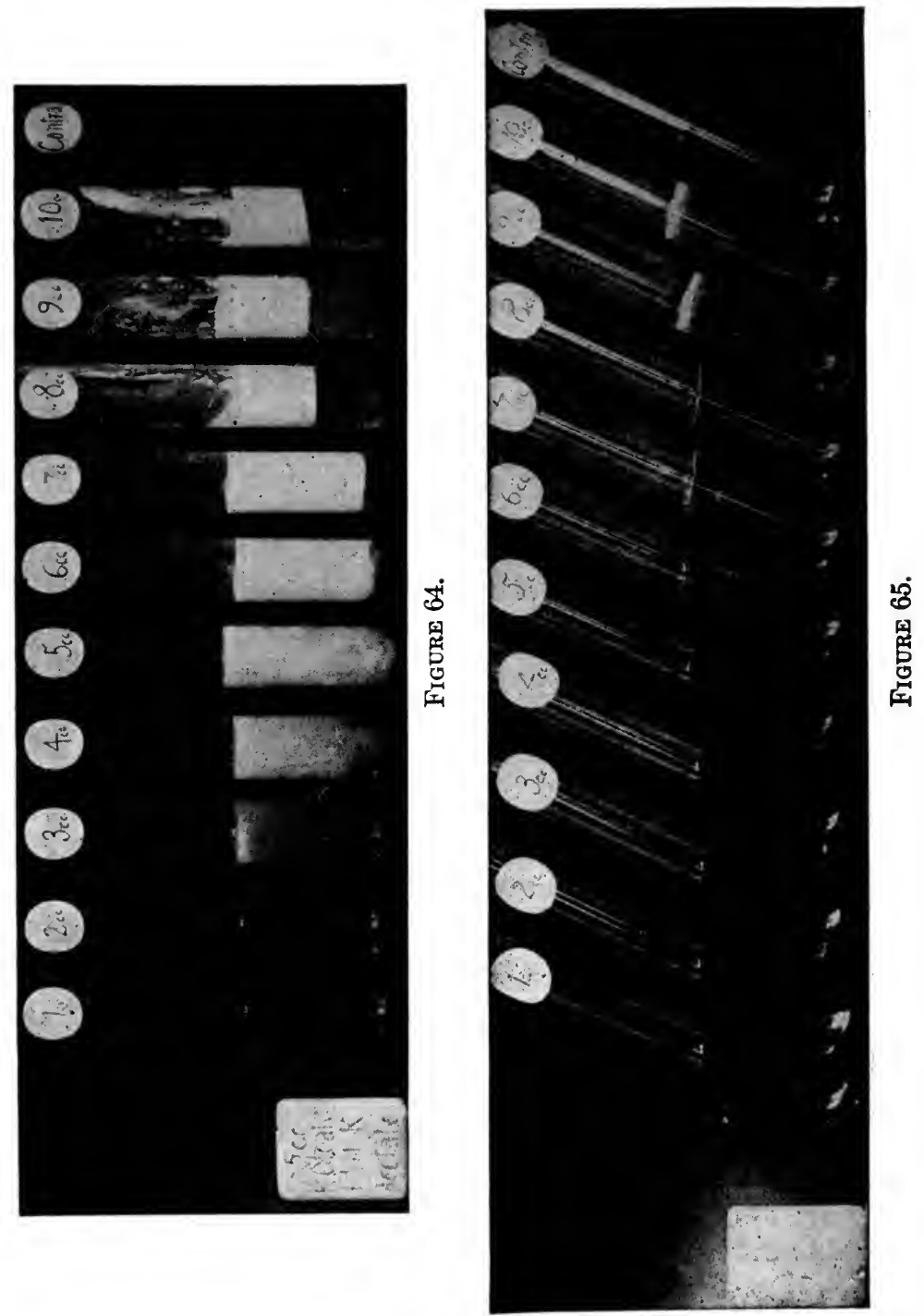
duce results practically identical with those of the potassium halogens when the effects of adding half molar concentrations of the former salts are compared with those of molar concentrations of the halogens.

Because of the limited solubility of potassium sulphate and of dipotassium tartrate, Tables XXXIX and XL and Figs. 65 and 66 only serve to show that with increase in the concentration of the added salts there is progressive increase in the viscosity of the soap until gelation or, beyond this, a secondary liquefaction occurs in the highest concentrations here employed.

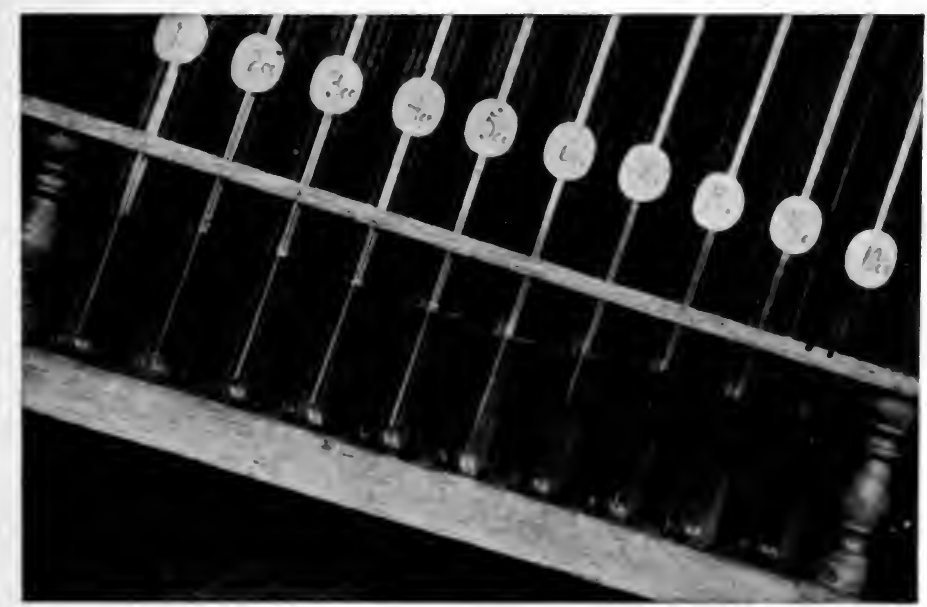

Figure 66.

However, by working at higher temperatures the concentration of both the sulphate and the tartrate may be increased to a point where the soap is " salted-out."

Tables XII and XLII with Figs. 67 and 68 show the effects of adding the potassium salts of two tribasic acids. Dipotassium phosphate (Fig. 67) and tripotassium citrate (Fig. 68) in increasing concentrations at first lead to gelation, then liquefaction and finally complete dehydration of potassium oleate. When compared with the action of monovalent salts, the tables and figures show that the initial gelations are obtained at about the same molar concentrations of the potsssium constituent of the systems, though subsequent liquefaction and dehydration occur somewhat 
earlier in the case of the polyvalent acid radicals than in that of the simpler ones.

4. The next problem was to determine the effects of adding alkali and salt together to potassium oleate. The effects of

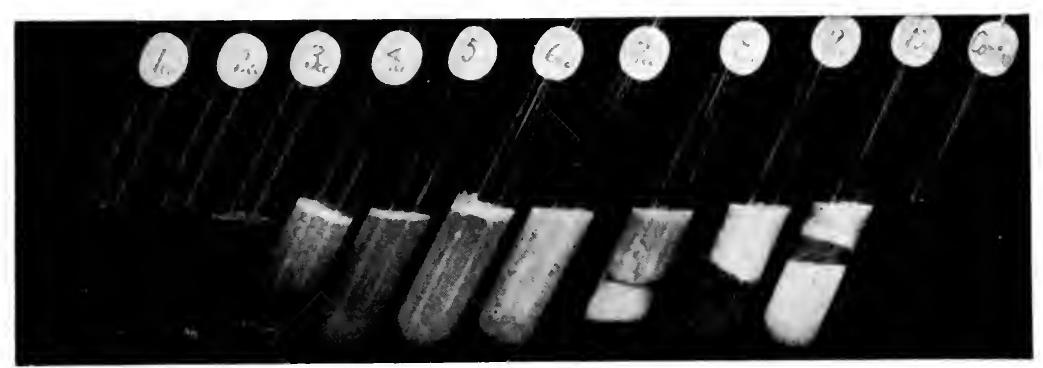

FIGURE 67.

different concentrations of potassium chlorid added to standard potassium oleate, containing two different concentrations of potassium hydroxid, are shown in Tables XLIII and XLIV.

So far as concentration of the potassium hydroxid is concerned, Table XLIII must be compared with the second tube

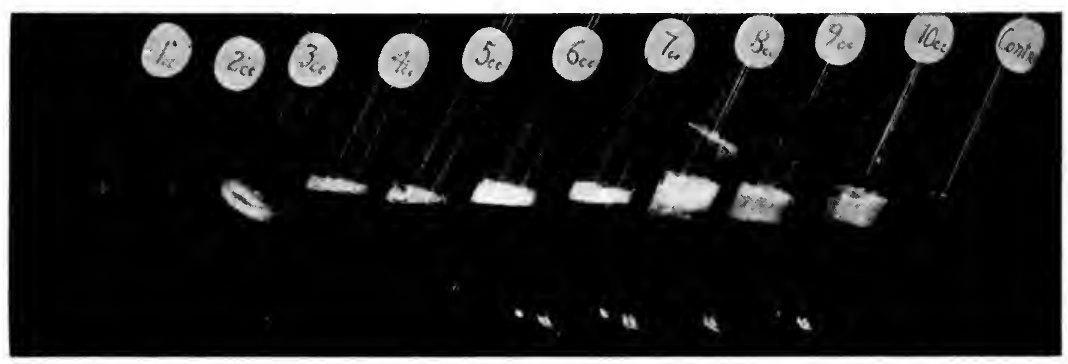

FigURE 68.

of Fig. 57 (Table XXVI); so far as the concentration of potassium chlorid is concerned, with the first five tubes of Fig. 60 (Table $\mathrm{XXX})$. When this is done it is observed that the effects of the alkali and of the added potassium chlorid are additive. In other words, gelation and secondary liquefaction are apparent earlier in the series in Table XLIII than in the corresponding tubes of Figs. 57 and 60. 
The alkali concentration of Table XLIV corresponds with that of tube 4 in Fig. 57 (Table XXVI). The non-dehydrating effects of the concentrations of potassium chlorid employed are clearly apparent by referring to Fig. 60 and Table XXX. While the concentration of alkali alone leads only to gelation of the potassium oleate, it will be seen in Table XLIV that the effect of the potassium chlorid adds itself to this, wherefore the first tube in the series shows a beginning dehydration which, with increase in the concentration of the added salt, becomes progressively greater until marked dehydration and separation from the clear dispersion medium is evident in the last tube.

Table XLV shows that such an additive effect is apparent also when in the presence of a fixed concentration of potassium chlorid different amounts of standard potassium hydroxid solution are added to the standard potassium oleate. While neither of the substances when used alone and in the concentrations prevailing in the first tube lead to gelation, the two together do so. When comparison is made with the proper tubes of Figs. 57 and 60 , it is also apparent that the secondary liquefaction and the dehydration begin earlier when alkali and salt are used together than when either is used alone.

To complete this series, we add Tables XLVI and XLVII. In Table XLVI the concentration of potassium hydroxid is fixed and that of sodium chlorid varies, while in Table XINII the concentration of sodium chlorid is fixed and that of potassium hydroxid varies. These tables should be compared with Tables XXVI and XLIX, or Figs. 57 and 70 . Such comparison shows that gelation with subsequent liquefaction and dehydration are obtained earlier when the alkali and chlorid are present together than when either is used alone in the concentration chosen. When the effects of sodium chlorid are compared with those of potassium chlorid, it is again apparent that the sodium salt acts more powerfully; in other words, the systems are shifted toward the regions of earlier gelation, earlier dehydration and earlier separation.

5. We next tried the effects of adding in equimolar concentrations various salts possessed of a common acid radical but different bases. We chose chlorids.

In Table XLVIII and Fig. 69 (introduced as checks on Table $\mathrm{XXX}$ and Fig. 60 and on the experiments about to be described) are shown the effects of adding successively higher concentra- 
tions of potassium chlorid. The control tube shows the familiar liquid soap. With progressive increase in the concentration of
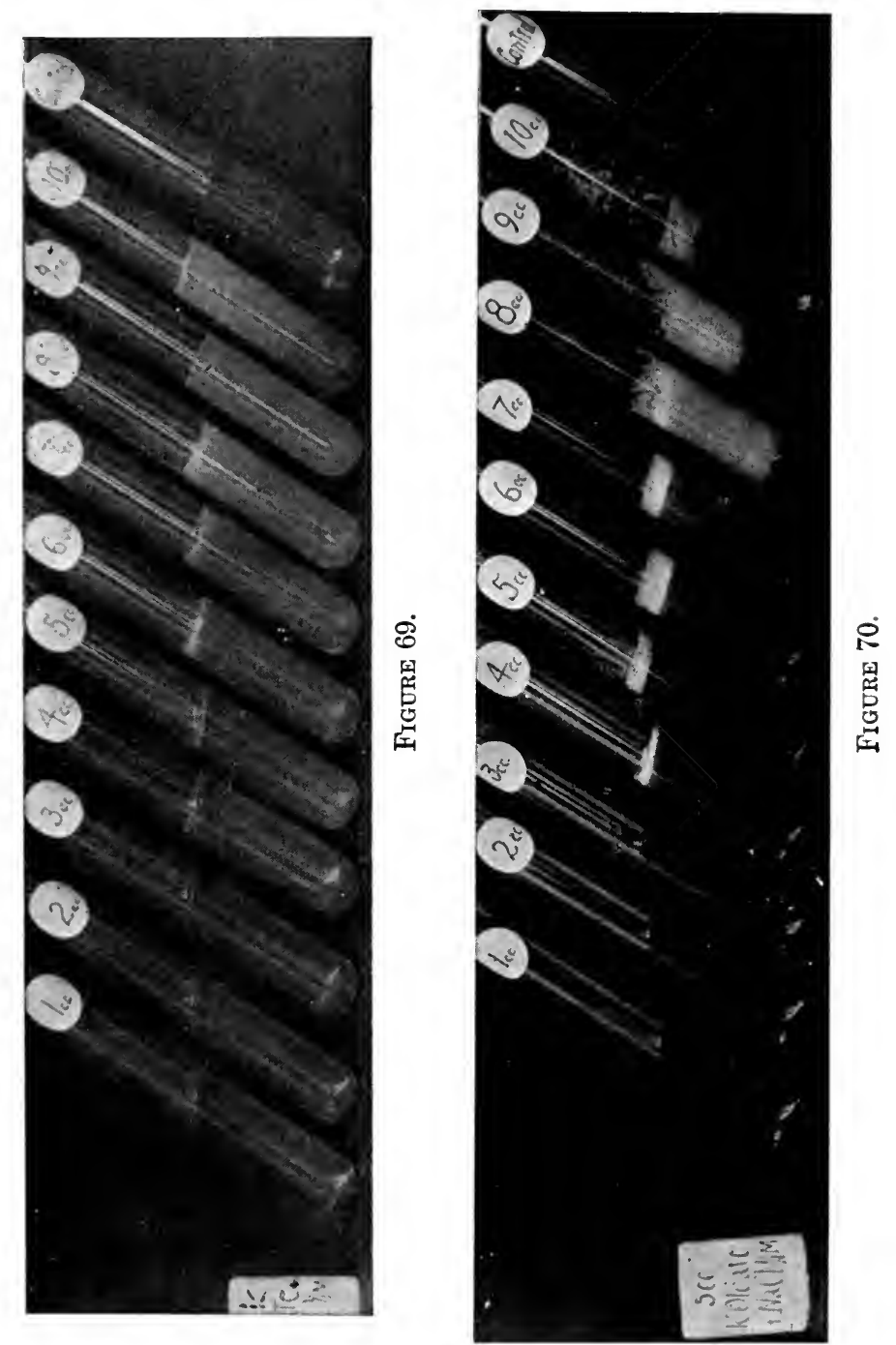

the salt, the viscosity of the soap mounts steadily until in the tube marked 10 such a solid gel is obtained that the tube may be turned upside down without spilling the contents. 
Sodium chlorid produces the same general effects as potassium chlorid, as shown in Table XLIX and Fig. 70. When the effects of the two salts are compared it is seen that at the same molar concentration the sodium salt acts more powerfully than the potassium salt. Initial increase in viscosity, gelation and frank separation of dispersion medium from the soap oceur earlier throughout in the tubes of Fig. 70 than in those of Fig. 69.

When ammonium chlorid is employed in the same concentration as that described above for potassium or sodium chlorid, an initial increase in viscosity in the lower concentrations of the ammonium salt is not to be observed. The first effect to be noted is a slight clouding of the soap mixture as shown in Fig. 71 and

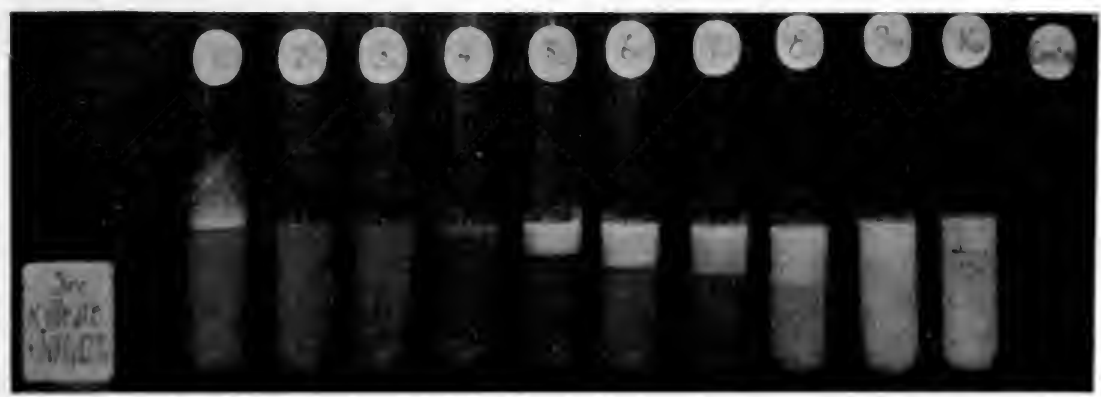

Figure 71 .

Table L. As more of the ammonium chlorid is added a white collar appears which grows progressively in thickness until the whole contents of the tube appear white. Microscopic examination shows this collar to be an emulsion (of freed fatty acid in the remaining hydrated soap). ${ }^{1}$

The effects of magnesium and of calcium chlorid upon potassium oleate are shown in Tables LI and LII and Figs. 72 and 73. There is no increase in viscosity to be noted in either series but only a progressive fall. This is due to the formation of the socalled "insoluble" calcium and magnesium soaps. It would be better to say that the change is due to the formation of less hydratable soaps for, as previous study has shown, ${ }^{2}$ the magnesium and calcium soaps absorb much less water than the corresponding motassium soaps. Since magnesium soap holds more water than 
calcium soap the former settles out with greater difficulty than the latter, as may be seen by comparing Figs. 72 and 73 . In the higher concentrations of the calcium salt, the calcium oleate comes down in very finely divided (colloid) form and so remains

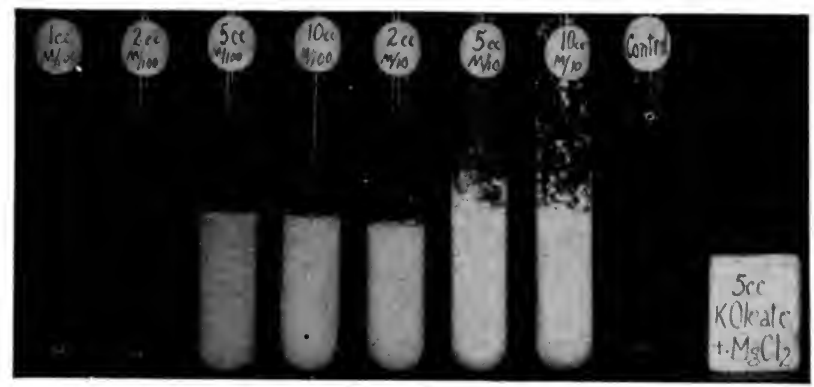

FIGURe 72.

suspended in the liquid as shown in the tubes marked 5 and 10 of Fig. 73.

The formation of the metallic soaps with their extremely low hydration capacities again dominates the picture when cupric or ferric chlorid is added to potassium oleate. As shown in

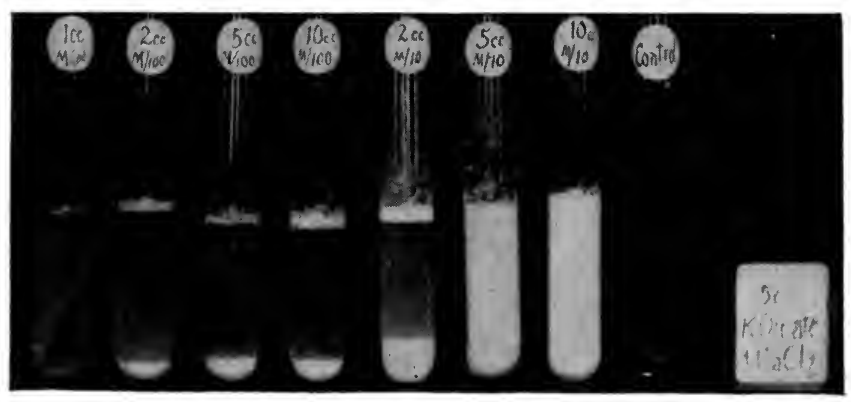

Figure 73.

Tables LIII and LIV the soaps as formed tend from the first to collect in hard, dry lumps within the freed dispersion medium. Matters are further complicated in these experiments by a partial separation of fatty acid due to the fact that the added salts yield an overplus of acid on solution and hydrolysis in water. 


\section{Critical and Historical Remarks}

a. Introduction. Considered in the broad, these experiments descriptive of the effects of different alkalies and of different neutral salts upon soap are as old as soap manufacture or chemical industry itself. The precipitation of "insoluble" metallic soaps by the addition of salts of the heavy metals to sodium or potassium soaps is a familiar procedure in the manufacture of various paint products; the addition of ammonium hydroxid to wash waters has long been known to have a value in laundering processes not shown by more fixed "lyes"; and the "salting-out" of soaps through the addition of an excess of the alkali used in making the soap or by the addition of ordinary sodium chlorid is a century or more old. The soap chemists are also familiar with the fact that in the salting-out process they often encounter a "gumming" of their soap mixtures or find that these "go stringy." Nevertheless, experimental details covering all these general subjects in more than partial fashion seem still to be meagre, and the nature of the simplest findings seems not yet to have emerged from the realm of harsh debate.

If the facts and theoretical considerations covering the hydration and solvation properties of the pure soaps themselves as previously outlined in these pages ${ }^{1}$ are kept in mind, it becomes possible, we think, not only to draw together under a common heading many of the empiric facts of chemical industry but to find an explanation for them in decidedly simpler terms than seem now to be in use. Before detailing the views of other workers in these fields we wish for the sake of clarity to divide the experiments of this section into three groups. While the phenomena discussed in any one of these commonly appear also in a second, or even in a third, such division will help to make clear what it is that dominates behavior in each of the groups.

The previous pages have shown that it is important to distinguish between the solubility of any sonp in water and the solubility of the water in that soap. Of immediate interest for our purposes is the fact that of the soaps of a given fatty acid but with different bases, ammonium soap is most soluble in water, potassium next and then sodium. The soaps of the alkaline earths are hardly soluble in water and those of the heary metals 
are generally regarded as completely insoluble. Looked at the other way about, the first named are the best solvents for water, while the alkaline earth soaps take a middle ground, and those of the heavy metals stand last. With these general truths in mind, it is obvious that we may classify the effects of adding an alkali hydroxid or of adding any salt to potassium oleate as follows:

(1) a soap is formed more soluble in water and a better solvent for water;

(2) a soap is formed less soluble in water and a poorer solvent for water;

(3) no change occurs in the solubility characteristics of the soap.

The last covers, perhaps, the item of greatest practical importance, namely, that of the ordinary salting-out of soaps, and that about which most debate has centered; but since in practice it is rarely seen in the pure form outlined in our experiments, but is more or less blurred through the simultaneous action of possibilities (1) or (2), it is best taken up last.

(1) A soap is formed more soluble in water and a better solvent for water. This happens when ammonium hydroxid is added in any amount whatsoever to a potassium (or sodium) soap. In this case the viscosity of the soap mixture regularly falls. This behavior of ammonium hydroxid is strikingly different from that of either potassium or sodium hydroxid, either of which first brings about a gelation of the soap solution followed by a secondary liquefaction and then a separation of the dehydrated soap from the dispersion medium (a solution of the alkali hydroxid in water). The effect of such fixed hydroxids is regularly attributed to "increases in alkalinity," "increases in hydroxyl ions" and the vaguer concepts of "adsorption" and "permeability." It is obvious that all such explanations are inadequate, for with enough ammonium hydroxid at hand any degree of "alkalinity" or any number of "hydroxyl ions" ought also to become available to bring about the effects observed with the fixed alkalies, yet, when ammonium hydroxid is used, these effects never do come about. The reason is that through interaction of the potassium (or other) soap with the ammonium hydroxid, ammonium soap is formed, and this is more soluble in water than the original potassium (sodium or other) soap. The system as a whole 
becomes "less colloid," approximates more nearly a " true" solution, and hence its viscosity can only fall.

The same general effect of the ammonium radical is still apparent when instead of ammonium hydroxid some salt like ammonium chlorid is added to potassium oleate (see Fig. 71 and Table L). Here again no initial increase in viscosity is to be observed. Since, however, ammonium chlorid is the salt of a weak base with a stronger acid the secondary effect of an overplus of acid formed through hydrolysis also appears. By means of this acid, fatty acid is liberated from the soap and then remains emulsified in the soap. A third effect is exerted in this illustration by the unchanged ammonium chlorid and the newly formed potassium chlorid which exert a dehydrating effect (see below) upon both of the soaps.

These ideas may be further verified by using ammonium acetate. There is still no perceptible initial increase in viscosity, and since the salt used is more nearly neutral, fatty acid is not set free. In the higher concentrations of this salt the soap merely separates out in the usual fashion.

(2) A soap is formed less soluble in, and a poorer solvent for, the dispersion medium. This is observed when magnesium, calcium, iron or copper salts are added to a solution of potassium (or sodium) oleate. Under these circumstances, too, the systems as a whole again become more liquid, though it is not in this instance because the soaps formed are more soluble in the solvent or more hydratable but because they are less soluble and less hydratable and so fall out, allowing the viscosity of the pure solvent (essentially salt water) to come to the front. In contrast to the systems described under (1), these regularly become milky or white while the former become more transparent (unless some secondary change like the liberation of fatty acid in emulsified form supervenes).

(3) The change in kind of soap is negligible or there is none at all. This happens, for example, when potassium hydroxid or a neutral potassium salt is added to a potassium soap. Under these circumstances, with increasing concentration of the added substances, all the changes described in the above experiments are seen to occur. There is, first, an increase in viscosity which, if the amount of the solvent is not too great, results in gelation, followed by a secondary liquefaction resulting ultimately in com- 
plete separation of the anhydrous soap from the dispersion medium. Since the nature of the changes seen under these circumstances covers the question of the theory of the "salting-out" process in soap manufacture (as well as that of the salting-out process in many other lines of chemical industry), and since many attempts have been made to explain these changes, it is well to interrupt our general argument here to review such theories, as far as they are known to us, before proceeding further with suggestions of our own.

b. Historical Remarks on the "Salting-out" of Soaps. F. HoFMEISTER ${ }^{1}$ recorded in 1888 what seem to be the first quantitative 'studies in this field when, in studying the "water-attracting" powers of various salts, he determined the minimal concentrations in which they would bring about the separation of a soap from its aqueous dispersion medium. Finding that the ordinary mixed soaps gave inconstant results, he set out to discover the lowest concentrations of various sodium salts necessary to bring about a beginning turbidity in solutions of sodium oleate. In determining this point he noted that his soap solutions frequently jellied. F. Botazzi and C. Victorow ${ }^{2}$ detailed, some twenty years later, the effects on viscosity of adding sodium hydroxid to a Marseilles soap solution. Their soap (in essence sodium oleate) had been dialyzed and contained in consequence free fatty acid and what is commonly designated, since the work of F. KRAFFT and $\mathrm{H}$. Wiglow, " acid soap." ${ }^{4}$ Addition of sodium hydroxid to such dialyzed soap was found to be followed by an increase in viscosity which at higher concentrations of the alkali gave way to a decrease.

${ }^{1}$ Franz Hofmeister: Arch. f. exp. Path. u. Pharm., 25, 6 (1888).

${ }^{2}$ F. Botazzi and C. Victorow: Accad. Lincei, 19 (1910), accessible only as review in Kolloid-Zeitschr., 8, 220 (1911).

${ }^{3}$ F. Kraffet and H. Wiglow: Ber. d. deut. chem. Gesell., 28, 2566 (1895).

4 If it is true, as generally supposed, that the fatty acids are monobasic it becomes a difficult mental maneuver to figure out how a partial saturation of the replaceable hydrogen is going to yield an "acid" soap. While the concept is widely accepted, no one has ever isolated such an acid soap and the only reason for believing in it seems to depend upon the fact that a clear solution or jelly may be obtained when a fatty acid is only partially neutralized with alkali in the presence of small amounts of water. But these are the ideal conditions for the production of emulsions, the emulsions in this case consisting of fatty acid in hydrated soap. When the indices of refraction of fatty acid and of hydrated soap lie close together the mixture looks homogeneous. See Martin H. Fischer and Marian O. Hooker: Science, 43, 468 (1916); Fats and Fatty Degeneration, 29 and 100, New York (1917). 
J. W. McBain and Millicent TAYLOR ${ }^{1}$ observed the same facts for sodium palmitate at $90^{\circ} \mathrm{C}$. Their "acid" sodium palmitate was first rendered "more colloidal" by the addition of sodium hydroxid and was then salted out entirely in concentrations of the hydroxid above 1.5 normal.

F. Goldschmidt and L. Weissmann ${ }^{2}$ also studied the changes in viscosity of potassium soap solutions when various eleetrolytes were added to them. With increasing eoncentration of the added salt, they observed a marked increase in viscosity "with a strong tendency to jelly." In a later study ${ }^{3}$ they verify this finding for the ammonium soap of palm kernel oil when various hydroxids or salts are added to it. Recently G. H. A. Clowes ${ }^{4}$ has corroborated these general findings for sodium oleate. He writes:

" $\mathrm{Na}$ oleate was treated with salt at different concentrations, and it. was found that at .4 to $.45 \mathrm{M} \mathrm{NaCl}$ complete precipitation of the soap took place. It was noted, however, that prior to precipitation a tendency to jelly formation was exhibited in the zone from .2M NaCl to .4 or $.45 \mathrm{M} \mathrm{NaCl}$. . . Further tests using varying proportions of soap, varying proportions of $\mathrm{NaOH}$, and of $\mathrm{NaCl}$ and other salts of $\mathrm{Na}$ brought out the remarkable fact that as long as the soap employed was not too greatly diluted and was slightly alkaline, a jelly would be formed at all points between $.2 \mathrm{M} \mathrm{Na}$ and $.45 \mathrm{M} \mathrm{Na}$, regardless of whether the $\mathrm{Na}$ was derived from $\mathrm{NaOH}$, from $\mathrm{NaCl}$ or other salts of $\mathrm{Na}$."

The explanations which the various authors offer of the phenomena observed - if they make the attempt at all-are for the most part extremely complicated. We confess to large inability at times to understand just what they mean, for not only do the different authors contradict each other but their individual concepts are often self-contradictory. As well as we can understand them, their views are about as follows:

Hofmeister does not attempt to account for the jelly formation at all, but considers the separation of the soap from the aqueous dispersion medium as due to the "water-attracting power" of the added salt. The soap, he holds, is deprived of its solvent because the added salt combines with the solvent. This notion of Hofmeisten has been much disparaged, but we

'J. W. McBain and Mulderst TaYuon: Zeitschr. f. physik. Chem., 76, 179 (1911).

2F. Goloschmior and L. Weissmass: Zeitschr. f. Elektrochem, 15, 380 (1912).

'F. Goldschmint and L. Wrissmans: Kolloid-Zeitschr., 12, is (1913).

- G. H. A. Clowes: Proc. Soc. Exp. Biol. and Med., 13, 114 (1916). 
are of the opinion that such a change does occur and that it is partly responsible for the phenomena observed in these colloid systems.

Botazzi and Victorow hold that the addition of alkali to their dialyzed, "acid soap" leads to the formation of neutral soap "which splits hydrolytically. The molecules polymerize with the formation a true colloid solution containing micellæ and ' colloid ions,' which then lead to an increase in viscosity because the water of the system is held more firmly through hydration or imbibition."

MCBAIN and TAYLOR, while originally insistent that their studies " undoubtedly prove, in opposition to the view of KRAFFT, that the normal soaps in concentrated solution are not colloids," conclude later, ${ }^{2}$ and more correctly we think, when working with sodium palmitate (at $90^{\circ}$ ) in the presence of sodium hydroxid, that they have in hand systems "in reversible equilibrium consisting of electrolyte, hydrosol and coagulum." The increase in colloidality observed in their studies they attribute, in the main, to the formation of "acid palmitate."

Goldschmidt and Weissmann hold that a satisfactory explanation of the changes in the viscosity of their soap under the influence of alkalies and salts is still a matter of the future. They emphasize as factors of possible worth changes in the hydrolytic cleavage of the soap and the formation of acid soap, though how such factors act they do not say.

Clowes' hypothesis reads as follows:

"A dispersion of $\mathrm{Na}$ oleate in water represents a dispersion of particles of oleic acid by means of $\mathrm{NaOH}$. Further additions of $\mathrm{NaOH}$ lead to a more perfect dispersion of the soap particles, owing to the fact that the $\mathrm{OH}$ ion is more readily adsorbed than the $\mathrm{Na}$ ion. $\mathrm{NaCl}$ exerts a similar effect to $\mathrm{NaOH}$, the $\mathrm{Cl}$ ions exerting a dispersing effect analogous to that of the $\mathrm{OH}$ ions, but since they are far less readily adsorbed than the $\mathrm{OH}$ ions their effect is considerably smaller... . The soap particles possess a negative charge attributable presumably to adsorbed anions. This charge prevents their coalescence until the concentration of the $\mathrm{Na}$ ions reaches such a point that they also come into play and by adsorption on the particles tend to counteract or diminish the negative charge conveyed by the previously adsorbed $\mathrm{OH}$ or $\mathrm{Cl}$ ions. When a certain

1 J. W. McBain and Millicent Taylor: Ber. d. deut. chem. Gesell., 43, 321 (1910).

${ }^{2}$ J. W. McBain and Millicent Taylor: Zeitschr. f. physik. Chem., 76 179 (1911). 
concentration of the cation is reached a critical zone commences in which jelly formation or precipitation appears to depend entirely upon the relative proportions of adsorbed cations and anions. If at the commencement of this critical zone the residual negative charge . . . is sufficient to maintain a perfect dispersion . . . jelly formation will ensue at higher concentrations. If this residual negative charge . . is insufficient . . . if agglutination, aggregation and sedimentation under the influence of gravity has already commenced, precipitation necessarily ensues at higher concentrations. ... If at the critical point the sum total of adsorbed anions is not sufficiently in excess of that of adsorbed cations to insure perfect dispersion, precipitation instead of jelly formation ensues. This explains the necessity for a certain minimum concentration of $\mathrm{NaOH}$ with its readily adsorbed $\mathrm{OH}$ ions to insure jelly formation in the case cited above."

The contradictory nature of the explanations here reviewed is self-evident. To secure the proper results Clowes holds that the soap must be "alkaline to phenolphthalein." Our own soap, which in practice worked quite like his, was prepared by adding to each other the chemically equivalent weights of fatty acid and alkali necessary to yield a " neutral " soap. In the concentrations in which we employed our stock soap it was not alkaline to phenolphthalein. The same kind of soap stock or one more decidedly "acid" was employed by all the other students in this field. In fact, it would seem that, with the exception of Clowes, the majority of observers had inclined to the belief that an overplus of acid in their soap systems was necesssary for an understanding of the viscosity changes. Nevertheless, and independently of all hypothesis, there is reported throughout the experiments of all these workers (including our own) the same sequence of observed facts which has been set down in detail in the preceding pages, namely, an initial increase in viscosity resulting ultimately (when the soap system is not too dilute) in gelation. followed by a decrease in viscosity and a gradually increasing dehydration and complete separation of the soap.

c. On the Theory of the "Salting-out" of Soaps. We refrain from a detailed criticism of the views of these authors. It is self-apparent how all too one-sided notions of jelly formation in soaps (like the electrical) must come to grief as soon as it is remembered that such jellies may be produced from non-aqueous solvents and anhydrous soaps and under circumstances which allow of none of the orthodox conditions deemed necessary for the develop- 

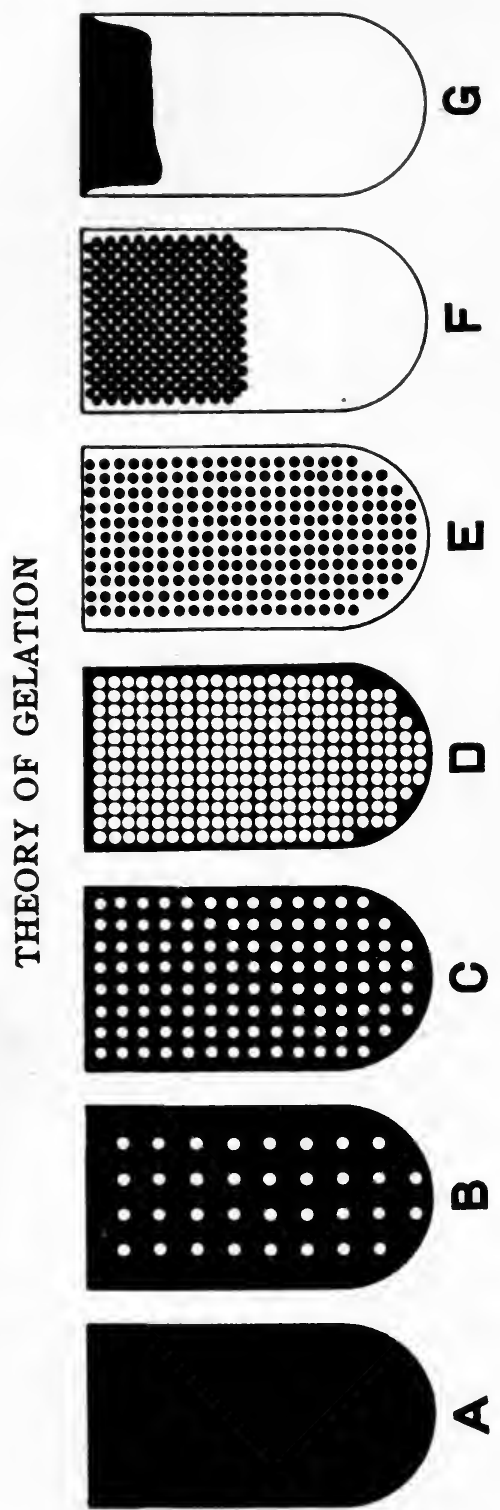

ment of electrolytic dissociation. ${ }^{1}$ The importance of " alkalinity" or of "hydroxyl ions" disappears when ammonium hydroxid is found incapable of doing what potassium hydroxid or potassium chlorid does; the "alkaline," "neutral" or "acid" character of the original soap stock can hardly be of fundamental importance when all three are seen to exhibit the same general behavior toward added substances.

If we attempt to explain the successive changes which follow the addition of fixed alkali or a neutral salt to potassium oleate (or any similar soap), and try to do this without recourse to too many or too violent assumptions, the following seems the simplest way out.

The entire series of changes observed in the salting-out of a soap by an alkali or a salt is readily understood if it is assumed that the added neutral salt or alkali hydroxid unites with the solvent to form a hydrate or solvate and that the consequent viscosity changes (including gelation) are dependent upon the changes in viscosity observed whenever one liquid is emulsified in a second.

${ }^{1}$ See the preceding sections (pages 30 to 77 ) on soap/alcohol and soap/ $x$ systems. 
It does not matter for our purposes whether such union with the "solvent" is brought about by the molecules or the ions or any other derivatives of the salt. The solvates (hydrates) after being formed then separate out in dispersed form in the potassium oleate.

Diagrammatically the successive changes are illustrated in Fig. 74. If, to simplify matters, we represent the original pure potassium oleate solution as a homogeneous system ${ }^{1}$ as indicated in tube $A$ of Fig. 74, the effeet of adding some molecules of fixed , alkali or salt may be represented by the diagram marked $B$. Hydration of the salt molecules has two effects: (1) It withdraws water from the original potassium system and thus through increase in the concentration of the potassium oleate tends to stiffen the system. But this effect is probably not large as compared with (2) the effects upon viscosity of the dispersion of one material in a second. The increase in viscosity due to such subdivision of one material in a second is observed under widely varying circumstances. A good example for our purposes is that represented by the increase in viscosity when one liquid (like cottonseed oil) is emulsified in a second (like a soap solution). The "mayonnaise" which results may become so stiff that it will stand alone. But the same type of change is observed when a dry sand (which "flows" readily) is mixed with a little water and a mass results that can be molded. Even a gas subdivided into a liquid will yield such "solid" structures as when air is beaten into a liquid white of egg to yield a "foam."

The viscosity of such diphasic systems - and it is well to bear in mind, in the case of the soaps, more particularly diphasic systems consisting of one liquid dispersed in a second or of a solid dispersed in a liquid-increases with every increase in the concentration of the internal dispersed phase and with every decrease in the size of the individual dispersed particles. The viscosity of an emulsion of liquid oil in liquid soap, for instance, increases as more and more oil is beaten into the soap; on the other hand, with a given amount of oil subdivided into a given volume of soap the viscosity of the mixture is increased if the previously coarse emulsion is made finer by "homogenizing." 2

'It is at least a diphasic system as emphasized on page 69 , but for our purposes we will call it a monophasic one.

${ }^{2}$ For references to the literature and specific studies of the emulsions see Martin H. Fischfor and Makian O. Hooker: Science, 43, 468, (1916); Fats and Fatty Degeneration, New York (1917). 
It is such increase in the number of hydrated salt particles with increasing concentration of the added salt that explains the progressive increase in the viscosity (see diagram $C$ ) which, when the amount of water in the system is not too high, culminates in gelation. If the concentration of the salt is still further increased, the time approaches when the number or size of the hydrated salt particles becomes so great that they touch each other (diagram D). When this happens a critical point has been reached and there must appear a change in the system, for the hydrated salt particles now become the continuous external phase while the soap particles form the internal divided phase. Such change in type of emulsion even without change in the quantitative relationship of the two liquids composing the emulsion is regularly followed by a change in viscosity. This situation is indicated in tube $E$ of Fig. 74. The viscosity of the system now tends in the direction of the salt solution and so, with progressive additions of salt, falls. This is the region of secondary liquefaction after the region of gelation in our experiments. At this point, however, the soap system also shows the first evidences of becoming turbid. This is because more and more water has been taken from the soap and as this becomes dehydrated its index of refraction changes. Being different from that of the dispersion medium the mixture appears milky. The dehydrated soap particles, being possessed of a lower specific gravity than that of the alkaline solution or salt solution constituting the dispersion medium, now begin to float to the top as indicated over $F$ in Fig. 74 . When enough salt has been added to the system, the soap is entirely dehydrated, as shown in diagram $G .{ }^{1}$

\section{On the "Salting-out" of Different Soaps}

The preceding pages have made clear the general laws which underlie the salting-out of a soap by different salts. We have now to consider the question of how different soaps behave when subjected to the salting-out effects of a single salt.

${ }^{1}$ It is self-evident that what has been here written of the salting-out process as observed in soap manufacture holds with equal force for the saltingout processes of many other technological procedures as in aniline dye, cheese, and butter manufacture. For the application of these principles to certain phenomena of "coagulation" as observed in milk, blood, muscle juice, etc., see page 233 . 
There have been many studies made of this question, but for the most part they refer to the salting-out of mixed soaps as obtained from different mixed fats. Under such circumstances we are obviously dealing with the salting-out of a series of soaps. ${ }^{1}$ We have been able to find only a single statement covering the salting-out of different pure soaps by a single salt. C. STIEPEL ${ }^{2}$ examined the behavior of the sodium soaps of caproic, heptylic, caprylic, pelargonic, capric, lauric, myristic, palmitic and stearic acids towards solutions of common salt. While sodium caproate

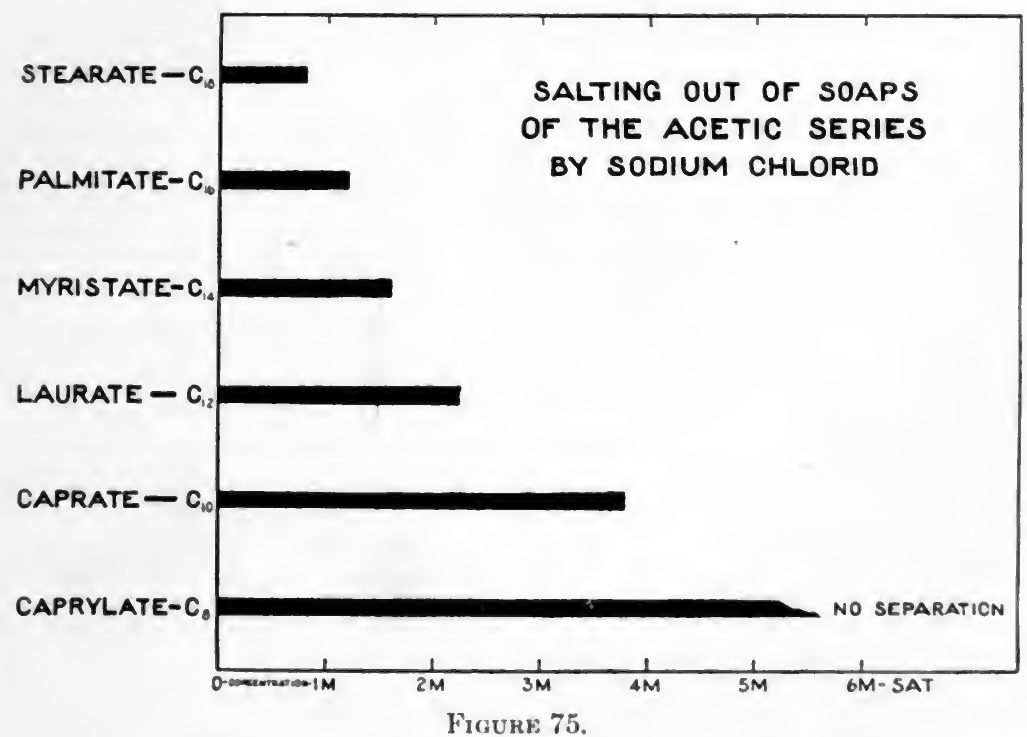

was not salted out by a saturated solution of sodium chlorid, and the succeeding four soaps remained gelatinous, the laurate, myristate, palmitate and stearate proved "insoluble" successively in 17.7 percent (3.02 molar), 9.03 percent ( 1.54 molar), 6.94 percent (1.19 molar) and 4.92 percent ( 0.84 molar) solutions of sodium chlorid.

These values have been verified by R. J. Kronachen, ${ }^{3}$ whose findings for a series of sodium salts are reproduced in Fig. 75 . (1911).

'See for example, J. Leimdörfen: Technologie der Seife, 1, 14, Dresden

'C. StiEpel: Weyl's Einzelschriften z. chem. Tech., 1, 348, Leipzig (1911).

3 R. J. Kronacher: Personal communication (1920). 
Molar equivalents of the different sodium soaps $(1 / 10 \mathrm{~mol})$ were dissolved in equal volumes of water $(1000 \mathrm{cc}$.) and the whole brought, into homogeneous solution at the temperature of a boiling water bath. Enough salt was then added at the high temperature so that on cooling the mixture to $18^{\circ} \mathrm{C}$. a first separation from the pure dispersion medium (salt water) was observed. It will be noticed that as the acetic series is ascended, a lower and lower concentration of sodium chlorid is required to bring about such separation. While in the concentrations of soap employed, sodium caprylate did not come out in even a saturated (over 5 molar) sodium chlorid solution, sodium stearate separated from the dispersion medium when less than a 1 molar sodium chlorid concentration prevailed.

A second series of experiments to illustrate these general truths is presented in Table LV and Fig. 76. While the arrangement in these experiments is intended for use under another heading later, the findings fit in at this point. The experiments show the effects of adding the same volumes of increasingly concentrated sodium hydroxid solution to equimolar amounts of the different fatty acids of the acetic series, only those members being used in which soap formation takes place at ordinary room temperature. (Soap is produced, in other words, by the so-called cold process.)

Fig. 76 and Table LV show that only clear solutions are obtained in the case of formic and acetic acids. At the same molar concentration, sodium propionate begins to be salted out in the higher concentrations of the sodium hydroxid. As we pass to the sodium butyrate, sodium valerate, sodium caproate, sodium caprylate, sodium caprate and sodium laurate, the saltingout effect moves little by little to the left. The experiment again shows therefore that a soap of the acetic series is salted out with increasing ease (by sodium hydroxid, in this instance) as we ascend the series.

Fig. 76 and Table LV illustrate, however, a second point previously commented upon. It will be observed that beginning with sodium butyrate and going up in the chemical series one or more tubes are filled with solid gels. This is because, as we ascend the series, soaps of an increasing gelation capacity are produced. The final picture seen in the photograph is therefore the composite represented by (a) the production of soaps possessed 

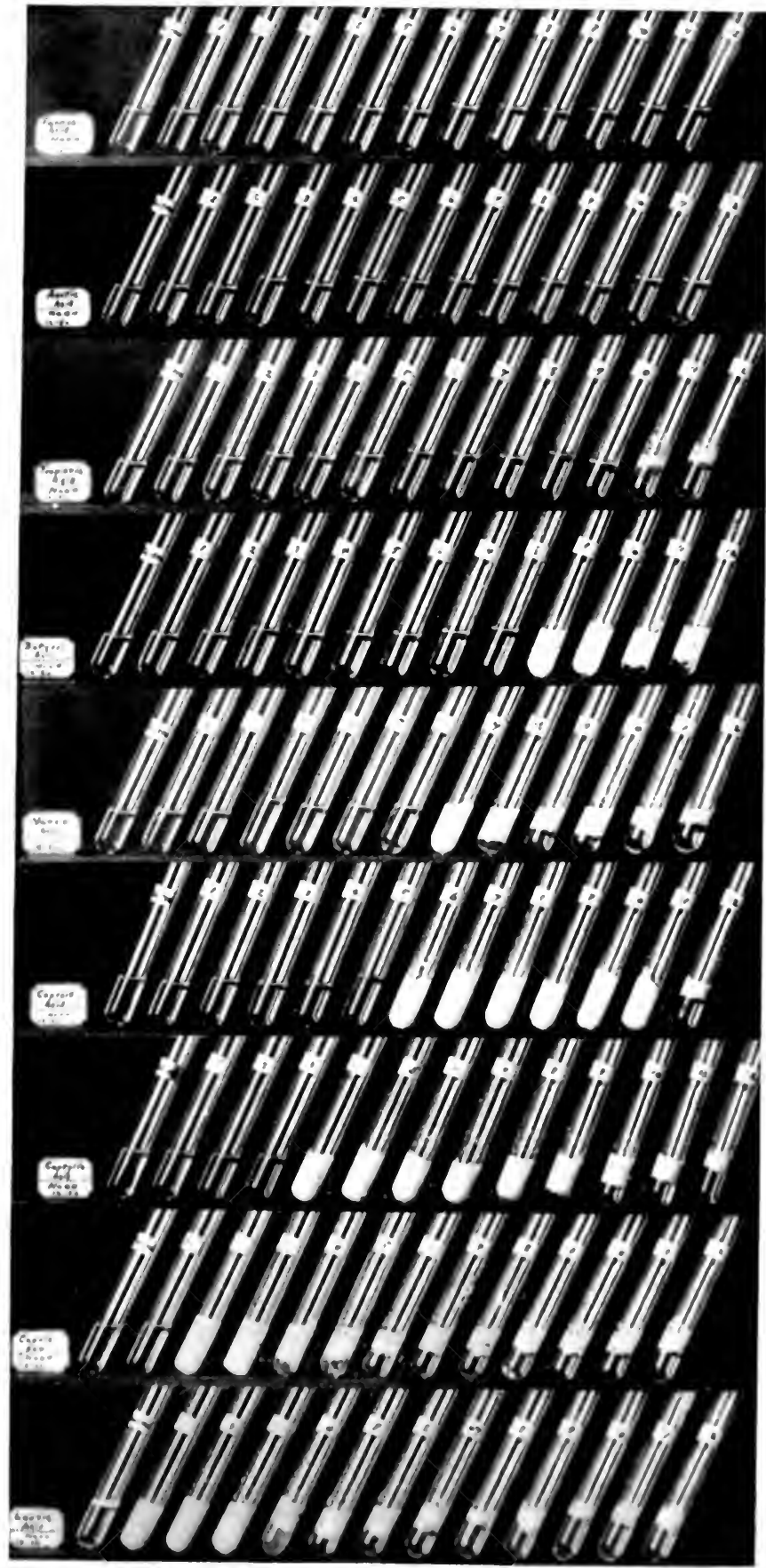

Figure 76. 
by themselves of an increasing gelation capacity and $(b)$ of an increased sensitiveness to the salting-out effect by an excess of sodium hydroxid.

TABLE XXVI

Potassium Oleate-Potassium Hydroxid

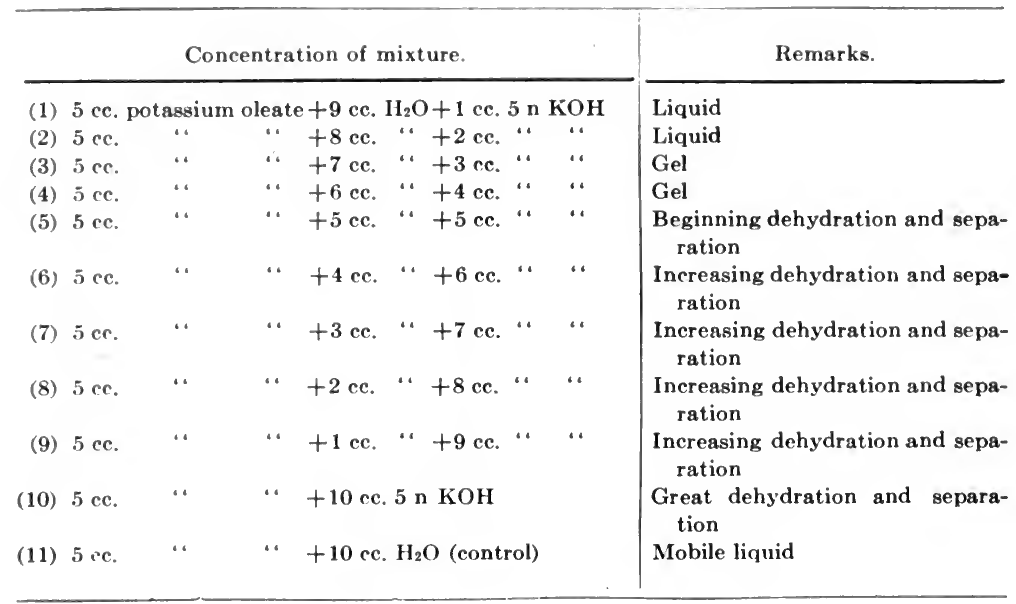

TABLE XXVII

Potassium Oleate-Sodium Hydroxid

Concentration of mixture.

(1) 5 cc. potassium oleate +9.5 cc. $\mathrm{H}_{2} \mathrm{O}+0.5$ cc. $5 \mathrm{n} \mathrm{NaOH}$ (2) $5 \mathrm{cr}$ " " " +9 cc. $"+1$ cc. " "

(3) 5 cc. “ $\quad$ “ +8 cc. " +2 cc. “ "

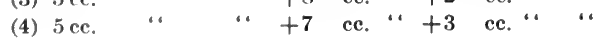

(5) 5 cс. $\quad$ “ $\quad+6$ cc. $“+4$ cc. $"$ “

(6) 5 cc. $\quad$ “ $\quad$ “ +5 cc. “ +5 cc. “ “

(7) $5 \mathrm{cc.} \quad$ “ $\quad+10$ cc. $5 \mathrm{n} \mathrm{NaOH}$

(8) 5 cc. “ $\quad$ “ +10 ce. $\mathrm{H}_{2} \mathrm{O}$ (control)
Remarks.

\section{Liquid}

Liquid

Gel

Beginning dehydration and separation

Increasing dehydration and separation

Increasing dehydration and separation

Great dehydration and separation

Mobile liquid 
TABLE XXVIII

Potassium Oleate-Ammonium Hydroxid

\begin{tabular}{|c|c|c|c|c|c|c|}
\hline \multicolumn{6}{|c|}{ Concentration of mixture. } & \multirow{2}{*}{$\frac{\text { Remarks. }}{\text { Mobile liquid }}$} \\
\hline (1) & 5 ce. & $\operatorname{tassi}$ & leate +9 cc. & $\mathrm{H}_{2} \mathrm{O}+1$ cc. $5 \mathrm{n}$ & $\mathrm{NH}_{4} \mathrm{OH}$ & \\
\hline (2) & 5 ce. & $\because$ & $\cdots \quad+8$ cc. & $\cdots+2$ cс. $\cdots$ & $\cdot \cdot$ & Mobile liquid \\
\hline (3) & 5 cc. & $\because$ & - +7 cc. & $\cdot+3$ cc. $\cdot$ & “. & Mobile liquid \\
\hline (4) & 5 ce. & $\because$ & $\cdots \quad+6 \mathrm{cc}$. & $\cdots+4$ ce. $\cdot$ & $\because$ & Mobile liquid \\
\hline (5) & $5 \mathrm{cc}$. & $\cdots$ & . $+5 \mathrm{cc}$. & $\cdot+5$ cc. $\cdot$ & 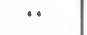 & Mobile liquid \\
\hline (6) & 5 cc. & $\because$ & . +4 cc. & $\cdots+6$ cc. $\cdot$ & ? & Mobile liquid \\
\hline (7) & 5 cc. & • & $\cdots+3$ cc. & $\cdots+7$ cc. $\cdots$ & “. & Mobile liquid \\
\hline (8) & 5 ce. & • & . +2 cc. & $\cdots+8$ cc. $\cdots$ & $\because$ & Mobile liquid \\
\hline (9) & 5 cc. & *. & - +1 cc. & $"+9$ cc. $"$ & “. & Mobile liquid \\
\hline (10) & 5 cc. & • & $\cdots+10 \mathrm{cc}$ & $.5 \mathrm{n} \mathrm{NH}_{4} \mathrm{OH}$ & & Mobile liquid \\
\hline (11) & 5 cc. & . & $\because \quad+10 \mathrm{cc}$ & $\mathrm{H}_{2} \mathrm{O}$ (control) & & Mobile liquid \\
\hline
\end{tabular}

TABLE XXIX

Potassium Ohente-Potassium Fluorid

Concentration of mixture.

(1) 5 cc. potassium oleste +9 cc. $\mathrm{H}_{2} \mathrm{O}+1$ cc. 2 m KF

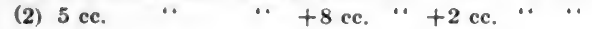

(3) 5 cc. $\quad \cdots \quad$ a +7 cc. $\cdots+3$ cc. $\cdots$.

(4) 5 cc. $\quad \cdots \quad \cdots+6$ cc. $\cdots+4$ cc. $\cdots \cdots$

(5) 5 cc. $\cdots \quad \cdots+5$ ce. $\cdots+5$ cc. $\cdots " \cdots$

(6) 5 cc. c. $"$ " +4 cc. " +6 cc. " "

(7) 5 cc. $\quad \cdots \quad$ * +3 cc. $\cdots+7$ cc. $\cdots \cdots$

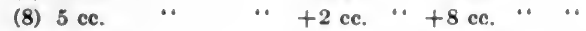

(9) 5 cc. $\quad \cdots \quad$ +1 cc. $\cdots+9$ cc. $\cdots$,

(10) 5 cc. $\quad$ - $\quad+10$ cc. $2 \mathrm{~m} \mathrm{KF}$

(11) 5 cc. $\quad \cdots \quad$. +10 cc. $\mathrm{H}_{2} \mathrm{O}$ (control)
Remarks.

Mobile liquid

Slightly viscid

Stiff gel

Stiffest gel.

Viscid, faintly turbid

Slightly viscid, turbid

Mobile, turbid

Mobile, turbid

Mobile, turbid, beginning dehydration

Mobile, increasing dehydration Mobile liquid 


\section{TABLE XXX}

\section{Potassium Oleate-Potassium Chlorid}

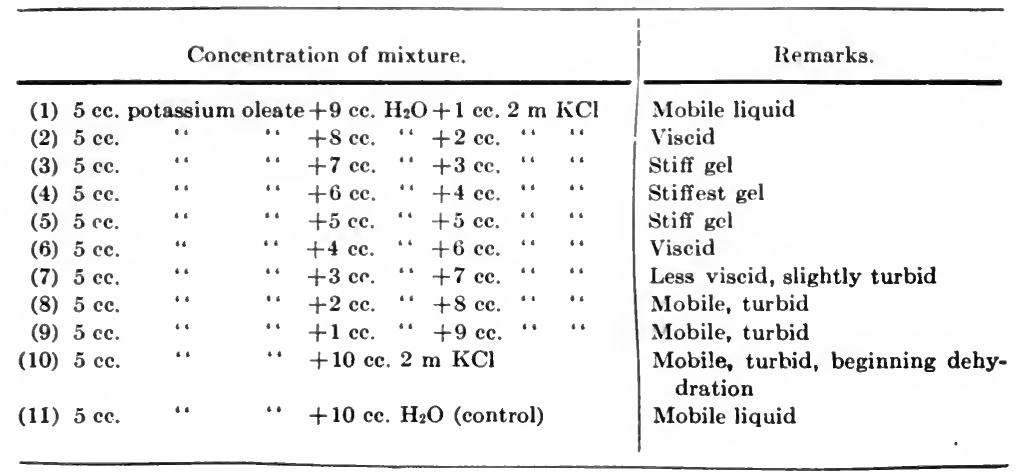

\section{TABLE XXXI}

Potassium Oleate-Potassium Bromid

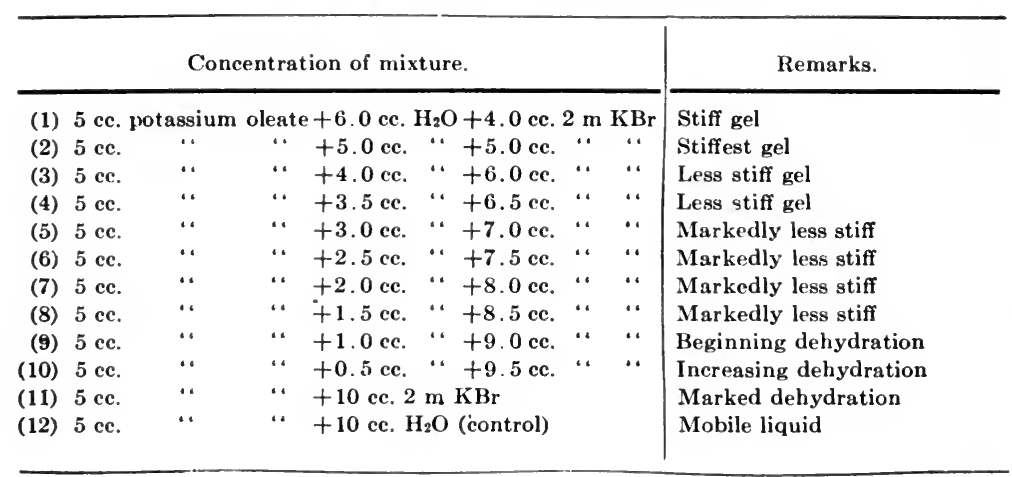

TABLE XXXII

Potassium Oleate-Potassium Iodid

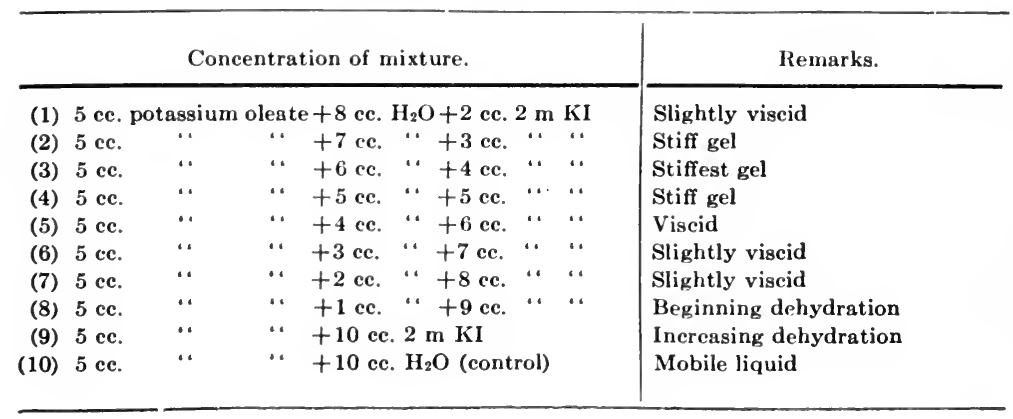


TARLE XXXIII

Potassiom Oleate-Potassium Nitrate

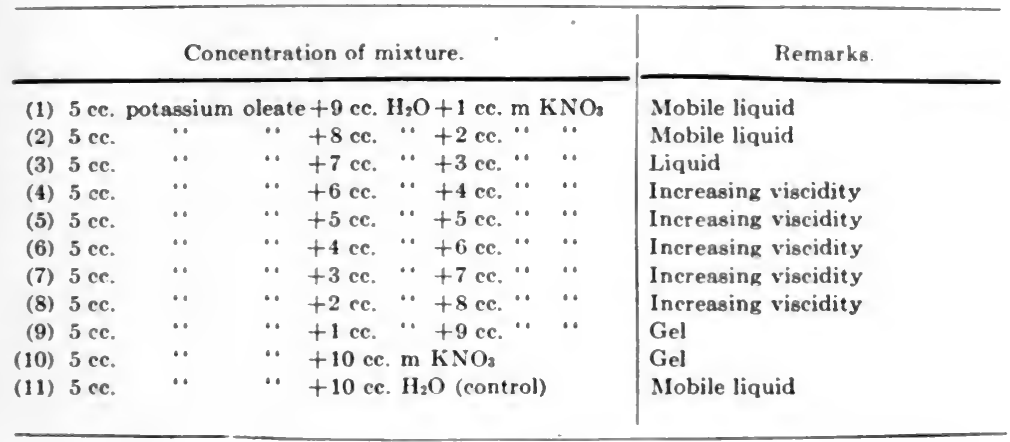

TABLE XXXIV

Potassium Oleate-Potassium Nitrate

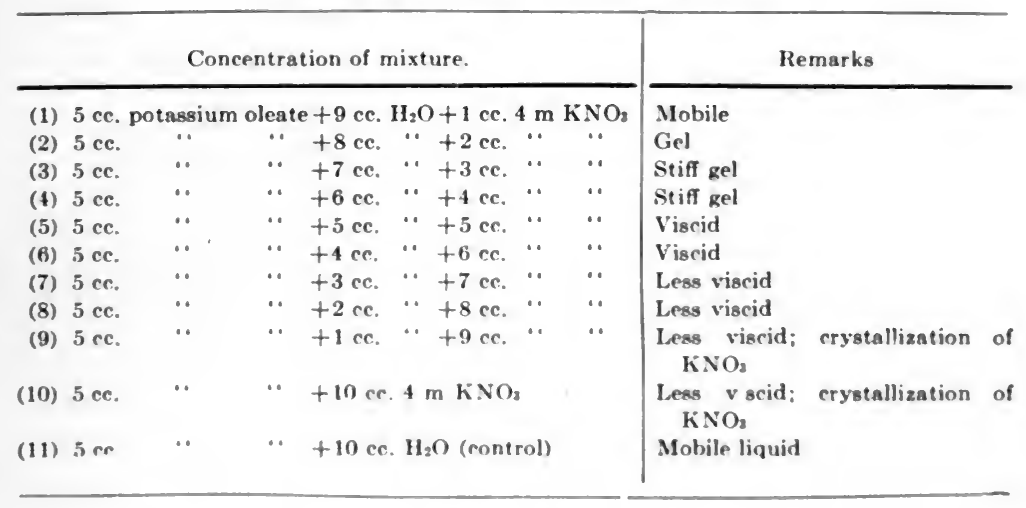

TABLE XXXV

Potassium Oleate-Polnssium Sulphocyannte

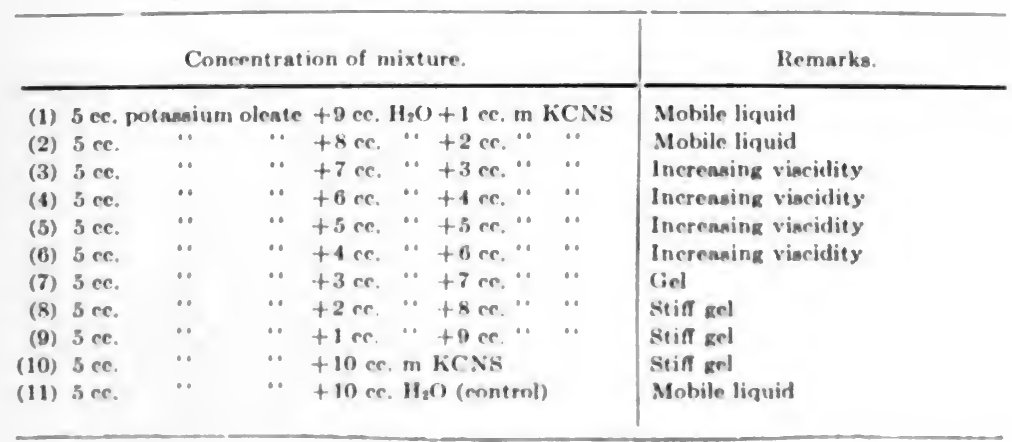


TABLE XXXVI

Potassium Oleate-Potassium Sulphocyanate

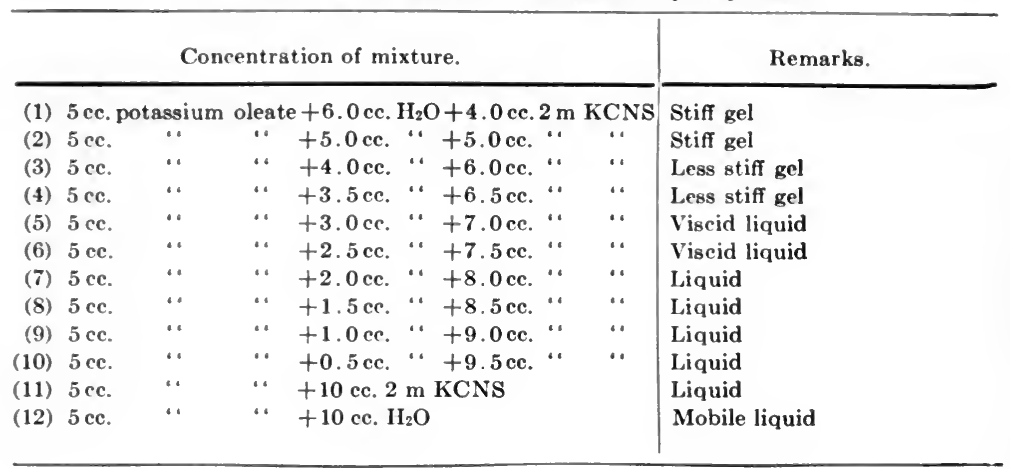

TABLE XXXVII

Potassium Oleate-Potassium Sulphocyanate

Concentration of mixture.

(1) 5 cc. potassium oleate $+6.0 \mathrm{cc} . \mathrm{H}_{2} \mathrm{O}+4.0 \mathrm{cc} .4 \mathrm{~m}$ KCNS

(2) $5 \mathrm{cc}$

(3) $5 \mathrm{cc}$

(4) $5 \mathrm{cc}$.

(5) $5 \mathrm{cc}$.

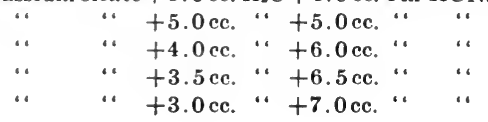

(6) 5 cc. $\quad$ " $\quad+2.5 \mathrm{cc} . "+7.5 \mathrm{cc} . "$ “

(7) 5 cc. " " $"+2.0 \mathrm{cc} . "+8.0 \mathrm{cc} . "$ "

(8) 5 cc. $\quad$ " $"+1.5 \mathrm{cc} . "+8.5 \mathrm{cc} . "$ "

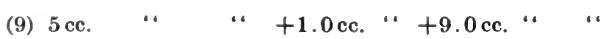

(10) 5 cc. $\quad$ “ $\quad+0.5 \mathrm{cc} . ~ “+9.5 \mathrm{cc} . "$ “

(11) 5 ce. $\quad$ “+ $+10 \mathrm{cc} 4 \mathrm{~m} \mathrm{KCNS}$

(12) 5 cc. “ $\quad$ “ +10 cc. $\mathrm{H}_{2} \mathrm{O}$ (control)
Remarks.

Turbid, liquid

Turbid, liquid

Turbid, liquid

Beginning dehydration

Increasing dehydration with decrease in amount of soap gel and increase in collar of dehydrated soap

Increasing dehydration with decrease in amount of soap gel and increase in collar of dehydrated soap

Increasing dehydration with decrease in amount of soap gel and increase in collar of dehydrated soap

Increasing dehydration with decrease in amount of soap gel and increase in collar of dehydrated soap

Increasing dehydration with decrease in amount of soap gel and increase in collar of dehydrated soap

Increasing dehydration with decrease in amount of soap gel and increase in collar of dehydrated soap

Increasing dehydration with decrease in amount of soap gel and increase in collar of dehydration soap

Mobile liquid 
TABLE XXXVIII

Potassium Oleate-Polassium Acetate

\begin{tabular}{|c|c|c|c|c|c|c|c|}
\hline \multicolumn{7}{|c|}{ Concentration of mixture. } & Remsiks. \\
\hline (1) & 5 cc. p & tassi & leat & e $+9 \mathrm{cc}$ & $\mathrm{H}_{2} \mathrm{O}+1$ cc. $\mathrm{m} \mathrm{I}$ & $\mathrm{KC}_{2} \mathrm{H}_{2} \mathrm{O}_{2}$ & Mobile liquid \\
\hline (2) & 5 ce. & “ & $\because$ & $+8 \mathrm{cc}$ & $\cdots+2$ cc. $\cdots$ & $\because$ & Mobile liquid \\
\hline (3) & 5 cc. & “ & $\because$ & $+7 \mathrm{cc}$ & $"+3$ ce. $"$ & “. & Viscid, slightly turbid \\
\hline (4) & 5 cc. & $\because$ & $\because$ & $+6 \mathrm{cc}$. & $\cdots+4 \mathrm{cc} . \cdot$ & $\because$ & More viscid and turbid \\
\hline (5) & 5 cc. & “ & $\because$ & $+5 \mathrm{cc}$ & $"+5$ cc. $"$ & “. & Soft, turbid gel \\
\hline (6) & 5 cc. & $\cdots$ & “ & $+4 \mathrm{cc}$ & $\cdots+6$ cc. $"$ & “ & Beginning dehydration \\
\hline (7) & $5 \mathrm{cc}$ & “ & $\because$ & +3 cc. & $"+7$ cc. $"$ & “ & $\begin{array}{l}\text { Increasing dehydration with sep- } \\
\text { aration of white soap }\end{array}$ \\
\hline (8) & $5 \mathrm{cc}$ & “ & $\because$ & +2 cc. & $\cdots+8$ cc. $"$ & $\because$ & $\begin{array}{l}\text { Increasing dehydration with sep- } \\
\text { aration of white soap }\end{array}$ \\
\hline (9) & $5 \mathrm{cc}$ & “ & $\cdots$ & $+1 \mathrm{cc}$ & " +9 ce. $"$ & $\because$ & $\begin{array}{l}\text { Increasing dehydration with sep- } \\
\text { aration of white soap }\end{array}$ \\
\hline (10) & 5 cc. & “ & $\because$ & $+10 \mathrm{cc}$ & c. $\mathrm{m} \mathrm{KC}_{2} \mathrm{H}_{3} \mathrm{O}_{2}$ & & $\begin{array}{l}\text { Increasing dehydration with sep- } \\
\text { arstion of white soap }\end{array}$ \\
\hline (11) & 5 ce. & $\because$ & $\because$ & $+10 \mathrm{cc}$ & c. $\mathrm{H}: \mathrm{O}$ (control) & & Mobile liquid \\
\hline
\end{tabular}

TABLE XXXIX

Potassium Oleate-Dipotassium Sulphate

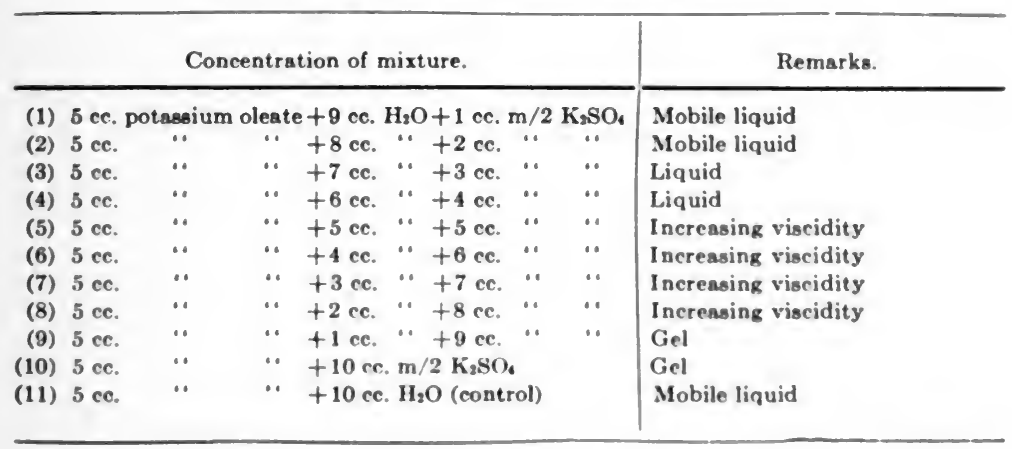


TABLE XL

Potassiom Oleat -Dipotassium Tartrate

\begin{tabular}{|c|c|c|c|c|c|c|}
\hline \multicolumn{6}{|c|}{ Concentration of mixture. } & \multirow{2}{*}{$\frac{\text { Remarks. }}{\text { Mobile liquid }}$} \\
\hline (1) & $5 \mathrm{cc}$. & tassi & leate +9 cc. & $\mathrm{H}_{2} \mathrm{O}+1$ cc. $\mathrm{m} \mathrm{K}$ & $\mathrm{C}_{4} \mathrm{H}_{4} \mathrm{O}_{6}$ & \\
\hline (2) & $5 \mathrm{cc}$. & “ & $\cdots+8 \mathrm{cc}$ & $"+2$ cc. $"$ & $\cdots$ & Liquid \\
\hline (3) & $5 \mathrm{cc}$. & “ & $\cdots \quad+7 \mathrm{cc}$. & $\cdots+3$ cc. $\cdots$ & $\cdots$ & Viscid liquid \\
\hline (4) & 5 cc. & *. & $\cdots \quad+6 \mathrm{cc}$ & $"+4$ cc. $"$ & “. & Gel \\
\hline (5) & $5 \mathrm{cc}$. & “. & “ +5 ce. & " +5 ce. $" \cdot$ & “ & Stiffest gel \\
\hline (6) & $5 \mathrm{cc}$ & “. & “ +4 cc. & $\cdots+6$ cc. $"$ & “. & Gel \\
\hline (7) & $5 \mathrm{cc}$ & “. & $\because+3$ cc. & $\cdots+7$ cc. $\cdots$ & “ & Gel \\
\hline (8) & $5 \mathrm{cc}$. & ." & $\cdots \quad+2$ rc. & $\cdots+8$ cc. $"$ & “ & Viscid liquid \\
\hline (9) & $5 \mathrm{cc}$. & “ & “ +1 cc. & $"+9$ cc. $"$ & “‘ & Liquid \\
\hline (10) & 5 cc. & “ & “ $+10 \mathrm{cc}$. & $\mathrm{m} \mathrm{K}_{2} \mathrm{C}_{4} \mathrm{H}_{4} \mathrm{O}_{6}$ & & Liquid \\
\hline (11) & $5 \mathrm{cc}$ & $“$ & “ $+10 \mathrm{cc}$. & $\mathrm{H}_{2} \mathrm{O}$ (control) & & Mobile liquid \\
\hline
\end{tabular}

\section{TABLE XLI}

Potassium Oleate-Dipotassium Phosphate

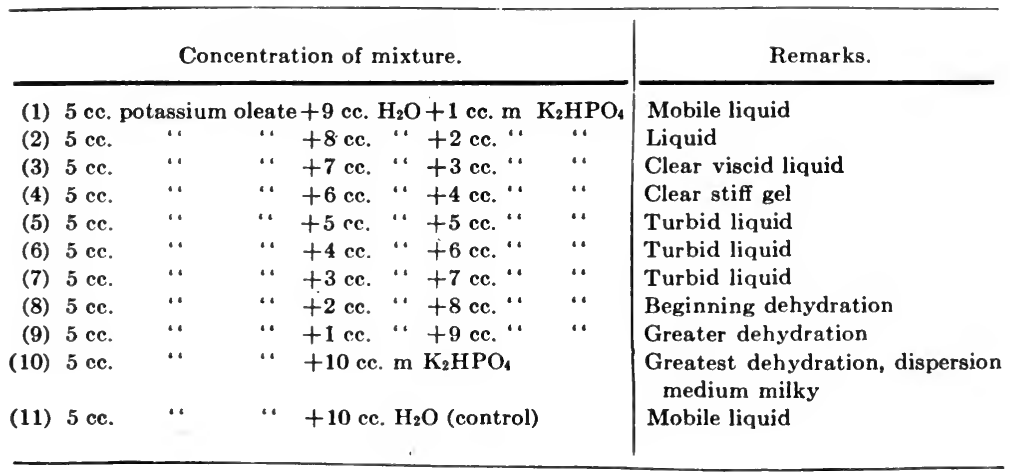

TABLE XLII

Potassium Oleate-Tripotassium Citrate

\begin{tabular}{|c|c|c|c|c|c|c|c|}
\hline \multicolumn{7}{|c|}{ Concentration of mixture. } & \multirow{3}{*}{$\begin{array}{l}\text { Remarks. } \\
\begin{array}{l}\text { Mobile liquid } \\
\text { Liquid }\end{array}\end{array}$} \\
\hline (1) & 5 cc. & asic & eate & +9 cc. & $\mathrm{H}_{2} \mathrm{O}+1$ cc. $\mathrm{m}$ & $\mathrm{K}_{3} \mathrm{C}_{6} \mathrm{H}_{5} \mathrm{O}_{7}$ & \\
\hline (2) & 5 cc. & “ & “ & +8 cc. & “+2 cc. $"$ & “‘ & \\
\hline (3) & $5 \mathrm{cc}$. & “‘ & “ & $+7 \mathrm{cc}$ & $"+3$ cc. $"$ & “. & Clear gel \\
\hline (4) & $5 \mathrm{cc}$. & “ & “ & $+6 \mathrm{cc}$ & $"+4$ cc. $"$ & “. & Clear viscid liquid \\
\hline (5) & 5 ce. & “ & “ & +5 cc. & $"+5$ cc. $\cdots$ & $\because$ & Clear liquid \\
\hline (6) & $5 \mathrm{cc}$. & “. & “ & $+4 \mathrm{cc}$ & $"+6 \mathrm{cc} . "$ & “. & Turbid liquid \\
\hline (7) & $5 \mathrm{cc}$. & ‘ & “. & +3 cc. & $\cdots+7$ cc.. & ‘ & Beginning dehydration \\
\hline (8) & $5 \mathrm{cc}$. & “. & “ & $+2 c c$ & $"+8$ cc. $"$ & “. & Great dehydration \\
\hline (9) & 5 cc. & “. & “. & $+1 \mathrm{cc}$ & $"+9$ cс." & “ & Great dehydration \\
\hline (10) & $5 \mathrm{cc}$. & “. & “. & $+10 \mathrm{cc}$. & $\mathrm{m} \mathrm{K}_{3} \mathrm{C}_{6} \mathrm{H}_{2} \mathrm{O}_{7}$ & & Great dehydration \\
\hline (11) & $5 \mathrm{cc}$. & “. & “ & $+10 \mathrm{cc}$. & $\mathrm{H}_{2} \mathrm{O}$ & & Mobile liquid \\
\hline
\end{tabular}


TABLE XLIII

Potassium Oleate-Potassium Hydroxid + Potassium Chlorid

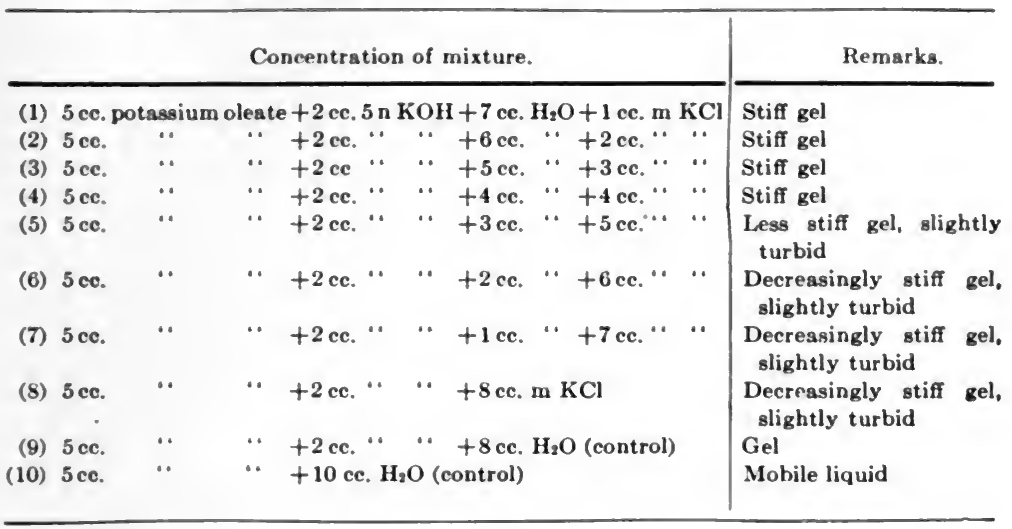

TABLE XLIV

Potassium Oleate-Potassium Hydroxid+Polassium Chlorid

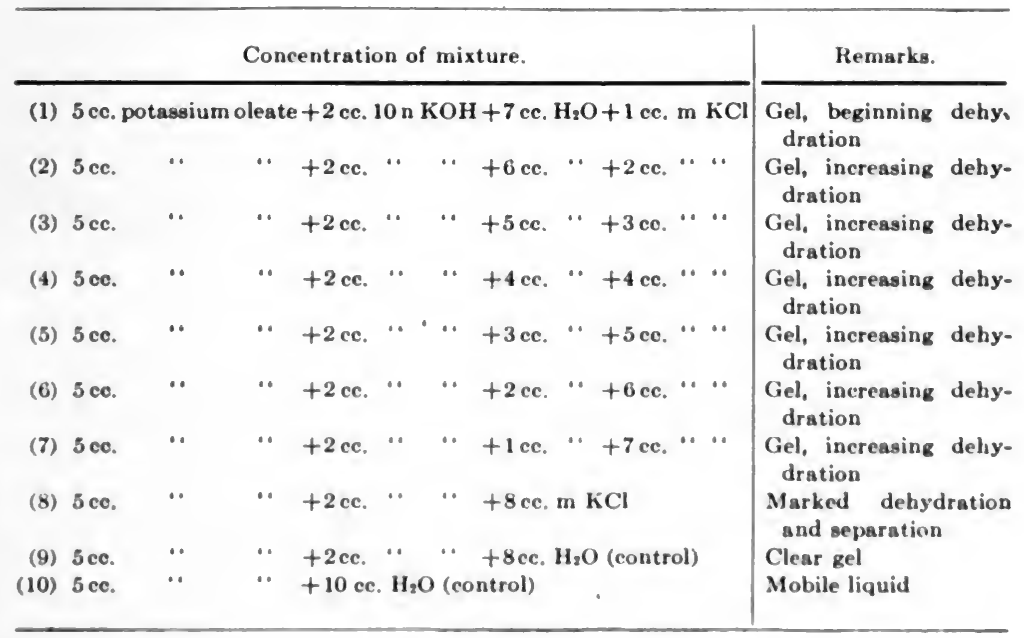


TABLE XLV

Potassium Olente-Polassium Chlorid+Potassium Hydroxid

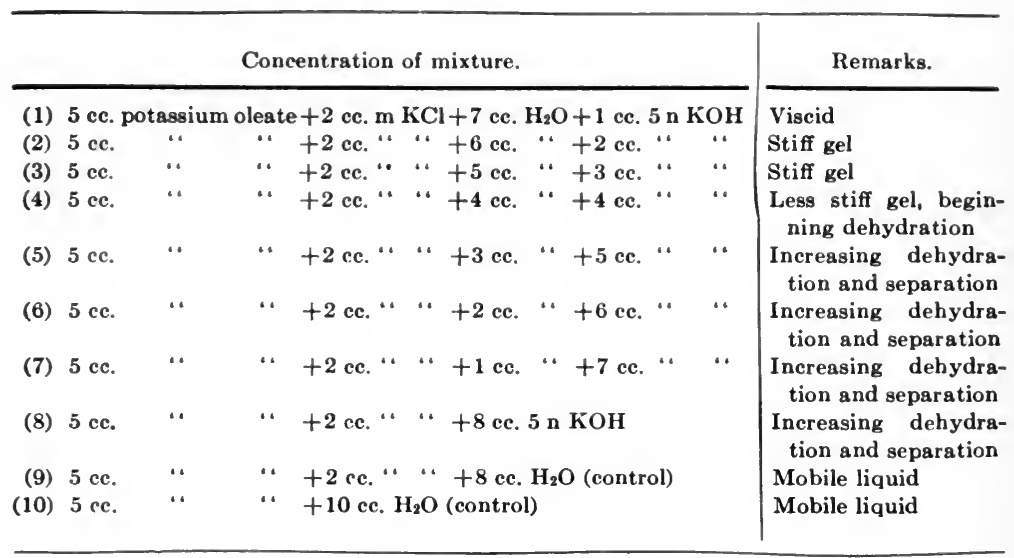

TABLE XLVI

Potassium Oleate-Potassium Hydroxid+Sodium Chlorid

\begin{tabular}{|c|c|c|c|c|c|c|c|c|c|}
\hline \multicolumn{9}{|c|}{ Concentration of mixture. } & \multirow{2}{*}{$\begin{array}{l}\text { Remarks. } \\
\text { gel }\end{array}$} \\
\hline (1) & 5 cc. 1 & assi & leat & +2 cc. $5 n$ & KOH & $\mathrm{H}+7$ cc. & $\mathrm{H}_{2} \mathrm{O}+1$ cc. $\mathrm{m} \mathrm{N}$ & $\mathrm{NaCl}$ & \\
\hline (2) & $5 \mathrm{cc}$. & .. & “. & +2 cc. " & “. & $+6 \mathrm{cc}$ & $\cdots+2$ cc. $"$ & “ & $\begin{array}{l}\text { Stiff gel, slight tur- } \\
\text { bidity }\end{array}$ \\
\hline (3) & $5 \mathrm{cc}$. & ‘ & “ & +2 cc. $"$ & “. & $+5 \mathrm{cc}$ & $"+3$ cc. $"$ & “ & $\begin{array}{l}\text { Stiff gel, slight tur- } \\
\text { bidity }\end{array}$ \\
\hline (4) & 5 cc. & “. & “‘ & +2 cc. $"$ & $\because$ & $+4 \mathrm{cc}$. & “ +4 cc. $"$ & “ & $\begin{array}{l}\text { Stiff gel, slight tur- } \\
\text { bidity }\end{array}$ \\
\hline (5) & $5 \mathrm{cc}$. & 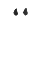 & “ & +2 cc. " & “. & +3 cc. & “ +5 cc. $"$ & “. & $\begin{array}{l}\text { Stiff, gel slight tur- } \\
\text { bidity }\end{array}$ \\
\hline (6) & 5 cc. & •. & “. & +2 cc. “ & “. & +2 cc. & $"+6$ cc. $"$ & “ & $\begin{array}{l}\text { Gel with beginning } \\
\text { dehydration and } \\
\text { separation }\end{array}$ \\
\hline (7) & $5 \mathrm{cc}$ & ‘. & “‘ & +2 cc. $"$ & 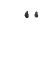 & +1 cc. & “ +7 cc. $"$ & “. & $\begin{array}{l}\text { Great dehydration } \\
\text { and separation }\end{array}$ \\
\hline$(8)$ & 5 cc. & “. & “ & +2 cc. “ & “. & $+8 \mathrm{cc}$ & $\mathrm{m} \mathrm{NaCl}$ & & $\begin{array}{l}\text { Great dehydration } \\
\text { and separation }\end{array}$ \\
\hline (9) & $5 \mathrm{cc}$. & “ & “ & +2 cc. ${ }^{\prime}$ & “ & $+8 \mathrm{cc}$ & $\mathrm{H}_{2} \mathrm{O}$ (control) & & Viscid \\
\hline (10) & $5 \mathrm{cc}$. & “. & “. & +10 cc. $\mathrm{H}$ & $\mathrm{I}_{2} \mathrm{O}(\mathrm{c}$ & control) & & & Mobile liquid \\
\hline
\end{tabular}


TABLE XLVII

Potassium Oleate-Sodium Chlorid + Polassium Hydroxid

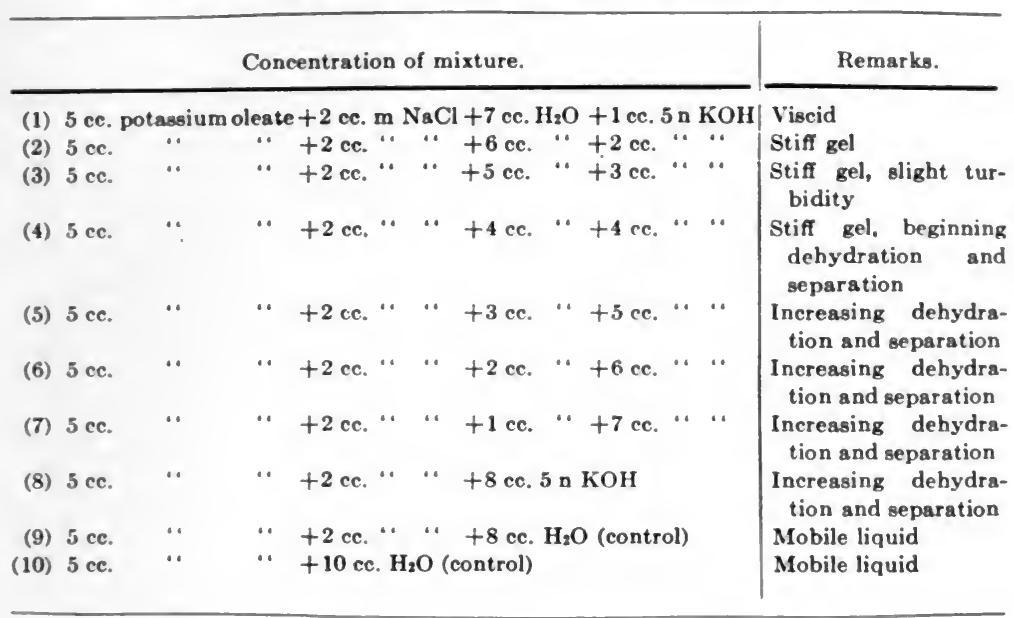

TABLE XLVIII

Potassium Oleate-Potassium Chlorid

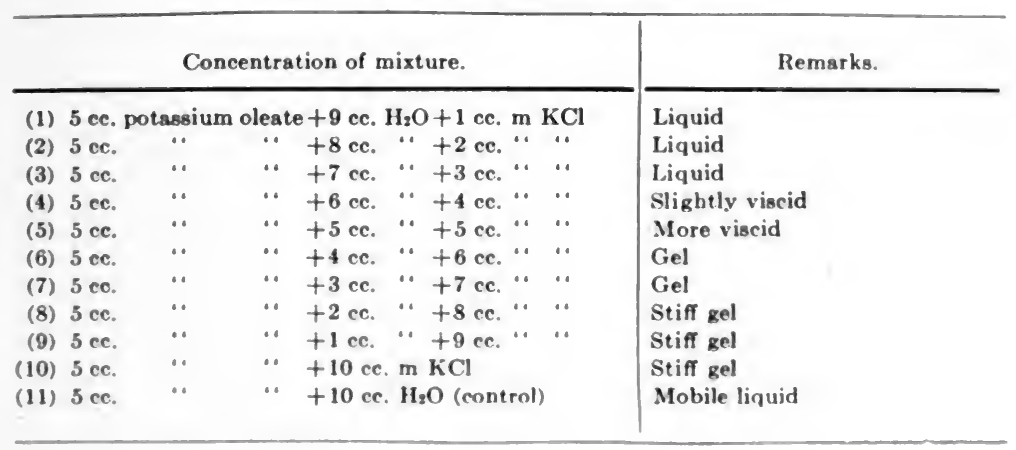


TABLE XLIX

Potassium Oleate-Sodium Chlorid

\begin{tabular}{|c|c|c|c|c|c|c|}
\hline \multicolumn{6}{|c|}{ Concentration of mixture. } & Remarks. \\
\hline (1) & $5 \mathrm{cc}$. & assi & leate $+9 \mathrm{cc}$ & $\mathrm{H}_{2} \mathrm{O}+1$ cc. $\mathrm{m}$ & $\mathrm{NaCl}$ & Liquid \\
\hline (2) & $5 \mathrm{cc}$. & “. & “ $+8 \mathrm{cc}$. & $"+2$ cc. $"$ & “ & Liquid \\
\hline (3) & 5 cc. & “. & . $+7 \mathrm{cc}$. & “ +3 cc. $"$ & “ & Slightly viscid \\
\hline (4) & $5 \mathrm{cc}$. & “. & “ $+6 \mathrm{cc}$. & “+4 cc. $"$ & “ & Gel \\
\hline (5) & 5 cc. & .. & “ $\quad+5 \mathrm{cc}$. & $\cdots+5$ cc. $\cdots$ & “. & Gel \\
\hline (6) & 5 cc. & *. & “ $+4 \mathrm{cc}$. & $"+6$ cc. $"$ & •. & Gel \\
\hline (7) & 5 cc. & “. & " +3 cc. & “ +7 cc. $"$ & “. & Less viscid gel \\
\hline (8) & $5 \mathrm{cc}$. & “. & $\because \quad+2$ cc. & $"+8 \mathrm{cc} . "$ & “. & $\begin{array}{l}\text { Beginning dehydration and sepa- } \\
\text { ration }\end{array}$ \\
\hline (9) & $5 \mathrm{cc}$. & “. & $\because \quad+1 \mathrm{cc}$. & “+9 cc. $"$ & “. & $\begin{array}{l}\text { Increased dehydration and sepa- } \\
\text { ration }\end{array}$ \\
\hline (10) & $5 \mathrm{cc}$. & “. & " $+10 \mathrm{cc}$ & $\mathrm{m} \mathrm{NaCl}$ & & $\begin{array}{l}\text { Increased dehydration and sepa- } \\
\text { ration }\end{array}$ \\
\hline (11) & 5 cc. & “. & “ $+10 \mathrm{cc}$ & $\mathrm{H}_{2} \mathrm{O}$ (control & & Mobile liquid \\
\hline
\end{tabular}

TABLE L

\section{Potassium Oleate-Ammonium Chlorid}

Concentration of mixture.

(1) 5 cc. potassium oleate +9 cc. $\mathrm{H}_{2} \mathrm{O}+1$ cc. $m$ NH4

(2) 5 cc. " " $"+8$ cc. " +2 cc. " "

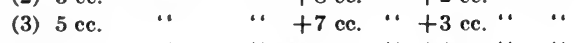

(4) 5 cc. " $"+6 \mathrm{cc}$. " +4 cc. " "

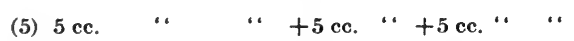

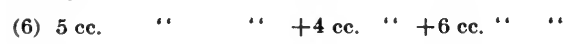

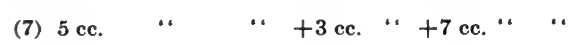

(8) 5 cc. $\quad$ “ $\quad+2$ cc. $~ "+8$ cc. “ ”

(9) 5 cc. " " +1 cc. “ +9 cc. “ "

(10) 5 cc. " $\quad$ “ +10 cc. $\mathrm{m} \mathrm{NH}_{4} \mathrm{Cl}$

(11) 5 cc. . $\quad+10$ cc. $\mathrm{H}_{2} \mathrm{O}$ (control)
Remarks.

Mobile, slightly turbid liquid Mobile, slightly turbid liquid Mobile, slightly turbid liquid Mobile, slightly turbid liquid with progressively thicker collar Mobile, slightly turbid liquid with progressively thicker collar

Mobile, slightly turbid liquid with progressively thicker collar

Mobile, slightly turbid liquid with progressively thicker collar

Mobile, slightly turbid liquid with progressively thicker collar

White mobile liquid

White mobile liquid

Mobile liquid 
TABLE LI

Potassium Olente-Magnesium Chlorid

Concentration of mixture.

(1) 5 cc. potasium oleate +9 cc. $\mathrm{H}_{2} \mathrm{O}+1$ cc. $\mathrm{m} / 100 \mathrm{MgCl}$

(2) $5 \mathrm{cc}$

(3) $5 \mathrm{cc}$

(4) $5 \mathrm{cc}$.

(5) 5 ce.

(6) $5 \mathrm{cc}$

(7) $5 \mathrm{cc}$.

(8) $5 \mathrm{cc}$
-

.

.

..

$\cdots$

$\cdots$

. $\cdots+8$ ce, $\cdots+2$ cc. $\cdots$.

$\cdots+5$ ce. $\cdots+5$ ce.

* +10 ce. $\mathrm{m} / 100 \mathrm{MgCl}$

$\cdots+8$ ce. $\mathrm{H}_{2} \mathrm{O}+2$ ce. $\mathrm{m} / 10 \mathrm{MgCl}_{2}$

+5 ce. $\cdots+5$ ce

- +10 cc. $\mathrm{m} / 10 \mathrm{MgCl}_{2}$

- +10 ce. $\mathrm{H}_{2} \mathrm{O}$ (control)
Remarks.

Mobile transparent liquid Slightly cloudy

Mobile milky liquid

Mobile milky liquid

Mobile milky liquid

Thick milky liquid

Thick milky liquid

Mobile liquid

TABLE LII

\section{Potassium Oleate-Calcium Chlorid}

\section{Concentration of mixture}

(1) 5 cc. potassium oleate +9 cc. $\mathrm{H}_{2} \mathrm{O}+1$ cc. $\mathrm{m} / 100 \mathrm{CaCl}_{2}$

(2) $5 \mathrm{cc}$.

(3) $5 \mathrm{cc}$.

(4) $5 \mathrm{cc}$.

$\cdots$

(5) 5 ce.

$$
\cdots
$$

(6) $5 \mathrm{cc}$.

(7) $5 \mathrm{cc}$.

..

(8) $5 \mathrm{cc}$.
. $+8 \mathrm{cc}$.

$\cdots+2$ ce

$\cdots+5$ cc. $\cdots+5$ ce.

- +10 ce. $\mathrm{m} / 100 \mathrm{CaCl}_{2}$

$\cdots+8$ cc. $\mathrm{H}_{2} \mathrm{O}+2$ cc. $\mathrm{m} / 10 \mathrm{CaCl}_{2}$

$\cdots+5$ ce. $\cdots+5$ ce.

.. +10 cc. $\mathrm{m} / 10 \mathrm{CaCl}_{2}$

- +10 ce. $\mathrm{H}_{2} \mathrm{O}$ (control)

\section{Remarks.}

More liquid than control Some white precipitate

Increasing amount of white precipitate

Increasing amount of white precipitate

Increasing amount of white precipitate

Milky white

Fluid as water

Mobile liquid 
TABLE LIII

Potassium Oleate-Cupric Chlorid

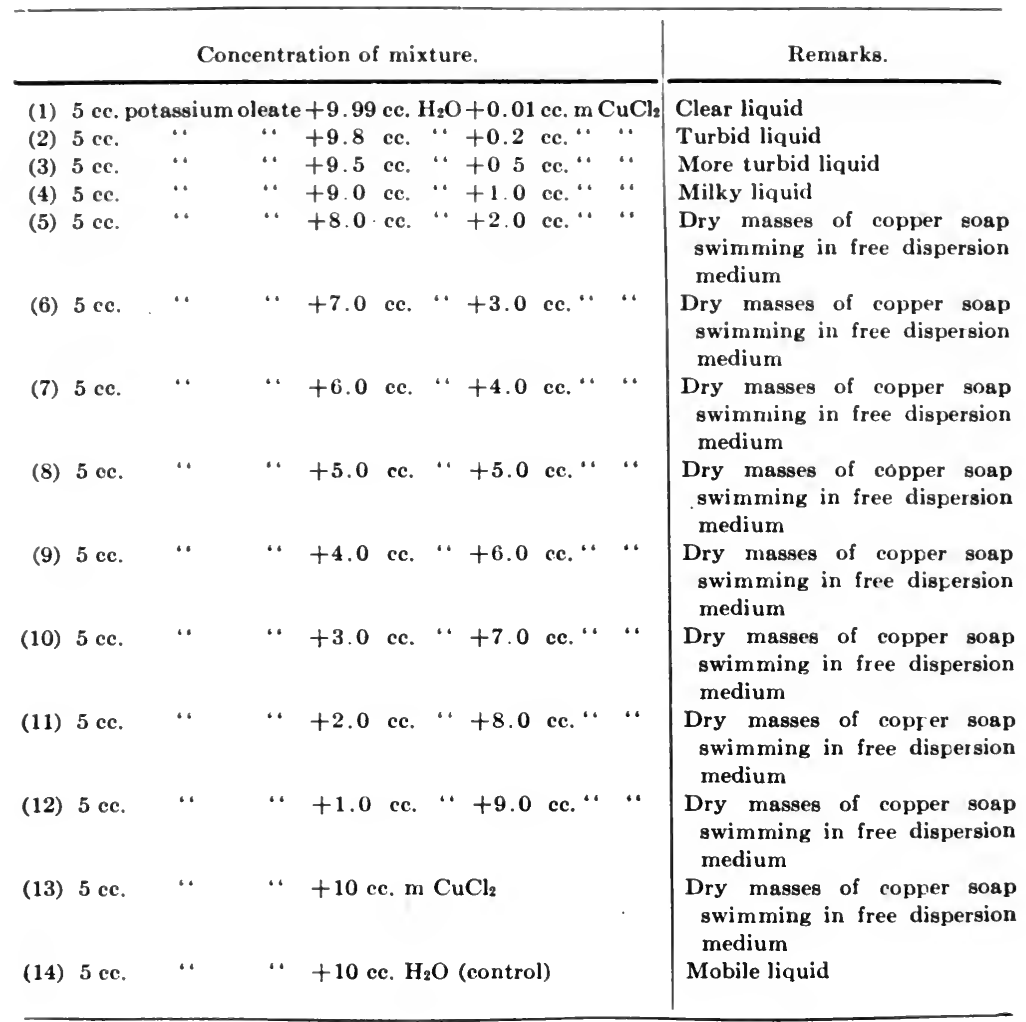


TABLE ILIV

Potassium Oleate-Ferric Chlorid

\begin{tabular}{|c|c|c|c|c|c|c|c|c|c|}
\hline \multicolumn{9}{|c|}{ Concentration of mixture. } & Remarks. \\
\hline (1) & 5 cc. 1 & assi & leat & +9 cc. & $\mathrm{H}_{2} \mathrm{O}$ & +1 cc. $m$ & $n / 10 x$ & $0 \mathrm{FeCl}_{3}$ & Turbid liquid. \\
\hline (2) & $5 \mathrm{cc}$. & $\cdots$ & $\cdots$ & $+8 \mathrm{ec}$ & “. & $+2 \mathrm{cc}$ & $\cdots$ & $\cdots$ & $\begin{array}{l}\text { Increasingly turbid liquid, sus- } \\
\text { pended particles of increasing } \\
\text { size }\end{array}$ \\
\hline (3) & 5 cc. & $\cdots$ & • & +5 cc. & * & $+5 \mathrm{cc}$ & * & $\cdots$ & $\begin{array}{l}\text { Increasingly turbid liquid, sus- } \\
\text { pended particles of increasing } \\
\text { size }\end{array}$ \\
\hline$(4)$ & 5 ec. & $\cdots$ & * & $+9 c c$. & “ & +1 ce. $n$ & $\mathrm{~m} / 10$ & $\mathrm{FeCl}_{3}$ & $\begin{array}{l}\text { Inereasingly turbid liquid, sus- } \\
\text { pended particles of increasing } \\
\text { size }\end{array}$ \\
\hline$\cdot(5)$ & $5 \mathrm{ce}$ & . & 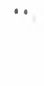 & +8 cc. & . & $+2 \mathrm{cc}$ & * & * & $\begin{array}{l}\text { Increasingly turbid liquid, sus- } \\
\text { pended particles of increasing } \\
\text { size }\end{array}$ \\
\hline (6) & 5 ce. & $\because$ & • & $+5 \mathrm{cc}$ & 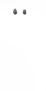 & $+5 \mathrm{cc}$ & $\cdots$ & • & $\begin{array}{l}\text { Increasingly turbid liquid, sus- } \\
\text { pended particles of increasing } \\
\text { size }\end{array}$ \\
\hline (7) & 5 cc. & “. & $\cdots$ & $+9 \mathrm{cc}$ & $\cdots$ & $+1 \mathrm{cc}$ & $\mathbf{m}$ & $\mathrm{FeCl}_{2}$ & $\begin{array}{l}\text { Reddish cosgulum of iron soap } \\
\text { floating in freed dispersion } \\
\text { medium }\end{array}$ \\
\hline (8) & 5 cc. & .' & * & $+8 \mathrm{cc}$ & “ & $+2 c c$. & “ & $\because$ & $\begin{array}{l}\text { Reddish congulum of iron sosp } \\
\text { floating in freed dispersion } \\
\text { medium }\end{array}$ \\
\hline (9) & $5 \mathrm{cc}$. & $\because$ & * & $+7 \mathrm{cc}$ & $\cdots$ & $+3 \mathrm{cc}$ & $\because$ & $\cdots$ & $\begin{array}{l}\text { Reddish coagulum of iron soap } \\
\text { floating in freed dispersion } \\
\text { medium }\end{array}$ \\
\hline (10) & 5 cc. & $\cdots$ & “ & $+2 \mathrm{cc}$ & • & $+8 \mathrm{cc}$ & “. & $\cdots$ & $\begin{array}{l}\text { Reddish cosaulum of iron soap } \\
\text { flosting in freed dispersion } \\
\text { medium }\end{array}$ \\
\hline (11) & 5 cc. & $\because$ & .. & $+10 \mathrm{cc}$ & $\mathrm{H}_{2} \mathrm{C}$ & $O$ (contro & ol) & & Mobile liquid \\
\hline
\end{tabular}


TABLE

Gelation and Salting-out of Various Fatty

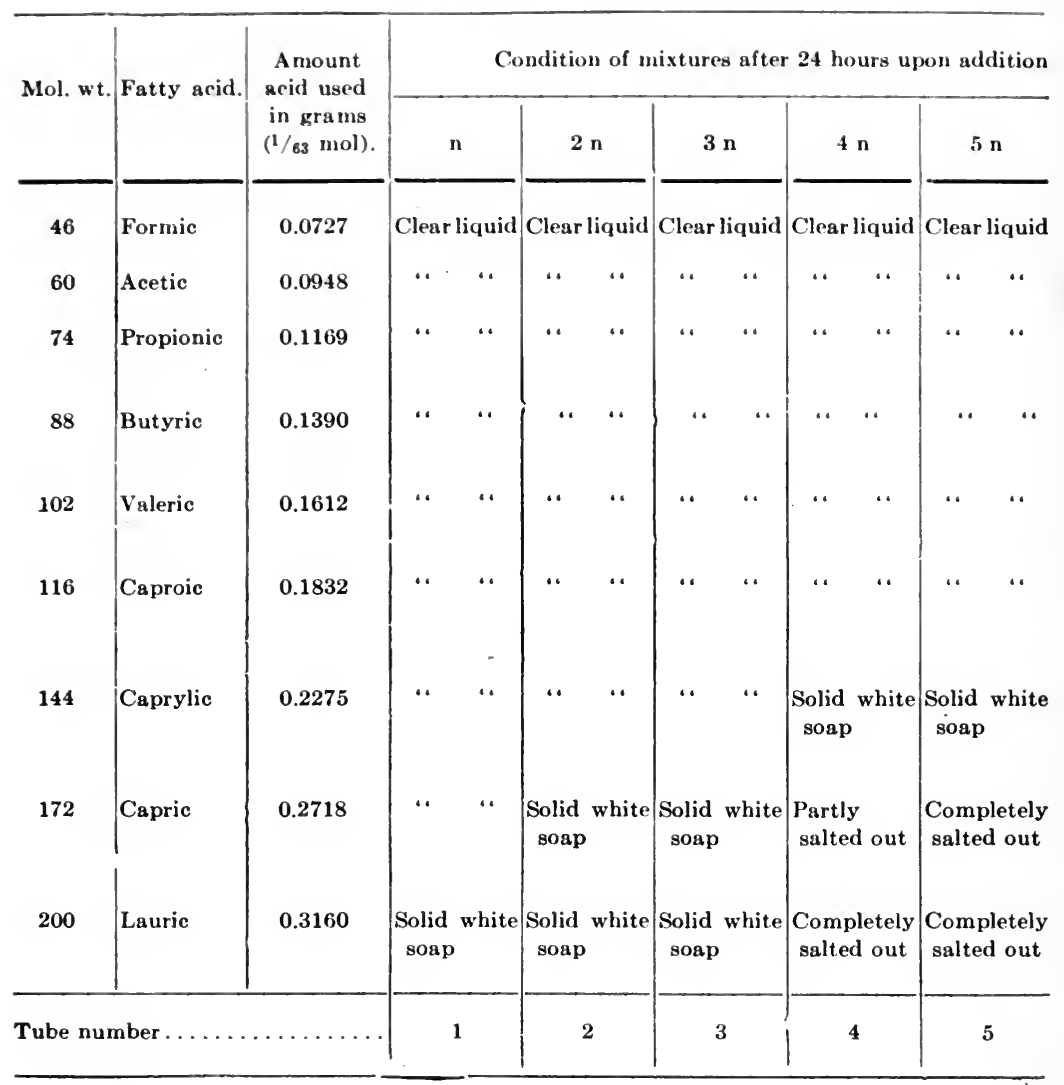


LV

Acid-Alkali Mixtures of the Acetic Series

at $20^{\circ} \mathrm{C}$. of $5 \mathrm{ce}$. sodium hydroxid of the following concentrations:

\begin{tabular}{|c|c|c|c|c|c|c|c|}
\hline $6 n$ & $7 n$ & $8 \mathrm{n}$ & $9 \mathrm{n}$ & $10 \mathrm{n}$ & $11 \mathrm{n}$ & $12 \mathrm{n}$ & $\mathrm{H}_{2} \mathrm{O}$ \\
\hline Clear liquid & Clear liquid & Clear liquid & Clear liquid & Clear liquid & Clear liquid & Clear liquid & Clear liquid \\
\hline . & ‘. & ‘ & . & . & ‘ & .. & .. \\
\hline . & .. & .. & . & $\begin{array}{l}\text { Slight salt- } \\
\text { ing out }\end{array}$ & $\begin{array}{l}\text { Completely } \\
\text { salted out }\end{array}$ & $\begin{array}{l}\text { Completely } \\
\text { salted out }\end{array}$ & $\cdots$ \\
\hline$\cdots$ & • $\quad$. & . $\quad \cdots$ & $\begin{array}{l}\text { Viscid white } \\
\text { soap }\end{array}$ & $\begin{array}{l}\text { Slight salt- } \\
\text { ing out }\end{array}$ & $\begin{array}{l}\text { Completely } \\
\text { salted out }\end{array}$ & $\begin{array}{l}\text { Completely } \\
\text { salted out }\end{array}$ & ‘. \\
\hline$\bullet$ & $\begin{array}{l}\text { Viscid white } \\
\text { soap }\end{array}$ & $\begin{array}{l}\text { Partly } \\
\text { salted out }\end{array}$ & $\begin{array}{l}\text { Completely } \\
\text { salted out }\end{array}$ & $\begin{array}{l}\text { Completely } \\
\text { salted out }\end{array}$ & $\begin{array}{l}\text { Completely } \\
\text { salted out }\end{array}$ & $\begin{array}{l}\text { Completely } \\
\text { salted out }\end{array}$ & \\
\hline $\begin{array}{l}\text { Viscid white } \\
\text { soap }\end{array}$ & $\begin{array}{l}\text { Viscid white } \\
\text { soap }\end{array}$ & $\begin{array}{l}\text { Viscid white } \\
\text { soap }\end{array}$ & $\begin{array}{l}\text { Solid white } \\
\text { soap }\end{array}$ & $\begin{array}{l}\text { Solid white } \\
\text { soap }\end{array}$ & $\begin{array}{l}\text { Solid white } \\
\text { soap }\end{array}$ & $\begin{array}{l}\text { Completely } \\
\text { salted out }\end{array}$ & $\begin{array}{l}\text { Acid float- } \\
\text { ing on } \\
\text { water }\end{array}$ \\
\hline $\begin{array}{l}\text { Solid white } \\
\text { soap }\end{array}$ & $\begin{array}{l}\text { Solid white } \\
\text { soap }\end{array}$ & $\begin{array}{l}\text { Partly } \\
\text { salted out }\end{array}$ & $\begin{array}{l}\text { Completely } \\
\text { salted out }\end{array}$ & $\begin{array}{l}\text { Completely } \\
\text { salted out }\end{array}$ & $\begin{array}{l}\text { Completely } \\
\text { salted out }\end{array}$ & $\begin{array}{l}\text { Completely } \\
\text { salted out }\end{array}$ & $\begin{array}{l}\text { Acid float- } \\
\text { ing on } \\
\text { water }\end{array}$ \\
\hline $\begin{array}{l}\text { Completely } \\
\text { salted out }\end{array}$ & $\begin{array}{l}\text { Completely } \\
\text { salted out }\end{array}$ & $\begin{array}{l}\text { Completely } \\
\text { salted out }\end{array}$ & $\begin{array}{l}\text { Completely } \\
\text { salted out }\end{array}$ & $\begin{array}{l}\text { Completely } \\
\text { salted out }\end{array}$ & $\begin{array}{l}\text { Completely } \\
\text { salted out }\end{array}$ & $\begin{array}{l}\text { Completely } \\
\text { salted out }\end{array}$ & $\begin{array}{l}\text { Acid float- } \\
\text { ing on } \\
\text { water }\end{array}$ \\
\hline $\begin{array}{l}\text { Completely } \\
\text { salted out }\end{array}$ & $\begin{array}{l}\text { Completely } \\
\text { salted out }\end{array}$ & $\begin{array}{l}\text { Completely } \\
\text { salted out }\end{array}$ & $\begin{array}{l}\text { Completely } \\
\text { salted out }\end{array}$ & $\begin{array}{l}\text { Completely } \\
\text { salted out }\end{array}$ & $\begin{array}{l}\text { Completely } \\
\text { salted out }\end{array}$ & $\begin{array}{l}\text { Completely } \\
\text { salted out }\end{array}$ & $\begin{array}{l}\text { Acid float- } \\
\text { ing on } \\
\text { water }\end{array}$ \\
\hline 6 & 7 & 8 & 9 & 10 & 11 & 12 & Control \\
\hline
\end{tabular}




\section{XI}

\section{THE FOAMING, EMULSIFYING AND WASHING PROPERTIES OF SOAPS}

There is still much debate as to what is the property of soaps (and similarly acting compounds) which when added to water favors the production and maintenance of foams or emulsions. Without first entering upon a discussion of the theories which have been proposed, what do the colloid-chemical facts outlined in the preceding pages contribute toward a possible solution of the problem? In the several series of soaps described we have thus far correlated their chemical composition and that of the various "solvents" used with them, with various physicochemical properties of the resulting systems. What is the relationship between such a property of a soap as its hydration capacity and its ability to yield a foam; or what is the relationship between this hydration value and the production and maintenance of an emulsion? A proper answer to these questions may prove of help for the solution of that secondary technological problem which concerns the washing properties of soap, which, as now held by various authors, are intimately associated with its foaming and emulsifying qualities. The following paragraphs show that the foaming, emulsifying and washing properties of soaps are a function, in the main, of their hydrophilic colloid character. Only those soaps foam or emulsify which under the conditions of their use yield liquid and hydrated colloids.

\section{The Foaming Properties of Soaps}

We need to begin these paragraphs by a definition of what constitutes a foam. As ordinarily understood, it is a subdivision of a gas in a liquid. There exist also, however, what may be termed solid foams, namely, subdivisions of a gas in a solid, as in ordinary pumice, but since such solid foams were invariably produced when the now solid phase was liquid, these are really only a subclass of the liquid foams. When not otherwise specified we refer in these pages only to the liquid foams and the conditions surrounding their production and maintenance: 
It is of importance next to distinguish between the production of a foam and its maintenance after production. Authors who have written on this subject have rarely done so. Mere contact between a gas and a foaming agent does not produce a foam-the gas must be stirred, blown or mixed into it. When we speak off-hand of a foam-producing material we really mean something which will stabilize the foam once it is produced.

\section{$\S 1$}

In order to discover if any relationship existed between the colloid properties (or more particularly the hydration capacities) of different soaps and their foaming qualities we chose for first study the sodium soaps of the acetic acid series. To obtain comparable results, $10 \mathrm{cc}$. of equimolar "solutions" of the different soaps were placed in tall test-tubes $(30 \mathrm{~cm} . \times 2 \mathrm{~cm}$.) and shaken. In order that all might be treated equally from the point of view of foam production, all the tubes were clamped in a frame, the shaking being continued for thirty seconds. For reasons which will become clear later, the temperature is an important factor and must be watched carefully. Moreover, since the systems resulting at any fixed temperature when soap/water mixtures are brought to the desired temperature from a higher point differ ${ }^{1}$ from those which result when they are brought to such temperature from a lower one, all the soap "solutions" about to be described were started at a low temperature and then brought to the higher ones. Tubes, water and soaps were therefore all first reduced to the lowest temperature used in these experiments, namely, $8^{\circ} \mathrm{C}$. After they had remained at this temperature for twenty-four hours the proper molar solutions were made by mixing the soaps with the water. After another period (twentyfour hours) of standing and careful mixture until (apparent) homogeneity had been attained, the tubes were shaken violently for thirty seconds to permit of the formation of foam. They were photographed after four minutes, then left to themselves for two hours, still in the thermostat, and photographed a second time. After this first series of observations, the tubes with their reaction mixtures were then warmed to the next higher temperature, namely, $26^{\circ} \mathrm{C}$. and kept at this for twenty-four hours. 
After shaking, photographing, allowing to rest and rephotographing, we repeated the whole process at $50^{\circ} \mathrm{C}$. and finally at $100^{\circ} \mathrm{C}$.

The results obtained in the case of the sodium soaps of the acetic acid series at the concentration $2 \mathrm{~m}$. are shown in the photographs of Figs. 77 and 78 . This was really an attempt to discover where in the series and at what concentration foaming will begin. At $8^{\circ} \mathrm{C}$. (the lowermost row of tubes in Fig. 77) it is apparent that no foam is formed by the formate, acetate, propionate, butyrate or valerate of sodium. There is just a suggestion of a foam in the case of the caproate, but clear formation of such does not begin until the caprylate is reached. At this temperature soaps higher ${ }^{1}$ in the series fail to yield homogeneous mixtures ("solutions") with the water. The mixtures also do not foam. The absence of the tubes from the series in this and the subsequent photographs expresses this fact.

When the temperature is raised to $26^{\circ} \mathrm{C}$. the findings are much the same except that the caproate shows no signs of foaming and the caprylate less than at the lower temperature. At $50^{\circ}$ and $100^{\circ} \mathrm{C}$. the picture is largely repeated - the caprylate alone foams, though less than at the lower temperatures. Fig. 78, which

1 These higher soaps take up the water offered them but yield such viscid systems that they are practically solid. In consequence, air cannot be easily shaken or beaten into them. Just as in the case of the emulsions (see MartiN H. Fischer and Marian O. Hooker: Fats and Fatty Degeneration, 36, New York (1917)) the production of a foam is best accomplished when the soap is present in a medium concentration and when the resulting system is essentially a liquid hydrated colloid. At ordinary temperatures the soaps of the acetic series, especially the higher ones, are all more solid even in the presence of considerable water, than the soaps of the less saturated fatty acids. For this reason none of them is as good a foaming or emulsifying agent as an oleate, linolate or other liquid soap.

In general, the melting points of the soaps of the acetic series lie parallel to but above that of their fatty acids. All the fatty acids below caproic are liquid near $0^{\circ} \mathrm{C}$. or below. Caprylic acid is liquid at $16.5^{\circ}$; capric at $31.3^{\circ}$; lauric at $43.6^{\circ}$; myristic at $53.8^{\circ}$; palmitic at $62^{\circ}$; margaric at $60^{\circ}$; stearic at $69.3^{\circ}$; arachidic at $77^{\circ} \mathrm{C}$.

The lowermost soaps of the acetic series are "soluble" in water and yield liquid systems even at a low temperature. In the middle of the series and at ordinary temperatures the acetic series soaps yield liquid hydrated colloid systems with water, and are the best foam producers. Above this they yield highly viscid to solid hydrated systems and less favorable ones for foam production. Rise in temperature shifts the whole arrangement to the right, the lower soaps going into the region of the true solutions of soap in water and thus losing their foaming qualities while the higher ones move from the region of the hydrated solid colloids into that of the hydrated liquid ones. 


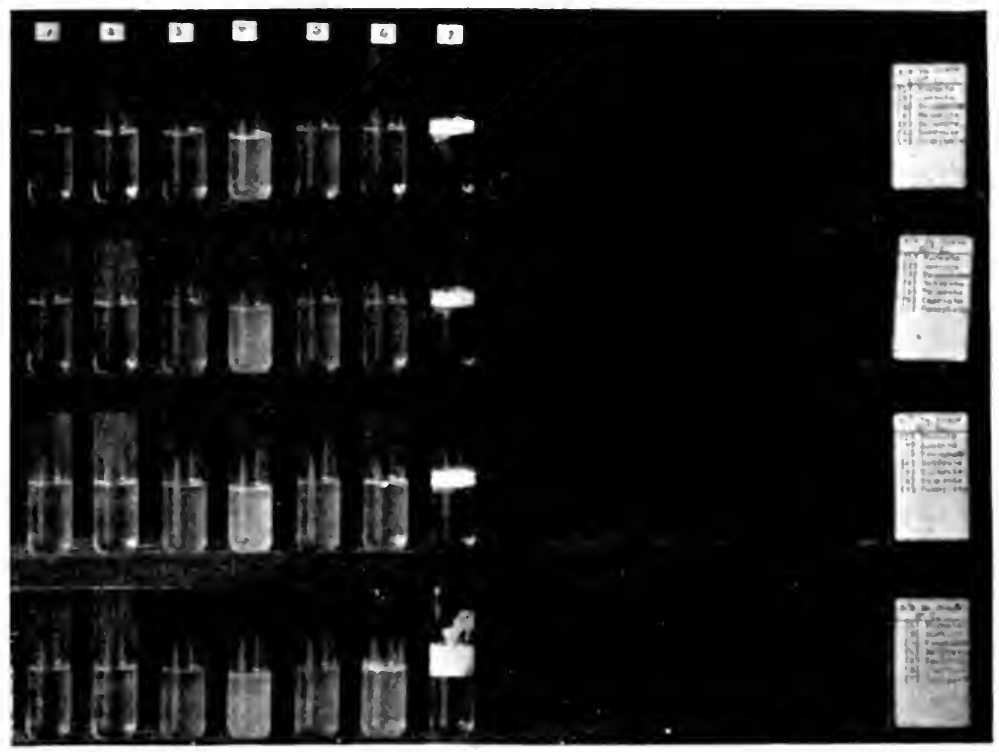

PIgURE 77.

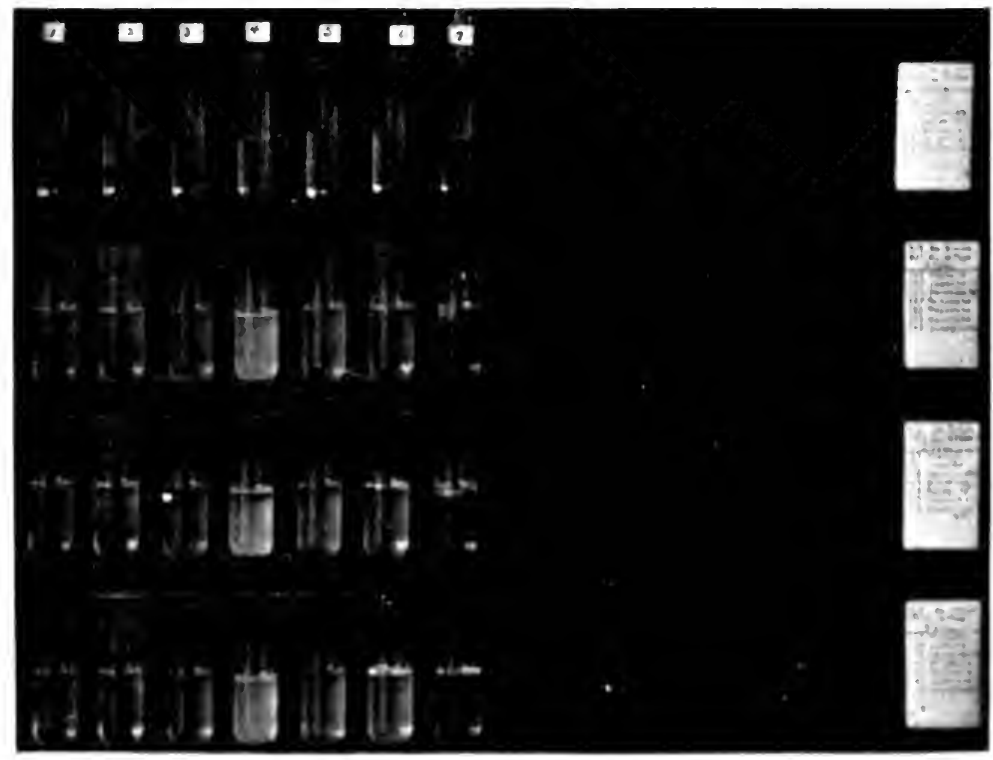

Pictere 78. 
shows the appearance of these tubes two hours later, indicates that the foams do not last. They die down fastest at the higher temperatures, the greatest permanency, in other words, being shown by the foams produced at the lower temperatures.

It is well to state at once what we hold to be the relationship between these findings and our previous considerations of the hydrophilic properties of these soaps. The lowermost soaps form only solutions in water, they show no hydrophilic properties, and they do not foam. Sodium caprylate, with its more distinct, even though still low, hydration capacity, yields the first satisfactory foam. It does this best, however, at a low temperature. At this it has its highest hydrophilic value. To raise the temperature of this soap/water system is to make the sodium caprylate go into true solution in the water, and as this happens the hydrophilic colloid properties of the system are diminished, and, similarly, the foaming properties. The higher soaps do not foam because not enough of them "goes into solution" to yield a (liquid) hydrated colloid system-the water, in other words, is either taken up to form an essentially solid mixture into which the air cannot be driven, or the soap is so "insoluble" that the water remains "free" and hence there is no lasting foam.

\section{$\S 2$}

It will be noticed that the first foaming qualities in these soaps developed in the experiment just described at the concentration $2 \mathrm{~m}$. If the experiment with these soaps is repeated at the concentration $\mathrm{m}$, the previously foaming soaps no longer foam while soaps higher in the series which did not foam now do so. The former of these truths is readily apparent if the vertical set of tubes marked 7 (the caprylate) in Fig. 77 is compared with the similarly numbered set of Fig. 79. To explain this finding we would say that in the lower concentration of sodium caprylate illustrated in Fig. 79 the soap is more nearly in " true " solution and that the hydrophilic properties of the system are diminished in proportion. But the next higher soap, namely, sodium caprate (the tubes 8 of Fig. 79) foam nicely. At $8^{\circ}$ the sodium caprate does not foam. Most foaming is obtained at $26^{\circ}$, with less at the two higher temperatures $50^{\circ}$ and $100^{\circ} \mathrm{C}$.

To explain these findings it must be recalled that at the tem- 
perature $8^{\circ} \mathrm{C}$. sodium caprate is still solid and remains essentially only mechanically subdivided in the water. When the temperature is raised to $26^{\circ} \mathrm{C}$. the "liquefaction" point of the soap in water is exceeded. In this region most of the soap is in the state of a (liquid) hydrophilic colloid, least in true solution, and the greatest foam production is in consequence manifest. At the two higher temperatures a shift in the soap/water system occurs in the direction of true solution of the soap in the water at the expense of the water in the soap fraction and hence the diminished tendency to foam.

Fig. 79 shows well how this general law is repeated as we ascend in the soap series. Sodium laurate fails to foam at the temperatures $8^{\circ}$ and $26^{\circ}$ C. At $50^{\circ}$ a decided foam appears as evidenced in the tubes marked 9 , the foaming being increased at $100^{\circ} \mathrm{C}$. Sodium myristate fails to foam at the three lower temperatures. At $100^{\circ} \mathrm{C}$, as shown in the tube marked 10 of the top row of Fig. 79, it foams beautifully. Not until the temperature lies above $50^{\circ}$ does the myristate yield a (liquid) hydrophilic colloid (and a foam). Even at this highest temperature sodium palmitate, as indicated in tube 11 of Fig. 79, foams only badly. The soap absorbs all the water offered, to yield a thick, gelatinous mass into which the air does not enter easily. The resulting foam is therefore practically a solid one.

Fig. 80 shows how the tubes just described look two hours later. It is easily observed that the foams die down most rapidly $(a)$ in the lower soaps and $(b)$ at the higher temperatures.

\section{$\S 3$}

Figs. 81 and 82 respectively show the foaming characteristics of the sodium soaps of the acetic series at the concentration $\mathrm{m} / 2$ immediately after the production of the foams and two hours later. It will be observed that at this concentration the caprate is the lowest member to yield a foam; the amount of foam produced in all the caprate tubes of this series (the vertical row marked 8) is distinctly less than in the corresponding set of tubes of Fig. 79. The laurate foams at this lower concent ration almost as well as at the higher concentration previously described. It is noteworthy, however, that in Fig. 79 (the concentration $\mathrm{m}$ ) the better foam is obtained at the temperature of $100^{\circ} \mathrm{C}$; in Fig. 
81 (the concentration $\mathrm{m} / 2$ ) at $50^{\circ} \mathrm{C}$. This is dependent, in our judgment, upon the more perfect solubility at the lower concentration of the laurate in the water, with diminution of its hydrophilic colloid properties as the temperature is raised.

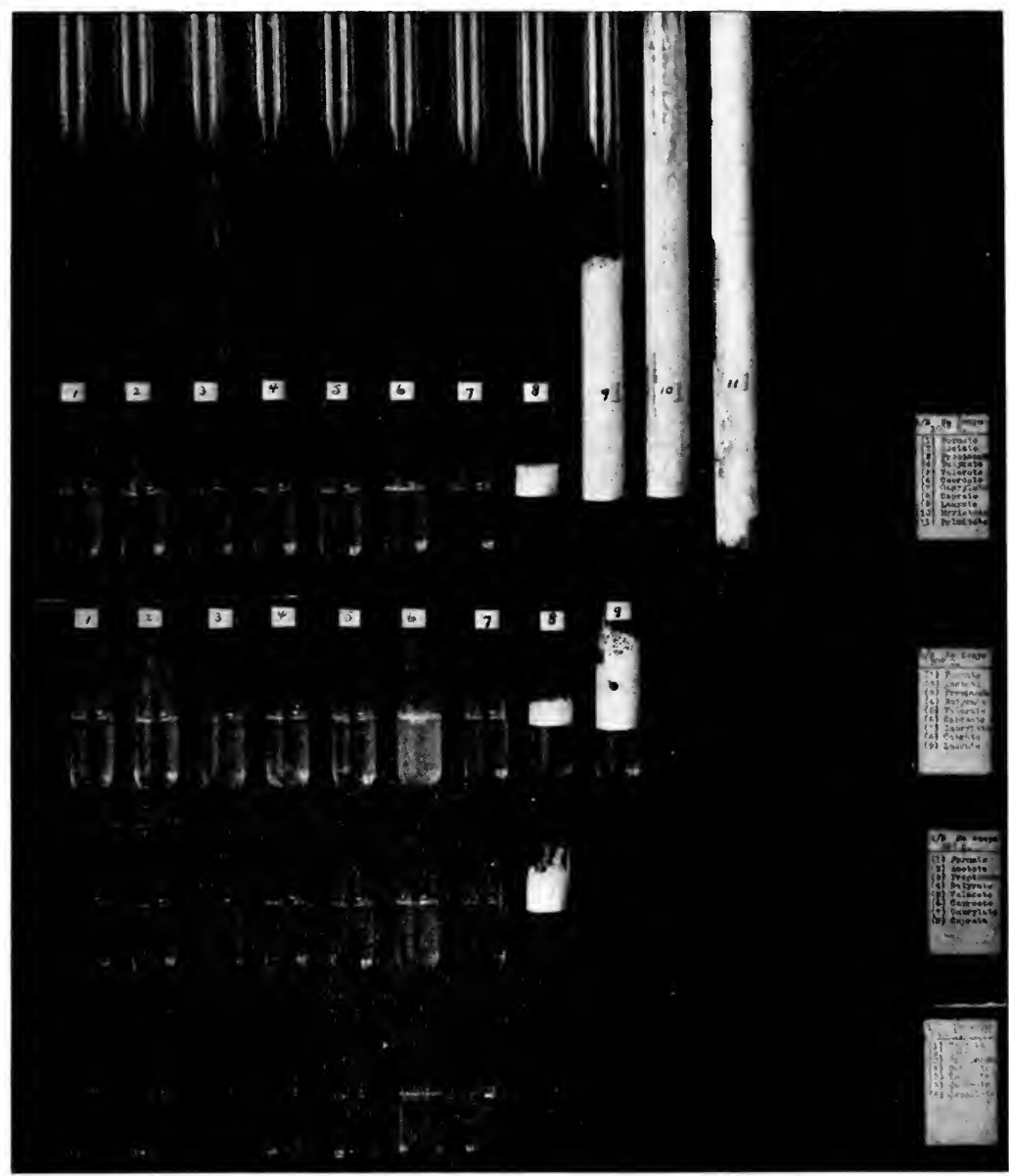

Figure 79.

Fig. 82 shows the appearance of the foaming soaps just described after having been left to themselves for two hours at the designated temperatures and again demonstrates that foams die down fastest in the lower soaps and at the higher temperatures. 


\section{$\S 4$}

In order to test further the general truth of the relationship between hydration capacity and foaming qualities of the different soaps, we next studied the potassium soaps of the acetic acid series. As previously described, ${ }^{1}$ the potassium soaps are more soluble in water and have a higher solubility for water than the corresponding sodium soaps. It was in consequence to be expected at a given concentration (a) that the potassium soaps would not begin foaming as early as the corresponding sodium soaps, (b) that this foaming quality would be lost earlier with increase in temper-

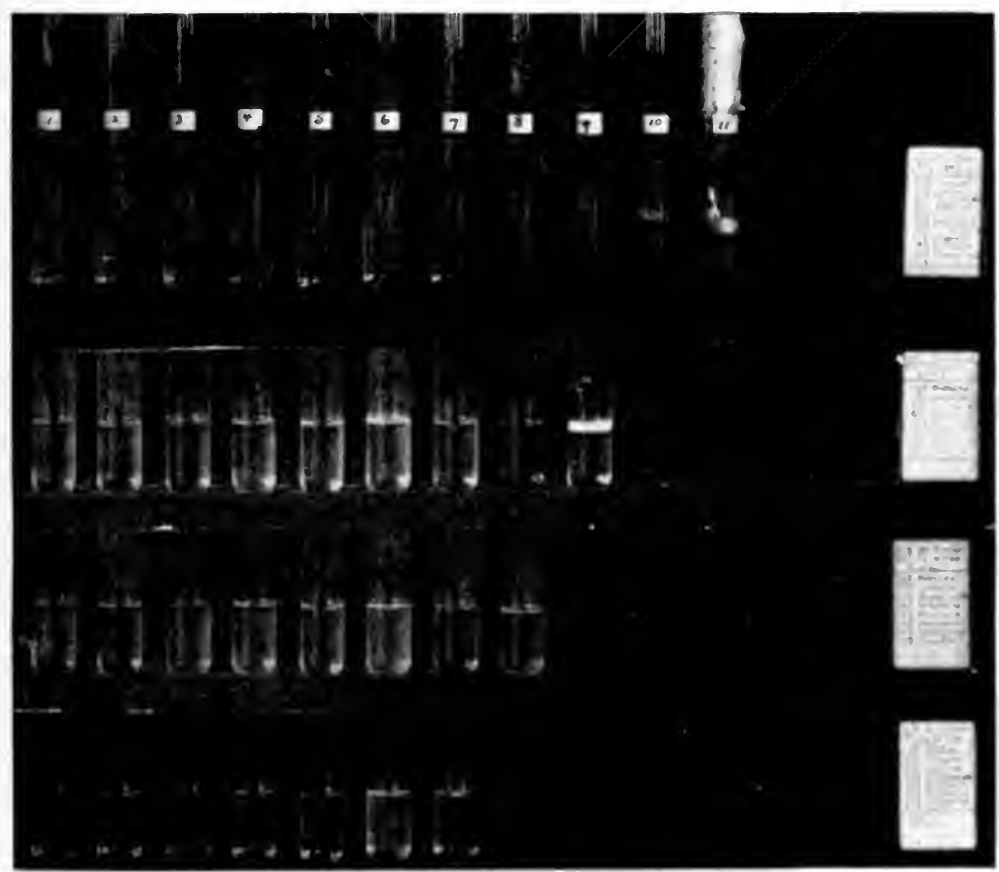

Frgun: 80.

ature and $(c)$ that the soraps of the higher falty acids would show distinet foaming qualities at temperatures at whch the corresponding sodium soaps would be so "insoluble" or yield such solid systems with water as to make foaming impossible. The truth of these 
general statements is illustrated in Figs. 83, 84, 85, 86, 87 and 88 .

Fig. 83 shows, when compared with Fig. 77 , that the foaming of $2 \mathrm{~m}$ potassium soaps at four different temperatures does not begin until potassium caprylate is reached. This soap foams slightly at $8^{\circ} \mathrm{C}$. but loses this quality as soon as the temperature is increased. The first potassium soap to show a lasting foam at the several temperatures is the caprate (the tubes 8 of Fig.

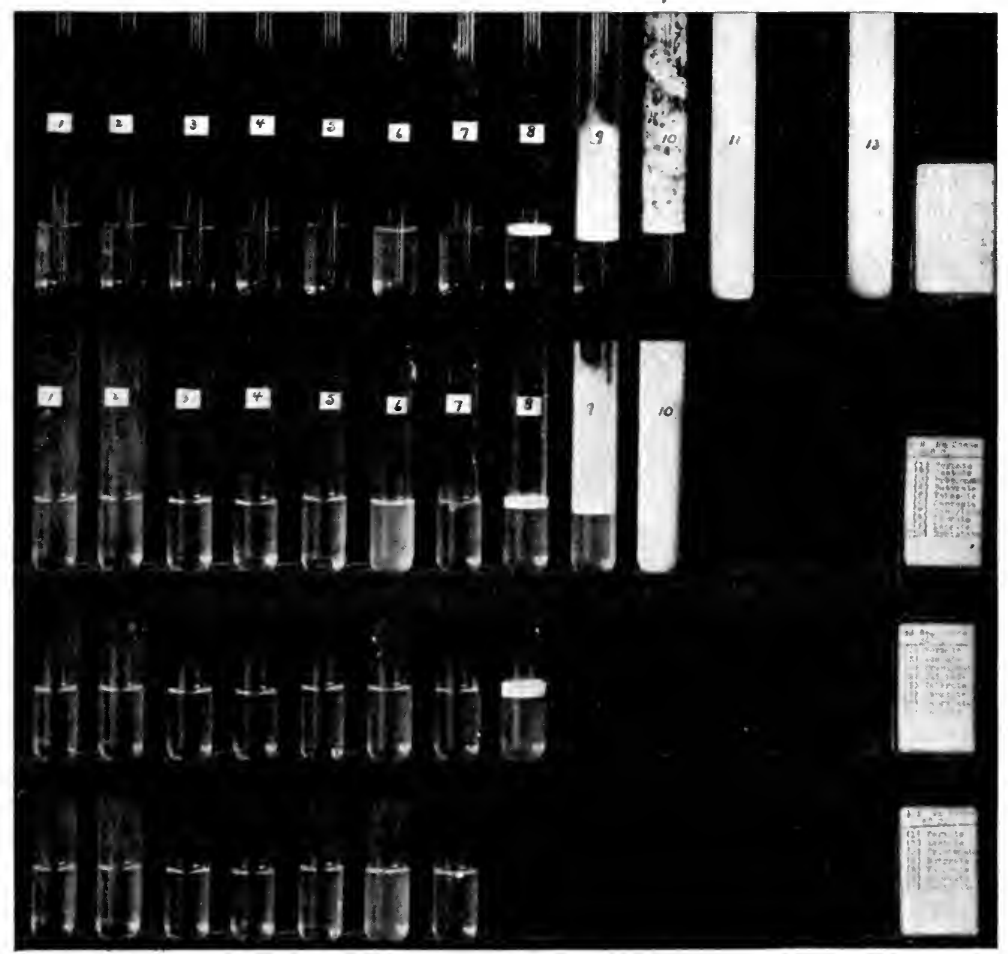

Figure 81.

83). Fig. 84 shows the appearance of these tubes two hours later. The foam has disappeared entirely from the only caprylate which showed foaming qualities and from the caprate kept at the highest temperature.

Figs. 85 and 86 show the behavior of potassium soaps of the acetic series at the concentration $\mathrm{m}$. The caprate is the first in the series to foam, but the laurate and myristate also foam: 
The potassium soaps, it is obvious, begin to foam at lower temperatures than the corresponding sodium soaps (see Fig. 79) but they also lose this quality sooner with increase in temperature. When the tube marked 11 of the potassium series (Fig. 85) is compared with the corresponding tube of the sodium series

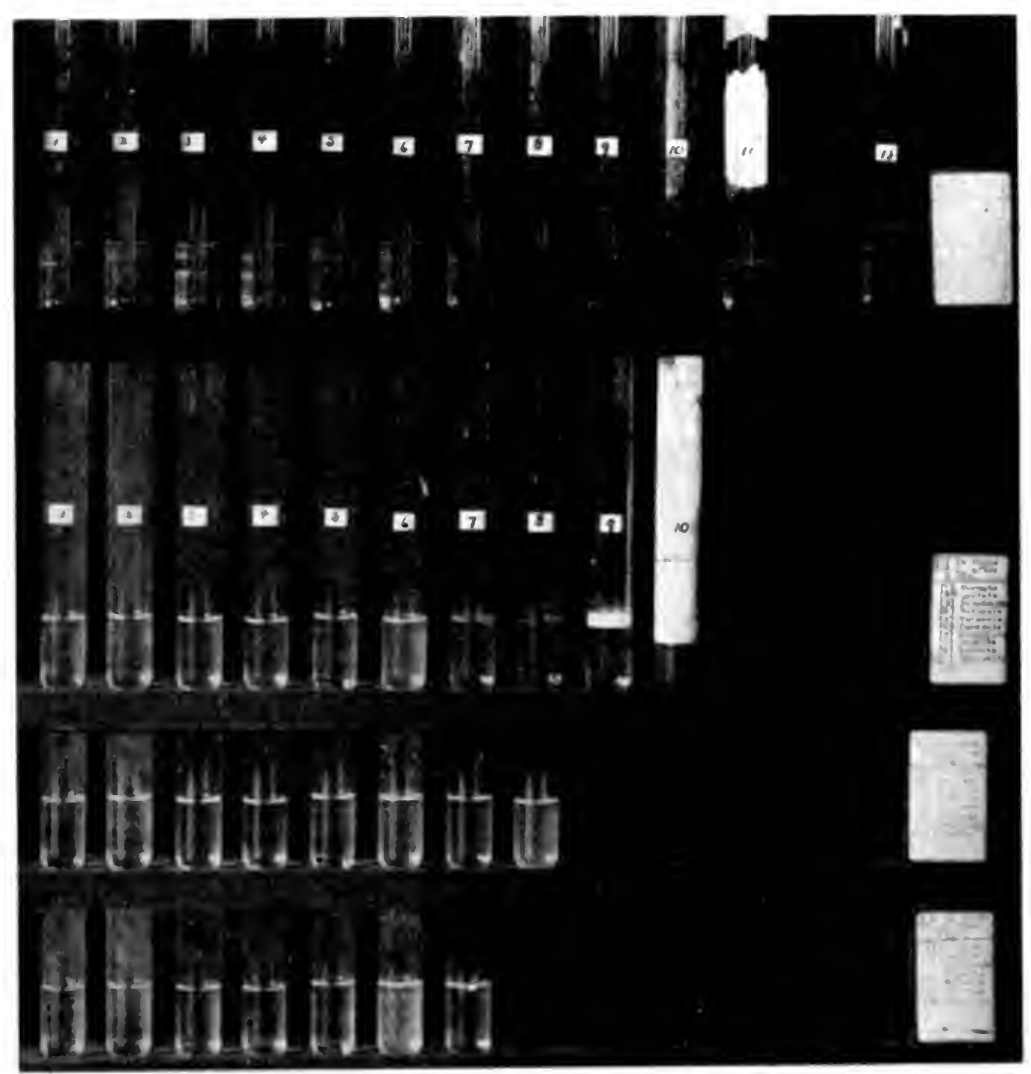

FIGUME 82.

(Fig. 79) the more licuid character of the potassium soap/water system evidences itsolf by the letter foam production. Fig. 86 shows how the foams of the potassium soaps look at the end of two hours. It is again obvious that they die down earlier in the series of the potassium soaps than in the corresponding sodium soaps, or, put another way, they last lengest in the higher members of the potassium soaps and at the lower temperatures. 


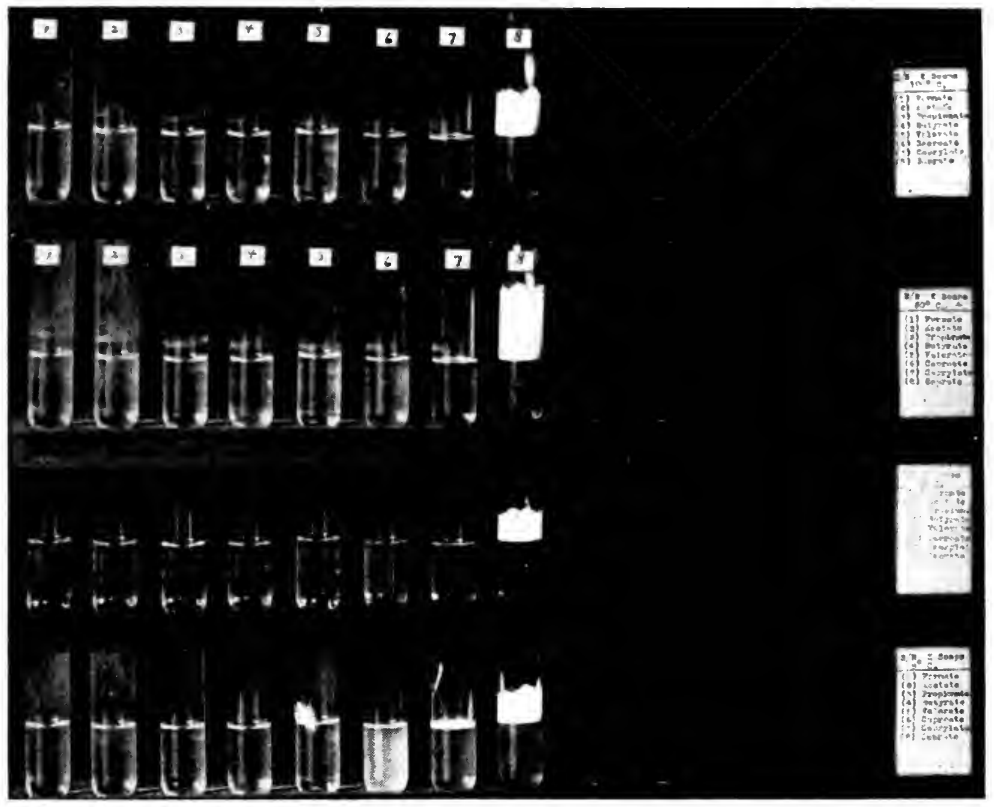

Figure 83.

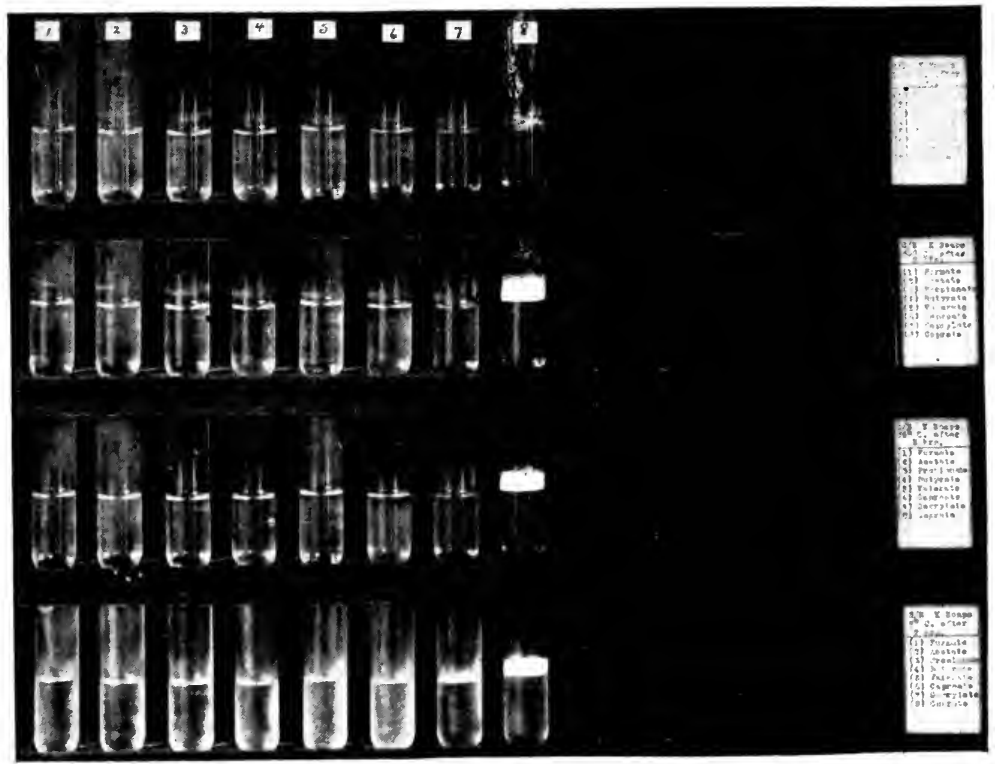

Figure 84. 


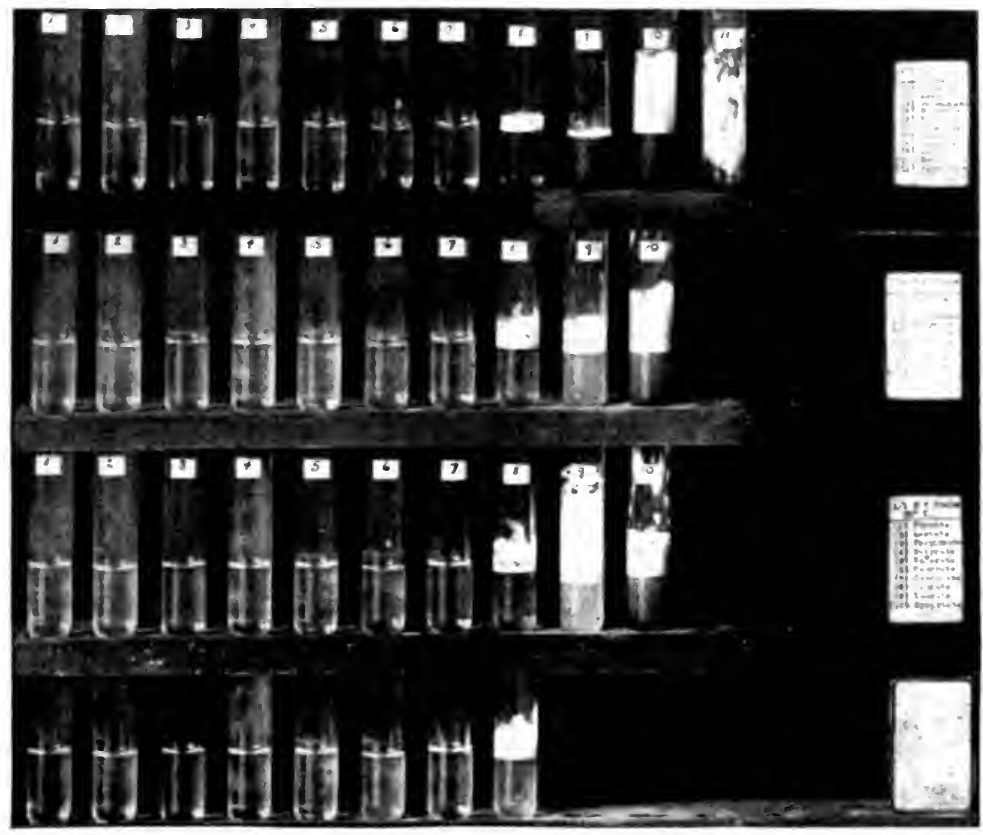

FigURe 85.

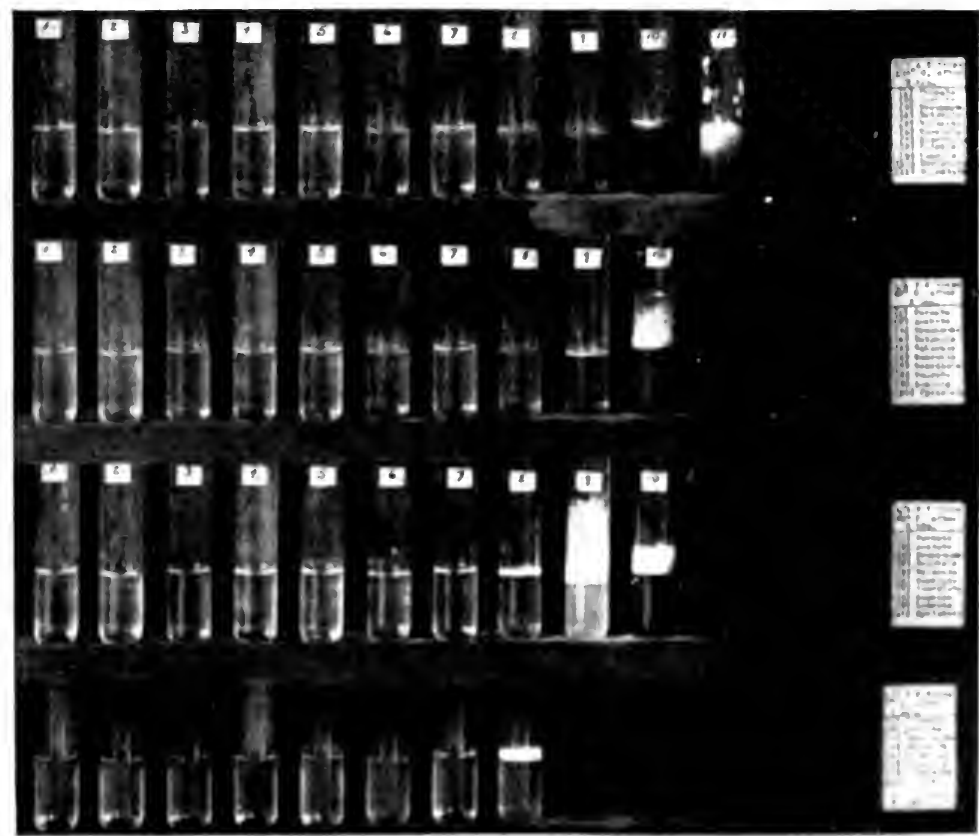


Fig. 87 illustrates the foaming qualities of the potassium soaps of the acetic series in the concentration $m / 2$. The first, soap to

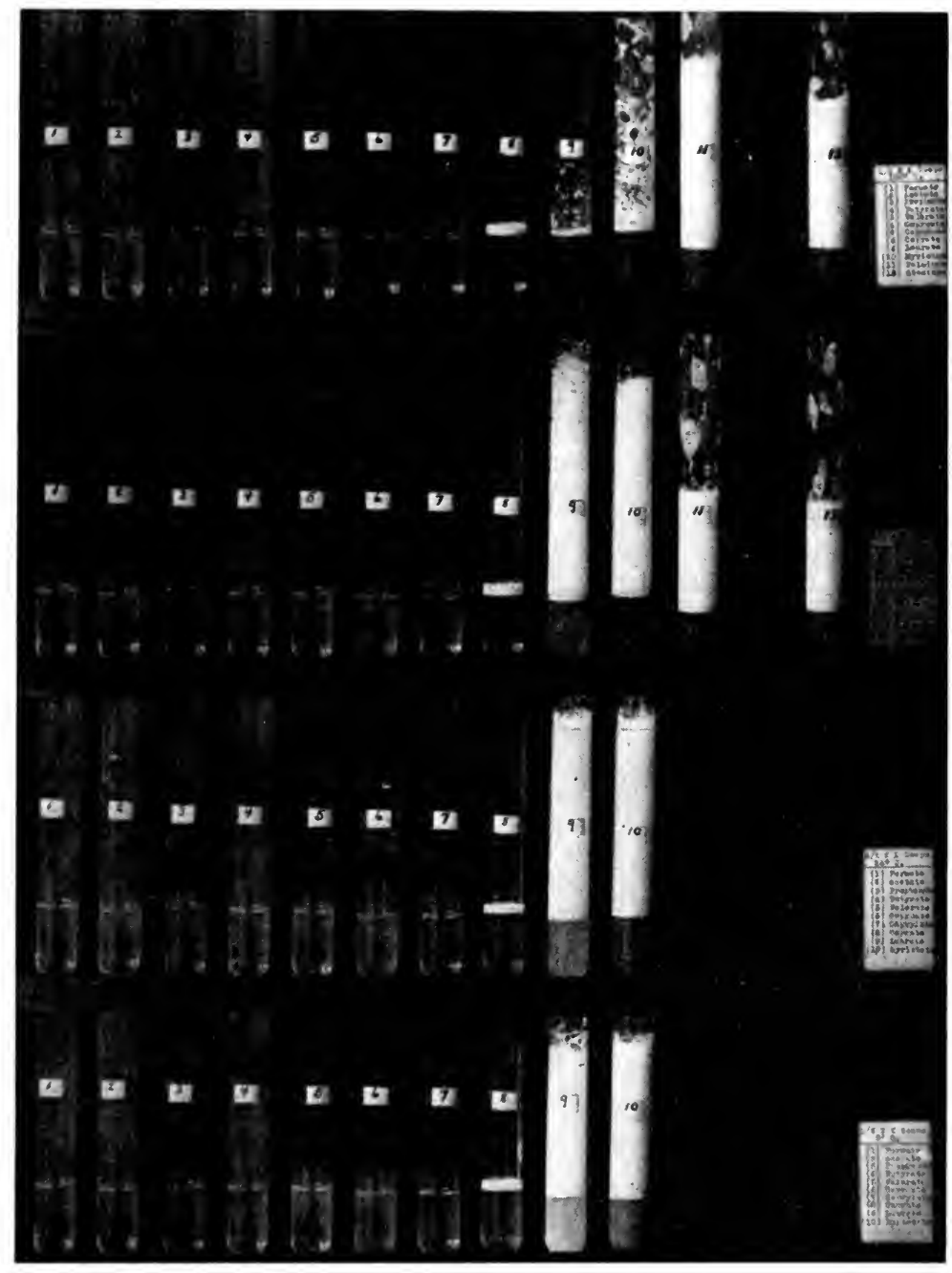

Figure 87.

show any foaming is the caprate, but its foam dies down completely in two hours, as shown by its absence in the series of tubes marked 8 of Fig. 88 . It will be observed when the laurate, myristate, 
palmitate and stearate tubes (the series 9, 10, 11, and 13 of Fig. 87) are compared with the similarly numbered tubes of Fig. 85 that these potassium soaps foam decidedly better at the $\mathrm{m} / 2$ concentration than at the higher concentration. The foams also last well, as evidenced when Fig. 88 is compared with Fig. 87 . Fig. 88, taken two hours after the foaming was produced, again shows that the persistence of a foam rises with the position of a soap in the series and falls with increase in temperature, once the

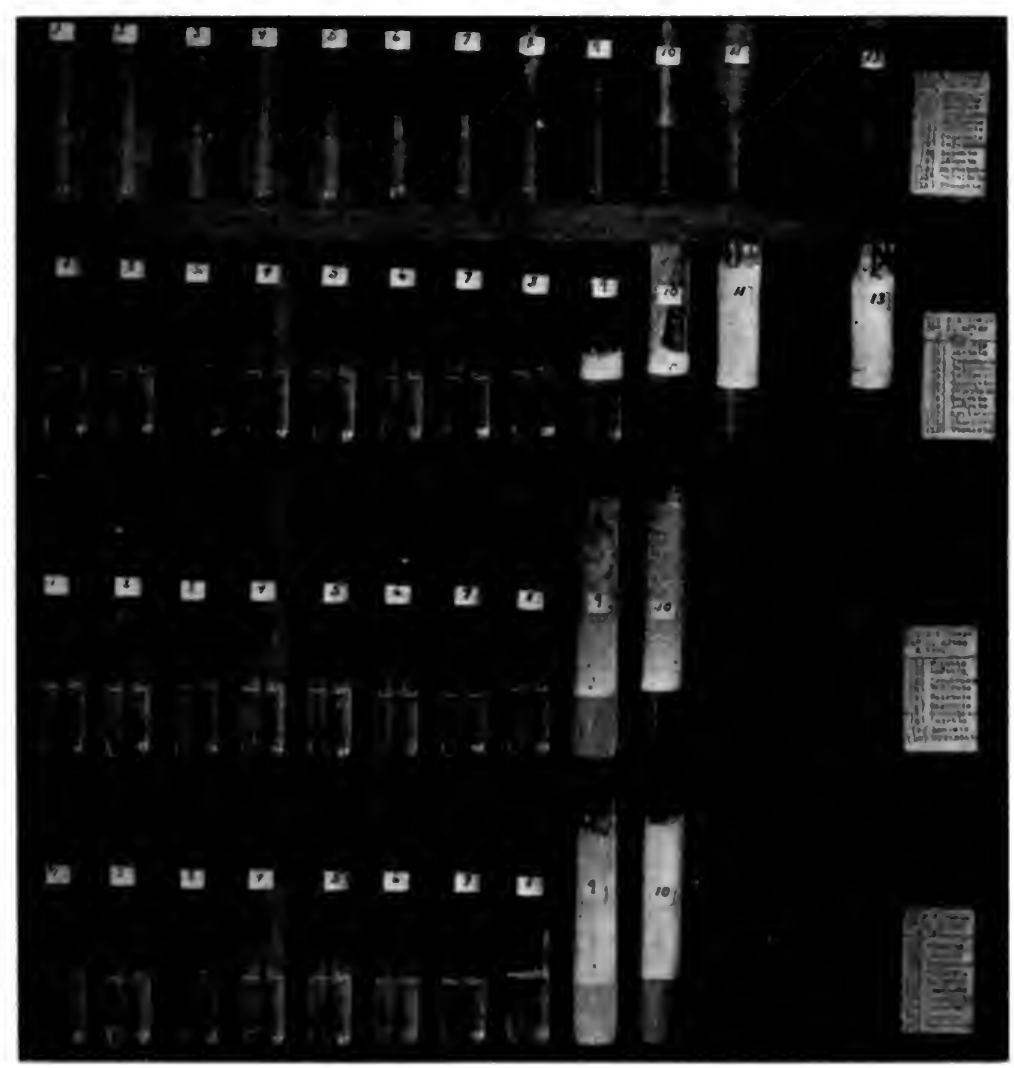

Frgure SS.

soap/water systems have been warmed above their liquefaction points. 


\section{The Emulsifying Properties of Soaps}

We wish now to discuss the relationship which exists between the emulsifying properties of the different soaps and their hydration capacity. Excepting as the concentration necessary for emulsification is different (usually higher) the same general truths hold for cmulsification previously expressed for foaming.

An emulsion is, by definition, a mixture of two immiseible liquids in each other. But from any two liquids such as oil and water, two types of emulsion may be prepared, the one consisting of a subdivision of oil in water, the other of water in oil. Milk, which readily mixes with water and wets a paper dipped into it, may be cited as an example of the former. Butter, which will mix with oil but not with water, which greases paper and imparts an oily feel to the touch, may be eited as an example of the latter. The type of emulsion important for an analysis of the emulsifying properties of the ordinary soaps is that represented by the subdivision of oil in water.

In the discussion of emulsification we must also distinguish between $(a)$ the mere production of an emulsion and $(b)$ its stabilization after production. Just as in the case of foams, the former represents essentially a mechanical process-the one liquid must by some means or other be divided into the second. When we talk about emulsification or emulsifying agencies without modifying clauses we usually mean methods or substances through which an emulsion produced by mechanical means may be stabilized.

It has been shown previously ${ }^{1}$ that an oil cannot be subdivided permanently into pure water, and that the so-called emulsifying agents which make possible the permanent subdivision of oil in water are hydrophilic (lyophilic) colloids. Among the best representatives of this group are the soaps. As ordinarily employed for emulsification purposes the soaps are, of course, mixed. The quantitative studies on the hydration capacities of the different pure soaps outlined in the preceding pages, now allow us to test out this whole concept of emulsification more accurately. What is the relationship between the hydrophilic properties of any soap and its emulsifying power?

${ }^{1}$ Martin H. Fischer and Martan O. Ноoker: Science, 43, 468 (1916); Kolloid-Zeitschr., 18, 129 (1916); Fats and Fatty Degeneration, New York (1917). 
In order not to lengthen this discussion unduly, the experimental facts in the case may be summed up as follows: those soaps are the best emulsifying agents which at the temperature of their use and in the presence of water yield essentially liquid systems of the type water-dissolved-in-soap. For this reason the oleates, linolates, etc., are, of all the soaps studied, the best emulsifiers at ordinary (room) temperatures because, besides having high hydration values, they are liquid.

The sodium soaps of the acetic acid series when used in equimolar coneentration show the following characteristics. The soaps of the lowermost members through the caproate yield no permanent emulsions. If a sodium caprylate or sodium caprate/water system is kept just above its liquefaction point, a permanent emulsion may be obtained. A slight rise in temperature, however, makes for separation of the oil from the water phase. The same is true for the sodium soaps of the higher fatty acids. At low temperatures sodium myristate, sodium palmitate, sodium stearate, etc., in water do not emulsify, but if the temperature of these mixtures is raised so that the soaps "go into solution" (in reality yield liquid colloid systems of the type water-dissolvedin-soap) permanent emulsions can be obtained at once. With too great increase in temperature, however, the emulsions again crack, and the oil separates off.

In interpretation of these general findings it may be said that the lowermost soaps do not emulsify because they yield only true solutions of the soaps in the water. The systems, in other words, have no hydrophilic properties or, put another way, the water in them is essentially "free" and permanent emulsification of oil in such "free" water cannot be obtained. With the development of distinetly hydrophilie properties by the soaps in the middle of the series emulsification becomes possible, but only while the systems are liquid and of the type water-dissolved-in-soap. Only slight further increase in temperature, however, is necessary in the case of soaps like the caprylate and caprate to carry them through this region into the realm of the true solutions of soap in water, and as this happens permanent emulsification again becomes impossible.

Similar facts hold for the soaps of the higher fatty acids. An oil cannot be emulsified in any of these higher soaps even when possessed of a high hydration capacity as long as they are 
solid. But as soon as the temperature is raised sufficiently the resulting liquid colloid systems emulsify splendidly. The matter is illustrated for the case of sodium palmitate in the right-hand bottle of Fig. 89. In this $60 \mathrm{cc}$. cottonseed oil were ground into $20 \mathrm{cc}$.

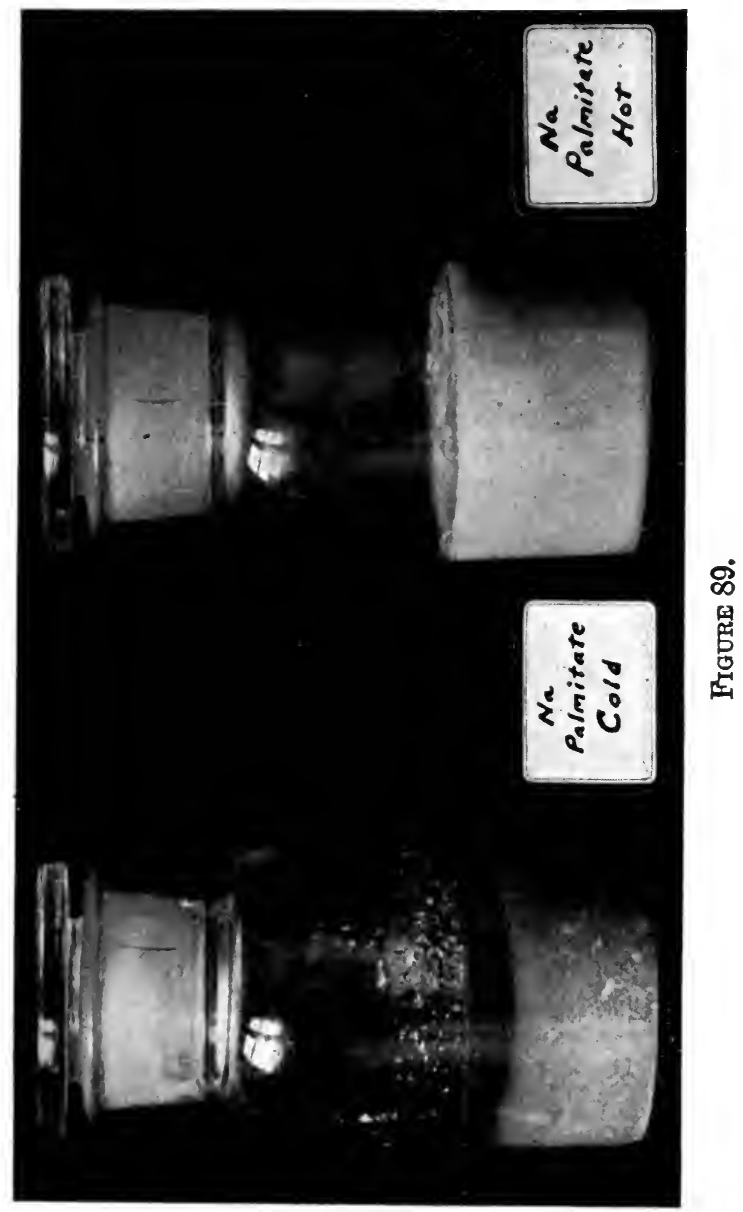

$\mathrm{m} / 16$ "solution" of the soap in a hot water bath. At this temperature a fine emulsion results. As soon, however, as the temperature is allowed to drop to $25^{\circ}$ for a few hours the system cracks, as shown in the left-hand bottle of Fig. 89. If, however, the temperature is maintained above the liquefaction point of 
the sodium palmitate/water system, permanent emulsification results, as evidenced in the right-hand bottle of Fig. 89. The higher soaps, moreover, maintain their high hydration values (as liquids) through a considerable range of temperature, wherefore

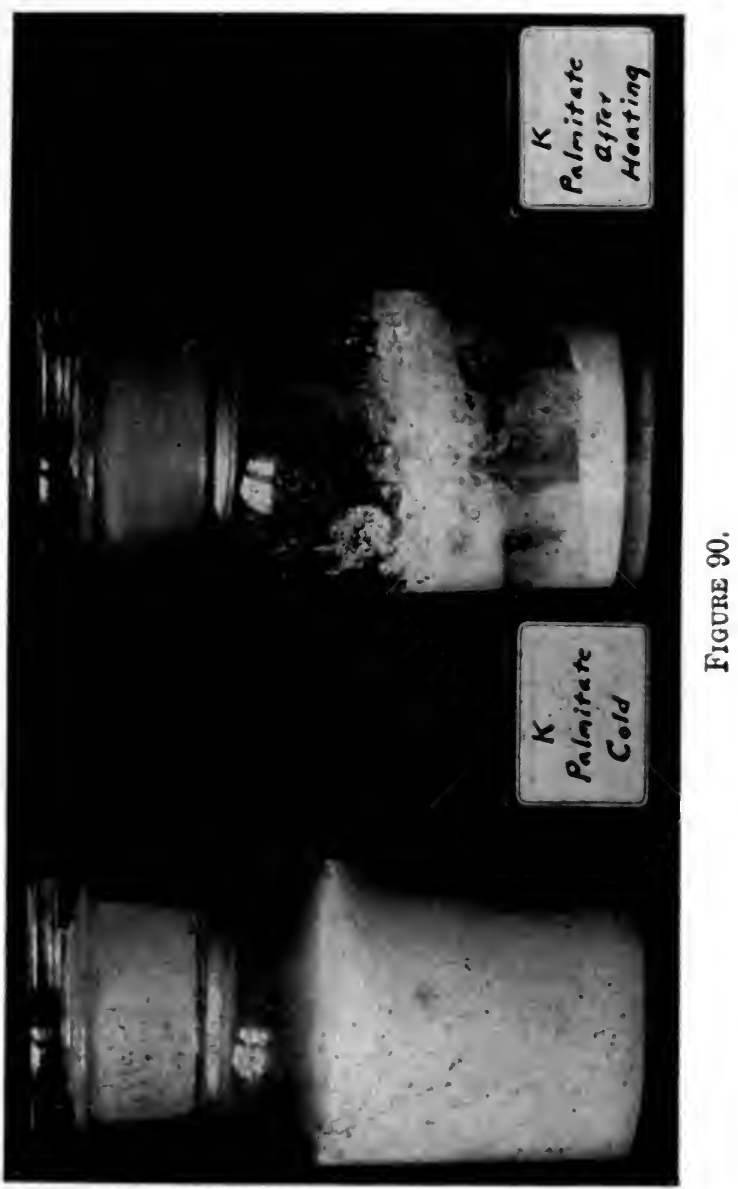

further increase in temperature does not serve so quickly to break an emulsion stabilized in these higher soaps as in the case of the lower ones. The higher soaps, in other words, do not pass as quickly as the lower ones into the class of the true solutions of soap in water. 
It is possible to test out these general notions by using the potassium soaps instead of the sodium soaps of the acetic acid series. The potassium soaps being in general more soluble in water and more nearly liquid at a given temperature than the corresponding sodium soaps, permanent emulsification requires either (a) a higher concentration of the potassium soap or (b) a lower temperature or $(c)$ a soap higher in the series. It therefore requires more of a soap low in the series like potassium caprylate or caprate to the unit volume of water to yield a permanent emulsion. The emulsions so produced also break easily upon slight inerease in temperature. On the other hand, the potassium soaps of the higher fatty acids, which in the presence of water yield more liquid systems even at ordinary temperatures than the corresponding sodium soaps, may be used to obtain permanent emulsions when the corresponding sodium soaps will not act. Potassium laurate, myristate or palmitate mixtures with water act as splendid emulsifying agents at low temperatures at which the corresponding sodium soaps are useless. Even potassium palmitate acts well when the temperature at which it is used lies but slightly above the ordinary room temperature. This is illustrated in the left-hand bottle of Fig. 90. The potassium soaps being more readily soluble in water than the corresponding sodium soaps with increase in temperature, the fine emulsion produced in hydrated potassium palmitate cracks as soon as the temperature is raised to that of a boiling water bath. This is shown in the right-hand bottle of Fig. 90. In this experiment also, 60 ce. cottonseed oil were emulsified in $20 \mathrm{cc} . \mathrm{m} / 16$ potassium palmitate by grinding in a mortar.

\section{On the Theory of Foaming and Emulsification}

While we have no direct interest in theories of foaming and emulsification, it is difficult to work in these fields without inquiring into the nature of the conditions which make foaming and emulsification possible.

It would seem from the experiments which have been detailed above and in our previous publications on emulsification that permanent foaming or emulsification is possible only as the liquid into which a gas or a second liquid is dispersed is changed from one possessed of the physico-chemical constants of the pure dis- 
persion medium into another possessed of those characteristic of a liquid hydrated colloid.

From a gas and a liquid, as from two immiscible liquids, it is possible, of course, to produce two types of systems represented in the first instance by the dispersion of a gas in a liquid (a foam) or of a liquid in a gas (a fog) and represented in the second instance by the dispersion of the liquid $a$ in $b$ (as oil in water) or the dispersion of the liquid $b$ in $a$ (as water in oil). When one regards as a whole the field of the dispersoids consisting of gas plus liquid and similarly that of the dispersoids consisting of liquid in liquid, one is quickly struck by the fact that lasting dispersions of gas in liquid (foams) can be more readily produced than the opposite type of system; while certain liquids $a$ can be more readily emulsified in a second $b$ than vice versa.

In trying to discover what is the first general relationship which determines this behavior, it has seemed to us that a previously expressed opinion ${ }^{1}$ covers the case satisfactorily. Other conditions remaining the same, that material is dispersed within any second which in response to mechanical deformation shows the shorter breaking length. Our meaning may be illustrated by reference to Figs. 91 and 92 . When air and some liquid like liquid hydrated soap are subjected to a deforming movement (like the beat of a flail) it is obvious that the gas

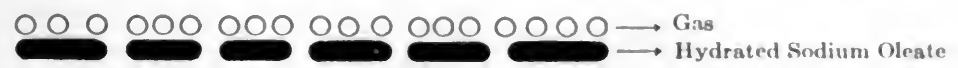

Ficiure 91.

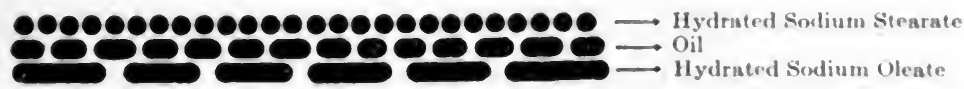

Figute 92.

will "break" sooner than the liquid columns of hydrated soap. The soap will, in other words, be drawn into longer threads or coherent surfaces than will the air, in consequence of which the gas will become enmeshed within the hydrated colloid, and a foam will result.

What happens in the case of two liquids is represented diagrammatically in Fig. 92. If the middle line of the diagram is taken

'Martin H. Fiscuen and Mamax O. Hooker: Fats and Fatty Dogenerntion, 32, New York (1917). 
to represent the breaking length of oil threads, the breaking length of a soap, like hydrated sodium oleate, is represented by the lower line of the diagram. For this reason, other things being equal, the oil tends to break into droplets sooner than the hydrated sodium oleate which in eonsequence remains the non-dispersed or enveloping phase. There are, however, other' soaps which, while capable of hydration, yield liquids whose fibers tend to break sooner when drawn into threads than does hydrated sodium oleate, or which at the ordinary temperatures employed are so nearly solid that they break into short fragments. Magnesium oleate, sodium stearate, etc., may be cited as hydrated soaps of this type. Their breaking length may be represented diagrammatically, as compared with the breaking length of an oil, by the upper line of Fig. 92. Other things being equal, these materials, therefore, tend to become enmeshed within the oil, yielding, in other words, emulsions of the type water-in-oil.

The experiments detailed above, in which were compared the emulsifying properties of different soaps (like sodium palmitate and potassium palmitate, sodium stearate and potassium stearate) or the behavior of these soap/water systems, when subjected to heat manipulation, prove the truth of this general contention. We have also tried to measure the breaking length of the different systems which may be used successfully for the production of foams, fogs or the two types of emulsions. We hope to be able to detail numerical values covering these points at another time. The so-called "finger tests" of the glue technologists permit one to predict what kind of system is most likely to result from dispersion in each other of a gas with a liquid or a liquid with a liquid.

We are not unconscious of the fact that there may be arranged under this conception many of the so-called theories of foaming and emulsification adduced to explain the behavior of these systems. As previously emphasized ${ }^{1}$ there is nothing mutually exclusive in the ideas of solvation and the relative breaking lengths of any two materials, and the changes in surface tension and viscosity, the quantitative relationship between the amounts of the two phases, the formation of a continuous third phase between the two general substances making up a foam or an emulsion, the

${ }^{1}$ Martin H. Fischer and Marian O. Hooker: Fats and Fatty Degeneration, 29, New York (1917). 
"surface activity" of various chemical substances in permitting the "wetting" of contiguous phases, etc., as drawn upon by various authors (S. Plateau, ${ }^{1}$ G. Quncke, ${ }^{2}$ F. G. Donnan, ${ }^{3}$ H. W. Hillyer, ${ }^{4}$ Walther Ostwald,${ }^{5}$ T. B. Robertson, ${ }^{6}$ S. U. Pickering, ${ }^{7}$ Ubbelohde and Goldschmidt: ${ }^{8}$ Wilder D. BanCroft, ${ }^{9}$ G. H. A. Clowes, ${ }^{10}$ S. A. Shorter ${ }^{11}$ and James W. $\mathrm{MCBAIN}^{12}$ ) to explain the nature of foaming and emulsification. When water is changed to a liquid colloid hydrate, the properties of the second are still the properties of a liquid, though quantitatively different from the first, and these properties include surface tension, viscosity, distribution of dissolved and suspended particles, etc. But were we to express a critical opinion of the theories of foaming and emulsification as developed by these various authors, we would say that each has failed in the opinion of some other author because he has used his theory as an exclusive one and as one necessarily universally applicable. As we have repeatedly emphasized, a number of faetors undoubtedly play a rôle, and the relative importance of each varies not only in different foams and in different emulsions but in one and the same foam or emulsion under different circumstances.

\section{The Washing Properties of Soaps}

Empiric practice seems to have succeeded in furnishing soaps of good washing properties for almost all teehnologic needs and for use under the most varied circumstances, and this in spite of the fact that we seem still to be largely ignorant of why in

is. Platejau: Ann. der. Physik., 141, 44 (1870).

${ }^{2}$ G. Quncke: Ann. der Physik., 271, 580 (1SSS).

${ }^{3}$ F. G. Donnan: Zeitschr. f. physik. Chem., 31, 42 (1S99).

'H. W. Hillyer: Jour. Am. Chem. Soc., 25, 511 (1903); ibid., 25, 524 (1903).

- Walther Ostwald: Kolloid-Zeitschr., 6, 103 (1910); ibid., 7, 64 (1910).

- T. B. Ronkizssos: Kolloid-Zeitschr, 7, 7 (1910).

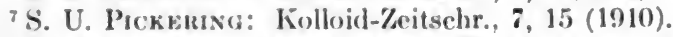

- Unseronde and Gospscumidt: Handbuch der Oele und Fette, 3, 11, Leipzig (1910); Zeitsehr. f. Elektrochem., 18, 380 (1912); Kolloid-Zoitschr., 12, 18 (1913); Kolloidchem. Beihefte, 5, 427 (1914).

- Whider D. Baxchort: Jour. Physical Chem., 17, 501 (1913).

10 G. H. A. Crowes: Jour. Physical Chem, 20, 415 (1916).

"S. A. Sноnтек: Jour. Soc. Dyers and Coloriste, 32, 99 (1916).

12 James W. McBan and C. S. SAlmox: Jour. Am. Chem. Soc., 42, 426 (1920). 
actual use the soaps act as they do. The following paragraphs do not pretend to bring a definitive answer to the problem, but in connection with the remarks of the preceding paragraphs it has seemed to us that they may help toward a formulation and solution of some of the general problems involved.

The oldest, perhaps, of the theories of washing holds that soap owes its cleansing virtues to the alkali which it liberates on solution in water. This factor as an important item in the washing process has been much discredited. While it is not to be denied that its importance was formerly overestimated, it is perhaps too extreme to deny it all virtue. The fact that even soft water alkalinized through the addition of sodium, potassium or ammonium hydroxid, sodium carbonate or borax washes better than the water alone would seem to make it impossible to deny the virtue of this factor entirely.

On the other hand, the alkali factor cannot be the main feature which gives soap its washing properties, for the very soaps which on hydrolysis yield the largest overplus of free alkali, namely, the soaps of the highest fatty acids, may wash most poorly. On the other hand, soaps which by test and under the circumstances of their use are strictly neutral may function as ideal cleansers. To explain the action of soap under such circumstances, its power to produce foams and to emulsify has been called into account, and this property has been paralleled with its cleansing virtues. If this conception is correct-and there is much to support the idea that it represents the major factor in the general washing power of the soaps-then the value of different common soaps as generally employed would, on the basis of our previous remarks, be about as follows:

To produce effective cleansing a certain minimum of mechanical washing methods are absolutely necessary. The soiled materials must be "soused" in the wash water, rubbed on a washboard or dragged about in a machine. This constitutes in the washing process the equivalent of the mechanical element so necessary for the production of foams and emulsions. The "dirt" in the clothes is emulsified in the hydrated soap of the wash water.

The soap must now be looked at from the point of view of favoring such emulsification and the stabilization of the emulsion after production. Obviously, of much importance in this matter will be (a) the concentration at which the soap is used, (b) the 
character of the soap and $(c)$ the temperature at which it is employed.

It is the common practice to rub solid or semi-solid soap directly upon the soiled materials or to soak them in a strong soap stock. Even after such soaking, more solid or semi-solid soap is commonly rubbed directly upon the more soiled areas. This is all expressive of the need for a hydrated colloid of high concentration, for only such will lead to easy and permanent stabilization of the " dirt" (fatty materials and mixed solids) in emulsified form in the " soap water."

The ordinary washing soaps (either laundry or toilet) are the sodium soaps of several fatty acids. It is of interest to note that manufacturers have long used mixtures of different fats for their soap stocks. Beginning as they usually do with a liquid fat (like cocoanut oil, olive oil, eottonseed oil) they add to this varying amounts of the higher fats (like tallow, hydrogenated cottonseed oil, ete.). The ultimate soap produced contains a long and varied list of fatty acids. Such mixtures must obviously satisfy most general needs. Because of the presence of soaps of the lowermost fatty acids, quick foaming and quick emulsification are obtained even at low temperatures. These lowermost soaps, however, dissolve so quickly that the frugal housewife considers them wasteful. Especially is this the ease when the soaps are used with hot water in which they pass quickly into the "true solution" stage. For this reason the presence of fatty acid soaps from the middle of the series will prove useful, for these work well in grdinary "lukewarm" waters. They too, however, lose much of their virtue if the temperature is raised. As effectively working soaps in waters near the boiling point, the soaps of the higher fatty acids are required. The palmitates and stearates, for example, still maintain their colloid characteristics when soaps lower in the series have lost theirs through "solution."

The facts reeited indicate why the temperature at which any soap is used has so much to do with its effectiveness. Where soaps are to be used in cold water, it is clear that none of the higher fatty acid soaps are of any particular use. Only those soaps which at low temperatures have definitely colloid characteristics, and which as ordinarily employed yield liquid colloid systems, are effective for washing under such circumstances. 
This is the reason why sodium and potassium oleate and the soaps made from oils rich in the lower fatty acids (cocoanut oil soap, palm kernel oil soap) are the soaps which, above all others, are held useful. On the other hand, for warmer waters it is of advantage to have present the soaps of the fatty acids higher in the series. Hence the common practice of adding tallow, hydrogenated cottonseed oil, etc., to the more liquid fats and oils used for the manufacture of toilet and laundry soaps in " civilized" countries. There is, however, a limit at this end of the series also. The sodium soaps above the stearate in the acetic series do not yield (liquid) hydrated colloid systems below the boiling point of water. In this proportion they are valueless as washing agents. Even the stearate which, since the introduction of hydrogenation methods, has been worked in increasing amounts into the common toilet and laundry soaps already comes close to the danger line. It will hardly foam or emulsify short of the boiling point of water. A way out of the difficulty, not only for the stearate, but also for some of the other higher fatty acids, may be found in the substitution of potassium for the sodium of the common soaps. This trick is employed in "shaving soaps" in which the waste of a more "soluble" soap is compensated for by its readier foaming and emulsifying properties. But the substitution of potassium for sodium has its defects at the lower end of the series - the potassium soaps, being more readily "soluble" both in cold and hot waters, pass too quickly through their working middle of liquid hydrated colloids and hence are "wasteful." 


\section{PART TWO}

THE COLLOID-CHEMISTRY OF SOAP MANUFACTURE 


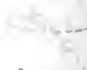

. 


\section{PART TWO}

THE COLLOID-CHEMISTRY OF SOAP MANUFACTURE

I

\section{PRINCIPLES OF HOT AND COLD PROCESS SOAP MANUFACTURE}

\section{Introduction}

IT will be the purpose of this chapter to review certain technical procedures followed in soap manufacture in order to see where the concepts developed in the preceding pages may be used as conscious substitutes for various empiric practices. In doing so we will be struck by an interesting fact. Faced on the one side by the myriad problems incident to the handling of a widely varying crude material and on the other by the demands on the part of the public for a product possessed of certain washing characteristics, the practical soap manufacturer has in nearly every instance hit upon both a satisfactory process and a satisfactory product.

The raw materials used by the soap chemist and, consequently, the soaps which he produces are so many and so various that a cumplete review of the situation is not possible. What is said in the following pages represents little more than a broad outline.

We should have an ideal starting point did we know, as a first foundation for our discussion, the qualitative and quantitative composition of the fats and oils which enter the soap kettle. Even when we ignore the presence, in the crude fats and oils employed, of unsaponifiable material, of alcohols other than glycerin, of admixed substances bearing no relationship to the esters which make up the mass of the fat or oil, etc., we are still handicapped by an inadequate knowledge of the complete com- 
position of even the commoner fats and oils. Or, where such complete analyses have been made or are available, they refer, of course, only to a specific sample and, as every oil and fat chemist knows, another sample obtained presumably from the same sources and under the same conditions may still show wide variations in composition. A single fat or oil varies for example with the seasons.

It lies without the limits of this volume to list more than a few of the fats and oils which have been or may be used in the manufacture of soaps and to indicate their approximate composition. The examples which follow are of interest either because they furnish much of the material which is used in soap manufacture or because their qualitative composition is such that they yield soaps with qualifications of interest to our discussion.

\section{The Oils, Fats and Waxes Entering the Soap Kettle}

From a purely chemical point of view there is little reason to distinguish between the "oils" and the "fats" of the technical chemists; and the same is true of the "waxes." All three substances are essentially nothing but mixtures of different esters. In the case of the oils and fats these are almost exclusively glycerids, and this still holds true for many of the waxes (as "Japan wax"). At other times the waxes are still esters, but some other alcohol may have taken the place of the glycerin. Nevertheless, this practical distinction between the three groups of substancesthe first being liquid at ordinary temperatures, the second semisolid or solid, the third definitely solid-has some value. The physical state parallels roughly the kinds and proportions of different fatty acids appearing in the various esters, the fatty acids with the lower melting points being those most common in the oils while those with the higher melting points predominate in the fats and waxes. This matter is of much importance, as will appear later, because of the physico-chemical differences in the soaps which are formed from these different stocks.

A distinction in soap manufacture between the fats of vegetable and those of animal origin has little purpose, for both contain qualitatively the same list of glycerids. Nevertheless it is well to remember that the two different origins may at times be of importance because of differences in the types of impurities which they bring along. 
Since the kind of soap formed and its properties are so largely a matter of the kind and relative proportion of the fatty acids which occur in the original soap stock it is well to begin by listing a few of the commoner oils, fats and waxes and giving their percentage composition. The series which follows is catalogued arbitrarily, those fats which contain the smallest number of fatty acids or such as have the lower melting points being given first. A more detailed discussion of this subject lies without the limits of this volume; for such the accepted handbooks ${ }^{1}$ or original papers dealing with this subject must be consulted.

Linseed Oil. A generally accepted average analysis is that of HAzURA and GRǗSSNER which reads as follows:

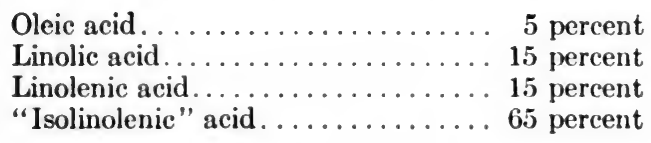

In the place of the above analysis, to which J. Lew коw Iтsch ${ }^{2}$ has raised objection, this author gives the following:

Solid fatty acids (palmitic, myristic, stearic, arachidic). 7.5 percent Linolic acid........................ 36.5 percent Linolenic acid.................... 56.0 percent

Poppy Seed Oil. The whole oil carries 6.67 percent of solid fatty acids (Tolman and Munson ${ }^{3}$ ). The liquid fatty acids consist, according to HazURA and Grüssner, of

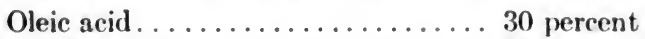

Linolic acid.............6. 65 percent

Linolenic acid............. 5 percent

Cottonseed Oil. According to Twitchell, Farnsteiner, TolMAN and Munson, ${ }^{4}$ the whole oil contains from 22.3 to 32.6 percent of solid fatty acids, consisting chiefly of palmitic acid with a small quantity of arachidic acid. The liquid fatty acids, accord-

'See for example J. Lewkowitscu: Oils, Fats and Waxes, 5th Fd., 2, London (1914); Мвккц:s: Etude sur la constitution des savons du commerce, Marseilles (1906) or in German translation by Franz Goldscumid, Halle a $/ \mathrm{s}$ (1907); Uинцонов-Gondscumt: Handbuch der Oele und Fette, Ieipzig (1910).

2J. Lewkowtsch: Oils, Fats and Waxes, 5th Ed., 2, 61, Iondon (1914).

2 L. M. Tolman and L. S. Musson: Jour. Am. Chem. Soc., 25, (Ho) (1903).

- Quoted by J. Lewкowrscu: Oils, Fats and Waxes, 5th lid., 2, 197, Iondon (1914). 
ing to HAZURA, consist approximately of 40 percent oleic acid and 60 percent linolic acid.

Sesame Oil. This oil contains, according to Farnsteiner, 12.1 to $\mathbf{1 4 . 1}$ percent of solid acids, the liquid acid making up the remaining fraction holding usually about 15.8 percent linolic acid and 72.1 percent oleic acid.

Olive Oil. According to Tolman and Munson, ${ }^{1}$ the solid fatty acids of this oil, as obtained from different sources, vary between 2 and 17.72 percent. These solid fatty acids are chiefly palmitic acid with a trace of arachidic. Stearic acid is absent. The liquid fatty acids, according to Hazura and Grïssser, consist of 93 percent. oleic acid and 7 percent linolic acid.

Castor Oil. The whole oil on standing in the cold deposits 3 to 4 percent of stearic and ricinoleic acids (KRAFFT ${ }^{2}$ ) and 1 percent dihydroxystearic acid (JUILLARD). The liquid fatty acids of castor oil consist chiefly of ricinoleic and some isoricinoleic acid. Oleic acid seems to be absent (Hazura and GrüssNER $\left.^{3}\right)$.

Cod Liver Oil. Crude cod liver oil contains a considerable portion of stearic and palmitic acids. The oil as it comes to market has usually been freed from these. In the liquid oil small quantities of acetic, butyric, valeric and capric acids have been found by various authors. There is an absence of oleic acid, and it is believed that the bulk of the fatty acids is made up of acids less saturated than those of the oleic acid series. According to HEYERDAHL ${ }^{4}$ the following percentages of different acids have been definitely isolated.

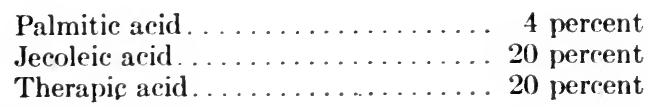

Palm Oil. This is a mixture of glycerids of oleic acid and various solid fatty acids. Ninety-eight percent of the solid fatty acids is palmitic acid and 1 percent or less is stearic acid. HazUrA and Grëssser have discovered linolic acid among the liquid fatty acids of this oil.

${ }^{1}$ L. M. Tolmax and L. S. Munsox: Jour. Am. Chem. Soc., 25, 956 (1903).

${ }^{2}$ F. Krafft: Ber. d. deut. chem. Gesellsch., 21, 2730 (1888).

${ }^{3}$ Quoted by J. Lew коw rтsch: Oils, Fats and Waxes, 5th Ed., 2, 398, London (1914).

${ }^{4}$ J. Lew kowitsch: Oils, Fats and Waxes, 5th Ed., 2, 430, London (1914) 
Nutmeg Butter. The composition of this fat is thus summarized by J. Lewкоwiтsсн. ${ }^{1}$

\begin{tabular}{|c|c|}
\hline acid. & percent \\
\hline Id. & percent \\
\hline nic acid............ & rcent \\
\hline erotic acids. & $\mathrm{sm}$ \\
\hline - $\quad 1$ & 12.5 \\
\hline ponifiable and resinous material. & 105 \\
\hline
\end{tabular}

Cacao Butter. This fat contains stearic acid to an extent of about 40 percent. Oleic acid is present in excess of 30 percent. Several other fatty acids have been declared to be present, but their amounts are debated. Palmitic, arachidic and linolic acids have been found and, according to debatable evidence, lauric and caprylic are also present.

Palm Kernel Oil. This interesting and much used fat, according to ELsDoN ${ }^{2}$ is composed of the following:

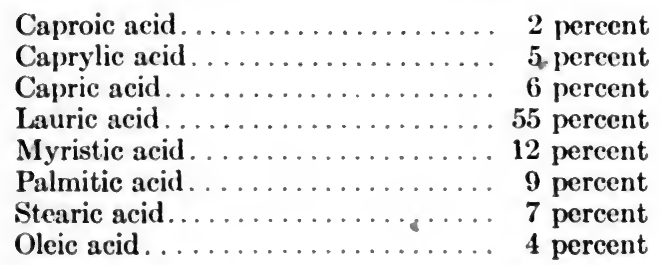

Palm kernel oil is largely used for soap making, chiefly in admixture with other oils and fats. Like cocoanut oil, it is eminently suitable for the manufacture of soaps by the "cold" process. The freshest oil is employed in the manufacture of vegetable butter.

Cocoamut Oil. J. Lewkowitsch uses the analysis of the fatty acids of cocoanut oil by PAULMYer to produce the following table:

\begin{tabular}{|c|c|}
\hline Caproic acid. & 0.25 percent \\
\hline Caprylic acid. & 0.25 percent \\
\hline Capric acid. & 19.50 percent \\
\hline Iasuric acid. & 40.0 percent \\
\hline Myristic acid & 24.0 percent \\
\hline Palmitic acid & 10.6 percent \\
\hline Oleic acid & 5.4 percent \\
\hline
\end{tabular}

1. Lewкow

2 Quoted by J. Lewкowitscu: Oils, Fats and Wuxes, 5th lid., 2, 621, London (1914). 
Lewkowitscu adds that the quantities of oleic, caproic and caprylic acids in this analysis are undoubtedly too low. An analysis by Euspon showed the following:

\begin{tabular}{|c|c|}
\hline Caproic acid & 2 percent \\
\hline Caprylic acid. & 9 percent \\
\hline Capric acid. & 10 percent \\
\hline Lauric acid. & 45 percent \\
\hline Myristic acid. & 20 percent \\
\hline Palmitic acid. & 7 percent \\
\hline Stearic acid & 5 percent \\
\hline Oleic acid. . & 2 percent \\
\hline
\end{tabular}

LEw kowitscr holds that the oleie acid figure in this analysis is also too low while that of stearic acid is much too high.

Japan. Wax. (Japan tallow). The important fatty acid constituent of this wax is palmitic acid. Among other acids, stearic, arachidic and oleic are said to be present. ${ }^{1}$

Goose Fat. This fat consists essentially of oleic, palmitic and stearic acids. There are present also small quantities of the lower volatile acids.

Hog Fat. According to Ernst Twitchell ${ }^{2}$ lard consists of the following:

$$
\begin{aligned}
& \text { Linolic acid ............. } 10.06 \text { percent } \\
& \text { Oleic acid . ............. 49.39 percent } \\
& \text { Solid acids (by difference)..... } 40.55 \text { percent }
\end{aligned}
$$

It is possible that linolenic acid is also present. In the group of the solid acids are lauric, myristic, palmitic and stearic.

Tallow. Tallow is essentially a mixture of palmitic, stearic, and oleic acids. According to an examination by Link in the laboratory of J. Lewkowitscir ${ }^{3}$ there are present 23.2 percent stearic acid, 28.4 percent palmitic acid and 48.4 percent oleic acid. It is possible that traces of other acids like linolenic also appear in tallow.

Butter fat. The following acids have been identified in butter fat: acetic (?), butyric, caproic, caprylic, eapric, lauric, myristic, palmitic, stearic, arachidic and oleic acids. It is held by certain authors that butter fat also contains hydroxylated acids. The presence of linolenic acid has been described. The percentages

2 J. Lewkowitsch: Oils, Fats and Waxes, 5th Ed., 2, 654, London (1914).

2 E. Twitchell: Jour. Soc. Chem. Industry, 515 (1895).

J. Lewrowitsch: Oils, Fats and Waxes, 5th Ed., 2, 767, London (1914). 
of the glycerids of the different fatty acids are as indicated in the following table, copied from LEwKowitsch.

\begin{tabular}{|c|c|c|c|}
\hline Glycerids. & J. BELL. & W. Bhyth. & SPAIIANZANR." \\
\hline \multirow[t]{2}{*}{ 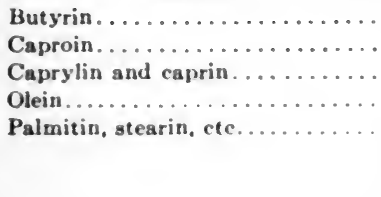 } & $\left\{\begin{array}{r}7.012 \\
2.250 \\
37.730 \\
52.978\end{array}\right.$ & $\begin{array}{r}7.7 \\
0.1 \\
42.2 \\
50.0\end{array}$ & $\begin{array}{r}5.0 \times 0 \\
1020 \\
0.307 \\
93.593\end{array}$ \\
\hline & 100 & 100 & 100 \\
\hline
\end{tabular}

* Spallanzani: Le Staz. Sperim. Ital., 23, 417 (1590).

Beeswax consists chiefly of free cerotic acid with a small quantity of free mellisic acid and small quantities of unsaturated fatty acids combined with alcohols. Ceryl alcohol appears free in beeswax. Beeswax contains little or no glycerin, other alcohols taking its place.

\section{Significance of Some Fat and Oil Constants for the Colloid-Chemistry of Soap}

Since complete analyses of the fats and oils which enter the soap chemist's kettle can scarcely be obtained, he must content himself in routine practice with a knowledge of their specific gravity, melting point, saponification value, R RIcitenT-M FissL value, iodin number, etc. For the non-technically trained, the meaning of these values and their probable significance indetermining in advance the colloid properties of the resultant soaps when more complete analyses of the fat are missing are appended.

Since the natural oils and fats are not definite chemical substances characterized by definite melting points, it becomes readily intelligible why discordant, results are obtained by any of the number of methods available for the determination of the melting points of oils and fats. In general, however, it may be said that the lower the melting point of a fat or oil, the higher the proportion in it of the lower melting point fatty acids, like the oleates, linolates or lower members of the aretic series.

The specific gravity of any pure fat. falls in any series with rise of the fatty acid in that series. Wide differences, however, exist between the specific gravities of the fatty acids of different. series. It is difficult for this reason, to find any relationship) 
between the specific gravity of mixed glycerids and the type of fatty acids found in the glycerids. In general, however, the lower the specific gravity of a fat the more likely it is to be found rich in the higher members of any fatty acid series.

The saponification value of an oil, fat or wax which indicates the number of milligrams of potassium hychroxid required for the complete saponification of one gram of the oil, fat or wax is indicative of the amount of potassium hydroxid required to neutralize completely the fatty acids in that oil, fat or wax. Other things being equal, a high saponification value therefore means a high content of the lower fatty acids.

The Reichert-Meissu value which shows the number of cubic centimeters of decinormal potash required to neutralize that portion of the volatile fatty acids which is obtained from 2.5 grams of a fat after distillation by the Reichent process, represents, obviously, the proportion of volatile fatty acid contained in any mixed fat most likely to yield soaps lying within the range of those commonly used for washing purposes.

The iodin value of a fat or fatty acid is a measure of the proportion of unsaturated fatty acids contained therein. It may be used as an index, in comparative studies, to the probable proportion of the unsaturated fatty acids present in any oil, fat or wax to those of the saturated fatty acids and, by inference, of the proportion of the soaps of these two series of fatty acids with their varying physico-chemical or colloid-chemical constants producible from the original material.

\section{Hot and Cold Process Soap Manufacture}

As familiarly known, soap manufacture may be carried on by either $(a)$ the cold process or $(b)$ the hot process. So far as the chemistry is concerned the two are supposed to yield the same result. In either case, a weighed amount of fat or oil has added to it the amount of caustic soda which analysis has shown the fat to require for conversion into neutral soap. What is obtained in the end is a neutral soap holding a certain amount of water plus the glycerin split off in the process of the conversion of the fat to soap.

It is a matter of practical experience that while the process of soap manufacture in the cold is the simplest, the results thus 
obtained are not always so satisfactory as when the process is carried out at a higher temperature. It is also a matter of empiric knowledge that certain fats readily yield satisfactory soaps when used in the cold while others, it might almost be said, never do so. The extremes are represented, on the one hand, by the use of such a fat as castor oil, cottonseed oil or even palm kernel oil; on the other hand, by the use of hydrogenated cottonseed oil, stearin or Japan wax.

What happens becomes intelligible when the qualities and quantities of the fatty acids found in these fats and oils are compared with the physico-chemical and colloid properties of soaps which are produced from the different fatty acids as illustrated in Figs. 1 to 13.1 Soaps are readily made by the cold process only from such fats as are approximately liquid or yield fatty acids which are liquid at the temperature at which the soap is manufactured. In the older schemes of soap manufacture this process was regularly employed with such oils as olive, cocoanut and cottonseed. Partly because larger and larger quantities of these materials are now used for food, and partly because the soaps from these materials are relatively soft and "wash away" easily (and for toilet purposes, for example, a somewhat firmer product is desired) the original oils have, with time, had admixed with them larger and larger fractions of fats with higher melting points. As this has happened the difficulty of making the soap by the "cold" process has increased, for the fats rich in palmitic acid, stearic acid, etc., cannot be thus saponified. At higher temperatures it is, of course, an easy matter. Since saponification represents an exothermic reaction, considerable heat is produced which warms the soap mixture. For this reason fatty acids melting at temperatures considerably above that of the surrounding medium can still be saponified in the " cold." The higher (solid) fatty acids also saponify more slowly than do the lower ones, whence the common practice of allowing the necessary fat-alkali reaction mixtures, when soin is produced by the "cold" process, to stand several days, while, to conserve the liberated heat, the vats or frames are protected with mattresses.

The now almost universally employed " hot" process of soap manufacture may be dismissed with the remark that at the higher temperature employed all the oils and fats used (or, in the Twirch-

\footnotetext{
'See pages 10 to 29 .
} 
ELL process, the fatty acids derived from them) are liquid and that their saponification in consequence occurs quickly and satisfactorily. Since only a few hours are necessary for complete saponification by the hot process, this is preferred by the manu-

facturer to the cold process which

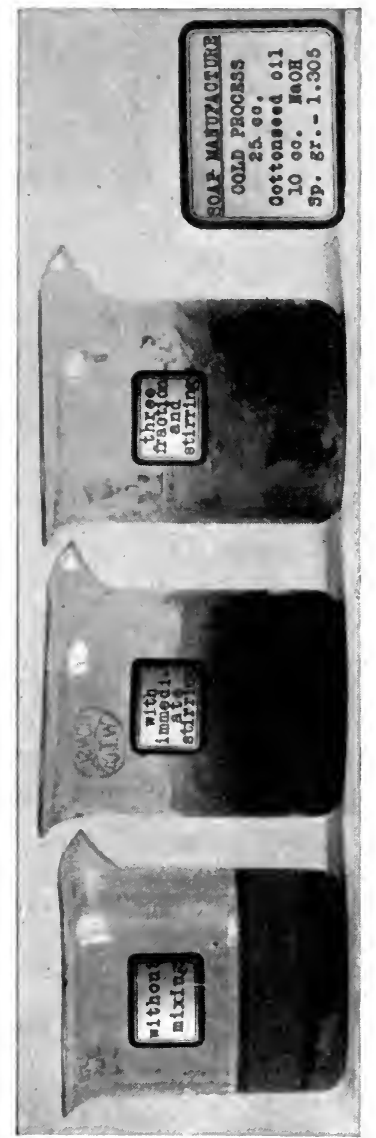
may require several days during which his vats, frames and machines are kept employed in the manufacture of a single batch of soap.

What has been written above may be readily illustrated in laboratory experiments which follow the practices of the soap chemist. In Fig. 93 are shown three beakers all containing the same mixtures of cottonseed oil and sodium hydroxid, the amounts having been so chosen as to yield a theoretically neutral soap. \% In the first beaker on the left and in the middle beaker, the sodium hydroxid solution has been poured in a single "charge" into the oil, the former having been left without stirring, the latter having been stirred immediately until the mixture showed signs of stiffening. In the beaker on the right, the sodium hydroxid was added in three separate "charges" (as is the practice in manufacturing), proper stirring following each new addition of alkali. The photograph was taken the following day. It will be observed that without stirring only a thin soap layer (very dry) forms between the oil and the watery alkali and saponification scems to come to a stop; that when added at once with satisfactory stirring a fine clear soap is obtained; that when added in three fractions a good soap but of less perfect appearance results. We shall return to these findings later, but it is evident at this time that from a low melting point fat a satisfactory soap 
may be obtained by the cold process if only the requisite amount of sodium hydroxid is added quickly and at once, the mixture is stirred until it shows definite signs of stiffening and is then left to itself.

Fig. 94 shows that when the cottonseed oil is hydrogenated, when, in other words, its oleic acid is converted into stearic (and similarly, perhaps, certain other unsaturated acids into saturated ones) the "cold" process no longer suffices to make soap. The appearance of the first beaker on the left in Fig. 94 must be compared with that of the middle beaker in Fig. 93. While no soap seems to have been produced in the cold, saponification of the hydrogenated fat is satisfactory as soon as the reaction mixture is heated for a time, as evidenced in the second beaker from the left of Fig. 94. The same general truths are brought out in the three right-hand beakers of Fig. 91 in which, to mimic accepted technical procedures more perfectly, a sodium hydroxid of lower concentration and a reaction mixture containing a larger total of water were used to accomplish saponification of the hydrogenated cottonseed oil. 'The middle beaker of the whole series shows that saponification is again impossible in the " cold." A partial result is obtained if the beaker is heated to above the liquefaction point of the fat and the mixture is stirred; but to get complete saponification the reaction mixture must be kept some time at

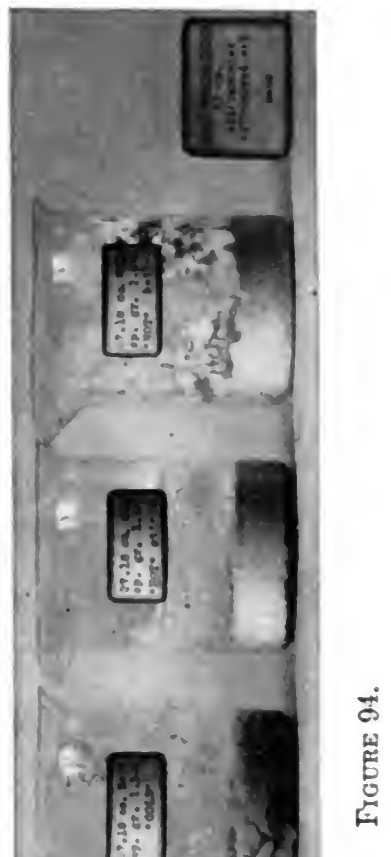
this high temperature as shown by the satisfactory result in the beaker on the extreme right of the series. 
Having observed how the type of oil or fat employed determines from a chemical point of view whether a cold or hot process of manufacture will yield best results, we need to review the whole process once more from the point of view of the changes which are incident to the mere mixing of any fat or oil with an alkali. The empiric instructions covering the process are again many. ${ }^{1}$ In the case of certain "oils" a stronger alkali may be used than when the more solid "fats" are employed; or in the case of the former all the alkali may be added more quickly or in one charge while in the latter several successive and smaller charges must be used. The soap maker has here again learned from practical experience what may be done with any individual oil or fat, or what may be accomplished by mixing or blending such. What do these things mean?

The older soap chemists recognized that, in their " cold" process of manufacture, emulsification of the fat played an important rôle; what happened in the hot process was not so clear.

\section{The Mixing of Fat with Alkali. Initial Emulsification}

J. LEIMDöRFER ${ }^{2}$ has correctly said that the colloid-chemistry of soaps begins with the commencement of their manufacture and in defense of this remark has emphasized anew the significance of emulsification in the cold method of soap manufacture. LEIMDÖRFER points out that when any fat is mixed with caustic soda solution the two are emulsified in each other and that in the "gum" or jelly which results, the process of saponification then proceeds to an end. According to LeimdörFer the soap formed "adsorbs" the alkali and the fat, the further reaction between these materials occurring in the soap gel itself, as it were. We shall have occasion to touch upon the "adsorption" phases of this explanation later. At this point we wish merely to consider in somewhat greater detail the initial process of emulsification.

It is held by various authors that the occurrence or nonoccurrence of this initial process of emulsification makes possible

${ }^{1}$ As an illustration of the technical literature extant see, for example, Alexander Watt: The Art of Soap Making, Ninth Imp., London (1918).

2 J. Leimdönfen: Technologie der Seife, 5, Dresden (1911). 
or impossible soap formation by the "cold" process. This conclusion has been drawn from the fact that the fats which do not emulsify readily in the cold also fail to saponify easily. While proper previous emulsification does accelerate saponification, the real difficulty is resident in the nature of the fatty acids present in the more solid fats - the higher (solid) fatty glyeerids being split with greater difficulty and the resulting fatty acids combining more slowly with alkali at low temperatures than do the more liquid oils with their lower and more nearly liquid fatty acids.

For the production of an emulsion, whether soap be made by the cold or the hot process and whether from neutral fat or the free fatty acids, it is necessary to hold distinctly in mind the mere making of the emulsion and its subsequent stabilization. Aid is rendered the first process by the mechanical agitation incident to the mere mixing of the soap-kettle constituents. Usually, also, a new bateh of soap is started by running the new mass of fat or oil to be saponified into a kettle containing the soap remnants left from a previous run. But even if a caustic alkali is run at once into a cold or a hot fat, soap formation begins very quickly, for rarely are these substances free from a certain amount of free fatty acid. As previously emphasized, it is not possible to emulsify fat in pure water. In soap manufacture, therefore, the fat.is not emulsified in water but, as is necessary in all such instances, in a liquid hydrated colloid. Hence the usefulness of beginning with a soap stock, the greater ease of emulsification if the fat used is liquid at the temperature employed and contains free fatty acid, and the exceeding simplicity of the whole process if all the soap is made from free fatty acid (by the TwiтcHELL process). The first portion of hydrated colloid found or produced in the soap kettle then permits the fats or fatty acids added subsequently to be properly and permanently cmulsified in them.

The ease with which such emulsification is obtained is in its turn resident in the physical qualities of the fat itself. It is obvious that emulsification can be obtained more easily in the case of a low melting point fat, like the liquid oils, than in that of the more solid fats, like tallow, stearin or Japan was. Finulsions are subdivisions of a liquid in a liquid. To get the more solid fats into this state an incrense in temperature is therefore 
demanded. It is for this reason that the high melting point fats, which are least likely to yield satisfactory emulsions (and

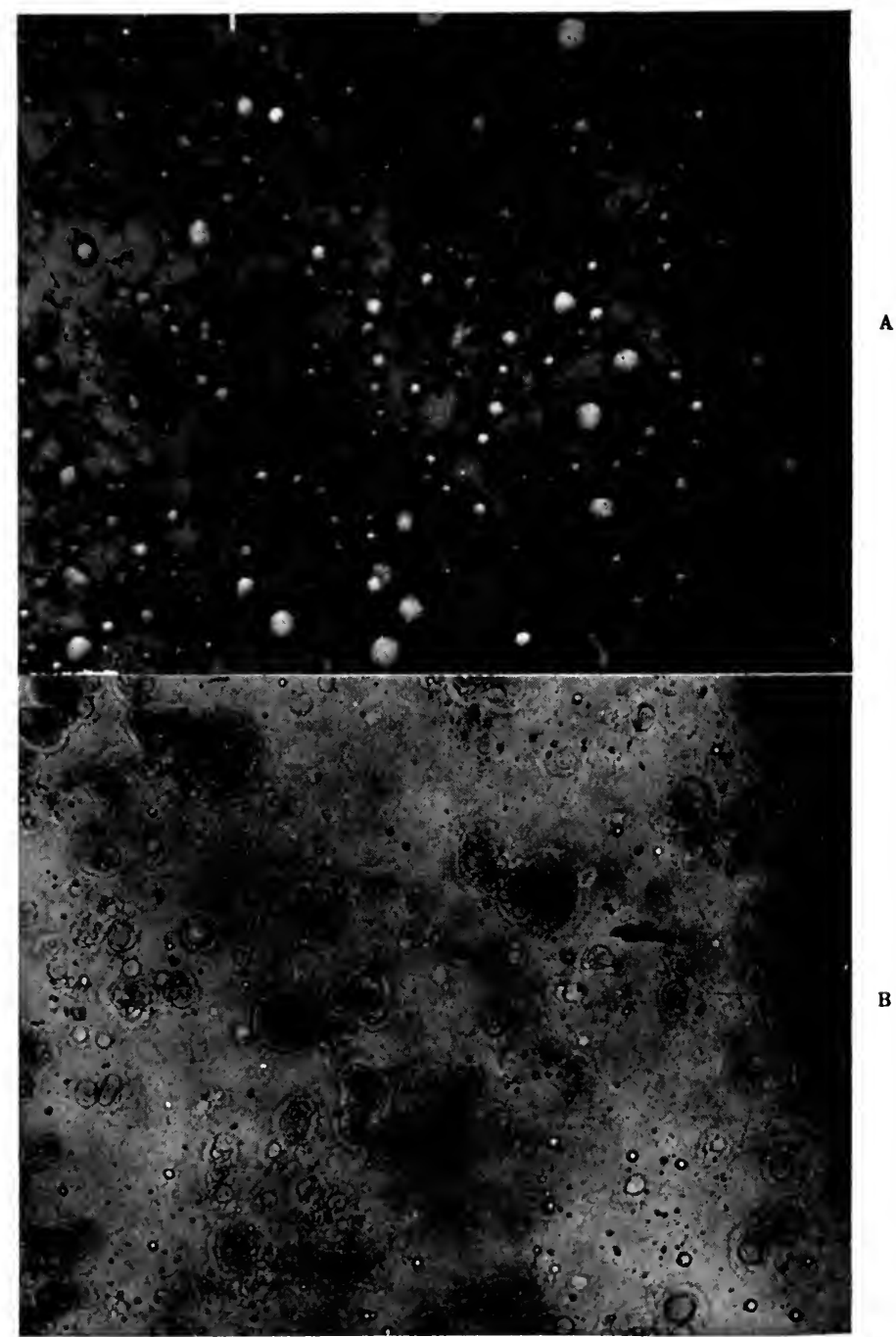

Figure

which saponify badly) at low temperatures, are best used at higher temperatures.

Another factor in this matter of emulsification is found in 
the properties of the soap formed to act as the colloid hydrate for the emulsification of the fat. For proper emulsification there

C
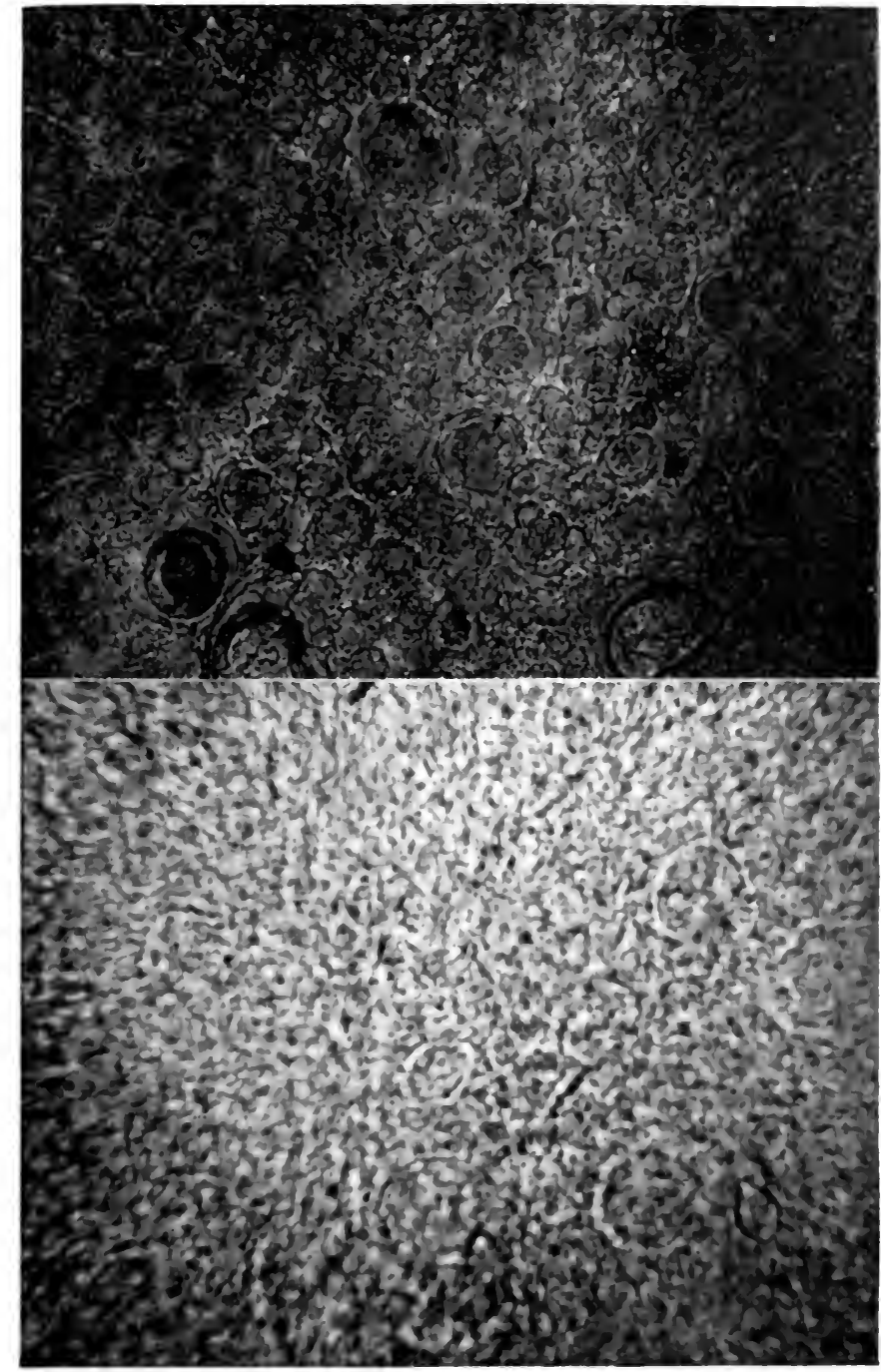

95.

is necessary not only an optimum couneontration of the soap) used, but alse a suitable kind of soaly.

For soap manufacture hy the cold process the soaps of the? 
lower fatty acids of the acetic series and the oleates, linolates, etc., act best as emulsifying agents, for these yield liquid hydrated colloids at the low temperatures prevailing in the reaction mixture. When, however, soap manufacture is carried out at a higher temperature it is obvious that soaps of the higher fatty acids will act better, for at these higher temperatures the soaps of the lower fatty acids will have "gone into true solution," thus losing their hydrophilic character. While the soaps of the higher fatty acids are solid in the cold process and of little use for cmulsification purposes, they become liquid hydrated colloids at the higher temperatures and stabilize any emulsion that may be formed.

It is of interest to examine microscopically the changes incident to this emulsification process. Fig. 95 shows the successive changes observable when soap is made by the cold process from cottonseed oil and caustic soda. After the two materials have been stirred into each other as previously described for the middle beaker of Fig. 93, a soap is rapidly formed (since cottonseed oil usually contains some free fatty acid) in which the unused portions of oil then become dispersed as shown in photomicrograph $A$ of Fig. 95. If a drop of this mixture is watched under the microscope for a little time, the oil droplets are found to diminish in size while becoming surrounded with an increasingly thicker halo of hydrated soap. This is shown in $B$. The halo grows in thickness until the whole alkali-fat mixture sets into a firm jelly, the appearance at this stage being represented by $C$. In the course of a number of hours or several days the whole reaction mixture comes to chemical equilibrium, when it presents the more or less uniform appearance of $D$. This final picture represents a hydrated mixed soap in which the soaps of the higher fatty acids tend to crystallize within the soaps possessed of lower melting points.

\section{Concentration of Alkali and Method of Adding it for Saponification}

We need now to go back over the course of soap making a third time in order to analyze for a moment some of the practical facts utilized in determining the method and the concentration at which an alkali is added to different fats and oils for their 
saponification. It may be stated as generally true that alkali may be added in high concentration or in a single charge of the theoretically necessary amount only to such liquid fats as cottonseed oil, castor oil, linseed oil, cocoanut oil or palm kernel oil. When tallow, stearin or Japan wax soap is to be made, the alkali must be added in several smaller charges and the concentration of alkali in the individual charges must be lower. To give specific examples the following may be eited. Linseed oil may be saponified by adding to it at once the requisite amount of sodium hydroxid at $24^{\circ}$ to $28^{\circ}$ Baumé (17.6 to 21.4 percent); cocoanut oil will tolerate a first charge at $16^{\circ}$ to $20^{\circ}$ Baumé (10.9 to 14.3 percent). Against these figures tallow must, be treated with a first fractional charge at $11^{\circ}$ Baumé ( 7.3 percent) succeeded by a second at $12^{\circ}$ to $15^{\circ}$ Baumé ( 8.0 to 10.0 percent). Even the final charge may not safely exceed $20^{\circ}$ Baumé (14.3 percent). What is the explanation for these empirically well known facts? It is not a matter merely of the readier saponification of the lower melting point fatty acids found in the oils or of the greater tendency of the higher fatty acid soaps to hydrolyze. Were this the case, then the higher concentrations of alkali should act best upon the higher melting point fats, while just the opposite is the case. It is the greater sensitiveness of the soaps of the higher fatty acids to salting-out effects (of the sodium hydroxid in this case) which explains these empiric findings. The soaps of castor oil, linseed oil and cocoanut oil can scarcely be salted out by sodium hydroxid at any concentration, while the sodium palmitate, stearate. arachidate, etc., formed from tallow, Japan wax, etc., come out in very low concentrations of alkali. ${ }^{1}$ The use of larger volumes of sodium hydroxid containing lower concentrations of the alkali in the production of the tallow soaps means that the soap as formed has more solvent present in which " to dissolve" while the concentration of alkali present in this solvent is not sufficient, to salt out the soap. The alkali added in a first charge is lost from the system as it combines with the fat to make soap, in consequence of which the second charge may be of higher concentration for this is quickly diluted on entering the soap kettle by the volume of water carried in with the first charge. With the second charge of alkali used up in saponification, the third charge is quickly diluted with the water left from the previous charges to 
a concentration which will not in its turn salt out the soap, for it is at all times the concentration and not the amount of alkali (or other salt) in the entire soap/water system which determines its salting-out effects.

Given the qualitative composition of a fat, the upper limit of the concentration of any hydroxid which may be used for its saponification is determined by the concentration at which the soap of the highest fatty acid found in that fat is salted out at the temperature prevailing in the soap vat.

\section{The Changes in Soap Systems Consequent upon Cooling}

The first change to be discussed as the temperature of a boiling soap/water system is lowered (whether it contains glycerin or not) is that of its tendency to change from what at the higher temperature was a solution of soap-in-water to that which at the lower is one of water-in-soap. The apparently contradictory findings and views which different authors have recited covering the nature of the changes observed may all be harmonized when these changes from one system to the other (including the possible intermediates of an "emulsion" of hydrated soap in soap water followed by one of soap water in hydrated soap) are kept in mind.

Beginning with the days of Chevreul, the soaps were held to be salts of the fatty acids containing a definite amount of water of crystallization which on solution in water yielded " solutions" like all other salts. Many physical chemists held to this view into the nineties of the last century, for pure and mixed soaps in dilute solution showed an osmotic pressure, an electrical conductivity, a depression of the freezing point or elevation of the boiling point quite like " normal" electrolytes. (James W. McBaIN, M. Taylor, C. C. V. Cornish and R. C. Bowden, ${ }^{1}$ McBain and TAYLOR $^{2}$ ). Following the studies of F. KRAFFT and H. WIgLOw, ${ }^{3}$

${ }^{1}$ James W. McBain, M. Taylor, C. C. V. Cornish and R. C. Bowden: Berich. d. deut. chem. Gesellsch., 43, 321 (1910); Jour. Chem. Soc., 101, 2041 (1913).

${ }^{2}$ McBain and Taylor: Zeitschr. f. physik. Chem., 76, 179 (1911); since this time, however, these authors have modified their views; see Jour. Am. Chem. Soc., 42, 426 (1920).

${ }^{3}$ F. KraffT and H. Wiglow: Berich. d. deut. chem. Gesellsch., 28, 2573 (1895). 
A. Smits, ${ }^{1}$ F. Goldschmidt and L. Weissmanx, ${ }^{2}$ these views received modification. KrafFT and WigLow observed that when the soaps of the higher fatty acids were studied at low temperatures these commonly did not lower the freezing point in the calculated amount; and Goldschmid found that the electrical conductivity was not as high as theory demanded. The same soaps when studied at sufficiently high temperatures did, however, show the behavior of normal electrolytes. Obviously the earlier observers and those working at high temperatures dealt with what were essentially true solutions of soaps in water; the latter students of the problem, working at lower temperatures and with higher fatty acid soaps, dealt with mixed systems. The former worked in the region $A$ of Figs. 48 and 49; the latter anywhere below this but still in regions in which were present solutions of soap-inwater admixed with solutions of water-in-soap. What characteristics of a "true" solution their mixtures still showed were dependent upon the presence of the former; the characteristics at variance with those anticipated, in other words, the "colloid" properties of the systems were dependent upon the latter.

\section{The Salting-Out of Mixed Soaps}

The salting-out of mixed soaps has been made the object of special study by MERKLeN ${ }^{3}$ and Leimdörfer. ${ }^{4}$ Both give excellent analyses of the content of soap, water and dissolved substances (like alkali and salts) present in the two main phases, the "lye" and the "curd" or "settled" soap, which may be obtained after complete or partial salting-out.

The observations detailed in the previous pages on the saltingout of the different soaps help us to explain, we think, in simpler fashion than is generally the case the series of changes observed in the contents of the soap kettle when salted and cooled. In the ordinary salting-out process common sodium chlorid is shoveled into the boiling soap kettle in dry form. Assuming that it goes into solution at once, it is obvious that there follows a progressive increase in the concentration of the salt in a soap/water system.

'A. Smits: Zeitschr. f. physik. Chem., 45, 608 (1903). (1912).

2 F. Goldschmirt and L. Weissmann: Zeitschr. f. Electrochem., 18, 380

'Francons Merklex: Die Kernseifen, trans, by Frasz Goldschmiot. Halle a/S (1907).

†J. Leimdörfer: Technologie der Seife, Dresden (1911). 
While it is ordinarily thought that all the soaps present in the mixture of soaps in the soap kettle begin to separate out as soon as a sufficient concentration of the salt has been obtained, the quantitative studies previously detailed show that this is by no means the case. A concentration of salt which will salt out the soaps of the higher fatty acids of the acetic series will obviously be reached sooner than one which will salt out the lower soaps. While, for instance, a sodium stearate is salted out in the eold by a $5^{\circ}$ Baumé sodium chlorid solution, sodium laurate requires a $17^{\circ}$ Baumé salt water (C. Stieper $\left.{ }^{1}\right)$. The general truth of this law finds expression in the fact that after apparent total separation of the mixed soaps as a curd from the spent lye, the latter still contains some soap. But the contained soaps are essentially those of the lower fatty acids. The eurd per contra is relatively poor in these.

During the process of salting-out, a soap mixture frequently "gums," "goes stringy" and tends to boil over, a situation which the practical soap maker has learned to meet by rapidly shoveling in more salt. The explanation of what happens is found in the experiments on the salting-out of soaps. Before complete salting-out is obtained the previously liquid soap mixtures tend to gel because of the emulsification within them of salt-water. Through the addition of more salt, however, the amount of this salt-water phase is increased and as this happens, change in type of emulsion occurs - the hydrated soap now becoming dispersed within the salt-water as the external phase,-and the viscosity of the kettle contents falls.

It is the common practice in the salting-out of soaps to add $d r y$ salt to the soap kettle. This represents economy, of course, from the point of view of the amount of salt needed, for it is the concentration of the salt in the total volume of water present which determines when the mixed soaps will " come out of solution." Solution of the crystals of salt in the soap kettle, however, takes time and even the shoveling in of more salt into the soap kettle does not at once increase the concentration of dissolved salt. The use of a proper brine under such eircumstances would work better and more rapidly in bringing the soap kettle contents to the safe side of the gelation point of the mixture.

${ }^{1}$ C. Stiepel: Fette, Oele und Wachse, usw., 112, Leipzig (1911). See also page 116 . 
There needs also to be explained the differences incident to the salting-out of soap at a high temperature and at a lower one. Soap being more soluble in water at a higher temperature, a highor absolute concentration of salt is required to salt it out at such than at a lower one. The slow reversal in the system from one of soap-in-water to one of water-in-soap with lowering of temperatture needs also to be kept in mind. This explains the slow gelation commonly observed in the "lye" after the whole soap-watersalt mixture has been allowed to stand for a number of hours. The soaps of the lower fatty acids which are still soluble in water at the higher temperatures, even when sodium chlorid or other salt has been added to the point where most of the soaps are salted out, slowly come out of solution, become hydrated, and if enough of such are present, the lye itself gels. ${ }^{1}$

\section{The Finishing of Soap}

Soap may be "finished " for market purposes in the soap ket te itself. More commonly, however, the "curd" obtained after complete salting-out of a soap is reheated, redissolved in more or less water and salted out more or less completely a second time by again being treated with sodium chlorid of different concentrations.

Depending, on the one hand, upon the kind of fatty acids and their quantitative relation to each other in a given mixture (factors commonly ignored), upon the other, on the amount of sodium chlorid added, there may be obtained (1) a grained or eurd soap, (2) a settled soap, (3) a half-settled soap or (4) a soft soap.

1 This is the system obtained in making a "settled" soap (the "Kernseife auf Leimniederschlag" of the Germans) and that upon which Mrrktes made most of his observations. He considers the gelatinous lye "a solution of soaps in an alkaline lye containing salts;" the soap curd also "a solution of soaps in an alkaline lye containing salts" and holds the two to represent

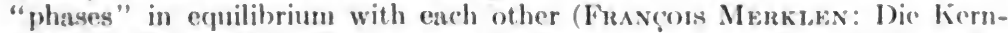
seifen 13, Hallea /S (1907)). As obvious from the above, the " curd " phase is a highly concentrated one of hydrated (higher fatty acid) soap containing some salt-water emulsified in it; the "lye" phase (when gelatinous) alse one of hydrated (lower fatty acid) soap of lower concentration and containing a high percentage of salt-water emulsified within it. See the succeeding section. 


\section{$\S 1$}

The grained or curd soap is obtained whenever enough sodium chlorid is added for complete salting-out of the soap. Under such circumstances the vat contents separate into two distinct phases; an upper consisting in essence of pure soap containing very little water and very little sodium chlorid, and a lower, in essence only a strong sodium chlorid solution containing practically no soap.

For the production of a settled soap a lower concentration of sodium chlorid is used. Under such circumstances separation into two phases also occurs. The upper is again essentially a curd soap but it is less dry this time. Because of the larger proportion of water the soap is smoother and of a more homogeneous structure. It also contains a larger fraction of salt. The lower phase is still in essence a "salt solution" but because of the less perfect salting-out of the soap (especially of those soaps least sensitive to salt action) this phase still contains so high a fraction of "dissolved" soap that on cooling it jellies. The soap system as a whole represents what the Germans call "Kernseife auf Leimniederschlag" and it is this system which FrançoIs MERKLen ${ }^{1}$ has studied in detail and to which he has applied the phase rule. We question whether the true nature of the two phases has been correctly understood by this author,-scarcely a matter of surprise when it is remembered that he worked throughout with mixed soaps. In our judgment, the series of changes observed and the nature of the two phases finally obtained seems to be as follows. The concentration of sodium chlorid added to the original soap solution is such as will salt out the various soaps unequally well and only partially. The soaps most sensitive to the presence of salt will obviously tend to come out first, whence the upper phase or "curd" (rich in soaps of the higher members of the acetic series, the oleates, linolates, etc., and relatively poor in water) caught in the meshes of which is a certain amount of salt water. The latter is responsible for the higher fraction of salt found in settled soaps when compared with pure curd soaps. Some soaps, especially those produced from the lower members of the acetic series, remain in solution in the lower or salt water phase but with time these, too, fall out of solution and become

${ }^{1}$ François Merklen: Étude sur la constitution des savons du commerce, Marseilles (1906). 
hydrated, whence the late jellying of the lower of the two phases in the vat. After such jellying has occurred, the lower phase is qualitatively similar to the upper phase but different in quantitative composition. The lower phase, too, is an emulsion of salt water in hydrated soap, but viewed as a whole this system is poorer in soap, and richer in water and sodium chlorid.

To produce half-settled soap, still less sodium chlorid is used in the finishing of an originally curded soap or, as commonly practiced, not enough salt is added to the hot contents of the soap kettle to get any salting-out. On cooling, the kettle contents simply become fairly solid. Separation into two distinct phases does not occur, the contents of the kettle or soap vat simply changing to a soap which in essence is an emulsion of salt water in a relatively highly hydrated soap.

If the attempt is made to increase still further the waterholding capacity of a soap, a mixture is finally obtained which is no longer definitely solid. We then have a so-called soft soap.

The above paragraphs have described the finishing process in soap manufacture as carried out with sodium chlorid. In practice, however, other materials having an action similar to that of sodium chlorid may be, and are, used to accomplish similar ends. Instead of being "filled" with sodium chlorid solution, soaps may be filled with ingredients more useful in washing, like sodium carbonate, borax or water-glass. ${ }^{1}$ Under such circumstances there are also obtained as final products, emulsions or " solutions" of these various materials in hydrated soap.

\section{$\S 2$}

The inequality in distribution of such a dissolved substance as sodium chlorid, alkali or sodium earbonate between the two phases commonly produced in a soap vat (the upper soaprich phase and the lower soap-poor phase) has often been interpreted in the terms of "adsorption." There is still much debate about the nature of adsorption, though it is generally assumed that the union between adsorbent and adsorbed material is of a physical character and that it follows the adsorption law, which states, in brief, that an adsorbent will take up relatively more of a dissolved substance from a dilute solution than from a more

'See the succeeding section, page 192. 
concentrated one. Without pointing out that none of the authors who have used the concepts of adsorption for the elucidation of various problems in soap-making have ever supported their contentions with any figures, it is obvious, if the views expressed above are correet, that what they have taken as evidences of "adsorption" between various so-called "dissolved" substances and the soaps (alkali, fat and soap in the original soap kettle; water, salt and soap in the salting-out process; sodium carbonate, waterglass and soap in the "filling" process, etc.) can all be more easily understood merely as the expression of the emulsification of one type of liquid (like fat or salt solution) in a second (the soaps of the various fatty acids with their variable hydration eapacities).

$$
\S 3
$$

In the finishing of soaps (particularly the toilet soaps) for the market, there is often added glycerin or some other alcohol. Under such cireumstances the product is more likely to be transparent. The reasons for this are found in the nature of the colloid-chemical system soap/aleohol as compared with that of soap/ water. The former is uniformly clearer than the latter. From certain soap/alcohol systems, like sodium palmitate with benzyl alcohol, finished soaps may be obtained which are glasslike in appearance.

\section{Some Physical Constants of Market Soaps}

\section{$\S 1$}

Exclusive of admixture with non-saponifiable materials, exclusive of the effects of all additions in the way of excess alkali, salts or fillers and exclusive also of variation in type of solvent (presence or absence of glycerin or other alcohols) a correct estimate of what will be the physico-chemical properties of any soap must evidently depend first, upon the kind, the number and the relative proportions of the fatty acids found in the original fat used for saponification. With a given base and with a constant solvent (water) the result is that obtained when such a mixture of different soaps is allowed to come together in the presence of a limited amount of water.

The ordinary bar of pure soap is therefore essentiaily only a sulid "solution" of water in a mixture of sodium soaps. Except 
in the instance of soaps designed to meet special purposes, the stock sodium soap contains a long list of different fatty acids and as such serves to meet technologic needs under the largest number of ordinary circumstances. Usually, in the manufacture of such soap some liquid oil or fat (like cocoanut oil) has had added to it smaller fractions of the more solid fats (like stearin, tallow or Japan wax). The result is a set of some eight to fifteen different soaps of widely varying "solubility" in water and sensitiveness to salt action, and possessed of a chain of fatty acids of progressively different melting points.

When such a mixed soap is completely salted out from its "solvent" as a curd soap it is a relatively dry affair, the yield from 100 parts of the original fat being only about 150 parts of finished soap. When neutral and carefully handled this is the basis of most of the common toilet soaps. The advantages of such a material for all ordinary purposes are obvious. The soap is free from any excess of alkali or sodium chlorid and the series of soaps present yields a satisfactory (liquid) hydrated colloid with water at any of the ordinary temperatures at which it may be used. Since, moreover, in the salting-out process, the higher acetic series soaps come out first and the lower ones with the oleate come out later, the arrangement of the different soaps within the solid bar is also such that the most readily "soluble" soaps become hydrated and dissolve first, thus favoring disintegration of the bar for the production of the hydrated liquid colloid required for washing.

It is well to discuss here the composition and nature of the so-called hot and cold water soaps and the marine soaps. A cold water soap is one which will in cold water yield the (liquid) hydrated colloid necessary for washing. Obviously only soaps rich in the lower fatty acids of the acetic series will do this, and hence the use of pure cocoanut oil for the production of such a soap, and the omission from the soap kettle of fats rich in palmitic, stearic and arachidic acids; for the same reason fats containing in essence only oleic, linolic and similarly constituted acids are used for such soaps. On the other hand a hot water soap must contain the higher fatty acids, for at higher temperatures the lower soaps "dissolve" and pass through the liquid hydrophilic colloid state into true solution too rapidly. The marine soaps are such as will maintain their hydrophilic colloid properties 
(and consequently will wash) even in relatively highly concentrated salt solutions, like sea water. The ordinary soaps rich in the stearates and palmitates are useless under such circumstances, but the soaps of pure cocoanut oil and similarly constituted fats work very well, for their entire soap series is largely unaffected by sodium chlorid of the concentration found in sea water.

The settled soaps, which are smoother and decidedly less dry than the curd soaps, owe these properties to the fact that they hold more water than the latter. In the curd soaps the higher, more solid and more erystalline soaps tend to fall out within the more liquid ones, thus making for non-homogeneous soap mixtures. When through such less perfect salting-out these higher soaps are permitted to hold a larger fraction of water the whole system appears clearer. Because of the higher water content 100 parts of the mixed fats commonly yield 175 to 200 parts by weight of finished soap of the settled type.

The half-settled soaps and the soft soaps are usually made from the kettle contents direct. They differ from eurd and settled soaps in containing a still larger fraction of water-commonly 250 to 600 parts of finished soap being obtained from 100 parts of fat. The water in these soaps is held in part in the soap itself, in equally large or even larger fraction, however, as water joined to filler. The filler may be sodium chlorid but commonly it is water-glass, excess alkali, sodium carbonate or sodium borate, or two or more of these in combination. When sodium soaps are filled with these materials a final product is obtained which is still fairly firm. The distinctly soft soaps are usually potassium soaps made from fats and fatty acids of low melting points. These may be and are filled with potassium salts so that the final yield may be as great as ten times the orginal weight of the fat used. When the filling of potassium soaps is carried out with sodium salts a partial conversion to sodium soap occurs which tends to make the final product less soft.

\section{$\S 2$}

In connection with the above facts which show how much water different soaps may be made to hold, it is of interest to introduce some experiments of C. STIEPEL ${ }^{1}$ on the hygroscopic

${ }^{1}$ C. Stiepel: Fette, Oele und Wachse, usw., 100, Leipzig (1911). 
properties of the sodium and potassium soaps of different fatty acids. STIEPEL found that 100 parts of the following dry soaps would take up from the air the following number of parts by weight of water:

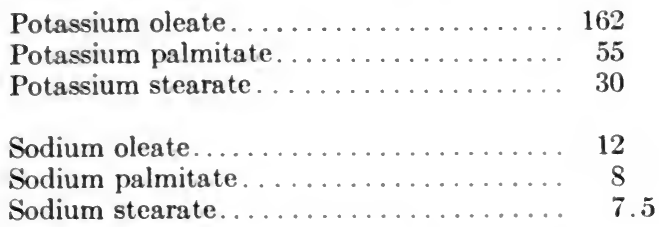

As we consider the water-holding power of different soaps against the forces of evaporation of much biological importance (since the metallic fatty acid compounds are analogous, in our minds, to the metallic amino (fatty) acid compounds which make up protoplasm ${ }^{1}$ ) we wish to insert here some experiments on the rate of water loss by various soaps when exposed to ordinary atmospheric conditions. The relationship between the chemical constitution of a soap and that of the rate at which any amount of water it holds in colloid-chemical union is lost to the air is shown by the following:

When 10 grams of half molar "solutions" of different soaps of the acetic series are placed in low evaporating dishes, $10 \mathrm{~cm}$. in diameter, and allowed to lose water at $18^{\circ} \mathrm{C}$., the relative percentages of weight lost at the end of seventy-two hours are as indicated in Table LVI. There is obviously an inhibition to water loss by evaporation as the acetic series is ascended and a greater water loss in the case of the sodium soaps than in that of the potassium soaps.

TABI.E I,VI

\begin{tabular}{|c|c|c|}
\hline & $\mathrm{Na}$ & $\mathbf{k}$ \\
\hline Propionate. ....... & 95.2 & 93.0 \\
\hline Butyrate........ & 92.0 & 93.0 \\
\hline Valerate.......... & 93.0 & 93.0 \\
\hline Caproste.......... & 91.0 & 90.0 \\
\hline Caprylate........ & 90.0 & 91.4 \\
\hline Caprate........... & 86.0 & 88.0 \\
\hline Laurate.......... & 87.0 & 87.0 \\
\hline Myristate. . . . . . . . . & 85.0 & 83.0 \\
\hline Palmitate......... & 83.0 & 30.0 \\
\hline Margarate......... & 85.4 & 15.4 \\
\hline Stearnte........... & 79.0 & 16.0 \\
\hline
\end{tabular}

I See page 205. 
When half molar " solutions" of sodium and potassium oleate are studied under similar circumstances the values differ as follows:

Oleate................ $\begin{array}{rr}\mathrm{Na} & \mathrm{K} \\ 86 & 81\end{array}$

\section{The Conversion of One Soap into Another}

The fact previously stated that one metal will never completely displace the metal from another soap but that the system will merely tend to the production of a state of equilibrium between the two has long been taken advantage of in various ways in practical soap manufacture, both in the direction of the production of a less "soluble" soap from a more soluble one and vice versa.

Under the first heading may be eited the production of sodium soaps from potassium soaps. While the process has been largely discarded, it remains an interesting illustration of how, empirically, good methods are followed even when the reasons for the practices are imperfectly understood. Especially in the manufacture of sodium "tallow" soap was it long considered best to start its production through the addition of caustic potash to the "tallow." After the fat was converted into potassium soap, this was changed into sodium soap and subsequently salted out through addition of sodium chlorid. It is self-evident that the procedure in reality represents the production of a potassium soap followed by its (partial) decomposition to sodium soap through addition of the sodium salt, and the subsequent saltingout of this mixed potassium-sodium soap by the excess of sodium chlorid mixed with the potassium chlorid formed through double decomposition. The process has been largely discarded in this country because of the high cost of potassium hydroxid and the lower cost of sodium hydroxid, but it is a question whether in so doing something of advantage in the quality of the soap produced has not also been sacrificed. "The "tallow" soaps (and still more those now produced from hydrogenated cottonseed and other oils) are soaps rich in the higher fatty acids (especially palmitic and stearic) and to produce in the soap kettle the potassium soaps of these compounds is to produce such as are decidedly more soluble (and hence more quickly obtained) 
than the corresponding sodium soaps. But even after their conversion into the sodium soaps, those made by the indirect process have advantages not possessed by the sodium soaps produced directly, the sodium soaps produced by the indirect process being not only softer and smoother but being generally more satisfactory in the matter of lathering and for washing purposes than the straight sodium soaps. These advantages are dependent upon the fact that through indirect manufacture the potassium soap is not completely converted to sodium soap; it continues to carry admixed a certain remnant of potassium soap, the technologic advantage of which over the sodium soap is particularly marked when the higher fatty acids are concerned.

Advantage of these general truths continues to be taken in the present day manufacture of the "shaving" soaps, which are essentially only carefully neutralized soaps, which in addition to sodium carry a certain amount of potassium as the base combined with the fatty acids. Because of their content of potassium soaps, especially of the higher fatty acids, the shaving soaps lather more easily than the pure sodium soaps and are subsequently less likely to "dry on the face."

Various patents and processes are known to the soap manufacturer in which fats and oils are first saponified with ammonium hydroxid and the ammonium soap is then converted into sodium soap through addition of sodium chlorid or sodium carbonate. The underlying principles are again the same; the advantages of the resulting soap are again those of having admixed in the sodium soap a certain amount of "more soluble" ammonium soap.

The reverse situation, namely, that of making a "more soluble" soap from a less soluble one is illustrated in the P. Kireniтz process of glycerin and soap manufacture. In this the fat or oil is first converted into calcium soap by boiling it with caustic lime. The granular calcium soap thus produced is then changed to sodium soap through the addition of sodium carbonate. As in the previously described process, in which a certain amount of potassium is carried over, the resultant soap in this instance carries over certain of the attributes of the original calcium soap. Soaps made by this process are therefore dryer, more brittle, and incline to be whiter than the corresponding pure sodium soaps made directly from the same fatty acids. 


\section{II}

\section{FILLERS FOR SOAPS}

The extensive use of various fillers in the manufacture of soaps necessitates touching upon this problem. It has been discussed from many points of view. Various inventors and manufacturers have been honest in stating that the primary purpose of such fillers is to meet the demand for " cheap" soap. Others, to justify the procedure, emphasize the improved washing characteristics of such soaps. Thus, a certain excess of alkali is actually necessary in the soaps used for cleansing wool; an excess of sodium carbonate acts as a softener, when, as is commonly the case, untreated water containing calcium or magnesium is used; water-glass, so commonly used to fill soaps, has colloid-chemical properties similar to those of soap itself. On the other hand, sugar tends to keep soaps transparent, while various sands and pumice give them abrasive properties which may be of serivee in various technologic procedures. The fact remains, however, that "fillers" are commonly materials decidedly cheaper than soap itself, that they tend, in general, to add weight or water to the finished product and that in most instances, as one of our soap chemist friends (C. P. LoNG) puts it, they hasten the millennium when the soap maker will be able to "get a bar of water to stand alone."

Our problem is fortunately not concerned with the necessities or the moralities of the situation, but with the question of what the mixture of soap with these materials means in the terms of colloid chemistry.

Most of the materials used to fill soaps (exclusive of inconsequential amounts of perfume, various coloring substances commonly employed, and certain " dirt" solvents like naphtha) may be listed with some one of the following three groups.

Group I. Sodium chlorid, sodium carbonate, sodium borate and sodium silicate.

Group II. Sugar solutions. 


\section{Group III.}

(A) Potato flour, tapioca meal, starches and seed husks.

(B) Clay, barytes, asbestos, chalk and solutions of magnesium salts (?)

From a colloid-chemical point of view, it is easiest to dispose of the third group first. With the exception of magnesium sulphate (which might more correctly be placed in the first group) all the substances used are earths or carbohydrates which, as employed, are largely colloid and possessed of a considerable capacity for hydration. As such they are therefore only materials which, when mixed with the soap, increase the volume of what is sold to the public as soap. This does not mean, of course, that, under certain circumstances, the sandlike properties of some of these fillers may not be of service or actually necessary in various washing processes. Since the washing properties of soaps are in large measure associated with their properties as hydrated colloids and as such properties are more or less common to all hydrated colloids whether inorganic (hydrated clays) or organic (swollen starch grains), this fact may, of course, also be emphasized. But unless the composition and such merits or demerits of the material which is sold to the public as soap are clearly stated, the motives behind their use cannot be held to be higher than those always incident to mere substitution.

With the market price of sugar what it is, the use of this material as a filler cannot be charged to any desire to increase yield while decreasing cost of production. The soaps may be "loaded" with the sugars (which carry with them not only high specific gravity but also a certain amount of water), yet the real reason for their use seems now to be that they give increased transparency to the product. How the sugars accomplish this is not yet settled. The sugars do not at any concentration "salt-out" the soaps so that any combination of the sugar with the solvent (as so frequently discussed in the case of the salts) must either be decidedly less or of a different type. The sugars clarify soap/water systems as do alcohols or aldehyds, which prompts us to the conclusion that they have an action like the last-named materials and so really owe their effects to the furnishing of such a substitute "solvent" for the pure water more commonly present in soap.

In the substances of the first group, we deal throughout with 
the production of systems similar to those previously discussed in the salting-out of soaps. ${ }^{1}$ The addition of sodium chlorid, sodium carbonate, sodium borate and sodium silicate represents nothing but a process in which advantage is taken of the fact that all these materials become hydrated and emulsified in the hydrated soap, thus yielding a stiffer and larger amount of mixture than would the soap alone. In this fashion soaps can be sold with a larger absolute water content and still appear "dry." Beyond this, the merits or demerits of these fillers depend upon their specific properties. Sodium chlorid is obviously entirely worthless,it has no " softening" or other action upon water and its presence interferes with the development of the washing effects of all soaps. Sodium carbonate and sodium borate do aid in the first-named direction and any excess thus unused yields an overplus of alkali (after hydrolysis in water) which in its turn is possessed of those advantages which any alkali may show in specific washing processes. The same may be said of sodium silicate (especially of the commercially employed "water-glass") which in addition to the properties already mentioned yields colloid silicic acid when diluted in the process of washing. The colloid silicic acid has some of the properties which give to soap itself its washing characteristics. From these advantages must, however, be subtracted certain disadvantages, as the fixation of the silicic acid upon the washed materials and their "felting," the smarting of the skin if the soap is used for toilet purposes, etc.

How sodium chlorid produces the "fill" when added to any soap has already been discussed. ${ }^{2}$ How sodium carbonate, sodium silicate, sodium borate and magnesium sulphate act in entirely analogous fashion is illustrated for two pure soaps (sodium and potassium oleate) in Figs. 96 and 97 and Tables LVII, LVIII, LIX, LX, LXI, LXII, LXIII and LXIV, which detail the experimental procedures followed. The purpose of the soap maker is to obtain, from such otherwise liquid mixtures as are contained in the control tubes shown at the extreme right of all these series, the solid soaps found in tubes nearer the middle of each of the series. The exact point at which such maximal stiffening of the soaps is obtained varies, however, both with the type of soap initially employed (whether a sodium or a potassium soap, for example) and the nature of the salt used as " filler." At the same 
molar concentration sodium carbonaic is least effective, sodium silicate takes a middle position and sodium borate is strongest. The photographs (and the experimental protocols) show how, as these different salts are used, the gelation point is shifted further toward the left. It will be noted that sodium borate at half the concentration of sodium silieate produces an equal degree of soap filling, and, also, that the sodium borate is as powerful in ultimate effects as double the concentration of magnesium sulphate. ${ }^{1}$ It is questionable, of course, whether the addition of magnesium sulphate to soap has any justification whatsoever save that of giving "load." Magnesium sulphate adds nothing to water which improves its washing characteristics and, as the lowermost series of tubes in Figs. 96 and 97 show, it also partially decomposes the sodium or potassium soap into the poorer magnesium soap.

It will be observed in comparing the two figures that there is a shifting of the gelation point toward the left as a sodium soap takes the place of an equally concentrated potassium soap. This is again identical with the similar shift observed in all the " saltingout" experiments previously described.

Ordinarily, in the manufacture of the filled soaps, the addition of water-glass, borax or other material is carried to the highest point possible short of the "cracking" or "liquefying" of the mixture, or the "salting-out" of the soap. This point is always, obviously, somewhere on this side of the optimum gelation point. When through careless mixing or error in judgment the filling of a soap is carried beyond this critical point (represented by transition from the system salt-water-in-hydrated soap to that of hydrated-soap-in-salt-water) what is to be done? What must be accomplished is the reversal in type of system through dilution of the salt and increase in the absolute amount of soap in the system. The proper result is not obtainable, however, through mere addition of more soap and water. One might think that it could be obtained by heating and subsequently cooling the mixture, but the soap in these mixtures is near the "stringing" point and therefore dangerous to heat; or the added compounds are of a type which will not stand boiling without suffering hydrolysis and permanent decomposition. The best way to proceed is to

'In such observations, obviously, lie interesting material facts covering the matter of the quantity of "hydration" suffered by different salts in solution. 


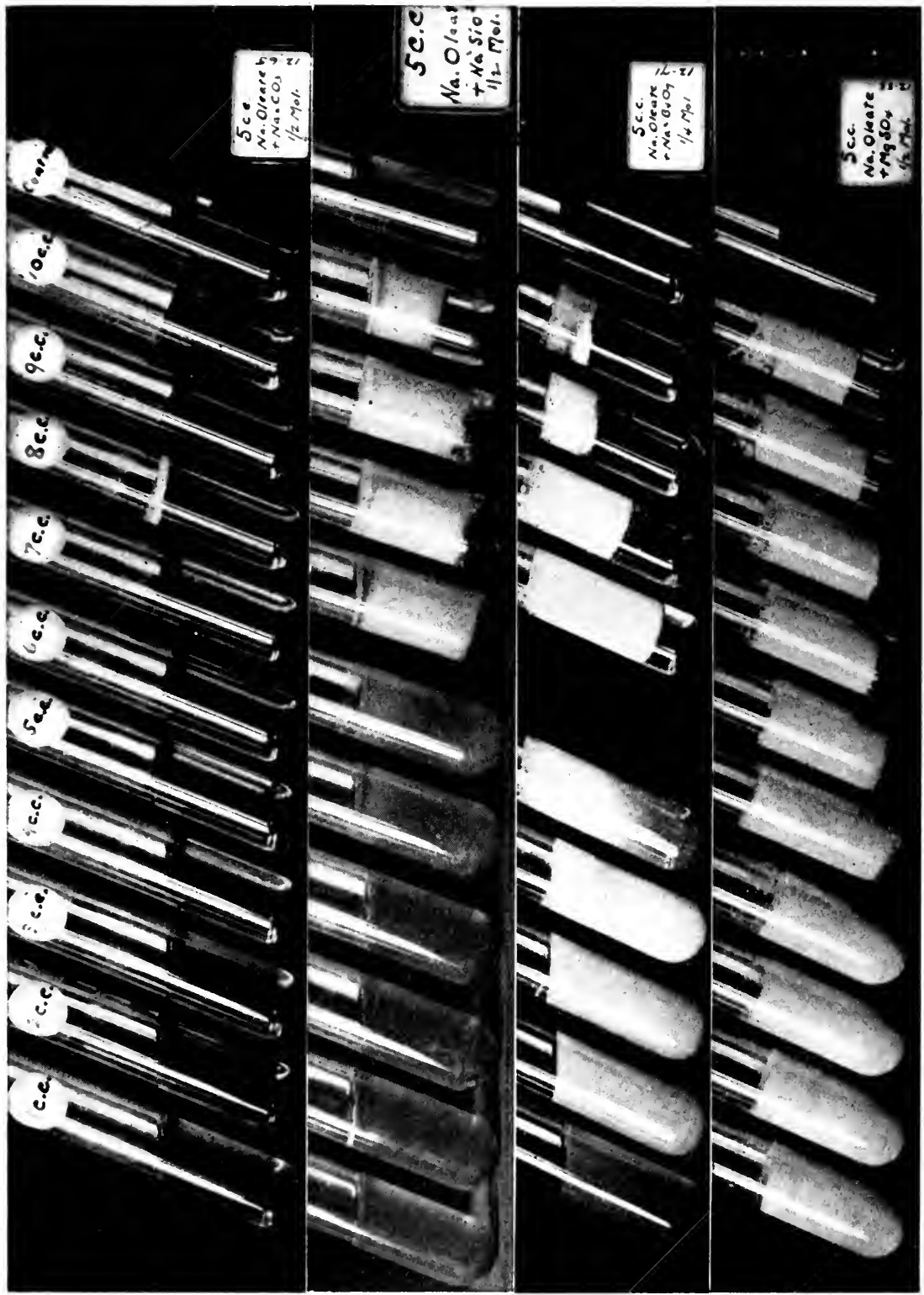


THE COLIOID-CHEMISTRY OF SOAP MANLFACTURE 197

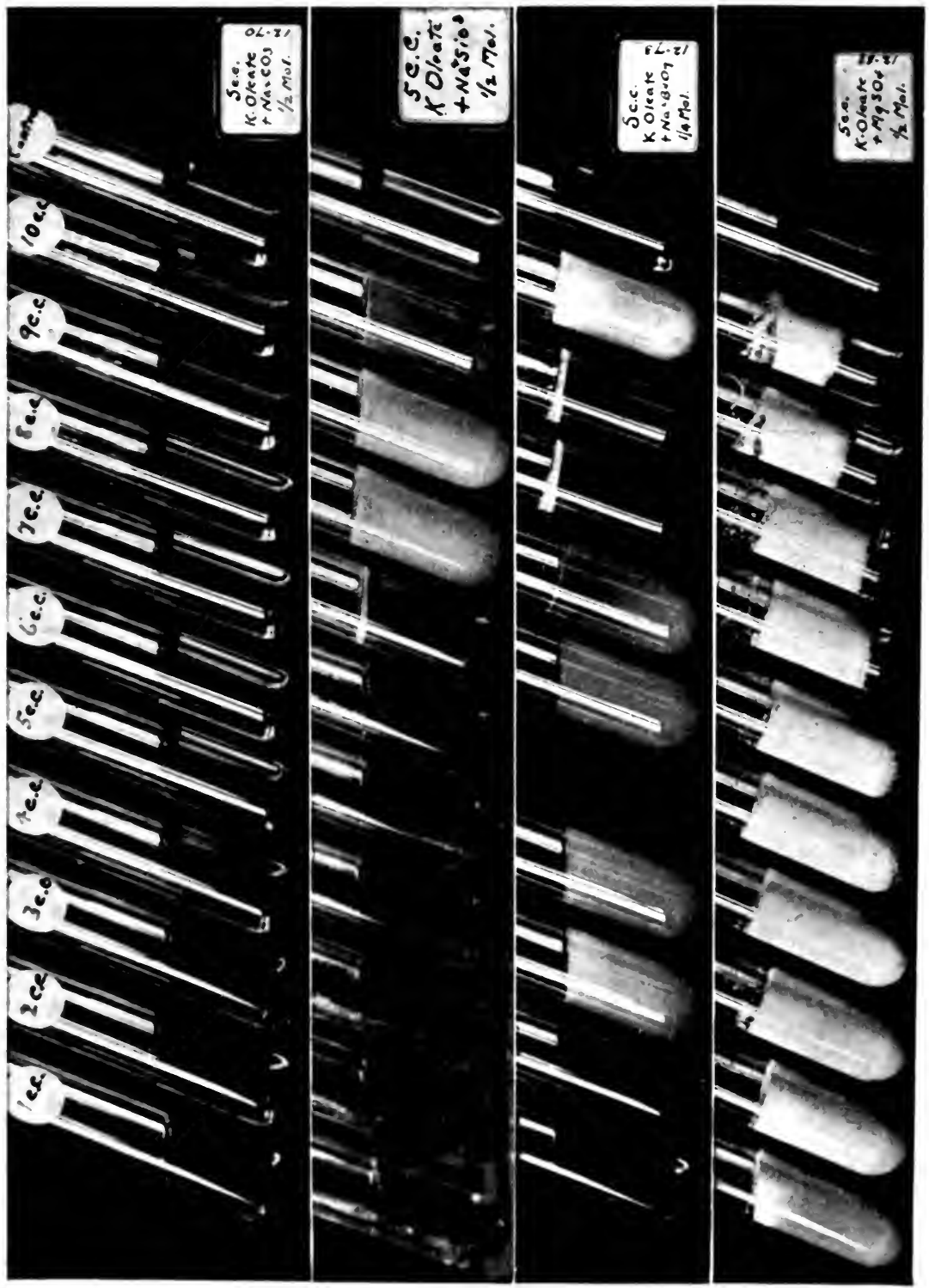


dilute the spoiled mixture and let it stand ${ }^{1}$ (thereby diluting the salt and allowing the soap to increase its hydration); more soap may then be added and more time given. This may by itself accomplish the desired end, but, if it does not, the whole batch should be mixed, with proper stirring and sufficient time, into the much smaller batch of soap/water stock thought necessary for the production of the correct ultimate system.

TABLE LVII

Sodium Oleate-Sodium Carbonate

\begin{tabular}{|c|c|c|c|c|c|c|}
\hline \multicolumn{6}{|c|}{ Concentration of mixture. } & \multirow{2}{*}{$\frac{\text { Remarks. }}{\text { Mobile liquid }}$} \\
\hline (1) & 5 cc. $\mathrm{m}$ & diu & leate +9 cc. & $\mathrm{H}_{2} \mathrm{O}+1$ cc. $n$ & $\mathrm{~m} / 2 \mathrm{Na}_{2} \mathrm{CO}_{3}$ & \\
\hline (2) & 5 ce. “ & $\cdots$ & “ $+8 \mathrm{cc}$ & “ $+2 \mathrm{cc}$ & “ & Mobile liquid \\
\hline (3) & 5 cc. " & * & $\cdots \quad+7 \mathrm{cc}$ & $\cdots+3 \mathrm{cc}$ & “ & Mobile liquid \\
\hline (4) & 5 cc. $"$. & “ & “ $+6 \mathrm{cc}$ & “ $+4 \mathrm{cc}$ & “. & Viscid liquid \\
\hline (5) & 5 cc. “ & ‘. & “ $+5 \mathrm{cc}$ & $\cdots+5 \mathrm{cc}$ & “ & Viscid liquid \\
\hline (6) & 5 cc. ${ }^{\cdots}$ & “. & “ $+4 \mathrm{cc}$ & $\cdots+6 \mathrm{cc}$ & “. & Very viscid \\
\hline (7) & 5 cc. $"$ & “ & $\cdots \quad+3 \mathrm{cc}$ & “ +7 cc. & “. & Solid gel \\
\hline (8) & 5 cc. “ & “. & “ $+2 \mathrm{cc}$. & “ +8 cc. & “. & Solid gel \\
\hline (9) & 5 cc. $" ~$ & ‘. & $\because \quad+1 \mathrm{cc}$. & " +9 cc. & “ & Solid gel \\
\hline (10) & 5 cc. $" ~$ & “ & $\cdots+10 \mathrm{cc}$. & $\mathrm{m} / 2 \mathrm{Na}{ }_{2} \mathrm{CC}$ & & Solid gel \\
\hline (11) & 5 ce. $"$. & “‘ & $\because+10 \mathrm{cc}$ & $\mathrm{H}_{2} \mathrm{O}$ (contr & rol) & Mobile liquid \\
\hline
\end{tabular}

${ }^{1}$ There is no element in technologic practice involving lyophilic colloids which is less considered and less properly employed than this of time. The chemist is so obsessed by the theories and so ruled by his experience with the dilute solutions that he believes that his colloid mixtures ought to act similarly. Whenever a lyophilic colloid is concerned it should be remembered that its solvation or its desolvation takes all the time which may be included in a process of diffusion, of solution and of chemical union - and these things are rarely instantaneous. Even when mixtures are correctly made from a quantitative standpoint, the result may be worthless if proper time is not given for the physico-chemical changes necessary to yield the proper ultimate system. 
TABLE LVIII

Sodium Oleate-Sodium Silicate

\section{Concentration of mixture.}

(1) 5 cc. $\mathrm{m}$ sodium oleate +9 cc. $\mathrm{H}_{2} \mathrm{O}+1 \mathrm{cc} . \mathrm{m} / 2 \mathrm{Na}_{2} \mathrm{SiO}_{3}$

(2) 5 cс. $\cdots \quad \cdots \quad \cdots+8$ cc. $\cdots+2$ cc. $\cdots$.

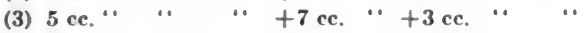

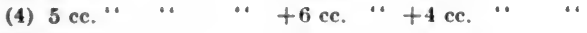

(5) 5 cc. " $"$ " $" 5$ cc. $"+5$ cc. $\cdots \quad \cdots$

(6) 5 ce. " $\cdots \quad \cdots+4 \mathrm{cc}$. $"+6 \mathrm{cc}$. $\cdots$

(7) 5 cc. $" \quad \cdots \quad \cdots+3$ cc. $\cdots+7$ cc. $\cdots \quad \cdots$

(8) 5 cc. $\cdots$. $\cdots+2$ cc. $\cdots+8$ cc. $\cdots$.

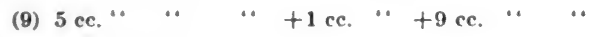

(10) 5 cc. ${ }^{\circ} \quad \cdots \quad \cdots+10$ cc. $\mathrm{m} / 2 \mathrm{Na}_{2} \mathrm{SiO}_{3}$

(11) 5 cc. " $\quad \cdots \quad \cdots+10$ cc. $\mathrm{H}_{2} \mathrm{O}$ (control)
Remarks.

Mobile liquid

Less mobile liquid

Viscid

Very viscid

Solid gel

Solid gel

Beginning separation

Great dehydration and scparation

Great dehydration and separation

Great dehydration and separation

Mobile liquid

TABLE LIX

Sodium Oleate-Sodium Borate

Concentration of mixture.

(1) 5 cc. $m$ sodium oleate +9 cc. $\mathrm{H}_{2} \mathrm{O}+1 \mathrm{cc} . \mathrm{m} / 4 \mathrm{Na}_{2} \mathrm{~B}_{4} \mathrm{O}_{7}$

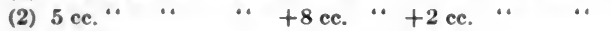

(3) 5 cc. $\cdots \quad \cdots \quad \cdots+7$ cc. $\cdots+3$ cc. $\cdots$.

(4) 5 cc. $"$ " $\cdots+6$ ce. $"+4$ ce. $\cdots " ~ \cdots$

(5) 5 cc. $\cdots \quad \cdots \quad \cdots+5 c c . ~ \cdots+5 c c . ~ \cdots \quad \cdots$

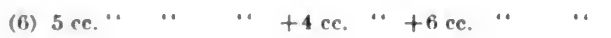

(7) 5 cc. $" \quad \cdots \quad$ $\quad$ + 3 cc. $\cdots+7$ cc.

(8) 5 cc. $\cdots \quad \cdots \quad$ “ +2 cc. $"+8 c c$.

(9) 5 cc. $"$ " $\quad \cdots+1$ cc. $"+9$ cc. $"$ " $\cdots$

(10) 5 cc. $"$ “ $"+10 \mathrm{cc}, \mathrm{m} / 4 \mathrm{Na}_{3} \mathrm{~B}_{4} \mathrm{O}_{7}$

(11) 5 cc. $" \quad \cdots \quad \cdots+10$ cc. $\mathrm{H}_{2} \mathrm{O}$ (control)

\section{Remarks.}

Mobile liquid

White, milky, mobile liquid

while, milky, mobile liquid

Milky soap on top, water on bottom

Milky soap on top, water on bottom

Milky soap on top, water on bottom

Milky soap on top, water on bottom

Milky soap on top, water on bo:tom

Yell , w soap on top. much water on bottom

Yellow soap on top, much water on bottom

Mobile liquuid 
TABLE LX

Sodium Oleate-Magnesium Sulphate

\begin{tabular}{|c|c|c|c|c|c|c|c|c|}
\hline \multicolumn{8}{|c|}{ Concentration of mixture. } & \multirow{2}{*}{$\frac{\text { Remarks. }}{\text { Fairly mobile milky liquid }}$} \\
\hline (1) & 5 cc. $\mathrm{m} \mathrm{s}$ & diur & leat & $+9.5 \mathrm{cc} .1$ & $\mathrm{H}_{2} \mathrm{O}+0.5 \mathrm{cc} . \mathrm{m}$ & $1 / 2$ & $\mathrm{IgSO}_{4}$ & \\
\hline$(2)$ & 5 cс. $"$ & ‘ & “ & $+9.0 \mathrm{cc}$ & $\cdots+1.0 \mathrm{cc}$ & “ & $\cdots$ & Solid white gel mixture \\
\hline (3) & 5 сc. “ & “ & “. & $+8.5 \mathrm{cc}$ & $\cdots+1.5 \mathrm{cc}$. & ‘ & “ & Solid white granular gel \\
\hline (4) & 5 сс. “ & “ & “ & $+8.0 \mathrm{cc}$ & $\cdots+2.0 \mathrm{cc}$ & “ & “ & Solid white granular gel \\
\hline (5) & 5 cc. $“$ & ““ & “ & $+7.5 \mathrm{cc}$ & $"+2.5 \mathrm{cc}$ & “‘ & “‘ & $\begin{array}{l}\text { Granular white soap, beginning } \\
\text { separation }\end{array}$ \\
\hline (6) & 5 cc. “ & “ & “ & $+7.0 \mathrm{cc}$ & $\cdots+3.0 \mathrm{cc}$ & “‘ & “ & $\begin{array}{l}\text { Granular white soap, more sep- } \\
\text { aration }\end{array}$ \\
\hline (7) & 5 cc. $“$ & “’ & “ & $+6.5 \mathrm{cc}$ & “ $+3.5 \mathrm{cc}$ & “ & “ & $\begin{array}{l}\text { Granular white soap, more sep- } \\
\text { aration }\end{array}$ \\
\hline (8) & 5 cc. $" “$ & ““ & “ & $+6.0 \mathrm{cc}$ & $"+4.0 \mathrm{cc}$ & “‘ & “ & $\begin{array}{l}\text { Granular white soap, more sep- } \\
\text { aration }\end{array}$ \\
\hline (9) & 5 cc. "“ & “ & “ & $+5.5 \mathrm{cc}$ & $"+4.5 \mathrm{cc}$ & “ & “ & $\begin{array}{l}\text { Granular white soap, more sep- } \\
\text { aration }\end{array}$ \\
\hline (10) & 5 cc. $“$ & “ & “ & $+5.0 \mathrm{cc}$ & $"+5.0 \mathrm{cc}$ & “ & “ & $\begin{array}{l}\text { Granular white soap, more sep- } \\
\text { aration }\end{array}$ \\
\hline (11) & 5 cc. $"$ & “ & “" & $+10.0 \mathrm{cc}$ & $\mathrm{H}_{2} \mathrm{O}$ (control & & & Mobile liquid \\
\hline
\end{tabular}

TABLE LXI

Potassium Oleate-Sodium Carbonate

\begin{tabular}{|c|c|c|c|c|c|c|}
\hline \multicolumn{6}{|c|}{ Concentration of mixture. } & \multirow{2}{*}{$\frac{\text { Remarks. }}{\text { Mobile liquid }}$} \\
\hline (1) & 5 cc. $m$ & assi & oleate +9 cc. 1 & $\mathrm{H}_{2} \mathrm{O}+1 \mathrm{cc} . \mathrm{m} /$ & $\mathrm{Na}_{2} \mathrm{CO}_{3}$ & \\
\hline (2) & 5 cc. $“$ & “. & “ $+8 \mathrm{cc}$ & $"+2$ cc. $"$ & $\cdots$ & Mobile liquid \\
\hline (3) & 5 cc. “' & “ & “ $+7 \mathrm{cc}$ & " +3 cc. " & “ & Mobile liquid \\
\hline (4) & 5 cc. “ & “‘ & “ $+6 \mathrm{cc}$ & “+ +4 cc. ." & “. & Mobile liquid \\
\hline (5) & 5 cc. $“$ & “. & “ $+5 \mathrm{cc}$ & “ +5 cc.. & “. & Mobile liquid \\
\hline (6) & 5 cc. "“ & “. & “ $+4 \mathrm{cc}$ & “ +6 cc. ." & “. & Less mobile liquid \\
\hline (7) & 5 cc. “ & “. & “ +3 cc. & “ +7 cc.. & “. & Viscid liquid \\
\hline (8) & 5 cc. “" & .. & “ +2 cc. & " +8 cc.. & “. & Very viscid liquid \\
\hline (9) & 5 cc. " & “ & “ +1 cc. & “+9 cc. " & “. & Almost stiff \\
\hline (10) & 5 cc. " & “ & “ $+10 \mathrm{cc}$. & $\mathrm{m} / 2 \mathrm{Na}_{2} \mathrm{CO}_{3}$ & & Almost stiff \\
\hline (11) & 5 cc. " & “ & “+ $+10 \mathrm{cc}$. & $\mathrm{H}_{2} \mathrm{O}$ (control) & & Mobile liquid \\
\hline
\end{tabular}


THE COLLOID-CHEMISTRY OF SOAP MANUFACTURE 201

TABLE LXII

Potassium Oleate-Sodium Silicate

\begin{tabular}{|c|c|c|c|c|c|c|}
\hline \multicolumn{6}{|c|}{ Concentration of mixture. } & \multirow{2}{*}{$\frac{\text { Remarks. }}{\text { Mobile liquid }}$} \\
\hline (1) & 5 ce. $\mathrm{ml}$ & assi & leate +9 cc. 1 & $\mathrm{H}_{2} \mathrm{O}+1$ ce. $\mathrm{n}$ & $\mathrm{n} / 2 \mathrm{Na}_{2} \mathrm{SiO}_{2}$ & \\
\hline (2) & 5 cc. ${ }^{.}$ & .. & $\because \quad+8$ ce. & $\cdots+2$ cc. & •. & Mobile liquid \\
\hline (3) & 5 cc. " & .. & “ +7 ec. & $\cdots+3 c c$ & •. & Mobile liquid \\
\hline (4) & 5 ce.. & $\cdots$ & $\cdots+6$ cc. & $\cdots+4$ cc. & “ & Mobile liquid \\
\hline (5) & 5 ce. ${ }^{\prime}$ & . & $\cdots \quad+5$ cc. & $\cdots+5 \mathrm{cc}$ & . & Viscid liquid \\
\hline (6) & 5 cc. ${ }^{\cdots}$ & 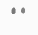 & $\cdots \quad+4$ ce. & $\cdots+6$ cc. & $\cdots$ & Viscid liquid \\
\hline (7) & 5 cc. ${ }^{\prime}$ & . & $\cdots \quad+3$ ce. & $\cdots+7$ cc. & “ & Viscid liquid \\
\hline (8) & 5 cc. ${ }^{\prime \prime}$ & • & $\cdots \quad+2$ ce. & $\cdots+8 \mathrm{cc}$ & “. & Solid gel \\
\hline (9) & 5 сс. $\cdots$ & * & $\because \quad+1$ cc. & “ +9 cc. & •. & Solid gel \\
\hline (10) & 5 ce. $"$ & “. & $\cdots \quad+10 \mathrm{cc}$. & $\mathrm{m} / 2 \mathrm{Na}_{2} \mathrm{SiC}$ & & Viscid liquid \\
\hline (11) & 5 cc.. & .. & . $+10 \mathrm{cc}$. & $\mathrm{H}_{2} \mathrm{O}$ (contr & rol) & Mobile liquid \\
\hline
\end{tabular}

TABLE IXIII

Potassium Oleate-Sodium Borate

Concentration of mixture.

(1) 5 cc. $m$ potassium oleate +9 cc. $\mathrm{H}_{2} \mathrm{O}+1$ cc. $\mathrm{m} / 4 \mathrm{Na}_{2} \mathrm{~B}_{4} \mathrm{O}_{7}$

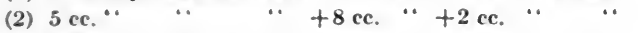

(3) 5 cс. $\cdots \quad \cdots \quad \cdots+7$ cc. $\cdots+3$ ce. $\cdots \quad \cdots$

(4) 5 cc. $" \quad \cdots \quad$ " +6 cc. $\cdots+4$ cc. $\cdots$ "

(5) 5 cc. $\cdots \quad \cdots \quad \cdots+5$ cc. $\cdots+5$ cc. $\cdots$ " $\cdots$

(6) 5 cс. $" \quad \cdots \quad$ " +4 cc. $\cdots+6$ cc. $\cdots \quad \cdots$

(7) 5 cс. $\because \quad \cdots \quad \quad \cdots+3$ cc. $\cdots+7$ cc. $\cdots$ $\cdots$

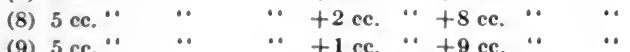

(10) 5 cс. ${ }^{\circ} \quad \cdots \quad$. +10 cc. $\mathrm{m} / 4 \mathrm{Na}_{3} \mathrm{~B}_{4} \mathrm{O}_{7}$

(11) 5 cc. $" \quad \cdots \quad \cdots+10$ cc. $\mathrm{H}_{2} \mathrm{O}$ (control)
Remarks.

Clear mobile liquid Cloudy mobile liquid Milky mobile liquid Milky mobile liquid Milky mobile liquid Milky, less mobile liquid Milky viscid liquid Milky, almost stiff Milky, almost stiff Milky, almost stiff Mobile liquid

\section{TABLE LXIV}

Potassium Olfate-Magnesium Sulphate

\section{Concentration of mixture}

(1) $5 \mathrm{cc}, \mathrm{m}$ potassium oleate $+9.5 \mathrm{cc}, \mathrm{H}_{2} \mathrm{O}+0.5 \mathrm{cc}, \mathrm{m} / 2 \mathrm{MgSO}$

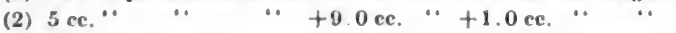

(3) $5 \mathrm{cc}, \cdots$

(4) 5 ce.

(5) 5 ce. "

(6) 5 ce. $"$

(7) $3 \mathrm{cc}$.

(8) $5 \mathrm{cc} . " \cdot$

(9) $5 \mathrm{rc}$.

(10) 5 ce. $" \cdot$

(11) $5 \mathrm{cc}$.
.. +8.50

$\therefore+8.5 \mathrm{cc}$

- $+1.5 \mathrm{cc}$.

$\cdots+8.0 \mathrm{ce}$

$\because+7.5 \mathrm{cc}$.

․ $+7.0 \mathrm{cc}$

$\because \quad+6.5 \mathrm{cc}$.

$\cdots+2.0 \mathrm{cc}$.

$\cdots+2.5 \mathrm{cc}$.

a $+3.0 \mathrm{cc}$

$\cdots+3.5 \mathrm{ce}$.

$\cdots+6.0 \mathrm{ce}$

$\cdots+5.5 \mathrm{ce}$.

. $+4.0 \mathrm{cc}$.

$\cdots+4.5 \mathrm{cc}$.

$\cdots+5.0 \mathrm{cc}$

$\because+5.0 \mathrm{cc}$.

- $+10,0$ ce. $\mathrm{H}_{2} \mathrm{O}$ (conerol)

\section{Remarks.}

Fairly mobile milky liquid Viscid milky liquid

Solid milky gel

Solid milky gel

Solid white soap at top

Solid white goap at top

Solid white goap at top

solid white anp at top

Solid white sonp at top

solid white map at ton

Mobile liquid 



\section{PART THREE}

THE ANALOGIES IN THE COLLOID-CHEMISTRY OF SOAPS, PROTEIN DERIVATIVES AND TISSUES 



\section{PART THREE}

THE ANALOGIES IN THE COLLOID-CIIEMISTRY OF SOAPS, PROTEIN DERIVATIVES AND TISSUES

\section{I}

\section{THE CHEMICAL AND COLLOID-CHEMICAL BEHAVIOR OF FATTY ACIDS AND THEIR DERIVATIVES AND THE ANALOGOUS BEHAVIOR OF "NEUTRAL" PROTEINS AND THEIR DERIVATIVES}

\section{Introduction}

THE experiments on the colloid-chemistry of the various pure soaps detailed in the preceding pages were undertaken originally in order to obtain a clearer conception of the nature of water absorption by proteins when various alkalies, acids or salts, alone or in combination, are added to them; this conception being wanted, in its turn, in order to understand the laws of water absorption as observed in living matter. It will be the purpose of the next paragraphs to show that the laws emphasized as goterning the "solution" and "hydration" of soaps are identical with those which govern the "solution" and "hydration" of various protein derivatives and that these, in turn, are the analogs of the laws which govern the absorption of water by cells, tissues and the whole living organism under physiological and pathological circumstances.

2. The Chemical Behavior of the Fatty Acids and the Analogous Behavior of the Amino-Acids (Neutral Proteins)

It is well to emphasize, first, some obvious chemical analogies existent between the fatty acids and the materials which may be derived from them (the soaps) and the so-called "neutral" 
proteins and the materials which may be produced from them. It is of interest to bear in mind that the proteins are not only polymerized amino-acids, but that frequently their constituent amino-acids are amino-fatty-acids, as witness, amino-acetic, amino-valeric, amino-caproic and amino-succinic acids. The alleged " neutral," "native" or "genuine" proteins are no more neutral than are any of the higher fatty acids. As the fatty acids may combine with base to form "soaps," even so may the polymerized amino-fatty-acids combine with base to form analogous "soaplike" compounds. It is important for our future discussion that this comparison of the neutral proteins with the free fatty acids be clearly kept in mind. ${ }^{1}$

What, now, are the solubility characteristics of the pure fatty acids and the pure neutral proteins in water and for water? Just as certain fatty acids (like the lowermost members of the acetic series) are readily soluble in water, so also do certain native proteins prove "soluble" in water (as witness the various salt-, acid- and alkali-free, "pure" albumins). On the other hand, as other fatty acids (like the higher members of the acetic series) prove insoluble in water, so also do various native proteins (as witness casein, fibrin, alkali-, acid- and salt-free globulins, etc.).

The solubility of water in the fatty acids or in the pure proteins is hardly to be found discussed as such. The simpler fatty acids "dissolve" so readily in water and are so universally thought of as "aqueous solutions" that the mere raising of the obverse question in their case will seem, to many, absurd. Water is, however, sufficiently souble in the higher fatty acids to make necessary its consideration, when, commercially, a given weight or volume of material is to be bought and paid for as fatty acid. In the case of the pure proteins these things are variable. In those commonly designated as "insoluble" (casein, for example) the solubility for water is so low as to be generally neglected.

${ }^{1}$ Of great interest in connection with this similarity between the colloidchemistry of the fatty acids and that of the amino-fatty-acids (the proteins) are some observations of KrafFT and WigLow [quoted by LEwkowitsch: Oils, Fats and Waxes, 1, 133 (1913)] whose work unfortunately we have not been able to find in the original. These authors note that the amins of the fatty acids behave like the corresponding fatty acids. While the alkali salts of the lower amino-fatty-acids on solution in water behave like crystalloids, those of the higher amino-fatty-acids fail to raise the boiling point of water the calculated amount and in other physico-chemical respects betray themselves as colloids. 
SOAPS, PROTEIN DERIVATIVFS AND TISSUFS 207

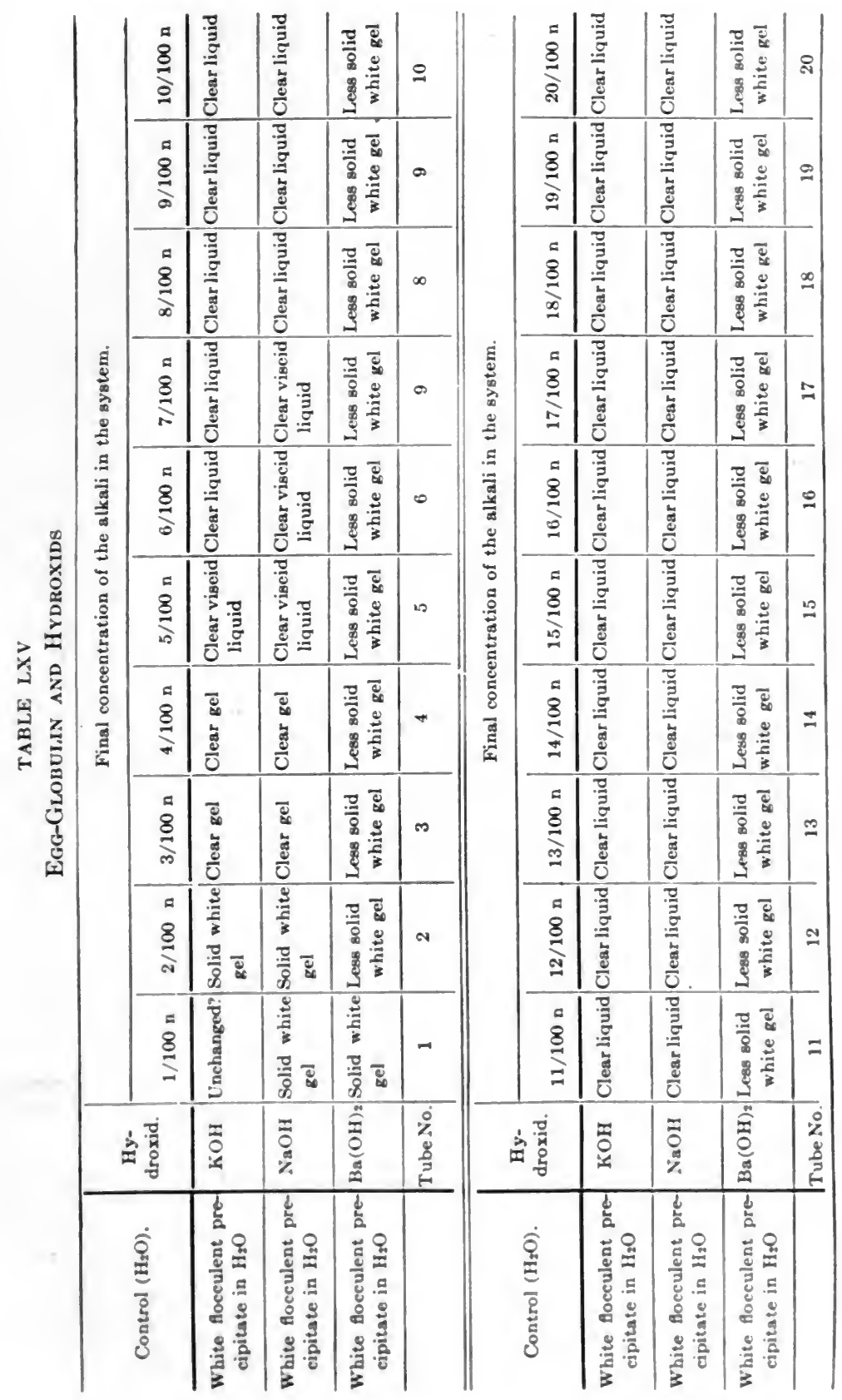


From this it may rise to great values, as witness the amount of fluid "absorbed" by neutral gelatin, by dry serum-albumin, etc., when these are thrown into water.

These characteristics of solubility in water and for water of the different fatty acids and the different pure, "neutral" proteins must be kept in mind if their colloid-chemistry or that of their derivatives is to be properly understood.

If we now write the formula of any fatty acid as:

$$
x-\mathrm{COOH}
$$

then that of any amino-fatty-acid (or its polymer, protein) may be written:

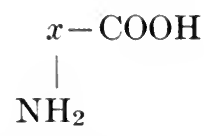

To produce a " soap," some base is substituted for the $\mathrm{H}$ in the first formula written above; to produce the analogous "soaplike" compound from the latter, the same base is substituted for the similarly placed $\mathrm{H}$ of the second formula. As we produce potassium, sodium, calcium and iron soaps we can also produce potassium, sodium, calcium and iron proteinates.

Every new soap and every new soap-like compound thus produced has solubility characteristics in water and for water different from those of the original fatty acid or the original amino-fatty-acid (protein) from which it was produced.

The amino-acids have, however, wider possibilities for easy union with other materials than have the fatty acids. While the latter, for example, do not unite readily with acids, the former, through their $\mathrm{NH}_{2}$ groups, do. In this way there may therefore be produced a second series of derivatives which may be designated as the chlorids, bromids, acetates, sulphates, phosphates, etc., of the proteins, each again possessed of its own solubility in water and solvent power for water.

We are now in a position to consider the colloid-chemistry of the pure proteins and that of their basic and acidic derivatives, not only to see how these mimic the colloid-chemical behavior of the pure fatty acids and their basic derivatives (the soaps) but in order to obtain what seems to us a simpler general conception of what happens when protein/water mixtures show the evidences, under different circumstances, of swelling, gelation, 
precipitation, irreversible "coagulation," etc. A detailed consideration of many proteins is impossible within the pages of this volume, but the two to be discussed may serve to illustrate the main types. For purposes of illustration we shall take up, in analogy to the similar types of pure fatty acids, (a) a protein which is "insoluble" in water, namely, egg-globulin and (b) another which is "soluble," namely, gelatin. What is said of egg-globulin may be taken to apply to all the globulins, casein, myosin and nucleic acid. What is said of gelatin may be applied to the various albumins. ${ }^{1}$

\section{The System Egg-Globulin/Water}

The "neutral" globulin used in the experiments about to be described was obtained by diluting strongly with distilled water (8. volumes) the whites of absolutely fresh eggs. The globulin which fell out at the end of twenty-four hours in an ice box was simply filtered off, washed several times with distilled water and used at once in its moist condition. While by more elaborate methods a "chemically" purer product might have been obtained, we feared the consequences of the more drastic chemical methods necessary to produce such upon the colloid properties of the final product. The globulin employed in the following experiments was all from the same lot, contained 92 percent water as used and 0.045 percent ash calculated upon the wet weight of the globulin.

Moist globulin (in analogy to the higher fatty acids) is obviously " insoluble" in water and as compared with gelatin, albumin, etc.. a relatively poor solvent for water (92 percent). We wished, first, to show that a soap-like compound (a basic globulinate) could be obtained from such globulin through treatment, with a proper alkali, which, in the presence of the right amount of water would (like the corresponding soap) yield a solid jelly, in other

1 The purest gelatins on which the ordinary colloid-chemical studies have been made, to which we refer here and upon which some succeeding experiments are bised (see page 218) still contain truces of salts. Wot.rosisa OstwabD has directed my attention to the fuct that when such gelatins are subjected to dialysis while an clectric current is passed through thom a gelatin free from all base and acid may be obtained. Such gelatin is, however, as "insoluble" in water and as little hydratable as the ordinary globulins. Obviously, under such circumstances, the behavior of all the proteins (including in other words gelatin and the "albumins") beeomes that of the type described under the globulins. 
words, a system representing a "solution" of water in the basic globulinate. For this purpose 2 grams of the moist globulin were carefully weighed into each of a number of test tubes and to each was then added 0.5 cc. of an alkali of proper strength to yield the final concentration in the whole of each of the systems indicated in Table LXV. The descriptions refer to the appearances of the mixtures at the end of twenty-four hours, twenty of which were spent in an ice box and four at room temperature. The photographic appearance of the three sets of tubes (all made at the same time, from the same globulin and under identical circumstances) is shown in the Figs. 98, 99 and 100. It is apparent that these potassium, sodium and barium globulinates (like the corresponding soaps) have greater solvent powers for water (and hence gel in the presence of a larger volume of the same) than has the original "neutral "globulin (or the original fatty acid). But of the three soap-like compounds the potassium globulinate is most soluble in water, wherefore it is the first to go through a jellying stage "into solution." Sodium globulinate occupies a middle position in this regard. Barium globulinate, while possessed of relatively low powers of hydration is so insoluble in water that it maintains its gel state throughout the series of experiments.

Having seen that with progressive additions of alkali, neutral globulin in the presence of a fixed volume of water passes successively from (1) a (relatively) non-hydrated material through (2) a state in which water is dissolved in it, into (3) a state in which it is dissolved in the water, we wished to see what were the effects of mere dilution upon the final system and if the basic globulinate thus formed could be precipitated a second time (salted-out) by further addition of the alkali (as can a soap). Fig. 101 and Table LXVI answer these questions. The first five tubes merely show again how with progressive increase in amount of alkali (sodium hydroxid), "solution" of a "globulin" (really solution of sodium globulinate) may be obtained. To such a tube as 4 much water ${ }^{1}$ may now be added without change, as evidenced

${ }^{1}$ Not, however, an unlimited amount, for in too much water hydrolysis of the sodium globulinate takes place and the free acid (globulin) again begins to fall out. This constitutes the principle upon which "globulins" are obtained through dilution with much water. It is not the sodium globulinate which falls out, or, in the terms of soap chemistry, it is not "the soap" which is "insoluble" in water but the "fatty acid" resulting from hydrolysis. 
SOAPS, PROTEIN DERIVATIVES AND TISSUES
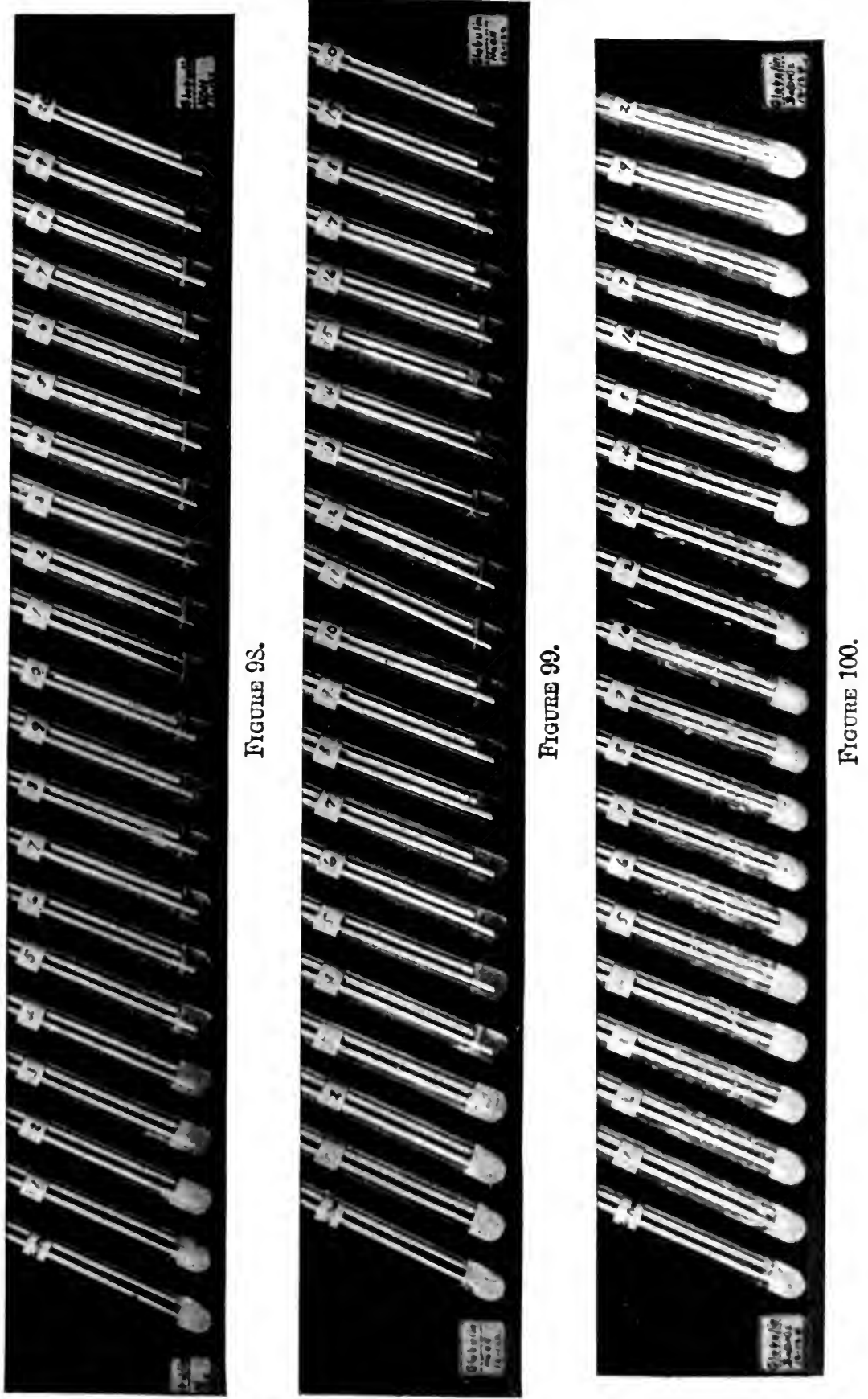
7 हx) $=1$

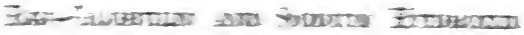

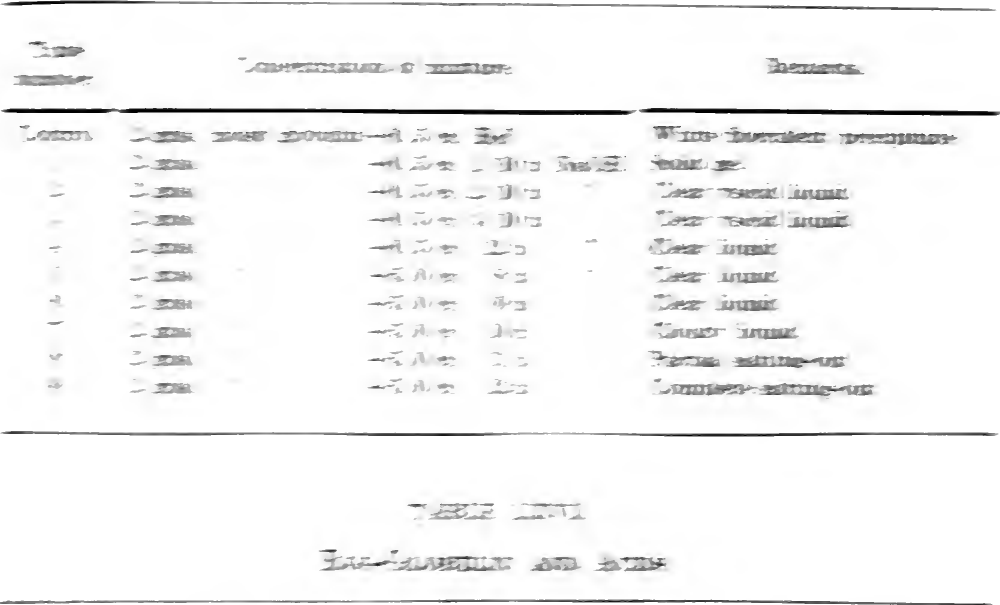

\begin{tabular}{|c|c|c|c|c|c|c|}
\hline \multirow{2}{*}{-mant 三os:- } & \multirow{2}{*}{-osec } & \multicolumn{5}{|c|}{ 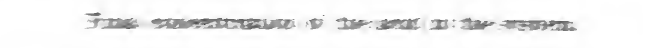 } \\
\hline & & $=70$ & $=367$ & $=10 \cdot 3$ & Di $34 \times$ & ENave \\
\hline 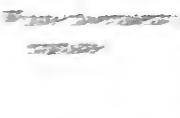 & 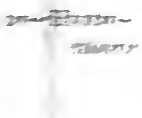 & 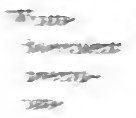 & 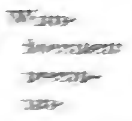 & 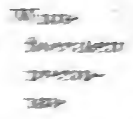 & 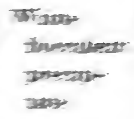 & 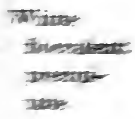 \\
\hline 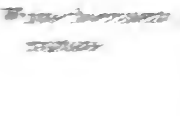 & sengon & 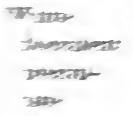 & 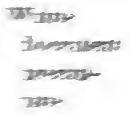 & 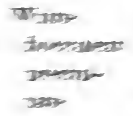 & 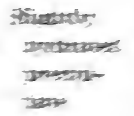 & 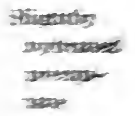 \\
\hline \multirow{2}{*}{ "nems J- } & & \multicolumn{5}{|c|}{ 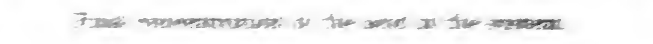 } \\
\hline & & $20=$ & -36) 140 & as $20=$ & as 20 & 3es Tukn \\
\hline 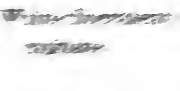 & 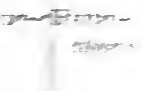 & 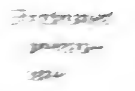 & 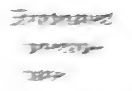 & 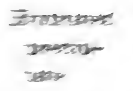 & 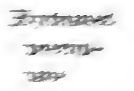 & 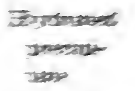 \\
\hline 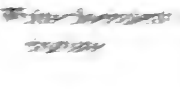 & $+\infty=0$ & 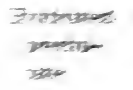 & 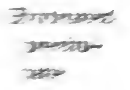 & 5 & 5 & $\therefore$ \\
\hline
\end{tabular}




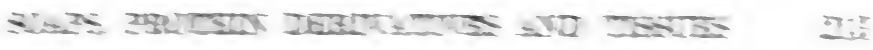

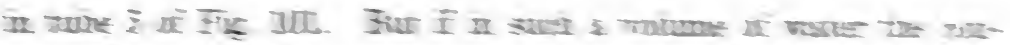

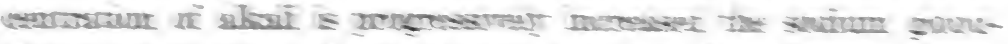

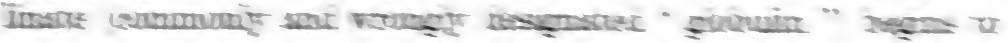

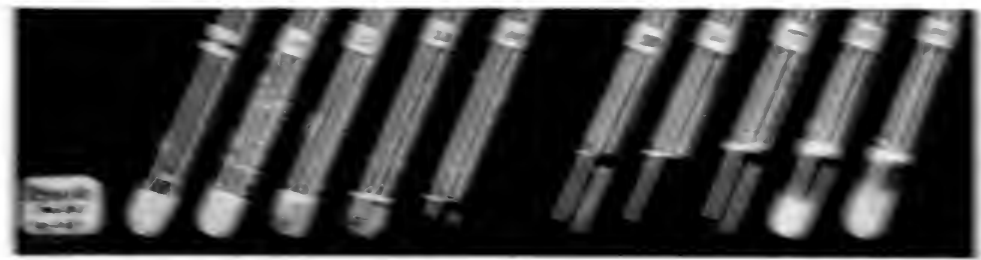

Fistews: JiI.

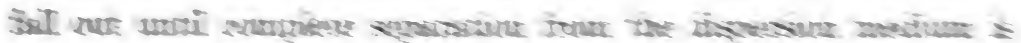

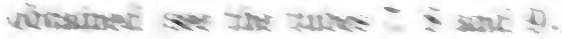

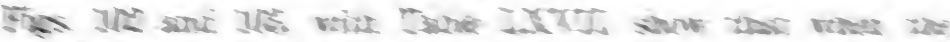

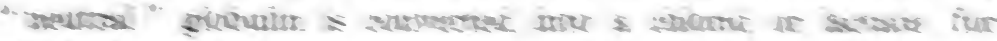

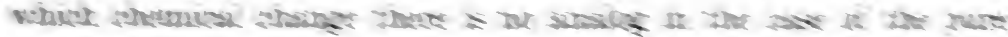

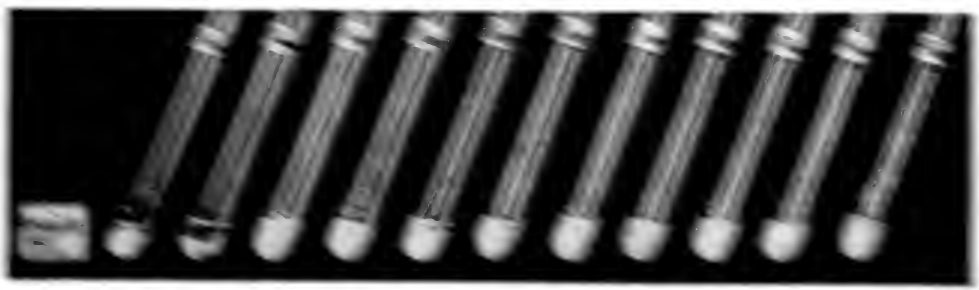

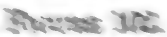

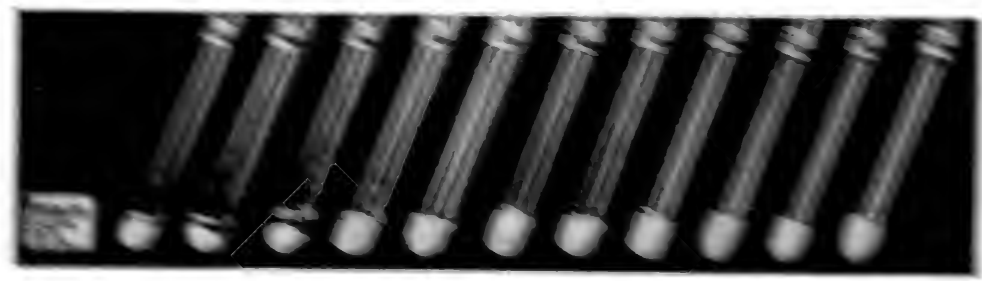

Mis net lix

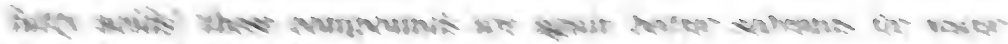

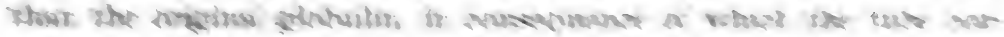

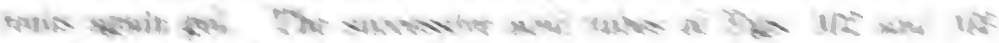

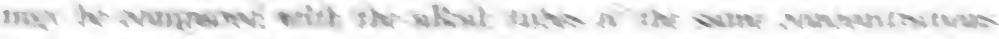

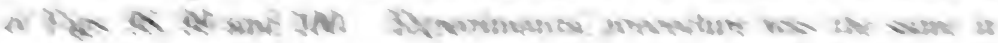


both. It should only be noted that the concentrations marked on the labels of Figs. 102 and 103 are those of the acid as added. The final concentrations are given in Table LXVII.

Such experimental findings as have just been described are more commonly listed, as by the physiological chemists, as experiments on the "solubility" of proteins; or by the physical and colloid-chemists as studies on the effects of alkalies and acids upon such " solubility" or some other of the general chemical or colloidchemical properties of the systems as a whole (as their viscosity, their electrical conductivity, their content of hydrogen and hydroxyl "ions," etc.). To understand these systems properly it is obviously necessary to recognize and carry in mind the effects of $(a)$ the quantitative relationships of the water content of the systems to the remaining material in them, $(b)$ the chemical conversions of " neutral " compounds into basic or acidic derivatives, (c) the alterations in solubility and hydration capacity accompanying such conversion, $(d)$ the types of systems produced (whether all hydrated colloid, all solution in water or subdivisions of the one in the other) and finally $(e)$ the changes in viscosity incident to "emulsification" or "suspension" of any of the original unchanged "globulin" in such hydrated derivatives as may be produced. How inadequate for the understanding of the colloidchemical behavior of such systems are the overplayed " stoichiometrical," " chemical," " electrical," " hydrogen and hydroxyl ion" notions, usually called upon to explain in some exclusive fashion all the changes observed, must be self-evident.

Stoichiometrical views cover only those parts of the whole problem which have to do with the quantities produced of differently hydratable or soluble compounds; "chemical" notions are no more adequate for the explanation of the problem than they are, at present, for the understanding of the whole problem of solution; electrical and ionic notions are hardly of service when it is remembered that the most stabile of these hydrated colloid systems are such as are composed of chemically produced, really neutral compounds of protein with base or acid, provided only that not more water is present in the system than can be absorbed by the hydration capacities of the protein derivatives. Yet these colloid systems contain no quantities of either hydrogen or hydroxyl cons measurable by ordinary laboratory means. The measurable hydrogen and hydroxyl ion contents of different protein/water systems 
upon which such emphasis has been laid for the explanation of their stability are only observable in relatively dilute systems; the ion contents are not inherent to, or necessary for, the stabilization; they are accidental accompaniments incident to the solution of some of the basic and acidic proteins in the excess of water and their hydrolysis with the production secondarily of an overplus of hydrogen or hydroxyl ions.

Evidence for the general truth of these contentions may be found in the following experiments in which " neutral" globulin in the presence of a constant volume of water is exposed to the action of various neutral salts. As ordinarily put, such "neutral " globulins are said to be "soluble" in dilute salt solutions. To our minds, this is not true. The salts again react with the neutral globulin to yield globulin derivatives of the general formula base-protein-acid which, like the previously described base-protein and protein-acid compounds, also have a higher hydration capacity and a greater solubility in water than the original globulin.

Figs. 104, 105, 106, 107 and 108 reproduce photographically the findings described in Table LXVIII. Obviously a hydration of "neutral" globulin may be induced through the presence of various neutral salts as readily as through the presence of alkalies or acids, in other words, in the absence of any such hydroxyl or hydrogen ion concentrations as are commonly alleged to be responsible for such a result. It is not the neutral globulin which is hydrated, but its salts. In the experiments just described, these are produced because globulin (like the lower fatty acids of the acetic series) has sufficient chemical reactivity to unite with the products of the hydrolysis of any neutral salt (acid and alkali).

Table LXVIII and the figures again show (in analogy to the similar soaps) that the potassium and sodium derivatives of globulin are sooner and more highly hydrated than the corresponding magnesium and calcium derivatives (the contents of the tubes holding the latter being not only less swollen but whiter). The, mercury derivative is so little hydrated that it remains a practically anhydrous, leather-like mass in all the tubes.

In order not to lengthen these pages unduly with protocols, it may suffice merely to state that findings entirely similar to those just described are obtainable with the neutral salts of the soluble sulphates. 


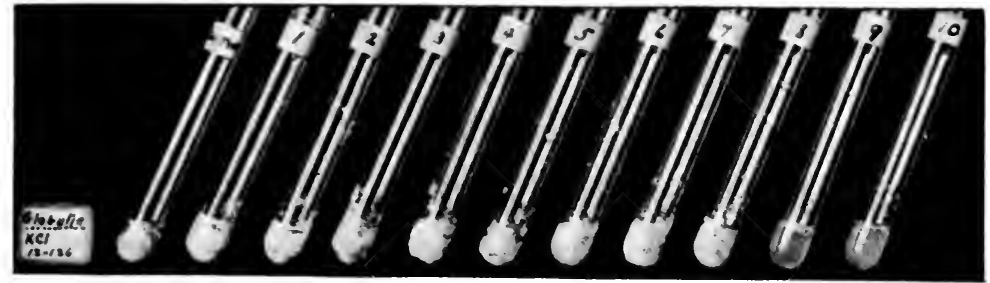

Figure 104.

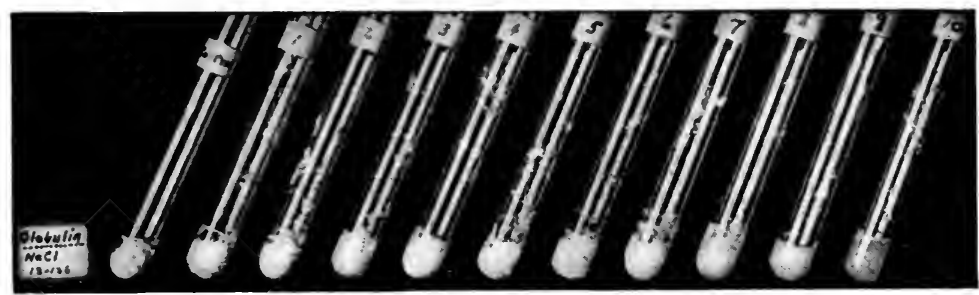

FigURe 105.

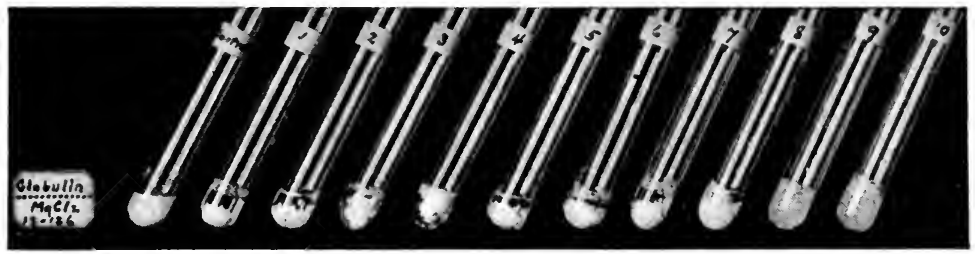

Figure 106.

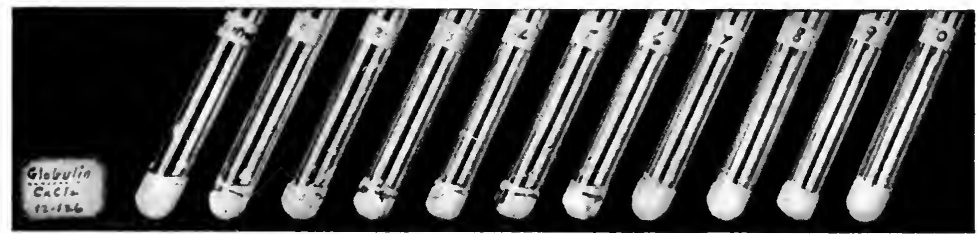

Figure 107.

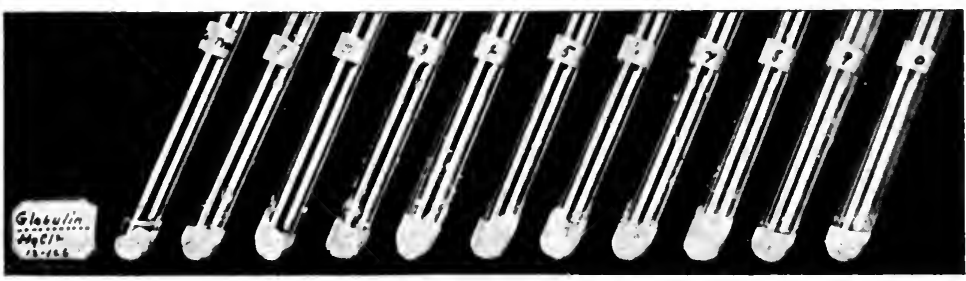

FigURE 108. 
TABLE LXVIII

\section{EgG-Globulin and Chlorids}

\begin{tabular}{|c|c|c|c|c|c|c|}
\hline \multirow{2}{*}{$\begin{array}{c}\text { Control } \\
\mathrm{H}_{2} \mathrm{O} .\end{array}$} & \multirow{2}{*}{ Salt. } & \multicolumn{5}{|c|}{ Final concentration of the salt in the system. } \\
\hline & & $1 / 45 \mathrm{~m}$ & $140 \mathrm{~m}$ & $1,35 \mathrm{~m}$ & $1 / 30 \mathrm{~m}$ & $1 / 25 \mathrm{~m}$ \\
\hline $\begin{array}{c}\text { White curdy } \\
\text { precipitate }\end{array}$ & $\mathrm{KCl}$ & $\begin{array}{c}\text { White curdy } \\
\text { precipitate }\end{array}$ & $\begin{array}{c}\text { White curdy } \\
\text { precipitate }\end{array}$ & $\begin{array}{c}\text { White curdy } \\
\text { precipitate }\end{array}$ & $\begin{array}{l}\text { White curdy } \\
\text { precipitate }\end{array}$ & $\begin{array}{l}\text { White curdy } \\
\text { precipitate }\end{array}$ \\
\hline $\begin{array}{c}\text { White curdy } \\
\text { precipitate }\end{array}$ & $\mathrm{NaCl}$ & $\begin{array}{l}\text { White curdy } \\
\text { precipitate }\end{array}$ & $\begin{array}{l}\text { White curdy } \\
\text { precipitate }\end{array}$ & $\begin{array}{c}\text { White curdy } \\
\text { precipitate }\end{array}$ & $\begin{array}{c}\text { White curdy } \\
\text { precipitate }\end{array}$ & $\begin{array}{l}\text { White curdy } \\
\text { precipitate }\end{array}$ \\
\hline $\begin{array}{l}\text { White curdy } \\
\text { precipitate }\end{array}$ & $\mathrm{MgCl}_{2}$ & $\begin{array}{c}\text { White curdy } \\
\text { precipitate }\end{array}$ & $\begin{array}{c}\text { White curdy } \\
\text { precipitate }\end{array}$ & $\begin{array}{c}\text { White curdy } \\
\text { precipitate }\end{array}$ & $\begin{array}{c}\text { White curdy } \\
\text { precipitate }\end{array}$ & $\begin{array}{l}\text { White curdy } \\
\text { precipitate }\end{array}$ \\
\hline $\begin{array}{c}\text { White curdy } \\
\text { precipitate }\end{array}$ & $\mathrm{CaCl}_{2}$ & $\begin{array}{c}\text { White curdy } \\
\text { precipitate }\end{array}$ & $\begin{array}{c}\text { White curdy } \\
\text { precipitate }\end{array}$ & $\begin{array}{c}\text { White curdy } \\
\text { precipitate }\end{array}$ & $\begin{array}{c}\text { White curdy } \\
\text { precipitate }\end{array}$ & $\begin{array}{l}\text { White curdy } \\
\text { precipitate }\end{array}$ \\
\hline $\begin{array}{c}\text { White curdy } \\
\text { precipitate }\end{array}$ & $\mathrm{HgCl}_{2}$ & $\begin{array}{l}\text { Tough white } \\
\text { curdy pre- } \\
\text { cipitate }\end{array}$ & $\begin{array}{l}\text { Tough white } \\
\text { curdy pre- } \\
\text { cipitate }\end{array}$ & $\begin{array}{l}\text { Tough white } \\
\text { curdy pre- } \\
\text { cipitate }\end{array}$ & $\begin{array}{l}\text { Tough white } \\
\text { curdy pre- } \\
\text { cipitate }\end{array}$ & $\begin{array}{l}\text { Tough white } \\
\text { curdy pre- } \\
\text { cipitate }\end{array}$ \\
\hline \multicolumn{2}{|c|}{ Tube number. ...... } & 1 & 2 & 3 & 4 & 5 \\
\hline \multirow{2}{*}{$\begin{array}{c}\text { Control } \\
\mathrm{H}_{2} \mathrm{O} .\end{array}$} & \multirow{2}{*}{ Salt. } & \multicolumn{5}{|c|}{ Final concentration of the salt in the system. } \\
\hline & & $1 / 20 \mathrm{~m}$ & $1 / 15 \mathrm{~m}$ & $1 / 10 \mathrm{~m}$ & $1 / 5 \mathrm{~m}$ & $1 / 1 \mathrm{~m}$ \\
\hline $\begin{array}{l}\text { White curdy } \\
\text { precipitate }\end{array}$ & $\mathrm{KCl}$ & $\begin{array}{l}\text { Partially } \\
\text { hydrated }\end{array}$ & $\begin{array}{l}\text { Partially } \\
\text { hydrated }\end{array}$ & $\begin{array}{l}\text { Partially } \\
\text { hydrated }\end{array}$ & $\begin{array}{l}\text { Transparent } \\
\text { gel }\end{array}$ & $\begin{array}{l}\text { Transparent } \\
\text { gel }\end{array}$ \\
\hline $\begin{array}{c}\text { White curdy } \\
\text { precipitate }\end{array}$ & $\mathrm{NaCl}$ & $\begin{array}{c}\text { White curdy } \\
\text { precipitate }\end{array}$ & $\begin{array}{l}\text { Partially } \\
\text { hydrated }\end{array}$ & $\begin{array}{l}\text { Partially } \\
\text { hydrated }\end{array}$ & $\begin{array}{l}\text { Partially } \\
\text { hydrated }\end{array}$ & $\begin{array}{l}\text { Transparent } \\
\text { gel }\end{array}$ \\
\hline $\begin{array}{c}\text { White curdy } \\
\text { precipitate }\end{array}$ & $\mathrm{MgCl}_{2}$ & $\begin{array}{c}\text { White curdy } \\
\text { precipitate }\end{array}$ & $\begin{array}{c}\text { White curdy } \\
\text { precipitate }\end{array}$ & $\begin{array}{c}\text { White curdy } \\
\text { precipitate }\end{array}$ & Milky gel & $\begin{array}{l}\text { Transparent } \\
\text { gel }\end{array}$ \\
\hline $\begin{array}{c}\text { White curdy } \\
\text { precipitate }\end{array}$ & $\mathrm{CaCl}_{3}$ & $\begin{array}{c}\text { White curdy } \\
\text { precipitate }\end{array}$ & $\begin{array}{l}\text { Partially } \\
\text { hydrated } \\
\text { white mass }\end{array}$ & $\begin{array}{l}\text { Partially } \\
\text { hydrated } \\
\text { white mass }\end{array}$ & $\begin{array}{l}\text { Partially } \\
\text { hydrated } \\
\text { white mass }\end{array}$ & $\begin{array}{l}\text { Partially } \\
\text { hydrated } \\
\text { white muss }\end{array}$ \\
\hline $\begin{array}{c}\text { White curdy } \\
\text { precipitate }\end{array}$ & $\mathrm{H}_{\mathrm{B}} \mathrm{Cl}_{2}$ & $\begin{array}{l}\text { Tough white } \\
\text { curdy pre- } \\
\text { cipitate }\end{array}$ & $\begin{array}{l}\text { Tough } \\
\text { slightiy } \\
\text { hydrated } \\
\text { white mass }\end{array}$ & $\begin{array}{l}\text { Tough } \\
\text { slightly } \\
\text { hydlrated } \\
\text { white mans }\end{array}$ & $\begin{array}{l}\text { Ieathery } \\
\text { white } \\
\text { mass }\end{array}$ & $\begin{array}{l}\text { Ieathery } \\
\text { white } \\
\text { mans }\end{array}$ \\
\hline \multicolumn{2}{|c|}{ Tube number. } & 6 & 7 & 8 & 9 & 10 \\
\hline
\end{tabular}




\section{The System Gelatin/Water}

We shall now consider a " neutral" protein which, when compared with the fatty acids, is not "insoluble" in water (as globulin) but " soluble," namely gelatin. The ordinary alleged acidand base-free gelatin ${ }^{1}$ will, by itself, with water, show all the four types of hydrophilic colloid systems described for the soaps. ${ }^{2}$

Dry gelatin absorbs water (to yield the system water-dissolvedin-gelatin) and has a limited solubility in water (to yield the system gelatin-dissolved-in-water). Between these extremes and depending merely upon the relative amounts of gelatin and water present there lie the systems gelatin-solution dispersed in hydrated-gelatin (gel) or, with more water, hydrated-gelatin dispersed in gelatinsolution ( $\mathrm{sol}$ ).

What is the action of alkalies (or acids) upon these systems?

Under variously worded headings this problem has received much study. The effects of alkalies (and acids) upon the lowermost of the four systems may be found described under the caption "swelling" of gelatin in the presence of acids and alkalies;" their effects upon the system gelatin-solution-in-hydrated-gelatin under the heading liquefaction and "solution" of gelatin; ${ }^{4}$ their effects upon the system hydrated-gelatin-in-gelatin-solution under studies in viscosity ${ }^{5}$ their effects upon the system true solution of gelatin-in-water as studies on the "solubility" of gelatin. ${ }^{6}$ What is the relationship between all these?

It is well to begin by inquiring into the relationship between the swelling of a "soluble" " neutral " protein and its " solution."

${ }^{1}$ See the footnote on page 209 .

${ }^{2}$ See page 69 .

${ }^{3}$ See for example K. SpIro: Hofmeister's Beiträge, 5, 276 (1904); Wolfgang Ostwald: Pflüger's Arch., 108, 563 (1905); Martin H. Fischer: Edema and Nephritis, 3rd Ed., 75, New York (1920) where references to the earlier studies may be found.

1 Martin H. Fischer: Seience, 42, 223 (1915); Kolloid-Zeitschr., 17, 1 (1915).

${ }^{5}$ See for example the work of Hofmeister, Padli, Hardy, von Schrofder, Handovsky, Sciorr, etc., on the viscosity of liquid proteins ("sols").

${ }^{6}$ Martin H. Fischer: OEdema and Nephritis, 3rd Ed., 513, New York (1920). As of similar import but upon other proteins may be cited some studies on wheat gluten. T. B. Wood and W. B. Hardy (Proc. Roy. Soc., London, Series B, 81, 38 (1908)) studied the "disintegration" and "solution" of gluten under the influence of aeids while F. W. UPson and J. W. Calvin (Jour. Am. Chem. Soc., 37, 1295 (1915)) studied its swelling under similar cireumstances. 
The notion that solution is but a continuation of swelling persists to this day. ${ }^{1}$ Investigation ${ }^{2}$ of the problem, however, has shown that this is not the case. The matter is easily proved by working with gelatin at concentrations and temperatures near its gelation or melting point. Since alkalies and acids increase hydration (increase swelling) the addition of these substances to a barely liquid gelatin-water mixture ought to stiffen it. As a matter of fact just the reverse occurs. By working with a stiff gelatin, a previously solid mixture is made to liquefy upon the addition of these substances.

The phenomena of swelling (hydration) and of "solution" 3 in such soluble protein gels as gelatin, while frequently associated, are therefore essentially different. Swelling is best understood as a change whereby the protein enters into physico-chemical combination with more of the solvent (water), as a change in the direction of greater solubility of the solvent in the protein; "solution" is best conceived of as a change in the direction of greater solubility (an increased degree of dispersion) of the colloid in the solvent. If reference is made to Figs. 48 and 49 (page 70) it will be noted that changes involving swelling occur in the region below the level marked $\mathrm{V}$; changes in the direction of liquefaction or "solution" above the level marked F. A

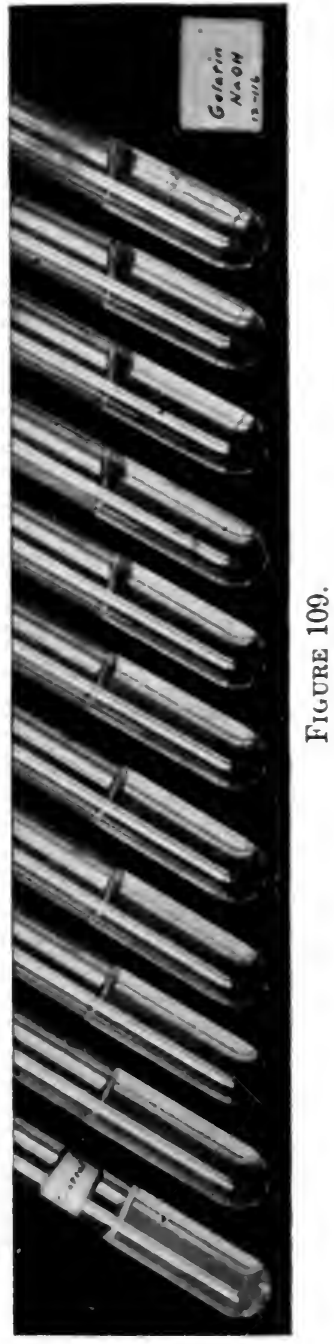

'See for example Wolfoang Paull: Kolloidchemie der Eiweisskörper, 63, Dresden (1920).

${ }^{2}$ Maktin H. Fischer: Science, 42, 223 (1915); Kolloid-Zeitschr., 17, 1 (1915)

"Since there are many opinions regarding the nature of "solution," ac'urate definition of the term is not easy. We are here using the term in its broadest sense as covering everything, in the case of the colloids, from their liquefaction point upwards to the accepted "true" solution of the physical chemists. 
single experiment, chosen from many, may serve to illustrate the point.

In Table LXIX and Fig. 109 is shown how the addition of a fixed alkali to an otherwise solid gelatin gel liquefies this.

TABLE LXIX

Neutral Gelatin Gel and Alkali

\begin{tabular}{|c|c|c|c|c|c|c|c|c|c|}
\hline Tube & \multicolumn{9}{|c|}{ Concentration of mixture. } \\
\hline 1 & \multicolumn{8}{|c|}{2 cc. 10 percent gelatin +8 cc. $\mathrm{H}_{2} \mathrm{O}$} & \\
\hline 2 & 2 cc. 10 & “. & “. & $+0.1 \mathrm{cc}$. & $/ 10$ & $\mathrm{NaO}$ & $\mathrm{I}+7.9 \mathrm{cc}$ & $\mathrm{H}_{2} \mathrm{O}$ & \\
\hline 3 & 2 cc. 10 & “. & “. & $+0.2 \mathrm{cc}$. & “ & “. & $+7.8 \mathrm{cc}$ & “. & \\
\hline 4 & 2 cc. 10 & “. & “. & $+0.3 \mathrm{cc}$. & “. & “. & $+7.7 \mathrm{cc}$ & “. & \\
\hline 5 & 2 cc. 10 & .. & .. & $+0.4 \mathrm{cc}$ & .. & “. & $+7.6 \mathrm{cc}$ & .. & \\
\hline 6 & 2 cc. 10 & “. & “. & $+0.5 \mathrm{cc}$. & “. & “. & $+7.5 \mathrm{cc}$ & “. & \\
\hline 7 & 2 cc. 10 & “. & .. & $+1.0 \mathrm{cc}$ & “. & “. & $+7.0 \mathrm{cc}$ & “. & $:$ \\
\hline 8 & 2 cc. 10 & “. & ." & $+1.5 \mathrm{cc}$. & “. & “. & $+6.5 \mathrm{cc}$ & .. & \\
\hline 9 & 2 cc. 10 & “. & . & $+2.0 \mathrm{cc}$ & “. & “. & $+6.0 \mathrm{cc}$ & “. & \\
\hline 10 & 2 cc. 10 & “. & ." & $+2.5 \mathrm{cc}$ & .. & “. & $+5.5 \mathrm{cc}$ & “. & \\
\hline 11 & 2 cc. 10 & “. & “. & $+3.0 \mathrm{cc}$. & “. & “. & $+5.0 \mathrm{cc}$ & .. & \\
\hline
\end{tabular}

The mixtures were liquefied in a warm-water bath. After standing for twenty-four hours at $25^{\circ} \mathrm{C}$. the gelatin in tube 1 was solid; that in tubes $2,3,4$ and 5 was also solid; in tube 6 the surface quivered on shaking. The gelatin in tube 7 flowed as a viscid liquid. In the remaining tubes the gelatin was entirely liquid.

TABLE LXX

Neutral Gelatin Gel and Acid

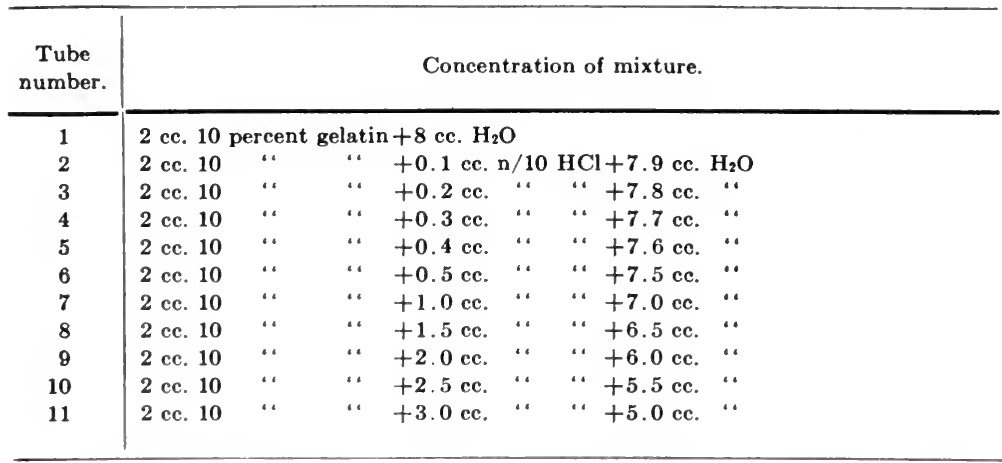

After these mixtures had stood for twenty-four hours the control gelatin in tube 1 was perfectly solid. The mixtures in tubes $2,3,4,5$ and 6 were so solid that they could be turned over, though on hard shaking they quivered; in tube 7 the gelatin flowed $a$ a viscid liquid; in tubes $8,9,10$ and 11 the mixtures were entirely fluid.

Table LXX brings out the same general truths for the addition of acid to an otherwise solid, " neutral " gelatin gel.

In interpreting the findings here described we would say that under the influence of the added alkali or acid the "neutral" 
gelatin is converted into a basic gelatinate or a gelatin chlorid. These compounds, at the same concentration. are more soluble in water than the neutral gelatin and hence the liquefaction of these systems.

TABLE LXXI

Sodium Gelatinate and Salt

\begin{tabular}{|c|c|c|c|c|c|c|c|c|c|}
\hline \multirow{2}{*}{$\begin{array}{c}\begin{array}{c}\text { Tube } \\
\text { number. }\end{array} \\
1\end{array}$} & \multicolumn{9}{|c|}{ Concentration of mixture. } \\
\hline & \multicolumn{9}{|c|}{2 cc. 10 percent gelatin +8 cc. $\mathrm{H}_{2} \mathrm{O}$} \\
\hline 2 & 2 cc. 10 & $\cdots$ & $\because$ & $+1.5 \mathrm{cc}$. & $1 / 10$ & $\mathrm{aO}$ & +6.5 ce. $\mathrm{H}_{2}$ & & \\
\hline 3 & 2 cc. 10 & “. & .. & $+1.5 \mathrm{cc}$. & $\because$ & $\because$ & +0.1 cc. $\mathrm{m}$ & $\mathrm{NaCl}$ & $\mathrm{I}+6.4 \mathrm{cc} . \mathrm{H}_{2} \mathrm{O}$ \\
\hline 4 & 2 сс. 10 & $\cdots$ & $\cdots$ & $+1.5 \mathrm{cc}$ & •. & $\because$ & +0.2 cс. $\cdots$ & $\cdots$ & $+6.3 \mathrm{cc}$. \\
\hline 5 & 2 cc. 10 & “. & “. & $+1.5 \mathrm{cc}$ & $\cdots$ & .. & +0.3 сc. $\cdots$ & $\cdots$ & +6.2 cc. $\cdots$ \\
\hline 6 & 2 cc. 10 & “. & $\because$ & $+1.5 \mathrm{cc}$ & *. & “. & +0.4 cc. ${ }^{\circ}$ & $\because$ & +6.1 cс. $\cdots$ \\
\hline 7 & 2 cc. 10 & $\cdots$ & . & $+1.5 \mathrm{cc}$. & “. & . & +0.5 cc. $\cdots$ & . & $+6.0 \mathrm{cc}$. \\
\hline 8 & 2 cc. 10 & * & .. & $+1.5 \mathrm{cc}$ & ‘. & . & +1.0 cc.. & “. & +5.5 cc. $\cdots$ \\
\hline 9 & 2 cc. 10 & $\because$ & “. & $+1.5 \mathrm{cc}$ & “. & .. & +2.0 cc. $"$ & “. & +4.5 cc. $\cdots$ \\
\hline 10 & 2 cc. 10 & $\cdots$ & $\cdots$ & $+1.5 \mathrm{cc}$ & $\cdots$ & .. & +3.0 cc. & .. & +3.5 cc. $\cdots$ \\
\hline 11 & 2 cc. 10 & “. & .. & $+1.5 \mathrm{cc}$ & “. & . & +4.0 cc.. & .. & +2.5 cc. $\cdots$ \\
\hline 12 & 2 cc. 10 & ". & $\because$ & $+1.5 \mathrm{cc}$. & .. & .. & +5.0 cc.. & “. & +1.5 cc. " \\
\hline
\end{tabular}

At the end of twenty-four hours the pure gelatin was solid; the gelatin plus the alkali was liquid. The tubes containing sodium chlorid in addition were all solid, the optimum stiffening effect of the salt being evident in tubc 7 .

TABLE LXXII

Gelatin Chlorid and Salt

\begin{tabular}{|c|c|c|c|c|c|c|c|c|c|}
\hline \multirow{2}{*}{$\begin{array}{c}\begin{array}{c}\text { Tube } \\
\text { number. }\end{array} \\
1\end{array}$} & \multicolumn{9}{|c|}{ Concentration of mixture. } \\
\hline & \multicolumn{9}{|c|}{2 cc. 10 percent gelatin +8 cc. $\mathrm{H}_{2} \mathrm{O}$} \\
\hline 2 & 2 cc. 10 & “. & $\because$ & $+1.5 \mathrm{cc}$ & $1 / 10$ & $\mathrm{HCl}+6.5$ cc. $\mathrm{H}_{2}$ & & & \\
\hline 3 & 2 cc. 10 & “. & “ & $+1.5 \mathrm{cc}$ & $\because$ & $\cdots+0.1$ cc. $m$ & $\mathrm{NaC}$ & $1+6.4$ cc. & $\mathrm{H}_{2} \mathrm{O}$ \\
\hline 4 & 2 cc. 10 & $\cdots$ & '. & $+1.5 \mathrm{cc}$. & “ & $\cdots+0.2$ cc. $\cdots$ & “ & $+6.3 \mathrm{cc}$. & *. \\
\hline 5 & 2 cc. 10 & “ & $\because$ & $+1.5 \mathrm{cc}$ & “ & $\cdots+0.3$ cc. ${ }^{\prime}$ & “. & $+6.2 \mathrm{cc}$ & “. \\
\hline 6 & 2 cc. 10 & '. & “. & $+1.5 \mathrm{cc}$. & “. & $\cdots+0 .+\mathrm{cc} . "$ & “. & $+6.1 \mathrm{cc}$ & .. \\
\hline 7 & 2 cc. 10 & '. & • & $+1.5 \mathrm{cc}$. & *. & $\because+0.5$ cc. $\cdots$ & $\because$ & $+6.0 \mathrm{cc}$ & .. \\
\hline 8 & 2 cc. 10 & $\cdots$ & “. & $+1.5 \mathrm{cc}$ & *. & $\cdots+1.0 \mathrm{cc} . "$ & “. & $+5.5 \mathrm{cc}$. & . \\
\hline 9 & $2 \mathrm{cc} .10$ & $\because$ & ' & $+1.5 \mathrm{cc}$. & “' & $"+2.0$ ce. $"$ & “ & $+4.5 \mathrm{cc}$. & . \\
\hline 10 & 2 cr. 10 & $\cdots$ & *. & $+1.5 \mathrm{cc}$. & “ & $\cdots+3.0$ ce. $"$ & $\because$ & $+3.5 \mathrm{cc}$. & .. \\
\hline 11 & 2 cc. 10 & $\cdots$ & “. & $+1.5 \mathrm{cc}$ & *. & $\cdots+4.0 \mathrm{ce}$. & ". & t-2s cc. & $\cdots$ \\
\hline 12 & 2 cc. 10 & . & “. & $+1.5 \mathrm{cc}$. & “. & $"+5.0 \mathrm{ce} . "$ & “. & $+1.5 \mathrm{cc}$. & “ \\
\hline
\end{tabular}

Twenty-four hours after the mixtuses had been prepared the pure gelatin in tube 1 was solid; the acidified gelatin in tube 2 was liguid. A distinct influesce of the sodium chlorid was evident even in tube 3 where the mixture barely flowed. The viacosity increnand progreasively from tube 4 to tube 7 in which the optimum effect of the modium chlorid was observed. Here the gelatin wan solid, but not guito so solid as thr pupr grlatin The gelatin mixtures in tubes $8,8,10,11$ and 12 were solid, but, on being tapped, quivered more easily than did the gelatin in tube 7. 
To illustrate, now, upon such basic (or acidic) gelatin the effects of a neutral salt (in mimicry of the salting-out effects observed upon soaps), Tables LXXI and LXXII are introduced. They show that the addition of a neutral salt in increasing concentration to a previously liquid gelatin at first increases its viscosity to an optimum point (gelation) and then decreases it. The same explanation holds for this finding as in the case of the soaps. The salt becomes hydrated and, as salt-water, becomes emulsified in the hydrated basic (or acidic) gelatin. With salt added beyond the optimum point the salt-water becomes the external phase and the viscosity of the system falls. With enough salt added the whole of the gelatin (as sodium gelatinate or gelatin chlorid and not as " neutral" gelatin) separates off in practically anhydrous form.

\section{Supplementary and Critical Remarks}

\section{$\S 1$}

It is necessary to keep clearly in mind that the possibilities for chemical and colloid-chemical change as thus far outlined for the fatty acids and the proteins constitute only a small fraction of those which may be induced.

While we have said that only alkalies will unite with the fatty acids and only alkalies and acids (or their salts) with the polymerized amino-acids ealled proteins, the former may be sulphonated, may be saturated with hydrogen, may be oxidized or iodized while the latter may also be oxidized, hydroxylated or have acids bound to them elsewhere in the molecule than at an $\mathrm{NH}_{2}$ grouping. As each of these chemical changes is induced the fatty acid derivative or the protein derivative assumes new properties of solubility for water and in water and as this happens the colloid-chemical properties (like the viscosity) of the system in which such a chemical change has been induced, must also change. ${ }^{1}$

To keep things simple we have also touched upon only the grosser of the phase differences present as neutral proteins unite with alkalies or acids. How much more complicated in fact are the systems which have been described is apparent when reference is made to Figs. 48 and 49 and the system, stearic acid/alkali/

${ }^{1}$ The derivatives listed have already been partly studied in our laboratory and will be reported upon later. 
water is considered and compared with the analogous system protein/alkali/water. ${ }^{1}$

If neutralization is not complete, the result is an emulsion of the uncombined fatty or proteinic acid in such hydrated " soap " as is produced. If neutralization is complete and the water content is sufficiently low, only pure hydrated alkali stearate or hydrated alkali proteinate is obtained. This obviously corresponds to the lowermost levels of the two diagrams. Depending upon the temperature either solid (Fig. 49) or liquid (Fig. 48) systems may be obtained. With sufficient water, only a true "solution" of the alkali stearate or alkali proteinate in water is obtained. We are then in the topmost levels of the two diagrams. In such solution, however, there follows hydrolysis of these compounds, so that in addition to molecules in solution there may appear, beside the soap, free fatty or proteinic acid and free alkali and along with these the ions of these substances. The presence of such ions in the case of protein/water systems has commonly been called upon to account for their colloid-chemical properties. Things are almost exactly the reverse. The most definitely colloid soap or protein/water systems, in other words the more concentrated ones, are at the other end of the diagrams and show no ions at all. Whenever such appear, they are the accidental products of dilution and hydrolysis. They begin to appear therefore as soon as soap or protein in true solution in water appears within the hydrated soap or protein, in other words in all the various mixed systems which lie in or above the level $Y$. The ions are, however, not in the hydrated colloid, but in those portions of these mixed systems which contain dissolved, dissociated and hydrolyzed soap or protein.

To illustrate the infinite variety of systems that may result from mixture of a base with a fatty acid or protein we need but list the following: fatty or proteinic acid emulsified in hydrated soap or basic proteinate, and vice versa; soap or protein "solution" in solid hydrated soap or basic proteinate, and vice versa; soap or protein "solution" in liquid hydrated soap or basic proteinate and vice versa; soap or protein " solution," pure and free. from ions or such as contains free fatty or proteinic acid, free alkali, and the whole gamut of ions;-all determined obviously

'Figs. 13 and 76 and Figs. 98 to 103 with the accompanying texts should be studied in this connection. 
by the concentrations of the various materials existing in any system, by the content of water in the system and the temperature.

Every one of these systems may be produced at will from fatty acids and alkali or from "neutral" proteins with alkali or acid.

\section{$\S 2$}

It will be noticed that the above remarks attempting to explain the colloid-chemistry of protein/water systems have called for no concepts outside those of mutual solubility and mutual emulsification or suspension, just as in the case of soap/ water systems. What then becomes of the chemical, electrical, surface tension, adsorption, etc., theories of stability in colloid systems proposed by various authors? The answer is, we think, simple. Their views are not always wrong, but they suffer universally from one-sidedness. They err either because they are inadequate to explain more than a part of the behavior of all colloid systems or because the explanation holds for only limited examples. If reference is again made to Figs. 48 and 49 it will be seen that those authors, for example, who try to see in all colloid systems nothing but special instances of modified "true solutions" are clearly trying to find the explanation of all colloid phenomena in regions lying above the level $\mathrm{E}$, and that often they are attempting to do this by the changes incident to mere passage from some one horizontal level to the next. Such a view is obviously too limited, for it ignores the behavior of all such systems as lie below the level V. Those authors, on the other hand, who hold that change in some one factor is responsible for the changes in stability of all colloid systems suffer from a similar limitation in point of view. It is difficult, for example, to conjure up electrical notions to explain the stability of colloid systems which consist merely of organic solvents and materials like fat or rubber. Stoichiometrical relationships lose their force when stabile colloid systems can be built of most variable proportions of fat and a hydratable carbohydrate (for example cottonseed oil in hydrated acacia, glycogen or dextrin). Surface tension views are inadequate when, with progressive change in surface tension relationship between any two substances, stabilization is obtainable only through a portion of the range, or, con- 
versely, throughout the whole range no matter what the surface values.

And yet these remarks must not be misunderstood. 'They do not, in the first place, diminish the value of the actual observations made by these different authors upon various colloid systems; nor do they deny that the factors they cite are not of some importance in some systems. The whole problem, obviously, moves back to an inquiry into still more fundamental ones: what is the nature of solution; what are the forces active in producing and maintaining emulsions; and what is the nature of solidification without or with a "solvent"?

We do not ourselves presume to answer these questions. In the matter of the nature of solution, however, we would like to emphasize our growing opinion that it is much more often union in quantitative relations between dissolved substance and the dissolving medium with the production of new compounds than is at present accepted by the "dilute solution" chemists; and that, especially in " concentrated" systems, this factor becomes so great that the added element of mere subdivision of one material in a second, so heavily stressed in the " dilute" solutions, largely disappears.

The forces active in stabilizing a colloid system may be any or all of those which make possible or give character to a " solution," or which permit of the stabilization of one material in a second to yield either (depending upon the physical state of the phases) an emulsion or a suspension. As all the facts of mutual solution cannot be understood upon any purely electrical basis, and as all the phenomena of cohesion, adhesion, suspension, stabilization, etc., cannot at present be understood through any single notion of viscosity, surface tension or other force, neither can purely chemical, purely electrical or purely surface tension concepts alone "explain" the behavior of these systems.

\section{On Peptization and Coagulation}

\section{$\$ 1$}

With the ideas of the preceding pages in mind we wish now to consider certain group reactions characteristic of different proteins, to see if some simpler concepts than we now possess 
regarding the fundamental nature of these group reactions, can not be discovered. Reference is made to their "peptization" and to their "coagulation" under various circumstances and to the colloid-chemical equivalents in types of change encountered in the physiology and pathology of protoplasm under the terms liquefaction, coagulation and necrosis.

The term "peptization" may be taken for our purposes as the antonym of " coagulation." The latter term has been applied to what represents at least several different types of change in protein/water systems. What these have in common, however, is a change in state from one in which the protein (or soap) is in solution or suspension, to one in which it is aggregated, separatedout or precipitated. In the terms of WolfGang Ostwald the changes characteristic of coagulation are essentially those of decrease in degree of dispersion, in other words changes in the direction of coarser division of the materials. Associated with such a change may be one in water-holding power, in optical properties, in viscosity, etc. There are those who would restrict the term "coagulation" to such changes as prove irreversible. An albumin would therefore be said to be coagulable through heat or a mercury salt (since lowering of temperature or dilution of the mercury salt does not bring back the albumin to its former " dissolved " state); it would not be coagulable, however, through saturated magnesium sulphate solution (for this on dilution allows the " albumin " to resume its former state). In the latter instance the change is often designated as a precipitation or "salting-out" of the "albumin." It does not matter, for our purposes, how the terms are used, for colloid-chemistry needs to consider them all. The distinctions are, moreover, arbitrary for, as long known, even heat coagulations are not completely irreversible if the high temperature is not maintained too long; and we shall see later that, just as in the case of the soaps, the heavy metal coagulations of the proteins can also be "redissolved." What light do the observations on soaps and the soap-like protein compounds already described cast upon the nature of these coagulative changes?

In order to illustrate how we think the views developed in the preceding pages should be applied for a better understanding of the procerses of "peptization" and " coagulation" in protein systems, we shall cite examples illustrating protein change (1) 
of the peptization and coagulation type, (2) of the heat coagulation type and (3) of the physiological coagulation type.

\section{$\$ 2$}

Peptization may be discussed by reference to the well-known changes suffered by a protein "insoluble" in water, such as casein, when this is subjected to the action of any of the light metal alkalies. Casein, like any of the pure higher fatty acids (for example palmitic), when mixed with water fails " to dissolve." Expressed in the terms developed in connection with the theory of the lyophilic soap colloids, ${ }^{1}$ the casein and the palmitic acid are neither soluble in water nor yet solvents for water. When, however, an alkali (like sodium hydroxid) is added to either, both become "soluble." In the case of the fatty acid we have long said that the change is coincident with transformation from fatty acid to a soap; in the ease of casein (and similar proteins) however, we have more commonly said that it is "soluble" "in alkaline solutions," that it is "peptized" by alkalies, that it " becomes colloidally dispersed through a requisite number of ${ }^{\circ} \mathrm{OH}$ ions," etc. It simplifies matters and is more eorrect to say that what happens is the same in both sets of materials. From the casein, too, is formed a soap-like compound (namely sodium caseinate) which is not only more soluble in water but also a better solvent for water than the original "neutral" casein. As the soaps are best thought of as definite compounds, each with its own solubility in water and its own solvent power for water, so also is it best to conceive of the basic and metallic proteinates also as definite chemical compounds possessed of their own solubility in water and solvent power for water.

The idea that alkalies (or acids) unite with protein to yield new compounds is, by itself, of course, not new. It was early expressed by S. Bugarsky and L. LizbrimanN ${ }^{2}$ and has, since their studies, been confirmed and developed by W. B. Hardy, ${ }^{3}$ Wolfgang PaUla, ${ }^{4}$

'See page 64

'S. Bugarsky and L. Lazbermans: Pflüger's Arch., 72, 51 (1895).

3 W. В. НАньу: Jour. Physiol., 33, 251 (1905).

- Wolfoang Pauli: Kolloidchemie der Eiweisskörper, 69, 1)resden (1920) where may be found the references to his earlier studies. 
E. Lacqueur, O. Sackur, ${ }^{1}$ L. L. Van Slyke, ${ }^{2}$ A. W. Bosworth, ${ }^{3}$ T. B. Robertson, ${ }^{4}$ etc.

The difficulty with the work of these authors, if we may express an opinion, is that with developmnt to quantitative levels of their chemical views covering such protein/electrolyte/water systems, they have seemed constantly to support the expressed or implied view that with the pure chemistry of these systems settled, an understanding of their colloid-chemical behavior followed as a self-evident corollary.

This view is, we think, fundamentally false. While union in stoichiometrical relations, qualitative and quantitative changes in electrical charge, the accepted theories of " dilute solution," etc., may all at times be factors appearing in a colloid system and may, in fact, in part determine the behavior of colloid systems, their quantitative appraisement is in no instance adequate to "explain" the colloid state. The colloid properties of a casein/sodium hydroxid/water system (ignoring for the present the presence of an overplus of either alkali or casein) are those of a sodium caseinate/water system and these, depending solely upon the concentration of the water in the system, vary from the extreme of a gelatinous solution of water in the caseinate on the one hand to a true solution of sodium caseinate in water on the other.

It is well to emphasize at once the proper significance to be given the electrical, ionic, viscosity, etc., properties which such a system may show. In the presence of sufficiently little water a chemically neutral sodium caseinate is not only solidly gelatinous but also neutral to an indicator like phenolphthalein, as witness the lower section of the test-tube shown in Fig. 110. While this finding is commonly interpreted in the terms of orthodox physical chemistry as proof that in such "highly concentrated solutions" (as in the highly concentrated soaps), there is no adequate hydrolysis and electrolytic dissociation to yield an overplus of $\mathrm{OH}$ ions, we ourselves hold that it is just as correct and more

${ }^{1}$ E. Lacqueur and O. Sackur: Hofmeister's Beitr., 3, 196 (1902).

${ }^{2}$ L. L. VAN Slyke and co-workers: Am. Chem. Jour., 33, 461 (1905); ibid., 38, 393 (1907).

${ }^{3}$ A. W. Bosworth and L. L. Van Slyke: Jour. Biol. Chem., 14, 203 (1913); ibid., 19, 67 (1914); Bosworth: ibid., 20, 91 (1915).

${ }^{4}$ T. B. Robertson: Jour. Biol. Chem., 2, 317, 337 (1907); ibid., 5, 493 (1909); ibid., 8, 287 (1910); Physical Chemistry of the Proteins, 85, New York (1918). Here references to the older literature may be found. 
reasonable to consider this proof that the system water-dissolved-in-sodium-caseinate is something different from a solution of sodium-caseinate-in-water. It must be admitted either (1) that indicator methods may not be applied to such a system or that if they are applicable (2) it contains no ions. We reëmphasize the point because to our minds the tissues of the body, including the blood and lymph, are such solutions of water. in protein (protoplasm) and that, like a concentrated sodium caseinate/water system, they are electrically neutral, that indicator methods cannot be applied to them without the greatest reserve and that it is fundamentally false to regard them as systems for which the laws of the ordinary dilute solutions may be expected to be valid.

Slight dilution of the concentrated sodium caseinate/water system with water suffices to turn it pink even when the system is still entirely solid. What turns pink is that portion of the emulsion thus formed which represents the phase, dilute solution of sodium caseinate in water subdivided in the unchanged (more solid) solution of water in sodium caseinate.

Still further dilution increases the amount of the dilute solution phase and therefore the intensity of the pink color (see Fig. 110). When sufficient water is added the system becomes more liquid since it is now composed of a subdivision of hydrated sodium caseinate particles within a "true" solution of sodium caseinate as an external, enveloping phase.

On extreme dilution the system becomes in-

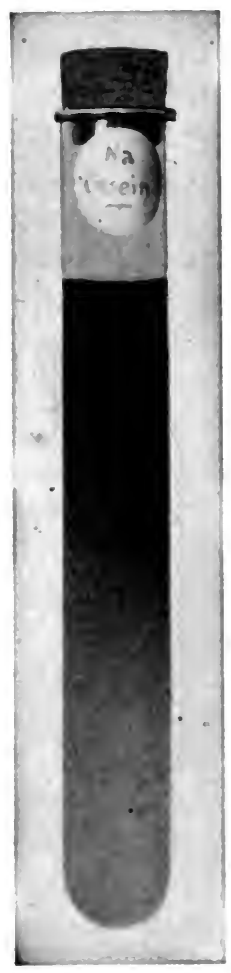

Figure 110. tensely red (see the upper sections of the tube in Fig. 110) because this is merely a dilute solution of sodium caseinate in water which has at the same time suffered great hydrolysis.

Just as the solubility and hydration properties of any fatty acid with different bases change as we pass from the alkali metals through the alkaline earths to the heavy metals, so also do the solubility and hydration capacities of easein, and in the same general fashion. The changes observed in the system as one 
metal displaces another explain much of what is ordinarily described under the head of the "peptization," "precipitation" or " coagulation" of the protein colloids.

When potassium hydroxid, for example, is added to a sodium caseinate/water system it is "peptized" and becomes more liquid; while through the addition of magnesium, calcium or iron salts precipitation or "coagulation" is produced. We prefer to say that in the first instance materials are formed (potassium caseinate) which are more soluble in water, wherefore the whole system tends in the direction of the less viscid true solution; while in the second, materials are produced which are less soluble in water and are possessed of a lower hydration capacity. Hence their separation from the dispersion medium.

As reversion from a state of low hydration, low solubility and precipitation to a state of higher hydration and "solution" is most easily obtained in the case of the soaps when the alkali metals are involved, is more difficult when those of the alkaline earths are considered and is generally said to be impossible in the case of the heavy metal soaps, so also in the case of the proteins are the similar reversions accomplished with increasing difficulty and more and more slowly as we pass from the alkalies through the alkaline earths to the heavy metals. The heavy metal salts are for this reason regularly listed as "coagulants" of the proteins, while those of the alkaline earths occupy an ambiguous middle ground. The light metal salts act merely as " precipitants" for the proteins. As previously emphasized ${ }^{1}$ and to be touched upon again ${ }^{2}$ these facts are of importance not only for the understanding of the nature of certain coagulations but embody the principles which must be employed when such coagulations appear in living matter in consequence of heavy metal poisoning.

\section{$\S 3$}

It is necessary now to discuss the effects of temperature upon the proteins, associated with which is the question of their heat coagulation in order to see where this set of phenomena has its analog in the colloid-chemistry of the soaps.

${ }^{1}$ Martin H. Fischer and Marian O. Hooker: Science, 43, 469 (1918).

${ }^{2}$ See page 240 . 
For a few of the proteins (as gelatin) in the presence of the light metal bases, the effects of temperature may be dismissed with the statement that raising the temperature merely moves the system in the direction of true solution in water. As ordinarily stated, the proteins are "more soluble" at the higher temperatures and are " not coagulable" by heat. The same might, of course, be said of the "solubility" of the lower fatty acids when these, in the presence of sodium or potassium hydroxid and water are raised in temperature. When the same proteins are examined in the presence of magnesium or calcium their behavior becomes "ambiguous," while in the the presence of heavy metals the proteins are uniformly coagulable at all temperatures. The reasons for this are to be found in the fact that many of the magnesium and calcium proteinates (like the magnesium and calcium soaps) are little more "soluble" at higher temperatures than at lower ones, while all the heavy metal proteinates, like the heavy metal soaps, have a low hydration capacity and a low solubility in water at all temperatures.

The accepted example of heat coagulation (or heat denaturization of the "protein ") is, however, best seen in certain of the proteins like various albumins and globulins. Here rise in temperature even in the presence of light metals does not favor hydration and solution of the "protein" but just the reverse. Where in the colloid-chemistry of the soaps do we encounter an analogous set of facts? Nowhere in the group of the systems composed of pure soaps and little water, but in the behavior of those in which through hydrolysis or otherwise the separation of insoluble free fatty acid is favored. In the case of the "heat coagulable" proteins it is also a matter, not of the coagulation of the potassium, sodium, etc., proteinates through increase in temperature but of the frce (proteinic) acid formed after hydrolysis. The items which favor such heat coagulation are the items which make for increase in hydrolysis or displacement of the system in the direction of a higher concentration of free proteinic acid. The heat itself does this, though the whole process is favored by dilution of the system with water, and the addition of small amounts of acid. Heat-coagulated protein/water systems are considered as among the most typical of the irreversible coagulations. Reversible, however, they are, as witness their swelling and solution when such "denatured "proteins are treated with light metal hydroxids. The same phenomena are observable 
in the soaps. On dilution and application of heat the light metal soaps, especially of the higher fatty acids, suffer great hydrolysis, and this hydrolysis is not reversible on simple lowering of temperature. But let the freed fatty acid be treated with more concentrated alkali, and reversion to a "swelling and soluble fatty acid "-to speak for the moment in the terms of protein chemistry-gradually comes about.

In a careful study of this problem $\mathrm{KRAFFT}^{1}$ boiled a unit weight (1 gram) of soap (sodium palmitate) with increasing volumes (200 to 900 cc.) of water. Just as when certain protein "solutions" are thus boiled, these soap mixtures become milky. On cooling, a shining precipitate settles out which on analysis shows a progressively lower percentage of sodium and higher percentage of fatty acid when compared with the composition of the pure soap, as the volume of water in which the soap was boiled is increased. The original soap contained 8.27 percent sodium. In contrast to this the cooled fraction when boiled with $200 \mathrm{cc}$. water showed but 7.01 percent; with 450 cc. water, 6.32 percent; with 900 ce. water, 4.20 percent. KRAFFT interpreted this finding as indicating that there was a splitting of the soap into sodium hydroxid and "acid-soap" (sodium bipalmitate). This idea has since been frequently adopted by other workers. It is, to our minds, only partly correct. There is, undoubtedly, with increasing dilution and increasing temperature, an increasing fraction of free alkali formed. This is the consequence of the better conditions offered for hydrolysis of the soap into free alkali and free fatty acid. But the mass which separates on cooling is certainly no true bipalmitate, for chemical reasons alone make it hard to see how a monovalent fatty acid can give rise to "acid" salts. The separated mass is not a chemical compound, but simply free fatty acid with which has been admixed mechanically a smaller and smaller amount of neutral soap.

What has been said of sodium palmitate holds also for sodium stearate and for all the higher members of the acetic series. It is true also for sodium oleate. The amount of such hydrolysis, however, decreases as the acetic series is descended so that for sodium caprate and for soaps lying below this it is very small indeed. Were we to convert this finding into the terms of "protein " coagulation," we would have to say that the "protein"

${ }^{1}$ KrafFt: Ber. d. deut. chem. Gesellsch., 27, 1747 (1894). 
is no longer heat-coagulable. The analog for the behavior of soaps of this type may be found in the basic derivatives of certain globulins.

$$
\S 4
$$

We wish, finally, to touch upon some biological coagulations in an attempt to define their nature more closely in the terms of colloid-chemistry. Reference is made to the coagulations typical of blood, milk and musele juice. In all these instances a protein body (fibrinogen, caseinogen, myosinogen) passes from a "soluble" state to an "insoluble" clot (fibrin, casein, myosin). Between the two extremes, however, the originally liquid "plasma" sets into a jelly which gradually develops signs of contracting with the squeezing off of a "serum." The clot finally swims in this serum as a relatively anhydrous mass. It is not our purpose to enter into the debate coneerning the chemical nature of the various elements which are neeessary for such eoagulation. All authors seem to agree that a substance $x$ ("fibrin ferment," rennin, muscle ferment) acts upon a seeond (fibrinogen, caseinogen, myosinogen) to produce the clot, the production of the latter being greatly favored by the presence of some of the earthy or heavier metals such as calcium or iron. It would not yet " explain " the physical changes accompanying the transformation of fibrinogen into fibrin even if it were proved (or disproved) that fibrin is a true chemical union between calcium and fibrinogen.

It will be apparent that the entire set of physical changes are such as may be observed in the simple salting-out of a soap ${ }^{1}$ and whatever the ultimately accepted chemical fundaments of "clotting," the physical transformation in the system must be of the same general type as observed in the salting-out of a soap. It is necessary, in consequence, to look at the soap system once more (see Fig. 74), to grasp correctly the analogous changes in protein systems when these " clot."

The liquid " plasma " of blood, milk or muscle juice is analogous to a liquid colloid system of the type sodium oleate/water. The substance $x$ (fibrin ferment, rennin, muscle ferment) which will bring about clotting may be anything which will lead to the separation of a second phase within the hydrated sodium oleate. It must in consequence be either (1) a substance which, like sodium

'See page 113. 
chlorid, combines with water while depriving the sodium oleate of its water or (2) one which acts upon the sodium oleate (like a weak acid) to produce from it a new substance (like fatty acid) which remains emulsified in the unchanged hydrated sodium oleate. In either instance the viscosity of the whole system must rise, as exemplified in the first stages of the salting-out of a soap or in the increase in viscosity observed whenever a " mayonnaise " is made by emulsification of a fat or fat-like body (fatty acid) in a hydrated soap or hydrated protein. With addition of more salt or more fat-like body the type of emulsion changes to one of soap-in-oil and as this occurs the viscosity of the system falls, "serum" separates off and the soap or fatty acid swims as a clot to the top. If the soap or fatty acid is crystalline at, the temperature of the clotting it may, of course, crystallize out. It is of interest therefore to note that in the case of blood coagulation the clot is definitely crystalline. ${ }^{1}$

We do not presume to say which of the two types of "coagulant," the "fibrin ferment," rennin or muscle ferment follows, but we incline to the view that it probably acts like a weak acid which splits the original fibrinogen (and not like the salt). The "ferment" nature of the different coagulants has been seriously questioned in late years, for they not only seem heat stabile, but disappear quantitatively as coagulation advances. It is not necessary, of course, that such "splitting" should be induced through a true ferment. The appearance in the reaction mixture of any substance which acts like a weak acid would do quite as well, for the addition of a limited amount of such a substance will not only stiffen a hydrated soap/water system but, similarly, any hydrated potassium, sodium or other basic proteinate system, as illustrated, for example, in the "souring" of milk.

How now may the "favoring" action upon coagulation of calcium, iron or other heavier salts be understood? It is necessary, here, to state just which part of the coagulatory process is " favored." Usually it means the earlier appearance of a free clot or the development of a "firmer" clot. Obviously the presence of the heavier metals must favor the development of fatty acid or proteinic acid derivatives which are possessed of low hydration capacities.

'See Stưbel: Pflüger's Arch., 156, 361 (1914); W. H. Howell: Am. Jour. Physiol., 35, 143 (1914). 


\section{ON THE THEORY OF POISONING BY AMMONIUM COMPOUNDS AND BY HEAVY METALS}

\section{General Remarks}

If we may apply to protoplasm the conclusions which have been reached in the previous pages it seems safe to us to say that the foundation of living matter is a polymerized amino-(fatty)acid to which normally are joined various bases (like potassium, sodium, magnesium and ealeium) and various acid radicals (like ehlorid, bromid, bicarbonate, sulphate and phosphate) the whole constituting a unit ${ }^{1}$ eapable of sucking up or "dissolving" a certain amount of water. It is in other words a basic-proteinacid compound in which water has been dissolved. Even the blood and the lymph have this colloid-chemical constitution. The secretions from the body, on the other hand, represent the opposite type of system-the urine and sweat, for example, are essentially " solutions" of protoplasmic material in water.

It is of interest now to study this hydrated protoplasmic mass (tissue and blood) to see what changes it may suffer when other than the normal bases or acids are introduced into it or the proportions of these constituents to each other are varied from the normal. Proper answer here has much to do with our fundamental theories of the physiology and pathology of cell behavior and of pharmacological action.

'From constant repetition in colloid-chemical, physiological and pharmacological action the grouping may be expressed approximately as follows:

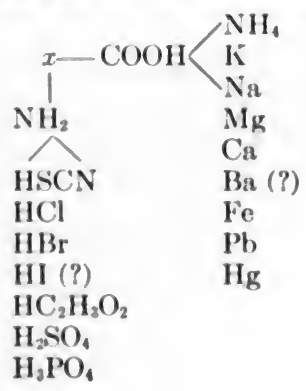


It is worthy of note, first, that sodium and chlorid are among the least poisonous of the listed constituents that may be introduced into cell protoplasm. It is for this reason that sodium chlorid is the main component of all "physiological" salt solutions. ${ }^{1}$ Not only do sodium and chlorid appear in protoplasm in largest amounts (in the list of the so-called inorganic " salts") but they yield, with protein, colloid systems which in physical behavior most closely approximate the physical characteristics of living matter. As we ascend or descend the list of the tabulated bases or acids from sodium or chlorid we encounter protein derivatives which are either more hydratable and soluble in water than normal protoplasm or which are less hydratable and soluble. It is this fact, we think, which is associated with the physiotogical, pathological and pharmacological action of these elements when introduced in more than normal concentration into the living mass. When, for example, potassium is introduced in more than normal amount it exerts a "poisonous" action which colloid-chemically evidences itself through an increased swelling and an increased fluidity of the affected protoplasm. Ammonium acts similarly, which explains why potassium and ammonium salts, for example, are used therapeutically to render more liquid the mucinous secretions of " catarrhally" affected mucous membranes.

${ }^{1}$ In connection with the analysis of physiological and pathological problems in the terms of colloid-chemistry, definition must be attempted of the nature of such "physiological" salt solutions. Pure water is poisonous because in contaet with it, protoplasm hydrolyzes. Free protein in consequence precipitates within the cell while "salts" diffuse into the distilled water. Presence of any salt in the pure water reduces such hydrolysis. The salt must, however, be of such nature and of such concentration as not to diffuse into the protoplasm and displace the normal equilibrium existing there between the various basic and acidic elements. Hence the superior value of an $\mathrm{NaCl}$ solution over that of any other one salt. But $\mathrm{NaCl}$ alone still permits of displacements and loss to the salt solution of constituents like $\mathrm{K}, \mathrm{Ca}, \mathrm{H}_{2} \mathrm{CO}_{3}$, ete. For this reason a RiNGEr solution (which contains small amounts of each of these in addition to $\mathrm{NaCl}$ ) is superior to simple salt solution. Solutions of the sugars (even when present in the same "osmotic" concentration) do not prevent such hydrolysis and hence are little better than distilled water. When properly prepared, a physiologieal salt solution will have a composition which, as a solution of salts in water, is in equilibrium with the system, solution of water in protoplasm. The protoplasm will now neither take up nor give off water, in other words the two systems will be "isotonic." The concentration of the individual salts in the water will, however, probably not be (and need not be) that of the concentration of these same elements in the hydrated protoplasmic mass. Whence the common finding that "isotonic" solutions are rarely (if ever!) isosmotic. 
The introduction of magnesium or calcium into protoplasm leads, on the other hand, to a "drying out" of the protoplasmic mass. While small amounts of these elements are necessary to maintain protoplasm in its normal state, larger ones begin to show a distinctly "poisonous" action. Such poisonous effect, with corresponding dehydration of the tissues, jumps enormously when salts of iron, silver, mercury or lead are used in pharmacological practice; hence the need of administering these substances in very small amounts, in medicine, if their use. is not to be pushed beyond the "physiological limit."

In the case of the heavier metals, the above considerations lead us to the obvious conclusion that these act as poisons to protoplasm because they unite with protoplasm to form compounds more sparsely hydratable than normal protoplasm. In pathology and medical practice the formation of such heavy metal protoplasmic compounds is generally considered to constitute an irreversible change and the affected protoplasm is commonly adjudged necrotic or dead. The mere fact, however, that individuals poisoned by any of the heavy metals do occasionally recover already indicates that such a conclusion overstates the facts; it was learned, moreover, in considering the colloid-chemical behavior of the analogous heavy metal soaps, that these could be converted into light metal soaps. We wish now to show that the heavy metal proteinates with their low hydration capacities can also be converted into the more highly hydratable lighter metal proteinates and that, as the latter are formed, colloid-chemical restitution to the condition which more nearly approximates the physiological state of protoplasm may be obtained. Before pointing out the obvious theory of intoxication and detoxication to which this fact leads, some experiments of Roвert A. Кеног ${ }^{1}$ must be detailed.

\section{Experiments on the Conversion of Heavy Metal Proteinates into Light Metal Proteinates}

A measured amount (5 ce.) of a viscid gelatin ( 2 grams in 100 cc. water) was gently stirred together with an equal volume of distilled water or an equal volume of $\mathrm{m} / 500$ silver nitrate. The appearance of five tubes forty-eight hours after being thus

' Roвert A. Кеное: Jour. Lab. and Clin. Med., 5, 443 (1920). 
prepared is shown in the upper row of Fig. 111. The tube on the left contains the gelatin-water control, the remaining tubes gelatin and silver nitrate. There was now added to the tubes, respectively from left to right, 5 cc. water, 5 cc. water, 5 cc. $\mathrm{m} / 3$ sodium sulphate, 5 cc. $\mathrm{m} / 3$ magnesium sulphate, 5 cc. $\mathrm{m} / 10$ potassium hydroxid. The lower row of Fig. 111 shows the effects of such treatment thirty-six hours later. The first two tubes are obviously unchanged. There has been distinct recession of the coagulating effects of the silver in the remaining tubes, restitution in the case of the $\mathrm{KOH}$ being apparently complete.

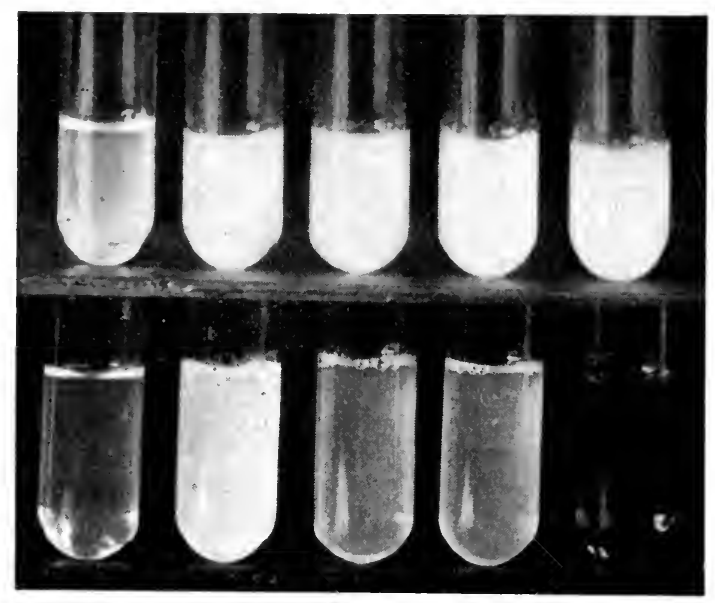

Figure 111.

Fig. 112 shows the reversing effects of these and other lighter metal salts when added to a series of 2 percent gelatin solutions (5 cc. each) previously coagulated through the addition of an equal volume of $\mathrm{m} / 500$ cupric sulphate, $\mathrm{m} / 1500$ ferric sulphate, $\mathrm{m} / 1000$ plumbic chlorid. After the coagulants had acted for forty-eight hours the reversing agents (5 cc. each) were added to the tubes ( $\mathrm{m} \mathrm{NaI}, 2 \mathrm{~m} \mathrm{MgCl}, \mathrm{m} / 20 \mathrm{KOH}, 2 \mathrm{~m} \mathrm{KCl}, 2 \mathrm{~m}$ $\left.\mathrm{MgCl}_{2}, \mathrm{~m} / 20 \mathrm{KOH}, 2 \mathrm{~m} \mathrm{KBr}, 2 \mathrm{~m} \mathrm{KCl}, \mathrm{m} / 20 \mathrm{KOH}\right)$. The photograph portrays the tubes twenty-four hours after such addition. The clear gelatin control appears on the extreme left. The unchanged heavy metal controls are the left-hand tubes in each of the remaining groups. The three remaining tubes of 
each of the series show that complete resolution of the original heavy metal coagulum has been obtained in all cases.

The importance of using enough of the lighter metal salts if reversion is to be accomplished is illustrated for mercury coagulation in Fig. 113. With the exception of the pure gelatin control, all the tubes contained 5 cc. of 2 percent gelatin to which had been added 5 cc. $\mathrm{m} / 1000$ mercuric chlorid. Twenty-four hours later 5 cc. distilled water were added to the pure gelatin and a mercury gelatin control; to the remaining tubes were added $5 \mathrm{cc}$. of potassium iodid of the concentrations $\mathrm{m} / 1$, $\mathrm{m} / 2, \mathrm{~m} / 4, \mathrm{~m} / 8$ and $\mathrm{m} / 32$. The photograph taken twentyfour hours later shows complete reversal of the coagulation only for the tube to which $\mathrm{m} / 1$ potassium iodid was added and less and less reversion as the concentration of the reversing salt was lowered.

Lest it be thought that these observations on " dead " proteins do not apply to "living " tissues the following observations of Kкнов ${ }^{1}$ may be of interest. The enzymatic reactions are perhaps as characteristic of living matter as any. KEноE finds that the starchsplitting activity of saliva may

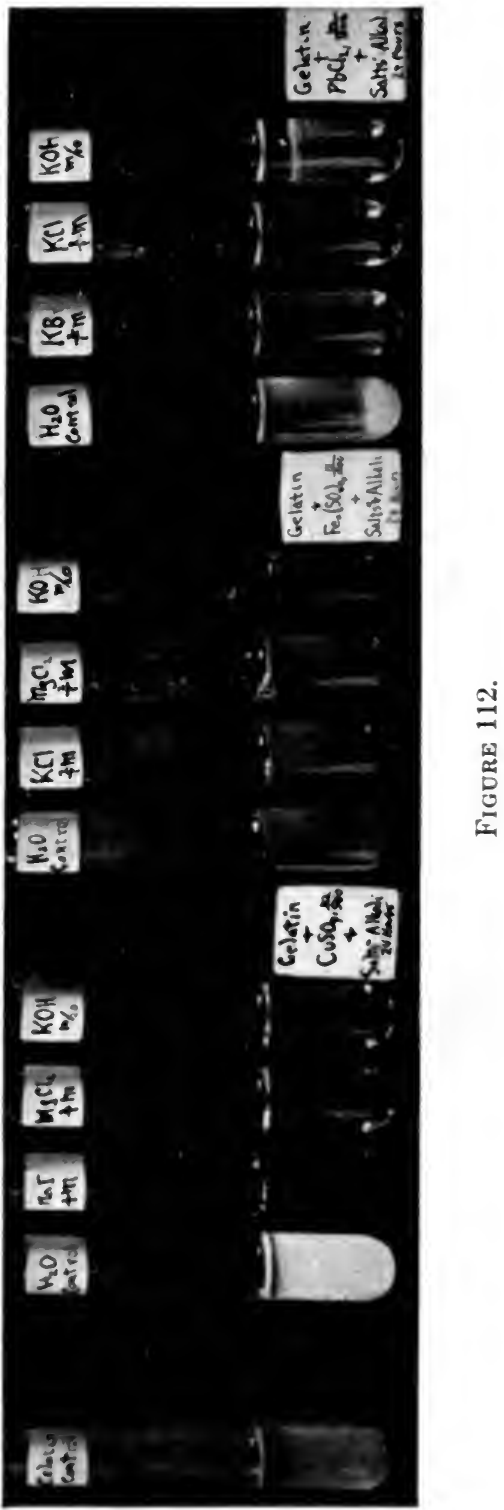

'Robert A. Kenok: Personal communication (1921). 
be "killed" through the addition of various heary metals. Saliva, thus " poisoned" for weeks, will again split starches to dextrose when any of the light metal salts are added to it. But here again interesting differences appear. While all the lighter metals act in this fashion, excessive addition of such metals as potassium will again kill the reaction. Apparently only when the enzyme (presumably a protein) has a medium grade of dispersion and

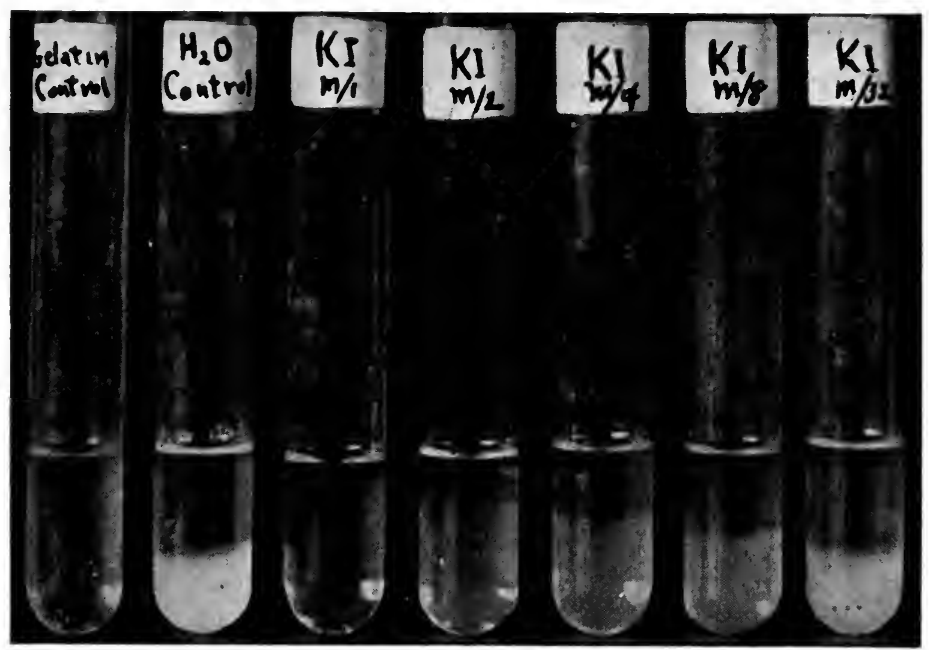

Figure 113.

hydration and not an excessive one with excessive solubility in water will it best exhibit its starch-splitting properties. ${ }^{1}$

\section{On the Nature and Relief of Heavy Metal Poisoning}

\section{$\S 1$}

It is perhaps fair to say that the present day treatment of heavy metal poisoning is an attempt, in the main, to discover some

${ }^{1}$ This idea that optimal enzymatic activity is associated with a certain degree of dispersion of the enzyme, independently arrived at by Кенов, was first discovered through other colloid-chemical methods by A. Fodor (Fermentforschung, 4, 191, 209 (1920)). Fodon found that the enzymatic activity (digestion of polypeptids) and ultramicroscopic picture of a phosphoprotein obtained from yeast was destroyed through the action of much acid but that both could be restored through neutralization of the acid and addition of $\mathrm{KCl}$. 
" antidote" which will throw the poisonous agent "out of solution" in "insoluble" form. Many facts in chemistry, pharmacology and therapy already suffice to indicate that such a notion regarding the action of antidotal agents is incorrect. Unless, for example, an exactly proper concentration is maintained, the administration of sodium or potassium iodid to individuals poisoned with lead or mercury does not result in the formation of insoluble lead or mercury salts, but may quite as easily yield soluble products. And yet the beneficent effects of iodid administration in the relief of various heavy metal intoxications, even when such concentration details are ignored, cannot be doubted. In the experiments of KеноE the concentration of the reversing salts was so chosen as to yield no precipitates of the heavy metal elements, and yet the more normal state of the previously coagulated protein was undoubtedly restored.

The heavy metal salts do not poison protoplasm because they are dissolved in it, but because they combine with the protein constituents of the cell to yield insoluble proteinates of low hydration capacity. Antidotes do not save such poisoned cells because they precipitate the heavy metal, but because they displace the heavy metal from its protein combination to unite themselves with the protein freed. The heavy metal previously insoluble because united to the protoplasm of the cell again becomes soluble and as such may be washed out of the body.

\section{$\S 2$}

The above considerations bring with them, we think, suggestions of practical value for the treatment of all the heary metal poisonings.

It is obvious that if the heavy metal proteinates revert under the influence of light metal salts to the proteinates of these lighter metals (which then more nearly approximate in physical state the proteins of the normal cell) a second reason appears for the administration of large doses of alkali to patients poisoned by the heary metals. A first reason was found and utilized some years ago ${ }^{1}$ when the administration of alkali was recommended to patients

'Martin H. Fischer: (Edema, 123, 133, New York (1910); Nephritis, 52, 125, 173, 186, New York (1912); (Filema and Nephritis, 2nd bi. 549, 648, New York (1915); Edema and Nephritis, 3rd Ed, 727, 789, New York (1921). Here numerous references to the older literature may be found. 
poisoned (or about to be poisoned for therapeutic reasons) by arsenic, mercury or lead. As discovered by F. Hoppe-SEYler and his pupils, T. Araki, T. Irasawa and H. Zillessen, the heavy metals interfere with the normal oxidation chemistry of living cells, resulting in an abnormal production and accumulation of acids in the involved cells. Such increased acid content is followed by an increased water absorption (œdema) of the involved cells which in the case of such organs as the brain, medulla and kidney may lead to a fatal issue. Associated with this pharmacological action of the heavy metals and the swelling of certain proteins is their other colloid-chemical action which results in the formation of less hydratable compounds (like the metallic globulinates). The combination of the swelling of certain proteins with the dehydration of others yields the anatomical picture which the pathologists call "cloudy swelling." To neutralize the acids formed and thus to reduce the swelling of the one while at the same time the attempt is made to uncoagulate the dehydrated second and thus clear the "clouding," heavy doses of alkali are needed (like the bicarbonates, carbonates and hydroxids of sodium, potassium and magnesium or, in general, any of the lighter bases in combination with organic acids oxidizable to carbonates). These substances alone, or better in mixture, must be given in sufficient amounts day and night to maintain a permanently neutral or even a slightly alkaline reaction of the urine. In order to float off in solution the liberated heavy metal, water is needed. It must, however, be remembered that water alone, especially when brought in contact with cells inclined to œdema, favors their swelling and solution. To offset such deleterious effects, the alkaline salts and water intake must be so controlled (whether given by mouth, rectum or intravenously) as always to have the combination touch the affected cells in hypertonic solution. ${ }^{1}$ How much may be accomplished in saving an extra fraction of those poisoned by the heavy metals by such methods may be deduced not only from my own studies ${ }^{2}$ but from the independent ones of William DEB. MACNider and H. B. Weiss. ${ }^{3}$

${ }^{1}$ For details regarding such treatment see Martin H. Fischer: GEdema and Nephritis, 3rd Ed., 667, 678, 783, New York (1921).

${ }^{2}$ Martin H. Fischen: (Edema, 123, 133, New York (1910); Nephritis, 52, 125, 173, 186, New York (1912); Udema and Nephritis, 2nd Ed., 549, 648, New York (1915); Cdema and Nephritis, 3rd Ed., 727, 789, New York (1921).

${ }^{3}$ William deB. MacNider: Jour. Exp. Med., 23, 171 (1916); ibid., 26, 


\section{Concluding Remarks}

In these concluding paragraphs we shall in rather dogmatic fashion try to group the results of the studies outlined in these pages with some older ones, ${ }^{1}$ all of which had in common the purpose of analyzing protoplasm colloid-chemically and of defining as accurately as possible the nature of various changes observable in the living mass when subjected to physiological or pathological change.

\section{$\S 1$}

Biological evidence indicates that of the five proximate principles found in protoplasm,- protein, carbohydrate, fat, salt and water-three constitute an irreducible minimum. While life may continue in the absence of carbohydrate and fat it ceases as soon as any of the other three is missing. What is the relationship of these to each other? In the common belief these materials exist "in dilute solution" in the cells which, plainly put, are held to be little bags of salt solution in which the proteins are either dissolved or "suspended." And yet, normal protoplasm even when very rich in salts has not a salty taste and does not yield any appreciable portion of its salt content to rain or dew ${ }^{2}$ or the distilled water in which it may be bathed. The salts are obviously not in dilute solution but combined with the protein. Biological reasoning therefore compels the same conclusion to which the analogies existent between the behavior of simple (protein) colloid systems and the behavior of living matter have led us. The so-called "salts" and the water of protoplasm (except in theoretical amounts) are not "free." The salts are combined with the proteins and the combination is not "dissolved" in water, but conversely, water is dissolved in it. Living matter is in essence a unit, a hydrated basic-protein-acid complex in which ionization, the laws of true solution and the presence of water in a state analogous to that seen in a glass are reduced practically to zero. ${ }^{3}$

1, 19 (1917); ibid., 28, 50, 517 (1918); Proc. Soc. Exp. Biol. and Med., 14, 140 (1917); H. B. Wesss: Jour. Am. Med. Assn., 65, 1618 (1917); ibid., 71, 1045 (1918).

I Makts H. Fischer and Marian O. Hooker: Fats and Fatty Degeneration, New York (1917); Mantix H. Fiscuer: (F)ema and Nephritis, 3rd Ed., New York (1921).

${ }^{2}$ See Joun Uni Liord: Eelectic Med. Jour., 75, 616 (1915)

"What is said here of the "salts"-which obviously are made when pro- 
It is as different from the ordinary dilute solution as a " solution" of water in phenol is different from one of phenol in water.

The experiments detailed in the preceding pages also indicate how the colloid-chemical nature of this hydrated protein colloid which constitutes the physiological basis of life may be changed, either from within or without, so as to give rise to the manifestations of physiology, or, when more accentuated, of pathology. Through temporarily or more continuously acting factors, be they mild or drastic in their action, the chemical character of protoplasm is changed and depending upon the hydration and solution characteristics of the new compounds formed, the physical state of the living mass is also changed.

In the list of the simpler changes which may thus be brought about are those which give character to oedema and abnormal water loss. The protoplasmic mass which in its "normal" state has sucked up as much water as it can, is possessed of what the physiologists call a normal water content or a normal turgor. If, for any reason, a cell takes up more than this normal amount of water, it becomes " odematous." The botanists say that the cell is then in a state of abnormally high turgor which, when extreme, results in destruction of the cell or "plasmoptysis." Obviously, anything which under physiological or pathological conditions brings about such change in the colloid mass, which, in other words, enables it to absorb such excessive amounts of water may be listed as a "cause" of cedema or increased turgor.

For this reason abnormal accumulations of acids or of alkalies within a cell may be listed as causes for oedema, for these so act upon the "normal" albumins of the cell as to convert them into albuminates which have a higher hydration capacity. But the amins, pyridin and urea also increase the hydration capacity of proteins (though in a different way) so they, too, are in proportion to their activity, "causes" for œedema. Or when one basic or acid radical is substituted for another in the normal protoplasm this may be a cause for œdema; for ammonium or potassium proteinates are more hydratable than sodium or magnesium proteinates, and protein chlorid swells more than protein toplasm is subjected to drying out, to the action of water, or to the action of analytical agents, is to our minds true also of many other components held to be preëxistent and "dissolved" in living matter. Alkaloids certainly do not exist as such in normal protoplasm-they are split off through the methods used to isolate them as JoHN URI LLOYD has so often insisted. 
sulphate. Such facts explain the "poisonous" and swelling effects of pure potassium or pure chlorid solutions upon normal cells which on exposure to these lose their sodium and calcium or their sulphate and phosphate, etc.

On the other hand, anything which decreases the water holding power of the protoplasmic colloids is to be listed as a cause for " abnormal water loss," for shrinkage of the cell or, to use the terminology of the botanists, "plasmolysis." Much effort has been made to bring these swellings and shrinkings into relationship with the laws of osmotic pressure. That all such attempts have failed will surprise no one,- - the laws governing the waterholding powers of cells are the laws which govern the waterholding powers of their " normal" colloid proteins and proteinates and of the new colloid derivatives produced from these when exposed to the action of different salts. Since the derivatives produced are possessed of entirely different hydration capacities even when the salts are applied in the same concentration the ultimate swellings and shrinkings must obviously also be different in spite of equivalence in "osmotic pressure."

As we previously listed various elements as "causes" of œdema we could now in similar fashion list others as causes of plasmolysis. In sufficient eoneentration all salts are such, but in their mode of action we must distinguish between at least two types of effects. Even without entering the protoplasmic mass, salt molecules may bind water and so take it away from the hydrated protoplasmic mass (shrinking it through "deprivation of solvent" as first suggested by Franz Hofmeister "); on the other hand the salt radicals may replace others in the protoplasmic mass binding themselves to the vacated bonds. In this way lead, mercury and similar proteinates are produced which, as compared with the more "normal" potassium, sodium and magnesium proteinates, suck up scarcely any water at all.

\section{$\S 2$}

The colloid-chemical variations accompanying chemical change in the fundament of the living cell are not, however, exhausted by this change in its water-holding power. Its solubility in water also changes. Generally speaking those proto-

'Pranz Hormeister: Arch. f. exp. Path. U. Pharm., 25, 6 (1S65). 
plasmic derivatives which have a greater capacity for swelling have also a greater tendency to "go into solution." The things that make for adema make also, therefore, for the appearance of protein ("albumin") in the surrounding medium. The swollen kidney in nephritis therefore yields albumin to the urine (albuminuria); the œedematous brain or spinal cord makes the protein content of the spinal fluid go up; etc.

\section{$\S 3$}

In association with these changes in the direction of increased swelling and increased solubility, or decreased swelling and decreased solubility, it is well to carry in mind a third type of change to be considered whenever salt in rather high concentration is added to protoplasm and when the possibilities for chemical reaction between the salt and the protoplasm are practically

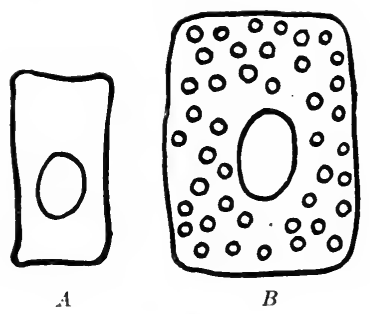

Figure 114. zero. The change about to be described scarcely appears when the normal (relatively dry) cell is up for consideration; it may be prominent when the cell is œdematous (or practically liquid). When a chemically non-active salt is applied to protoplasm in relatively high concentration it tends to shrink the normal cell (see $A$ of Fig. 114) concentrically; when mixed with a more liquid protoplasm the salt particles unite with water within the protoplasmic mass (see B of Fig. 114). Dehydration of the (protein) colloids of the cell occurs in both instances, but volume change (in the sense of a decrease) may not appear in the second.

The matter is of much importance in the analysis of the principles which must guide us in the treatment of codema. As so often insisted, all salts, including sodium chlorid, decrease the hydration capacity of a protein in the presence of an acid and for this reason should be administered in as high a concentration as possible to the odematous individual. It has, however, been insisted by various clinicians that the administration of salts (especially sodium chlorid) does not decrease, but may actually increase œedema. While many of the observations intended to 
prove this point are subject to serious question, the observations detailed in this volume ${ }^{1}$ show how such occasional findings may be explained.

After the state described in $B$ of Fig. 114 has been attained it needs to be remembered that every salt water droplet is enclosed within a hydrated colloid membrane. But these are now osmotic systems; for the so-called semipermeable membranes of the physical chemists, which allow water to pass through them but (as commonly alleged) no dissolved substances, are also nothing but hydrated colloid membranes. None of them are really impermeable to dissolved substances, but they allow the passage of such only very slowly. The œedematous cell dehydrated from within may therefore swell still more if water is given, for it has been converted into a series of tiny osmotic systems, in other words droplets of concentrated salt solution in semipermeable bags of hydrated colloid.

These remarks must not, however, be misunderstood. The normal cell is no such system and the play of osmotic forces within it is practically zero.

From their observations on œdema the clinicians have come to the false conclusion that the way to treat it is to withhold salt. What is necessary is to give salt but to withhold water.

\section{$\S 4$}

We may now return to the general question of the possibilities for the development of osmotic properties by any cell under physiological or pathological circumstances.

Obviously, whenever the hydrated protein mass moves under the influence of physiological activity or in consequence of injury, etc., in the direction of increased hydration and increased solubility in water it moves also, in the direction of "increased osmotic pressure," increased electrical conductivity, increased fluidity and decreased viscosity; while changes in the direction of decreased hydration capacity and decreased solubility make for an opposite set of changes. It is well to bear in mind the simple nature of these changes, for in them is carried the "explanation" of the biological terms which to-day impede progress in physiology or pathology. 
When it is observed that the colloid-chemical interplay between protein colloids, water and various so-called "electrolytes" is governed both qualitatively and quantitatively by the same laws which govern various physiological functions (like water absorption, muscular contraction, nerve conduction, sense of taste, digestion, enzymatic reaction, etc.) it follows that the essence of these physiological reactions must also be found in such colloidchemical changes in the protein fraction of the protoplasmic mass. We locate, in other words, the portion of the living mass in which physiological behavior has its seat. And in pathology, it is again obvious that if the laws governing various pathological changes are those which govern the colloid-chemical behavior of proteins we obtain here, too, an answer to the nature of these changes while discovering, at the same time, the principles which must guide us in their treatment.

Protoplasm when "stimulated" or injured manifests subsequently a " current of action " or " reaction to injury." Physiologically we know that the irritated or injured protoplasm becomes more acid, that its electrical potential toward an uninjured or less injured part changes, and that it shows an increased osmotic pressure; pathologically we observe the injured protoplasm to swell, to undergo, perhaps, a "cloudy" swelling or "albuminous degeneration," which when sufficiently severe may be followed by "fatty degeneration" and death of the involved part (" necrosis").

The concepts developed in the preceding pages may serve to indicate how these physiological, anatomical and pathological entities hang together. The production of acid in a part, either through activity or injury, must, of necessity, bring with it an electrical change, succeeded by a chemical one in which the proteins of the involved protoplasm are given an increased hydration capacity and so, if water is present, are made to swell. Such swelling will, however, be manifested only by proteins of the albumin type. The globulins, on the other hand (which as sodium, magnesium or calcium globulinate have in this form a higher hydration capacity), will be robbed of their bases, and, as the less hydratable "free" "globulinic acid" tend to be precipitated. The combination yields a precipitated material within a swollen one, in other words, the anatomical picture of cloudy swelling. But the swollen proteins are also more soluble in water. 
The involved protoplasm will therefore not only tend to $\mathrm{mix}$ with its. surrounding medium, but (except for the globulin fraction) will itself be moving from a system represented by a solution of water in colloid material towards a system represented by a true solution of the colloid material (the protoplasm) in water. As this happens there will be observed a "liquefaction" of the protoplasm, a decrease in its viscosity, an increased diffusibility and (if such diffusion is impeded by hydrated colloid walls) manifestations of an increased osmotic pressure.

The several changes described make for a steady decrease in the amount of hydrophilic colloid present in the unit volume of protoplasm and the appearance of more and more "free" water. But under such circumstance any fat previously held apart in finely divided form within the protoplasm begins to run together into larger globules. As this happens we get the anatomical picture of "fatty degeneration."

We have not thus far considered the question of whether a reversal in the circumstances producing the series of changes described (with their accompanying alterations in function) allows these changes to rcverse or not. If reversion is possible the condition is "curable"; if not, the involved protoplasm dies, or, to say it in Greek, it suffers necrosis.

Considering that in a thousand pages of pathology the subjects of œdema, cloudy swelling and fatty degeneration scarcely take up a dozen, it may impress the reader that too much has been made of them in the pages of this volume and preceding ones. If the matter needs justification then it is written in the fact that all disturbance in function and all the changes of disease which are reversible and therefore curable are contained within the confines of these lowly concepts. Cells once dead may be replaced by others, but the physician does not do this. If he has a problem it is that of how to maintain the physiological; to understand the nature of the pathological; and to use, not with hope only, but with conscious power his knowledge of these things in order to aid nature in her efforts to restore an injured cell to the normal.

To hasten such solution our efforts have not brought us far. To do it in the terms of morphology is to end in pictures; to do 
it in the terms of pure chemistry is to end in formulæ. Perhaps to do it in the terms of colloid-chemistry as attempted in the preceding pages is also inadequate, but if it is, the fault is resident in the misapplications which have been made, not in the inadequacies of colloid-chemistry to the task. 


\section{PART FOUR}

\section{APPENDIX}





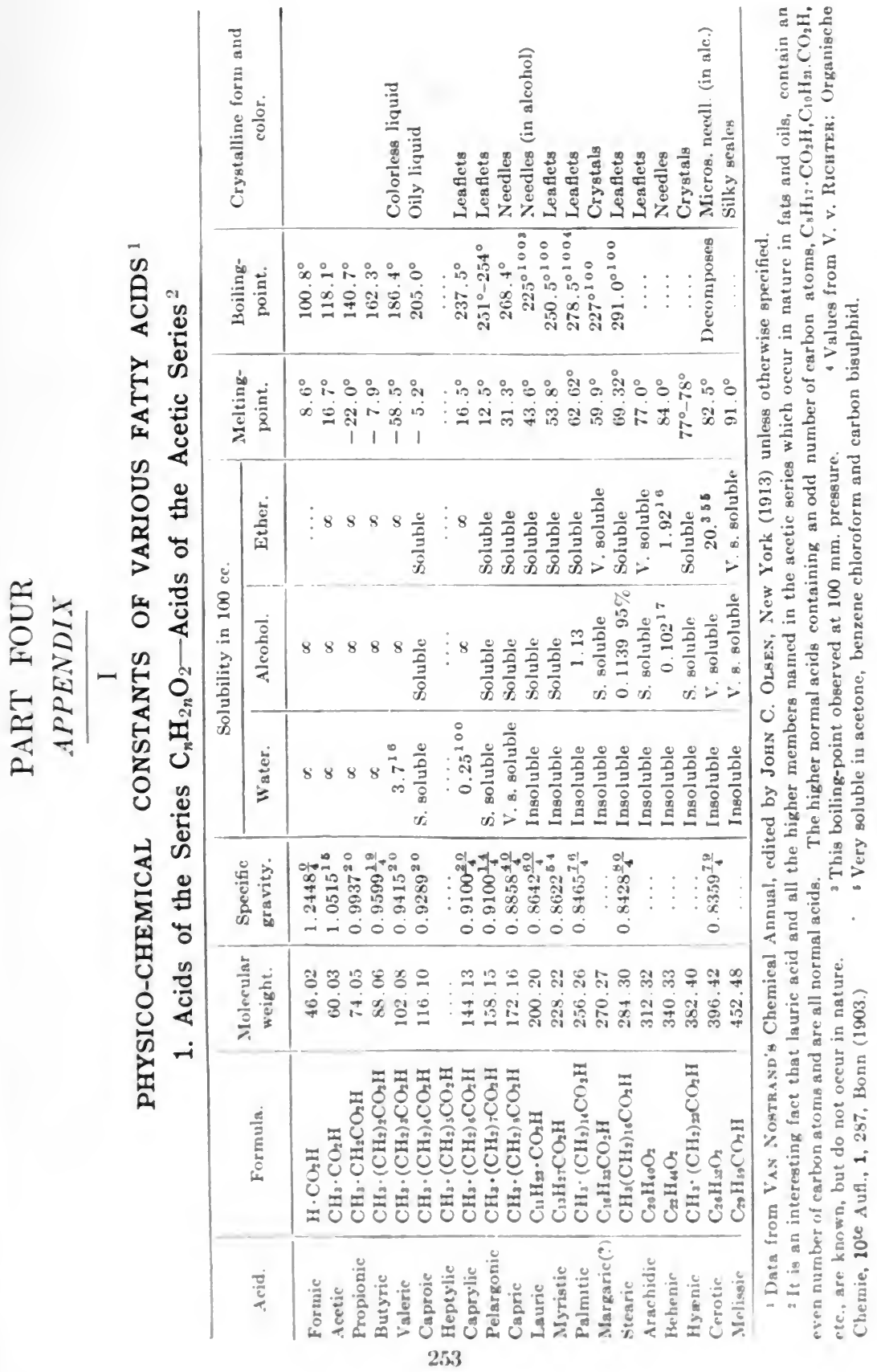




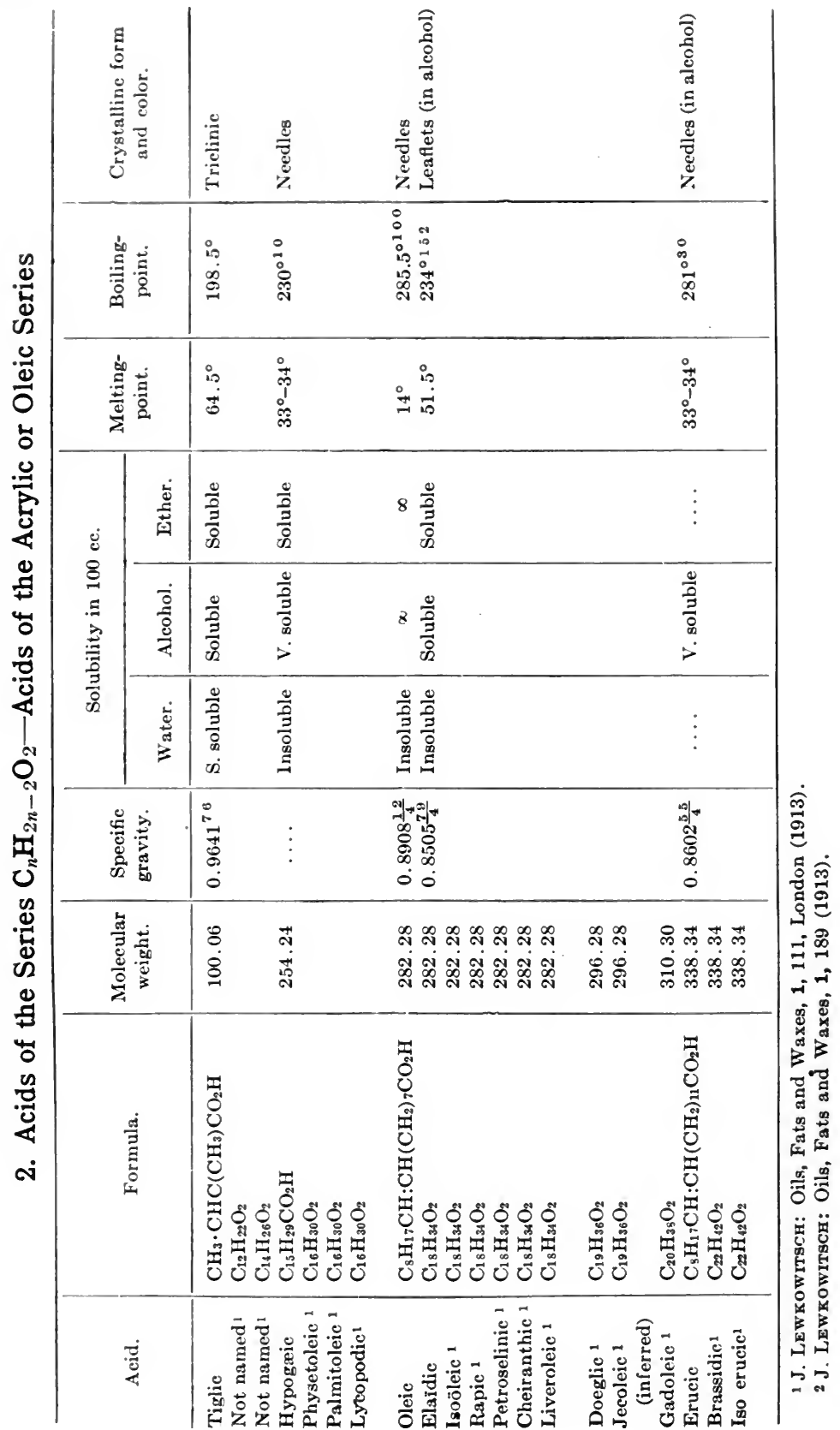




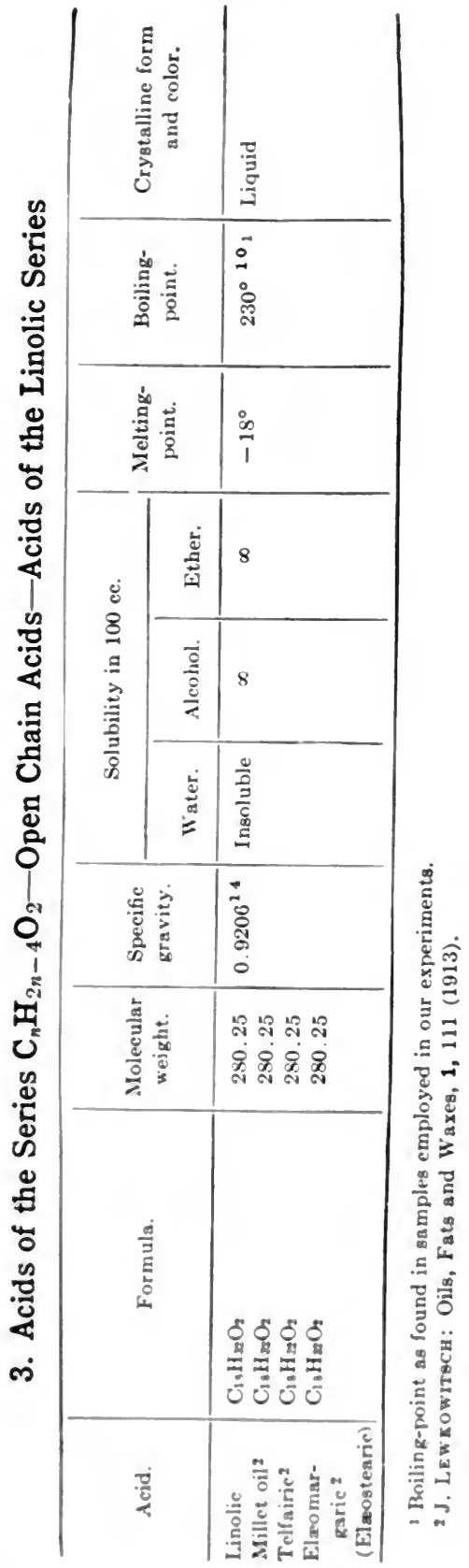


II

PHYSICO-CHEMICAL CONSTANTS OF VARIOUS ALCOHOLS ${ }^{1}$

1. Monatomic Alcohols of the Formula $\mathrm{C}_{n} \mathrm{H}_{2 n+1} \mathrm{OH}$

\begin{tabular}{|c|c|c|c|c|c|}
\hline Alcohol. & Formula & $\begin{array}{l}\text { Molecular } \\
\text { weight. }\end{array}$ & $\begin{array}{l}\text { Specific } \\
\text { gravity. }\end{array}$ & $\begin{array}{l}\text { Melting- } \\
\text { point. }\end{array}$ & $\begin{array}{c}\text { Boiling- } \\
\text { point. }\end{array}$ \\
\hline Methyl & $\mathrm{CH}_{3} \mathrm{OH}$ & 32.03 & $0.7913^{\frac{20}{4}}$ & $-97.8^{\circ}$ & $66.78^{\circ}$ \\
\hline Ethyl & $\mathrm{C}_{2} \mathrm{H}_{5} \mathrm{OH}$ & 46.05 & $0.78510^{\frac{26}{4}}$ & $-112.3^{\circ}$ & $78.4^{\circ}$ \\
\hline Propyl & $\mathrm{C}_{3} \mathrm{H}_{7} \mathrm{OH}$ & 60.06 & $0.80358^{\frac{20}{4}}$ & $\cdots$ & $97.4^{\circ}$ \\
\hline Butyl & $\mathrm{C}_{4} \mathrm{H}_{9} \mathrm{OH}$ & 74.08 & $0.8138^{\frac{1}{1} \frac{5}{5}}$ & & $117.02^{\circ}$ \\
\hline $\begin{array}{l}\text { Amyl } \\
\text { Capryl }\end{array}$ & $\mathrm{C}_{5} \mathrm{H}_{11} \mathrm{OH}$ & 88.10 & $0.8168^{20}$ & $\ldots$ & $137.8^{\circ}$ \\
\hline Heptyl & $\mathrm{C}_{7} \mathrm{H}_{15} \mathrm{OH}$ & 116.13 & $0.830^{16}$ & $-36.5^{\circ}$ & $175.8^{\circ}$ \\
\hline Octyl & $\mathrm{C}_{8} \mathrm{H}_{17} \mathrm{OH}$ & 130.15 & 0.8375 & $\ldots$ & $195.5^{\circ}$ \\
\hline Nonyl & $\mathrm{C}_{9} \mathrm{H}_{19} \mathrm{OH}$ & 144.16 & $0.8346^{\frac{10}{4}}$ & $-5.0^{\circ}$ & $215.0^{\circ}$ \\
\hline
\end{tabular}

2. Diatomic Alcohols

\begin{tabular}{l|c|c|c|c|c}
$\begin{array}{c}\text { Ethylene } \\
\text { glycol } \\
\begin{array}{c}\text { Trimethylene } \\
\text { glycol 2 }\end{array}\end{array}$ & $\mathrm{C}_{2} \mathrm{H}_{4}(\mathrm{OH})_{2}$ & 62.05 & $\ldots$ & $-17.4^{\circ}$ & $197.37^{\circ}$ \\
$\mathrm{C}_{3} \mathrm{H}_{6}(\mathrm{OH})_{2}$ & 76.06 & $\ldots$ & $\ldots$ & $216.0^{\circ}$
\end{tabular}

\section{Triatomic Alcohols}

\begin{tabular}{l|l|l|l|l|l} 
Glycerin & $\mathrm{C}_{3} \mathrm{H}_{5}(\mathrm{OH})_{3}$ & 92.06 & $1.2604^{\frac{20}{4}}$ & $17^{\circ}$ & $290.0^{\circ}$
\end{tabular}

\section{Other Alcohols}

\begin{tabular}{l|l|r|c|c|c} 
Allyl & $\mathrm{C}_{3} \mathrm{H}_{5} \mathrm{OH}$ & 58.05 & $0.8491^{\frac{25}{25}}$ & $-129^{\circ}$ & $96.69^{\circ}$ \\
Benzyl 3 & $\mathrm{C}_{7} \mathrm{H}_{7} \mathrm{OH}$ & 108.06 & $\ldots \ldots$ & $\ldots$ & $206.0^{\circ}$ \\
Cinnamyl & $\mathrm{C}_{9} \mathrm{H}_{9} \mathrm{OH}$ & 134.08 & $1.0397^{\frac{35}{36}}$ & $33^{\circ}$ & $257.5^{\circ}$ \\
& & & & & \\
\hline
\end{tabular}

1 Data from Van Nostrand's Chemical Annual, edited by John C. Olsen, New York (1913), unless otherwise specified.

2 V. v. Richter: Organische Chemie, $10^{\text {te }}$ Aufl., 1, 340 (1903).

a W. H. Perkin and F. Stanley Kipping: Organic Chemistry, 451, London and Edinburgh (1911). 


\section{BIBLIOGRAPHY}

The following is a list of publications in which were originally expressed the views summed up in running form in the foregoing pages.

1. Martin H. Fischer and Marian O. Hooker: On the Physical Chemistry of Emulsions and its Bearing upon Physiological and Pathological Problems. Science, 43, 468 (1916).

2. Martin H. Fischer and Marian O. Hooker: Ueber das Entstehen und Zergehen von Emulsionen. Kolloid-Zeitsehrift, 18, 129 (1916).

3. Martin H. Fischer and Marian O. Hooker: Fats and Fatty Degeneration, New York (1917).

4. Martin H. Fischer and Marian O. Hooker: Ternary Systems and the Behavior of Protoplasm. Science, 48, 143 (191S).

5. Martin H. Fischer: Further Studies in Colloid Chemistry and Soap. Science, 49, 615 (1919).

6. Martin H. Fischer and Marian O. Hooker: On the Hydration Capacity of Some Pure Soaps. Chemical Engineer, 27, 155 (1919).

7. Martin H. Fischer: Non-Aqueous Lyophilic Soap Colloids. Chemical Engineer, 27, 184 (1919).

8. Martin H. Fischer and Marian O. Hooker: On the Colloid Chemistry of Potassium Oleate and the "Salting-Out" of Soaps. Chemical Engineer, 27, 223, 253 (1919).

9. Martin H. Fischer: On the Reaction of Soaps to Indicators. Chemical Engineer, 27, 271 (1919).

10. Martin H. Fischer: Colloid Chemistry of Soaps and Proteins. Proceedings American Society of Biological Chemists, 5, 23 (1919).

11. Mantis H. Fischer and Geonge D. Mclaughls: A Third Model Illustrating Some Phases of Kidney Secretion. Journal of I aboratory and Clinical Medicine, 5, 352 (1920). 



\section{AUTHOR INDEX}

\section{A}

Araki, T., 242

\section{B}

BachmaNe, W., 6, 9

Bancroft, Wilder D., 157

BELL, J., 169

BLYTI, W., 169

Bosworth, A. W., 228

Botazzi, F., 6, 9, 110, 112

Bowden, R. C., 180

BUgarsky, S., 227

\section{C}

Calvin, J. W., 218

Chevreul, 3, 180

Clowes, G. H. A., 111, 112, 113, 157

Cornish, C. C. V., 180

\section{D}

Donnan, F. G., 157

$$
\text { L }
$$

Llasdon, 167, 168

\section{I}

FarNsteiner, 165,166

Fischeir, Martix H., 9, 30, 64, 73, $75,81,82,93,110,115,138,150$, $155,156,218,219,230,241,242$, 243,257

Fonor, A., 240

Freunduich, H., 65

Frtedtänder, J., 66, 65, 69

\section{G}

Goloschmint, F., 6, 9, 111, 112, 157 , 165,181

Granam, Тиомаs, 76

Grussner, 165, 166

\section{H}

Handovsky, H., 218

HALDY, W. B., 66, 69, 218, 227

HAZURA, $165,166^{\circ}$

Heyerdahl, 166

Hillyer, H. W., 157

Hofmeister, Franz, 6, 9, 110, 111 , 218,245

Hooker, Marian O., 9, 30, 64, 73. $75,93,110,115,13 S, 150,155,156$, $230,243,257$

HOPPE-SEYLER, F, 242

HoweLL, W. H., 234

IRASAWA, T., $242^{\text {I }}$
JUHLLARD, $166^{\mathrm{J}}$

K

Kвнов, Roневт A., 237, 239, 240, 241

Kifping, F. Stanley, 256

Kinafrt, F., 6, 9, 70, 110, 112, 166, $180,181,206,232$

Кгевітz, P., 191

lironacher, R. J., 117

\section{I}

Lacqueur, E., 228

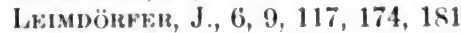

Lkw кошітвсн, J., 7, 9, 165, 166, 167, $168,169,206,254$

I,IEBERMAN, I., 227

LINK, 165

LLOYD, JoHN URI, 243, 244

LONG, C. P., 192

\section{M}

MACNIDER, WI, DER, 242

Mathews, A. P., 69 
McBain, James W., 111, 112

McLaughin, George D., 257

Meissl, 169, 170

Merklen, F., 165

Munson, 165,166

Noyes, A. A., 65

Olsen, John C., 253, 256

Ostwald, Walther, 157

Ostwald, WolfGang, $64,65,66,68$, $69,209,218,226$

\section{$\mathrm{P}$}

Pauli, Wolfgang, 218, 219, 227

Paulmyer, 167

Perkin, W. H., 256

Perrin, J., 65

Pickering, S. U., 157

Plateau, S., 157

Quincke, G., $157^{\mathrm{Q}}$

$\mathrm{R}$

REICHERT, 169, 170

Richter, V. VON, 253, 256

RINGER, 236

Robertson, T. B., 157, 228

Rothmund, V., 66, 68, 69

Sackur, O., 228

Salmon, C. S., 157

SChORR, KARL, 218

Schroeder, P. von, 218

Shorter, S. A., 157

Smits, A., 181

Spallanzani, 169

Spiro, K., 218

Stiepel, C., 117, 182, 188, 189

STÜBEL, 234

T'

Tolman, 165, 166

Twitchell, Ernst, 5, 6, 165, 168

UBBELOHDE, 157, 165

Upson, F. W., 218

\section{$\mathrm{V}$}

VAN Slyke, L. L., 228

Victorow, C., 6, 9, 110, 112

W

Watt, Alexander, 174

Weimarn, P. P. von, 65, 69

Weiss, H. B., 242, 243

Weissmann, L., 6, 9, 111, 112, 181

Wiglow, H., 6, 9, 110, 180, 181, 206

Wood, T. B., 218

\section{Z}

Zillessen, Hermann, 242 


\section{SUBJECT INDEX}

ACFTiC ACID, 7, 253.

A

Acetic Series, fatty acids of, 7, 253; soaps of, 16.

Acetic Series Soaps, 16, salting-out of, 117, 135; gelation of, 135; and foaming characteristies, 138, 141; and emulsifying characteristics, 136, 150; and washing characteristics, $136,157$.

AcID, acetic, 7, 253; butyric, 7, 253; valeric, 7, 253; caproic, 7, 253; caprylic, 7,253 ; capric, 7, 253; lauric, 7, 253; ficocerylic, 7; myristic, 7, 253; isocetic, 7; palmitic, 7, 253; margaric, 7, 253; stearic, 7, 253; arachidic, 7,253 ; behenic, 7,253 ; lignoceric, 7 ; carnäubic, 7 ; pisangcerylic, 7 ; cerotic, 7, 253; montanic, 7; melissic, 7; psyllostearylic, 7; tiglic, 7, 254; hypogaeic, 7, 254; physetoleic, 7, 254; palmitoleic, 7, 254; lycopodic, 7,254 ; oleic, 7,254 ; elaidic, 7,254 ; isoöleic, 7,254 ; rapic, 7 , 254; petroselinic, 7, 254; cheiranthic, 7, 254; liver oleic, 7, 254; doeglic, 7,254 ; jecoleic, 7, 254; gadoleic, 7, 254; erucic, 7, 254; brassidic, 7,254 ; isoerucic, 7, 254; linolic, 8, 255; millet oil, 8, 255; telfairic, 8, 255; elæomargaric, 8, 255; elæostearic, 8, 255; tariric, 8; hydnocarpic, 8; chaulmoogric, 8 ; linolenic, 8 ; isolinolenic, 8 ; jecoric, 8 ; isanic, 8 ; therapic, 8 ; clupanodonic, 8 ; arachidonic, 8 ; sabinic, 8 ; juniperic, 8 ; lanopalmic, 8 ; coceric, 8 ; ricinoleic, 8 ; isoricinoleic, 8 ; ricinelaïdic, 8 ; ricinic, 8 ; quince oil, 8 ; dihydroxystearic, 8 ; lanoceric, 8 ; heptadecamethylenedicarboxylic, 8 ; octodecamethylenedicarboxylic, 8 ; japanic, 8 ; formic, 253; propionic, 253; heptylic, 253; hyaenic, 253; pellargonic, 253.

AcIDs, fatty, $7,8,253$; of the series $\mathrm{C}_{n} \mathrm{H}_{2 n+1} \mathrm{COOH}, 20$; amins of fatty, 206; solubility of fatty in and for water, 206; and union with proteins, 227.

ACID SoAp, 112.

Acrulic Acid Series, 7, 254.

Adpitive Salt EFFects, 102.

Ansolerrios, in soap systems, 185.

Albumin Content of Secretions, 246.

Aliuminous Drgeneration, 248.

Aliuminuria, 246.

Alconots, ethyl, 30, 31, 34, 56, 57; amyl, 34, 56, 57; capryl, 34, 56, 57; heptyl, 34, 56, 57; methyl, 34, 56, 57; octyl, 34, 56, 57; nonyl, 34, 56, 57; propyl, 34, 56, 57; monatomic, 44, 56; allyl, 49, 53; benzyl, 49, 55; cinnamyl, 49; diatomic, 50, 58; triatomic, 52, 59; and sodium oleate, 46; and sodium elaidate, 46; and sodium crucate, 47; and sodium linolate, 48.

ALOHOL/SOAP Sratems, 30 .

ALKALEs, and salting-out effects on potassium oleate, 120, 121; and union with proteins, 227; and heavy metal poisoning, 241 . 
Alkaloids, and protoplasm, 244.

Allyl Alcohol, 49, 53, 256.

Amino-ACIDS, 205.

AMINO-FATTY-ACIDS, 206.

Ammonium linolate, 24; oleate, 25; stearate, 26; palmitate, 27; laurate, 28.

Ammonium Chlorid, and salting-out of soaps, 121, 130:

Ammonium Hydroxid, and salting-out of soaps, 121.

Amyl Acetate, 61.

Amyl Alcohol, 34, 56, 57, 256.

Axalogies, in colloid-chemistry of protein derivatives and tissues, 205.

Antidotes, 241.

Arachidic Acid, 7, 253.

Arachidonic Acid, 8.

Asbestos, 193.

B

BArium linolate, 24, oleate, 25, stearate, 26, palmitate, 27, laurate, 28.

BARYTES, 193.

BeEswaX, 169.

Behenic Acid, 7, 253.

BENZALDEHYD, 61, 63.

Benzene, 61, 63.

Benzyl Alcohol, 49, 58, 256.

Bibliography, 257.

Biological Coagulations, 233.

Blood Coagulation, 233.

Borax, as soap filler, 185 .

Brassidic Acid, 7, 254.

Brine, and salting-out of soaps, 182.

Butter Fat, 168.

Butyl (Iso) Alcohol, 56, 57, 256.

Butrric ACID, 7, 253.

\section{C}

Cacao Butter, 167.

Calcium Chlorid, and salting-out of soaps, 131.

Calcium Hydroxid, in soap manufacture, 93.

Calcium linolate, 24; oleate, 25; stearate, 26; hydroxid, 93; chlorid, 131.

CAPric ACID, 7, 253.

Caproic Acid, 7, 253.

Capryl Alcohol, 34, 56, 57, 256.

Caprylic Acid, 7, 253.

Carbon Tetrachlorid, 61, 63.

Carnäubic Acid, 7.

Casein, 228, 233; systems, 288.

Caseinogen, coagulation of, 233.

Castor Oil, 166.

Cells, osmotic phenomena in, 247.

Cerotic Acid, 7, 253.

Chalk, 193.

Chaulmoogric Acid, 8.

Chaulmoogric Acid Series, 8.

Cheiranthic Acid, 7, 254.

Chloroform, 61, 63. 
Cinnamyl Alcohol, 49, 256.

Clay, 193.

Cloudy Swelling, 248.

Clupanodonic Acid, 8 .

Clupanodonic Acid Series, 8.

Congulation, 225; definition of, 226; of protein systems, 230; through heat, 230.

Coconnut Oil, 167.

Cocceric Acid, 8.

Cod Liver Oil, 166.

Cold Process Soap Manufacture, 170.

Cold Water Sonps, 187.

Collords, definition of lyophilic, 64; theory of, 64; classification of, 64; lyophobic, 65; difference between lyophilic and lyophobic, 65; lyophilic and lyophobic, 72; hysteresis, swelling, liquefaction, gelation capacity, solvation capacity, syneresis and sols of, 74 ; swelling of, 75 ; sweating of, 76 ; as fillers for soaps, 193.

Colloid-chemical Changes, and physiologieal reactions, 248.

Collord-chemistry, of soap-making, 6 ; of protein derivatives, 208; of derivatives of egg-globulin, 210.

Collord IoNs, 112.

Colloid Systems, stabilization of, 225; reaction of, to indicators, 229.

Comparison, of soaps, 23; of soap systems with gelatin systems, 223; of soap systems with protein systems, 223.

Constants, of fats and oils, 169 ; of market soaps, 186; of fatty acids, 253 ; of alcohols, 256.

Conversion, of one soap into another, 190; of heavy metal proteinates to light metal proteinates, 237.

Cottonseed Oil, 165; saponification of, 172.

Critical Mixtures, 66.

Critical Temperature, 68.

CUpric Chlorid, and salting-out of soaps, 132.

Cupric Sulphate, 238.

Curability, 249.

Curd Sonp, 181, 183.

Current of Action, in protoplasm, 248.

Crchic Acids, 8.

DеАти, 248.

DrhydRation, by sodium chlorid, 246.

Drpivation of Solvent, 245.

Diatomic Alсоноц, 50, 58, 256.

Dibasic Acids, 8.

DiHydroxylated Acids, 8.

Diuydroxysteanic ACID, 8.

Diphasic Srstems, viscosity of, 115.

DOEglic ACI1), 7, 254.

Drying of soAps, 189, 191

E

EgG-glonulis, and hydroxids, 207; and water systems, 209; colloil-chemistry of derivatives of, 210; and acids, 212; and salts, 217. 
Eleomargaric Aंid, 8, 255.

F.t.eostearic Acid, 8, 255.

Elaïdic Acid, 7, 254.

Emulsification, theory of, 154; in soap manufacture, 174.

Emulsifying Properties of Soaps, 136, 150.

Emulsion, 73.

ENzYmes, and heavy metal action, 239; and elegree of dispersion, 240.

Erucic ACID, 7, 254.

Ethers, 61.

Ethyl Aicohol, 34, 56, 57, 256; and soap systems, 30, 34 .

Ethyl Alcohol/Sodium Oleate systems, 31.

Ethyl (Enanthate, 61, 63.

Fithyleneglycol, 50, 58, 59, 256.

Eutectic Mrxtures, 20.

Fat Constants, 169.

FATS, 3; in soap making, 164.

Fatty Degeneration, 248.

Ferric Chlorid, and salting-out of soaps, 133.

Ferric Sulphate, 238.

Fibrinogen, eoagulation of, 233.

Ficocerylic ACID, 7.

Filled Soaps, 185.

Filler for Soaps, borax as, 185; sugar solution as, 192; colloids as, 193; nature of action of, 194; use of, in excess, 195.

Finishing of SoAps, 183.

FlOUR, 193.

Fonming, of soaps, 136; soaps effective for, 138; effect of temperature upon, 138; theory of, 154.

FoAMs, solid, 136; liquid, 136, production of, 137; maintenance of, 137.

Formic ACID, 253.

Gadoleic Acid, 7, 254.

G

Gas in Gas, 64.

Gas in Liquid, 64.

Gas in Solid, 64.

Gasoline, 61, 63.

GEL, 21 ; theory of soap, 69 .

Gelatin, 209, 218; swelling of, 75, 218; and water systems, 218; solution of, 218; independence of swelling and solution in, 219; hydration and solution of, 219; liquefaction of, 220; and alkali, 220; and acid, 220, and salt, 221.

Gelatin Chlorid, 221.

Gelatin/Water Systems, 218.

Gelation Capacities, 74, 76; of sodium soaps, 21.

Globulins, and heat coagulation, 233.

Glycerin, 59, 256.

Goose Fat, 168.

Grained Soaps, 183.

Graining of Soaps, 5 .

Gumming of Soaps, 182. 
Half-SeTtled Soaps, 183.

Heat Coagulation, 230; of protein and soap systems, 231; of biological fluids, 233.

Heavy Metals, nature of poisoning by, 241.

Heavy Mgtal Poisoning, nature and relief of, 241.

Heavy Metal Proteinates, 192, 237.

Heptadecamethylenedicarboxylic ACid, 8.

HeptaNe, 61, 63.

Hepty. Alconol, 34, 56, 57, 256.

Heptylic ACID, 253.

Hog FAT, 168.

Hot Process Soap Manufacture, 170.

Hot Water Soaps, 187.

Hyaenic ACID, 253.

HYDNOCARPIC ACID, 8.

Hydrates, 114, 115.

Hydration, of gelatin, 219; and solution of proteins, 219.

HyDRoGEN Ions, of protein/water systems, 214.

Hydrogenated Cottonseed Oil, saponification of, 173.

Hydrogenation, 13.

Hydrolysis, of soaps, 79.

Hydroxids, and egg-globulin, 207.

HydroxyL IoNs, of protein/water systems, 214.

Hydroxylated ACIDS, 8.

Hygroscopic Properties, of soaps, 189.

HYPOGEIC ACID, 7, 254.

Hrsteresis, 74.

INDiCATORs, 77; and protein systems, 229.

INJURY, to protoplasm, 82.

IODIN VALUE, 170.

Ionization, in protoplasm, 82, 243.

Ions, colloid, 112.

IsANiC ACID, 8.

Isobutrl Alconol, 56, 57.

ISOCETIC ACID, 7.

IsOknucic ACID, 7, 254.

ISOLINOLENIC ACID, 8.

ISOÖLEIC ACID, 8, 254

IsOHCINOLEIC ACID, 8.

Isosmotic Solutions, 236.

Isotonic Solutions, 236.

JAPAN WAX, 168.

JaPANIC ACID, 8.

JECOLEIC ACID, 7, 254.

JECORIC ACID, 8.

JELLYING, of soaps, 111.

Juniperic ACID, 8 .

KERNgetFe, 183. 
LANOCERIC ACID, 8.

L

LaNopalmic Acid, 8.

LARD, 168.

LAURATES, 14, 28.

LAURIC ACID, 7, 253.

LEAD linolate, 24 ; oleate, 25 ; stearate, 26 ; palmitate, 27 ; laurate, 28.

Lead Chlorid, 238.

Leimniederschlag, 183.

Light Metal Proteinates, 237.

Lignoceric ACID, 7.

Limonene, 61, 63.

LinOLATES, 10, 24.

LiNOLENIC ACID, 8.

Linolenic Acid Series, 8.

Linolic Acid, 8, 255.

Linolic Acid Series, 8.

Linseed Oil, 165.

LiquefaCtion, 74.

Liquid Foams, 136.

Liquid in Gas, 64.

Liquid in Liquid, 64.

Liquid in Solid, 64.

Lithium Oleate, 25.

Liver Oleic Acid, 7, 253.

Lycoponic Acid, 7, 254.

LYE, 5, 181.

Lyophilic Colloids, 71; general theory of, 64; definition of, 64.

Lyophobic Colloids, 65, 72.

\section{M}

MaGnesium linolate, 24; oleate, 25; stearate, 26; palmitate, 27; laurate, 28.

Magnesium Chlorid, and salting-out of soaps, 131.

Magnesium Sulphate, and sodium oleate, 200.

Manufacture, of soap, 163.

Margaric AcID, 7, 253; as eutectic mixture, 20.

Marine Soaps, 187.

Mayonnaise, 115.

Melissic ACID, 7, 253.

Mercuric Chlorid, 239.

Mercury oleate, 25; stearate, 26.

Methyl Alcohol, 34, 56, 57, 256.

Milk Coagulation, 233.

Millet Oil Acid, 8, 255.

Mixed Systems, $73,83,84,85,86,87,88,89$.

Monatomic Alcohols, 44, 56, 256; and sodium oleate, 46; and sodium elaïdate, 46 ; and sodium erucate, 47 ; of the series $\mathrm{C}_{n} \mathrm{H}_{n} \mathrm{OH}, 49$; constants of, 256.

Monatomic Alconol/Soap Seiries, 30.

Montanic Acid, 7.

Mutual Solubility, 66.

Myosinogen, coagulation of, 233.

Myristic ACID, 7, 253. 
Necrosis, 248.

\section{$\mathrm{N}$}

Neutral Soaps, 78.

Non-Aqueous Solvents, and soap, 60, 63.

Novyl Alcohol, 34, 56, 57, 256.

NutMeg Butter, 167.

OCTdDecaMethyLeNEdicarboxylic ACID, 8.

Oстуд Alcohol, 34, 56, 57, 256.

CEnema, 244; action of sodium chlorid in, 246.

Oil Constants, 169.

Orss, 3; used in soap making, 164.

Oleates, 10, 24.

Oleic ACID, 7, 254.

Oleic Acid Series, 7, 254.

Olive Oin, 166.

Open Chain Acids, 8, 255.

Osmotic Systems, 247; nature of, 247.

Palm Kernel Oil, 167.

$\mathbf{P}$

PALM Oil, 166.

Palmitates, 14, 27.

PALMitic ACID, 7, 253.

Palmitoleic Acid, 7, 254.

Paraldehyd, 61, 63.

Pelargonic Acid, 253.

Peptization, 225; definition of, 226; of fatty acids and proteins, 227.

Petroselinic Acid, 7, 254.

Phenol/Water Systems, 66; salting-out of, 68.

Phenolphthalein, 78, 113.

Physetoleic Acid, 7, 254.

Physical State, of soap mixtures, 83.

Physico-chemical Constants, of fatty acids, 253; of alcohols, 256.

Physiological Reactions, and colloid-chemical changes, 248.

Puysiological Salt Solution, 236.

Pinene, 61, 63.

Pisangceryud Acid, 7.

Plasmolysis, 245.

Plasmoptysis, 245.

Plumic ChLorid, 238.

Poisoning, by ammonium compounds and heavy metals, 235.

Poppy Seed On, 165.

Potassium, linolate, 24 ; oleate, 25 ; stearate, 26 ; palmitate, 27 , laurate, 28 ; oleate, $93,94,95,102,108,110,120,121,127,128,129,134,135,200,201$. hydroxid, 120, 127; fluorid, 121; chlorid, 122, 127, 128, 129; bromid, 122; iodid, 122; nitrate, 123 ; sulphocyanid, 123; sulphocyanate, 124 ; acetate, 125; sulphate, 125; tartrate, 126; phosphate, 126, citrate, 126; poisonous action of, 245 .

Potassium ACETAte, 125.

Potassivm Bromid, 122.

Potassium Chionid, 122, 127, 128, 129.

Potassium Citrate, 126. 
Potassium Fluorid, and salting-out of soaps, 121.

Potassium Hynroxid, and salting-out of soaps, 120, 127.

Potassium Iodid, 122.

Potassium Nitrate, 123.

Potassium Oleate, salting-out of, 93; effects of water upon, 94 ; effects of alkalies upon, 94; effects of salts upon, 95; effects of alkali and salt together upon, 108; historical remarks on the salting-out of, 110; saltingout effects of alkalies upon, 120,121, 127, 128, 129,134, 135; salting-out effects of neutral salts upon, 121, 122, 123, 124, 125, 126, 127, 128, 129, 130, 131, 132; and sodium carbonate, 200; and sodium silicate, 201; and sodium borate, 201; and magnesium sulphate, 201.

Potassium Phosphate, 126.

Potassium Sonps, 16, 23; foaming properties of, 143; foaming properties of, of the acetic series, 148 .

Potassium Sulphate, 125.

Potassium Sulphocyanate, 123, 124.

Potassium Tartrate, 126.

Potato Flour, 193.

Propandiol $(1,3), 50$.

Propionic ACID, 253.

Propyl Alcohol, 34, 56, 57, 256

Protein, swelling of, 75, 219; acid and basic derivatives of, 206; colloidchemistry of derivatives of, 208; solution of, 218; action of acids and alkalies upon, 218; salting-out of, 226; coagulation of, by different bases, 230; congulation of, by heat, 233; and heavy and light metals, 237 .

Protein Derivatives, 205; solution of, 205; hydration of, 205; solubility of, in and for water, 206.

Protein Systems, compared with soap systems, 223.

Protein/Water Systems, stability of, 214; independence of swelling and solution in, 219.

Protoplasm, solution of water in, 78; ionization in, 82,243 ; injury to, 82 , 247; fundamental chemical constitution of, 235; as solution of water in, 235; effects of introducing different bases into, 236, 237; fundamental composition of, 243; salts in, 243; and alkaloids, 244; solubility of, for water, 244; solubility of, in water, 245 ; reaction of, when injured, 247; electrical conductivity of, 247 ; cloudy swelling in, 248.

Psyllostearylic ACID, 7.

Quince Oil Acid, 8.

ReAction to Injury, in protophasm, 82, 248.

RAPIC ACID, 7, 254.

Reichert-meissl Value, 170.

REVERSIBILITY, in soaps, 89.

Ricinelaïdic Acid, 8.

Ricinic ACID, 8.

Ricinoleic ACid, 8.

Ricinoleic Acid Series, 8.

Ringer Solution, 236. 
SABINic ACId, 8.

SAliva, and heavy metals, 240.

Salting-out, of soaps, 5, 68, 50, 93, 1S2; of phenol/water system, 68; of potassium oleate, 93 ; historical remarks on, of soaps, 107, 110; theory of, of soaps, 113; of different soaps, 116; of acetic series soaps, 117; effects of concentrations of sodium chlorid upon, of soaps, 117, 128, 129, 130; of mixed soaps, 1S1, of proteins, 226 .

SALTS, effects of, on potassium oleate, 95; water attracting power of, 110, 111 ; and gelatin, 222; relation of, to protoplasm, 243.

SAPONification, effect of concentration of alkali upon, 179.

Saponification Value, 170.

Secretions, as solutions of protoplasm in water, 235; albumin content of, 246.

Seed Husks, 193.

Sesame OIL, 166.

Settled SoAp, $181,183$.

Shaving Soaps, 191.

Silver Nitrate, 238.

SoAp, definition of, 3 ; graining of, 5 ; by Twitchell process, 5 ; preparation of, 10 .

SOAPs, gelation capacities of, 10 ; with different basic radicals, 10 ; with different acid radicals, 15; of acetic aeid series, 16 ; and water concentration, 22 ; and non-aqueous solvents, 60,63 ; salting-out of, 68 ; as normal electrolytes, 70, 180; as colloids, 70,112, 181; neutral, 78, 113; hydrolysis of, 79 ; reversibility in, 89 ; salting-out of, 93,182 ; historical remarks on salting-out of, 107, 110; jellying of, 111 ; aeid, 112, 113; as true solutions, 112; alkaline to phenolphthalein, 113; theory of salting-out of, 113; salting-out of different, 116; gelation and salting-out of various, of the acetic series, 135; foaming properties of, 136; emulsifying properties of, 136, 150; washing properties of, 136, 157; changes in, on cooling, 180 ; salting-out of mixed, 181 ; eurd, 181, 183; settled, 181, 183; graining of, 182, 183; "going stringy" of, 182; finishing of, 183; half-settled, 183; filled, 1S5; transparent, 186; physical constants of market, 186; cold water, 187; hot water, 187, marine, 1S7; hygroscopic properties of, 189; water loss by, 189; conversion of one into another, 190; shaving, 191; fillers for, 192; hydrolysis in, 231; heat coagulation of, 231, 232.

Sonp/Azconol Systras, 30; with different soaps, 31; with different alcohols, 31 .

Sonp Gris, as mutually soluble systems, 66,69 ; theory of, 69 .

SOAP IN Wateir, 69.

SOAp KeTtuF, 164.

Soap Making, 6.

Sonp Manufacture, 163; by cold process, 170 ; by hot process, 170; mixing of fat with alkali in, 174; cmulsification in, 174; microscopic changes observed during, 176 ; addition of alkali in, 178 .

Sonp Mixtukes, 83.

Sonp Systras, effects of temperature on, 71 ; compared with gelatin systems, 223

Soap/Water Systems, 9.

Sonum caproate, $17,19,38,54,56,58$; caprate, $19,39,54,56$, 55; laurata, 19 , $28,39,54,56,58,59$; myristate, $19,40,54,56,58,59$; palmitate, 19, 27, $41,54,56,58,59$; arachidate, 20,54 ; margarate, 20, 42, 54, 56; stearate, $20,26,43,54,56,58,59$; claidate, $21,55,57,58,59$; erucate, $21,58,59$; 
linolate, $21,24,57$; oleate, $21,25,55,57,58,59$; acetate-alcohol systems, 31 ; butyrate-alcohol systems, 31 ; caproate-alcohol systems, 31 ; capratealcohol systems, 31 ; caprylate-alcohol systems, 31 ; erucate-alcohol systems, 35 ; elaidate-alcohol systems, 35 ; caprylate, $38,54,56,58$; elaïdate and different alcohols, 46; oleate and different alcohols, 46; erucate and different alcohols, 47; linolate and different alcohols, 48; butyrate, 54 , 56 ; valerate, 54 ; acetate, 55 ; formate, 55 ; propionate, 55 ; oleate and indicators, 78 ; stearate and indicators, 79 ; oleate-sodium stearate mixtures, 83, 84, 88; oleate-sodium palmitate mixtures, $83,85,88$; linolatesodium stearate mixtures, 86,88 ; caprylate-sodium stearate mixtures, 87, 89; chlorid, 117, 128, 129, 130, 185, 246; hydroxid, 120; carbonate as soap filler, 185 ; borate as soap filler, 185; silicate as soap filler, 185; gelatinate, 221 ; easeinate, 229.

Sodium Acetate, 55; -alcohol systems, 31.

Sodium Arachidate, 20, 54.

Sodium Borate, as soap filler, 185; and sodium oleate, 199.

Sodium Butyrate, 54, 56; -alcohol systems, 31 .

Sodium Caprate, 19, 39, 54, 56, 58; -alcohol systems, 31 .

Sodium Caproate, 17, 19, 38, 54, 58; -alcohol systems, 31.

Sodium Caprylate, 38, 54, 56, 58; -alcohol systems, 31 ; -sodium stearate mixtures, 87,89 .

Sodium Carbonate, as soap filler, 185; and sodium oleate, 198.

Sodium Caseinate, 229.

Sodium Chlorid, and sodium soaps, 80; effects of concentrations of, for salting-out of soaps, 117, 128, 129, 130; as soap filler, 185; and dehydration of protoplasm, 246.

Sodium Elaïdate, 21, 55, 57, 58, 59; -alcohol systems, 35; and different alcohols, 46.

Sodium Erucate, 21, 58, 59; -alcohol systems, 35; and different alcohols, 47.

Sodium Formate, 55.

Sodium Gelatinate, 221.

Sodium Hydroxid, and salting-out of soaps, 120.

Sodium Laurate, $19,28,39,54,56,58,59$.

Sodium Linolate, 21, 24, 57; and different alcohols, 48; -sodium stearate mixtures, 86,88 .

Sodium Margarate, 20, 42, 54, 56.

Sodium Myristate, $19,40,54,56,58,59$.

Sodium Olea'te, 21, 25, 55, 57, 58, 59; and ethyl alcohol, 31 ; and different alcohols, 46; and indicators, 78; -sodium stearate mixtures, 83, 84, 88; -sodium palmitate mixtures, $83,85,88$; and sodium carbonate, 198; and sodium silicate, 199, 201; and sodium borate, 199; and magnesium sulphate, 200.

Sodium Palmitate, 19, 27, 41, 54, 56, 58, 59; -sodium oleate mixtures, 83, $85,88$.

Sodium Propionate, 55.

Sodium Silicate, as soap filler, 185; and sodium oleate, 199, 201.

Sodium SoAPs, 16, 23; of the acetic acid series, 29,44 ; of the oleic aeid series, 29; of the linolic acid series, 29; and diatomic alcohols, 50; and triatomic alcohols, 52; and glycerin, 52 ; and ethyl alcohol, 54; and alkali, 80; and sodium chlorid, 80; foaming properties of, 139; production from potassium soaps, 190; production from calcium soaps, 191; production from ammonium soaps, 191. 
Sodicm Stearate, 20, 26, 43, 54, 56, 58, 59; and indicators, 79; -sodium oleate mixtures, $83,84,88$; -sodium linolate mixtures, 86,88 ; -sodium caprylate mixtures, 87,88 .

Sodium Valerate, 54.

SoFt Soap, 83.

Sol, $74,76$.

Solid Foams, 136.

SOLID in Gas, 64.

Solid in Liquid, 64 .

SOLID in Solid, 64.

Solid Tissues, 81 .

Solubilitr, mutual, 66.

Solution, 17; definition of, 69,221 ; of proteins, 218 .

Solvates, 114, 115.

Solvation Capacity, 74, 76.

Solvent, deprivation of, 245.

Solvents, 30.

Starch, 193.

Stearates, 10, 26; reversion of, from heavy to light metal soaps, 92 .

STEARIC ACID, 7, 253.

Stimulation, of protoplasm, 248.

Sugar Solutions, as fillers for soaps, 191.

SUSPENSION, 73.

Sweating, of colloids, 76.

Swelling, 74, 75; of protein, 218.

Syneresis, 17, 30, 74, 76.

System, soap/water, 9; soap/alcohol, 30; soap/x, 60; phenol/water, 66; gelatin/water, 218; casein/water, 228.

Srstems, viscosity of diphasic, 115; stabilization of, 225; osmotic, 247.

TALLOW, 168.

TAPIOCA, 193.

TARIRIC ACID, 8.

Tariric Acid Series, 8.

Telfairic Acin, 8, 255.

ТнЕокч, of salting-out of soaps, 113; of washing, 157; of emulsification, 157 .

Theirapic ACid, 8.

Trguc Acid, 7, 254.

Trme, as factor in production of colloid systems, 198.

Tissues, 205.

Toluene, 61, 63.

Transparent Soaps, 186.

Triacetin, 61, 63.

Triatomic Alconols, 52, 59, 256.

Trimethyleneglycol, 50, 58, 59, 256.

'Turgor, 244.

TURPENTINE, 61, 63.

Twitchell Process, 5.

VAlemic Acin, 7, 253.

VAR1АBLES in soap vat, 4 .

Viscositr, of mixed systems, 115. 
W

Washing Properties, of soaps, 136, 157.

Water-attracting Power, of salts, 110, 111.

Water Dissolved in $\mathbf{X}, 81$.

Water/EgG-globulin Systems, 209.

Water/Gelatin Systems, 218.

WAter-gLASs, 185, as soap filler, 185.

Water in Soap: 69.

WATER Loss, by soaps, 189.

Waxes, used in soap making, 164.

Wheat Gluten, 218.

X Dissolved in W ATER, 81.

Xylene, 61, 63. 


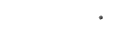





\section{-}

\section{-}

.

, 


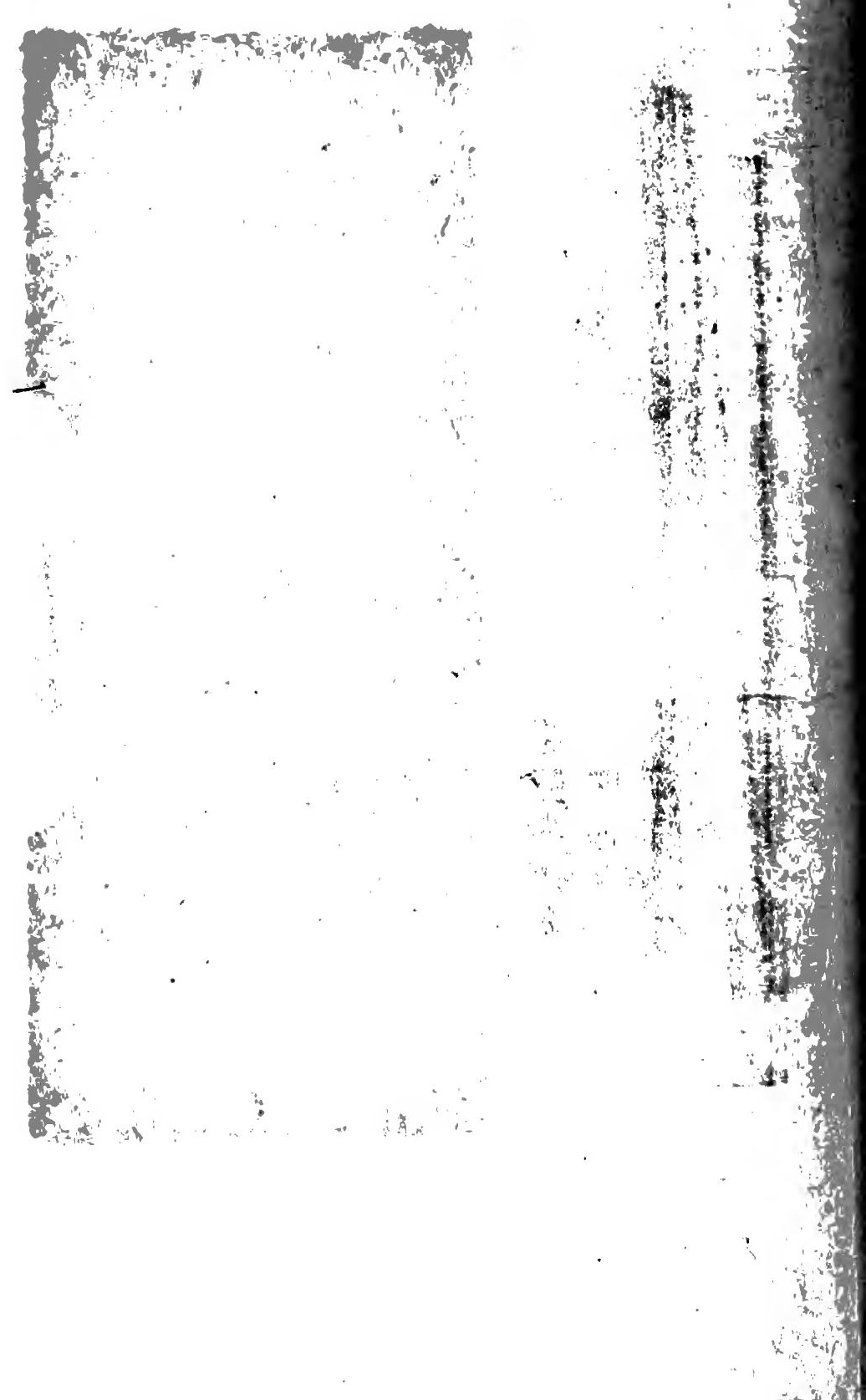




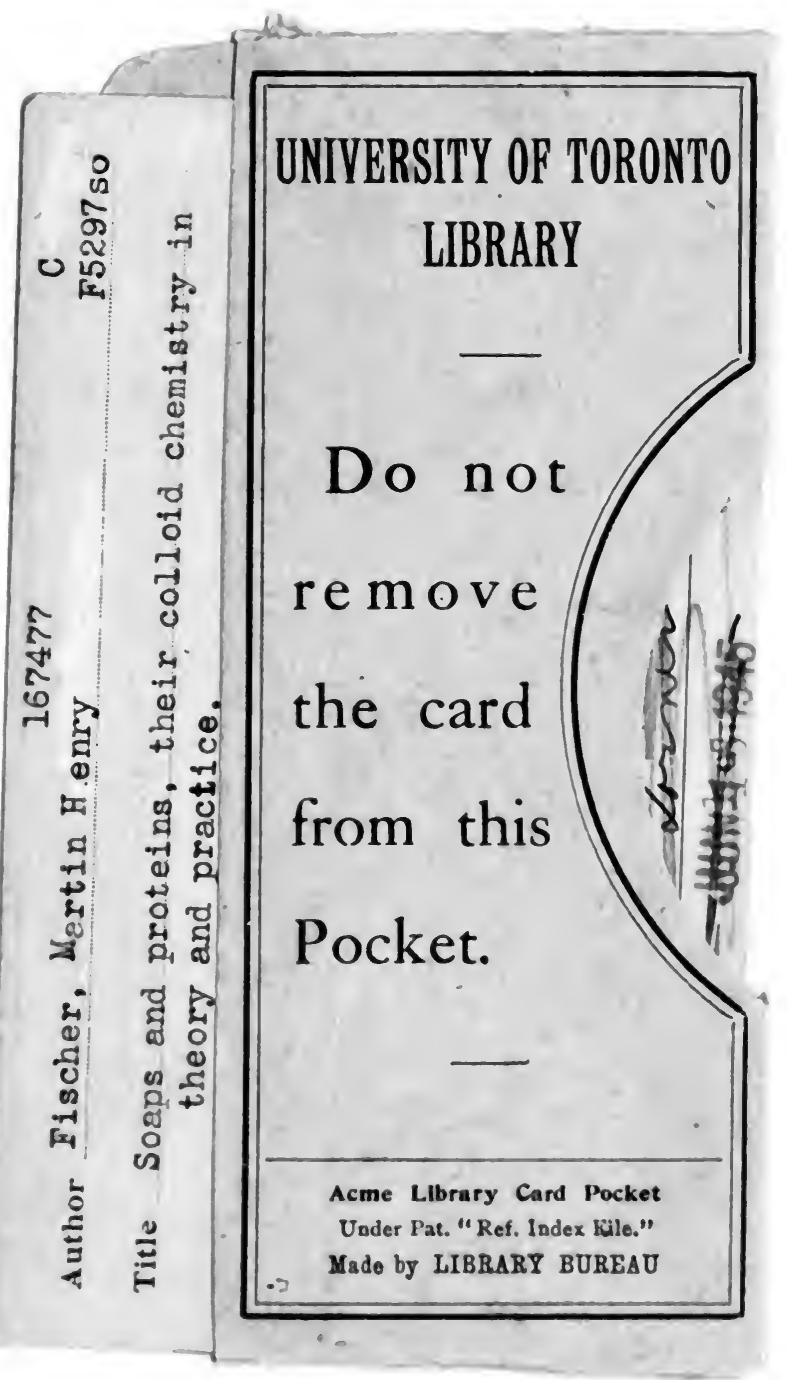


(9)

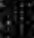

